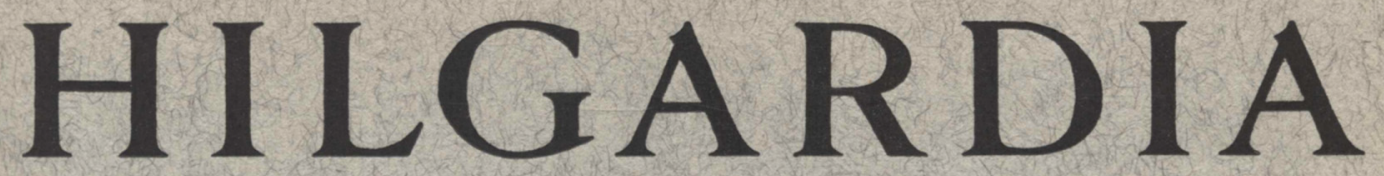

A Journal of Agricultural Science Published by the California Agricultural Experiment Station

\title{
FIG VARIETIES: A MONOGRAPH
}

\author{
IRA J. CONDIT
}

UNIVERSITY OF CALIFORNIA • BERKELEY, CALIFORNIA 
INTRODUCTION . . . . . . . . . . . . 323

ACKNOWLEDGMENTS . . . . . . . . . . . . . 325

VARIETIES OF THE CAPRIFIG TYPE . . . . . . . . . 326

Suggestive Key for Identification of California Caprifigs,

Profichi Crop . . . . . . . . . . . . . . . 327

Caprifigs with Interior Violet or Purple; Skin Green . . . . . . 328

Caprifigs with Interior Violet or Purple; Skin Green, Tinged with

Darker Shades of Brown or Violet . . . . . . . . . . 332

Caprifigs with Interior White; Skin Green . . . . . . . . 335

Caprifigs with Interior White; Skin Brown or Purplish . . . . 339

Miscellaneous Caprifigs; Interior Color not Determined . . . . 340

VARIETIES OF THE SMYRNA TYPE .... . . . . . . . 342

Smyrna-type Figs with Skin Green or Yellow; Pulp White,

Amber, or Very Light Red . . . . . . . . . . . . 343

Smyrna-type Figs with Skin Green or Yellow; Pulp Various Shades of Red .. . . . . . . . . . . . . . 345

Smyrna-type Figs with Skin Dark (Various Shades of Violet to Black); Pulp White or Amber . . . . . . . . . . . . 354

Smyrna-type Figs with Skin Dark (Various Shades of Red, Brown, or Violet to Black); Pulp Various Shades of Red . . . . . 354

Smyrna-type Figs Lacking Complete Descriptions. . . . . . . 359

VARIETIES OF THE SAN PEDRO TYPE . . . . . . . . . . . 359

San Pedro-type Figs with Skin Green; Pulp Red . . . . . . . 360

San Pedro-type Figs with Skin Bronze or Violet; Pulp Amber or

Red... . . . . . . . . . . . . . 364

VARIETIES OF THE COMMON TYPE ... . . . . . . 369

Suggestive Key for Identification of Common-type Figs at

Riverside, California . . . . . . . . . . . . . . 370

Common-type Figs with Skin Green or Yellow; Pulp Amber or White . . . . . . . . . . . . . . . 372

Common-type Figs with Skin Green or Yellow; Pulp Various Shades of Red . . . . . . . . . . . . . . . . . 381

Common-type Figs with Skin Green or Yellow; Pulp Color not Designated

Common-type Figs with Skin Dark (Various Shades of Red, Brown, or Violet to Black); Pulp White or Amber . . . . 414

Common-type Figs with Skin Dark (Various Shades of Red, Brown, or Violet to Black); Pulp Various Shades of Red . . 420

Common-type Figs with Skin Dark (Various Shades of Red, Brown, or Violet to Black); Pulp Color not Designated . . . 477

Common-type Varieties not Classified as to Color . . . . . . .479

INDEXED ALPHABETICAL LIST OF FIG VARIETIES . • . 481

LITERATURE CITED . . . . . . . . . . . . . . . 497

PLATES . . . . . . . . . . . . . . . . 511 


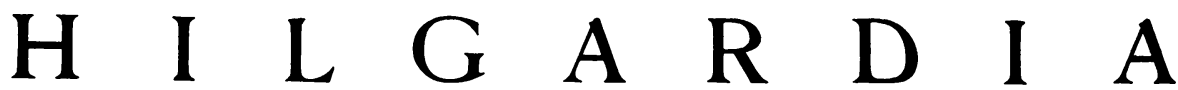

A Journal of Agricultural Science Published by

the California Agricultural Experiment Station

VoL. 23

FEBRUARY, 1955

No. 11

\section{FIG VARIETIES: A MONOGRAPH ${ }^{1,3}$}

\section{IRA J. CONDIT ${ }^{3}$}

\section{INTRODUCTION}

THE COMMON FIG occurs in a great number of varieties, which have evolved mainly as natural seedlings during the many centuries in which this fruit has been under cultivation. As early as the fourth century B.c., Theophrastus $(1916)^{4}$ reported that most good fruits, including the fig, had received names. Ulysses, the hero of the Odyssey, obtained from his father twenty fig trees, all with names. In the first century of the Christian Era, Pliny (1855) listed twenty-nine varieties, with the localities in which they were grown, and quoted Cato, who also had given names to several varieties. Pliny further stated: "Since his [Cato's] day there have been so many names and kinds come up, that even on taking this subject into consideration, it must be apparent to everyone how great are the changes which have taken place in civilized life."

Various authorities maintain that certain figs now being grown in Italy are directly descended by asexual propagation from the clonal varieties listed by Pliny, and are therefore identical with them. Barnissotte, for example, is referred by Gallesio to "Fico Africano" of Roman times. The Mission (Franciscana) fig of California, which was introduced into the New World over four hundred years ago by the Spanish explorers, had undoubtedly been previously propagated in southern Spain for many centuries.

Pliny listed names of figs and gave the color of mature fruits, but did not describe varieties in detail. Porta, in his Pomarium of 1583 and his subsequent much larger work of 1592 , did little more than list varieties of that period, but he gave citations to previous authorities on synonymy. Beginning with Aldrovandi in 1668, and more specifically with Cupani in 1696, the accounts were sufficiently detailed to enable later writers to compare characters and to identify varieties with more or less certainty. Subsequent accounts or descriptions of fig varieties are numerous, as shown in the appended bibliography. Many have been purposely omitted from this monograph. be-

\footnotetext{
${ }^{1}$ Received for publication March 4, 1954.

${ }^{2}$ Paper No. 829, University of California Citrus Experiment Station, Riverside, California.

${ }^{3}$ Professor of Subtropical Horticulture, Emeritus, and Subtropical Horticulturist, Emeritus, in the Experiment Station.

"See "Literature Cited" for citations, referred to in the text by author and date.
} 
cause the descriptions were very evidently not based on personal studies, but had been copied from previous authorities. Too often, we find, writers copied verbatim, but failed to mention the source of their information or to give credit to other authors.

This is not the first attempt to publish a monograph of fig varieties. A writer in Revue Horticole (1865, p. 31) told about an Italian, Suffren de Salerne, who had prepared a monograph covering the descriptions and illustrations of 360 varieties. Apparently the publication never got beyond the manuscript stage. Various authors call attention to a compilation by Geny (1867) entitled "Les figuiers spontanés et cultivés dans les Alpes Maritimes, Nice." According to Eisen, this unpublished manuscript, which consisted of colored plates without text, could not be located for his study in 1901. Several accounts of fig varieties are excellent and detailed; examples are Vallese (1909), Mauri (1939), and Simonet et al. (1945). These deal mostly with restricted localities, and are not monographic in character.

Probably the most complete publication is that of Eisen (1901), in which there were described or listed some 348 common figs, 10 Smyrna figs, and 19 caprifigs. Students of fig varieties have cause for regret that Dr. Eisen could not have been more specific as to which crop he was considering in his descriptive notes, and that he failed in most cases to state the locality in which the specimens were grown. Obviously, much has been published in the ensuing fifty years, and horticulturists are enabled to study the behavior of varieties under widely separated and varied climatic conditions.

Citations to early nursery catalogues in the United States are not included. Perusal of several such catalogues by H. R. Fulton, United States Department of Agriculture, shows that from 1771 to 1866, trees of numerous fig varieties were offered for sale at prices ranging from fifty cents to one dollar each. Prominent among these nurseries were the following: William $R$. Prince, Parsons and Co., and Stephen F. Mills, all of Flushing, Long Island; John Bartram and Son, Philadelphia; William Kenrick, Newton, Massachusetts; Hovey and Co., Boston; and Ellwanger and Barry, Rochester.

This monograph of fig varieties is based upon personal observations and studies extending over a period of more than thirty years, mostly in California, but also including notes taken during visits to France, Algeria, Italy, Greece, Turkey, Spain, and Portugal. A few standard varieties were found growing even in Japan and China when the author traveled in those countries in 1934-1935. Much has been learned from the so-called Chiswick collection of figs, grown in four distinct localities of California. Introduced in 1894 by the United States Department of Agriculture from the Royal Horticultural Society of England, scions of each variety (some sixty-six in all) were successfully grafted on trees in the orchard of the California Nursery Company at Niles.

A prized possession of the library of the University of California Citrus Experiment Station at Riverside, is the record book containing penciled notes as well as outline drawings made by John Rock and Gustav Eisen of these figs as grown at Niles and at Biggs. Subsequently, the collection was transferred to the United States Plant Introduction Garden, near Chico, where the author made notes on the varieties in 1916, 1918, and 1921. Cut- 
tings of most of the varieties were established in a plot at Fresno in 1920, at Riverside in 1928, and again at Fresno in 1950. Numerous introductions have been made from other parts of the United States and from foreign countries, mostly through the Division of Exploration and Introduction, United States Department of Agriculture. These are referred to in the text under Plant Introduction (P.I.) numbers.

As to variety names, Starnes and Monroe wrote, in 1907, that "no fruit, comprising as in this case but a single species, is so badly mixed as is the fig in its nomenclature." Reference to the text shows that the Brunswick has had at least twelve different names attached to it, and the Brown Turkey has at least fourteen synonyms. This confusion in nomenclature is emphasized by a comment from a correspondent in Algeria, “... but the names change from one village to another for the same variety, and it would need a volume to establish complete synonyms." Such varieties as Brown Turkey, Brunswick, and the Ischia figs are undoubtedly identical with varieties grown over a long period in some Mediterranean districts.

Recognized names have been established for the five commercial varieties grown in California: Mission, Kadota, Adriatic, Calimyrna, and Brown Turkey. Any of their various synonyms may be found in use in other areas. ${ }^{5}$ We have tried to clarify, so far as possible, the nomenclature of all varieties treated in this monograph. Four types of varieties are treated, namely, the Caprifig, the Smyrna, the San Pedro, and the Common.

The use of Condit's publication (1941a), entitled Fig Characteristics Useful in the Identification of Varieties, is suggested for those who wish to become more familiar with the descriptive terms used in this monograph.

\section{ACKNOWLEDGMENTS}

In presenting this monograph of fig varieties, I wish to acknowledge with sincere appreciation the assistance given by each of the many friends and co-workers during the long years in which I have familiarized myself with the peculiar characters of this subtropical fruit. I am especially grateful to the following persons: Julius Enderud, who for nearly twenty years has faithfully helped to maintain various fig plots, has kept records of their performance, and has been of assistance in other innumerable ways; Richard $\mathrm{H}$. Burnett, whose ability as an illustrator is shown in several of the outline drawings of fig fruits; B. R. Amend, Portland, Oregon, who, during the past fifteen years, has supplied me with propagating material of many varieties and has given me notes on their behavior; Robert Warner, Director of Research, and members of the Research Committee, California Fig Institute, Fresno, for conducting variety tests at Fresno and Merced; Stoughton Sterling, Philadelphia, who is conducting at the family home, Crisfield, Maryland, a commercial fig orchard and a test plot of promising varieties; and Avery Field, Riverside, for the excellent color plates, numbers 6 to 12.

The United States Department of Agriculture has kindly cooperated in various ways. To the following members of the Department particularly I

\footnotetext{
${ }^{5}$ See the alphabetical, cross-referenced list of variety names, starting on page 481 . This also serves as a finding list, or index, so that the description of any variety may be readily located.
} 
wish to express my appreciation: H. R. Fulton, Plant Pathologist, Beltsville, Maryland, now retired, in whose company two very interesting and rewarding trips were taken to historic places of Virginia and Maryland, resulting in the collection and identification of at least fourteen varieties, including several grown by the early colonists; B. R. Morrison, formerly Head, and C. O. Erlanson, now Head, of the Division of Plant Exploration and Introduction, Beltsville, Maryland, who have diligently pursued requests for introduction of fig material from various parts of the world; Perez Simmons, entomologist, Fresno, California, for photographs of trees shown in plates 3 and 4; and J. R. Magness, Bureau of Plant Industry, for establishing and maintaining a fig-variety collection at Fresno State College, Fresno, with Elmer Snyder and L. A. Thompson in direct charge.

\section{VARIETIES OF THE CAPRIFIG TYPE}

Caprifigs are characterized by the presence inside the syconium of shortstyled pistillate flowers, the ovaries of which may be inhabited by the larvae of the fig insect, Blastophaga psenes Cav. In one or more crops, staminate flowers which produce pollen may be present. Three crops of a caprifig tree are generally recognized and, as Eisen (1896) predicted, their Italian names have become household words in various fig-growing countries. These names are: Mamme, the first or winter crop, maturing in California in early April; profichi, the second or spring crop, maturing in June; and mammoni, the third crop, maturing in late summer. Further details about these names and crops may be found in numerous publications, among which are the following: Eisen (1896, 1901), Rixford (1918a), and Condit (1920a).

Caprification, the practice of providing for the pollination of the longstyled flowers of edible figs, has been carried on since ancient times in Asia, Africa, and Europe, and varieties of caprifigs were undoubtedly recognized and names applied to them. Contrary to the statement of Eisen (1901) that no caprifigs had previously been described, Gasparrini published descriptions and illustrations of several varieties over a century ago. Eisen himself described fifteen varieties under variety names, and four more under numbers. The most fully detailed descriptions with illustrations are those of F. Vallese (1909) and N. Mauri (1939a).

There are very few records of attempts to classify caprifig varieties into groups or to separate them by means of a key. One such key, published by W. T. Swingle (1905), included seven principal varieties of Neapolitan caprifigs distinguished from each other by size, shape, and lobes of leaves, length of petiole, and form and color of fruit. A key to the identification of caprifigs can be constructed for the varieties commonly grown in any one district but, like most botanical keys, it can hardly be sufficiently perfected to avoid mistakes in identity, owing to local variation in size, shape, color, or other characters. A sample dichotomous key to the principal caprifigs grown in California is given here. 


\section{Suggestive Key for Identification of California Caprifigs, Profichi Crop}

Internal color of figs white with no trace of pink, violet, or purple.

External color green or yellowish green.

Figs becoming soft and edible when mature, with little if any pollen;

blastophagas seldom issuing from them................. Croisic

Figs not pulpy when mature, usually with numerous pollen-bearing stamens and insect-inhabited flowers.

Body of fig longer than broad; neck and stalk often somewhat curved; base of leaf truncate; tree with rounded top,

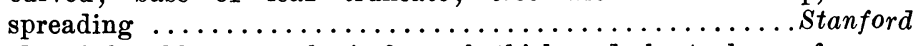

Body of fig oblate or spherical; neck thick and short; base of leaf shallowly subcordate; tree with upright branches.Maslin No. 150

External color violet, purplish black, or green shaded with violet.

Fruit stalk or peduncle slender, generally up to $1 / 4$ inch long, or longer.

Figs green until almost mature, then changing to purplish black; leaves variable, nonlobed, or only shallowly lobed to lyrate or

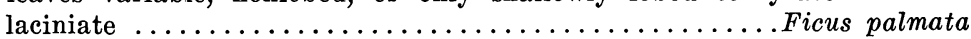

Figs when immature colored brown, purplish black when mature; leaves 3- to 5-lobed........................Ficus pseudo-carica

Fruit stalk or peduncle mostly thick and short.

Figs small, seldom over $1 \frac{1}{4}$ inches in diameter; leaf petioles and twigs purplish brown and densely pubescent; neck generally some-

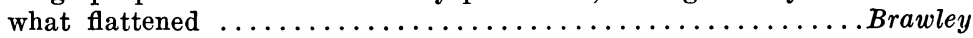

Figs larger, 11/2 inches or more in diameter; leaf petioles and twigs green, not pubescent; green color of fruit persisting until maturity, then becoming purplish black; neck round in cross section.. Maslin No. 91 Internal color of figs purple or violet.

Figs without a distinct neck.

Eye in center of a depression; bloom conspicuous; size medium or above;

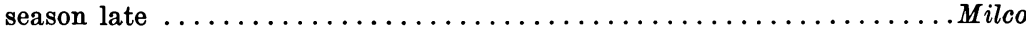

Eye slightly protruding; bloom delicate; size medium or below; season

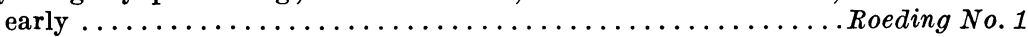
Figs with a distinct neck.

Neck not prominent, short and thick, seldom up to $1 / 4$ inch long.

Ribs prominent; surface corrugated.................Roeding No. 4

Ribs, if present, not forming corrugated surface.

Eye protruding from broad, rounded apex; size medium or below; neck short ...........................Roeding No. 1

Eye not protruding.

Eye more or less flush with the surface.

Flecks of white inconspicuous; size below medium to small; tree with slender, upright branches; bark of

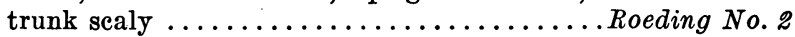

Flecks of white very conspicuous; size medium to large; tree dense; bark of trunk furrowed ............Samson

Eye somewhat depressed; bloom conspicuous.............Milco Neck more or less prominent.

Neck flattened in majority of specimens.

Bark of tree trunk scaly; figs below medium to small; skin color reddish brown when mature..................Roeding No. 2 Bark of trunk smooth; figs medium; color green.........Roeding No. 4 
Neck round or angular in cross section.

Size medium, $1 \frac{1 / 2}{2}$ inches or less in diameter.

Body of fig obovate, top-shaped, or oblate; white flecks very conspicuous; circular mosaic spots present on many figs early in the season, causing them to become malformed and to drop prematurely; color deep green; bark of trunk

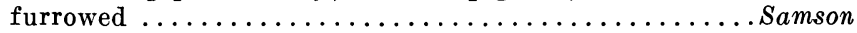

Body of fig spherical; white flecks small, fairly prominent; color light green; bark of trunk smooth.........Roeding No. 1

Size above medium to large, over $1 \frac{1 / 2}{2}$ inches in diameter.

Tree densely branched.

Terminal buds tawny; lateral fruit buds colored violet; bark of trunk smooth.................Roeding No. 3

Terminal and lateral buds green; bark of trunk fur-

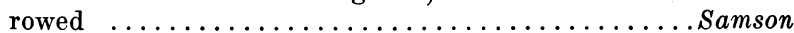

Tree open, with upright habit of growth; terminal buds green; figs very large....................Excelsior

\section{Caprifigs with Interior Violet or Purple; Skin Green}

The following list of varieties is divided into groups, based first on internal color of meat and pulp, and secondly on external color of skin. A miscellaneous group includes those which cannot be classified, because of inadequate descriptions.

Agouat. Described by Mauri (1939a); found near Sidi-Aich, vicinity of Beni-Ourlis, Algeria. Tree vigorous and productive; leaves and fruits resemble those of Tit-en-Tsekourt, but figs are larger and longer, with eye not so rosy; interior violet.

Akoran. Described and illustrated by Mauri (1939a) from trees at BeniAissi, Algeria. Tree vigorous, productive; leaves large, generally 5-lobed. Fruit large, 2 inches broad by $11 / 2$ inches long, depressed at the apex, green at maturity; texture firm, well able to withstand transportation; interior violet.

Amellal. (Name signifies "white," because of the light color of the mature fruit.) Described and illustrated by Mauri (1939a); a variety of which one tree only has been propagated in the vicinity of Mekla.

Tree diffuse, very productive; season early; leaves large, 3- or 5-lobed. Fruit large, 2 to $2 \frac{1}{4}$ inches in diameter, resembling that of Illoul, but less ribbed; green at maturity; interior violet.

Arzagane. Described by Mauri (1939a); found at Beni-Aissi, where it is also called "Amerzagou." Tree vigorous, productive, somewhat later than Tit-en-Tsekourt. Fruit pyriform; interior violet.

Azigzaou. (Name signifies "green," referring to the color of the mature fruit.) Described and illustrated by Mauri (1939a) ; fairly well distributed near Mekla.

Tree very vigorous, requiring a warm and sunny exposure, compact and erect; season late; leaves almost entire, thick, and deep green. Fruit large, 2 to $21 / 4$ inches broad, up to 2 inches long, somewhat oblate; stalk short; color green; eye scales tinged red; interior violet. Texture firm, especially good for transport.

Beurzel. Described and illustrated by Mauri (1939a). Variety found in the vicinity of Sidi-Aich, where it is called "Azigzaou"; also confused with 
Adras Violet; resembles Agouat, but is earlier. Profichi large, less elongated than fruits of Adras Violet, green at maturity; interior violet.

Excelsior (syn. Taylor). A seedling first distributed by G. P. Rixford, United States Department of Agriculture; grown and fruited about 1916 by H. P. Taylor, Exeter, California, who sold numerous cuttings at one dollar a foot; described by Condit (1928a) and illustrated by him (1928c).

Tree vigorous and upright; terminal buds green; leaves medium; lateral sinuses medium; petiolar sinus broad; base truncate to subcordate. (Plate 13. $)^{\mathrm{e}}$

Mamme crop fair, with many fruits imperfect; figs large, up to $1 \frac{1}{2}$ inches in diameter, pyriform, with short, thick neck; ribs fairly prominent; eye slightly depressed; color green; interior light purple.

Profichi crop good; figs very large, up to 2 inches in diameter and 3 inches in length, pyriform, with long, thick neck; ribs fairly prominent and elevated; eye in center of a slight depression; white flecks conspicuous; color green; interior purple; pollen abundant; cavity rather small for such a large fig. A midseason caprifig of large size, but otherwise of no particular merit; not grown commercially.

Forbes (syn. Forbes Hardy). A seedling also distributed by G. P. Rixford; grown and fruited by C. T. Forbes, Fresno, California ; described by Condit (1928a) and illustrated by him (1928c).

Tree with spreading habit of growth; terminal buds green.

Mamme crop fair ; figs medium, spherical to pyriform, with short, flattened neck; ribs fairly prominent; color green ; interior purple.

Profichi crop fair only; figs medium, turbinate, with distinct neck generally compressed or flattened; ribs prominent and somewhat elevated; white flecks large, scattered; color green to yellowish green; interior purple. A caprifig of no particular value, and no longer propagated.

Heiny No. 1. A seedling developed by Francis Heiny, Brawley, California ; seldom found in commercial fig orchards.

Tree moderately vigorous; terminal buds green. Leaves medium, somewhat glossy above, 3- to 5-lobed; upper sinuses moderately deep and narrow, lower shallow; base subcordate to truncate; margins coarsely crenate to dentate.

Mamme figs medium, turbinate, with short neck; skin color dark green; interior purple.

Profichi crop fair; figs medium, turbinate, with thick neck; white flecks conspicuous ; eye scales straw color; skin green; interior purple; season late.

Kearney. A seedling distributed by G. P. Rixford under his No. 2,830 in 1916, and fruited at Kearney Park, Fresno. Described by Condit (1928a) and illustrated by him (1928c); also described by Brooks and Olmo (1946); seldom found in commercial fig districts.

Tree vigorous, spreading, with green terminal buds; leaves above medium, 3 - to 5-lobed; sinuses of medium depth; base truncate to subcordate; outer margins coarsely serrate.

Mamme crop good; figs large, turbinate, with very short, thick neck and stalk, or neck absent; ribs prominent; color green, often tinged with violet; white flecks very conspicuous; scales of eye often tinged violet; interior purple.

${ }^{6}$ All plates will be found at back of this issue, in a consecutively numbered group. 
Profichi crop inclined to be small; figs large, turbinate to spherical; neck and stalk short, thick; color light green; interior purple; meat white tinged with violet; inclined to become soft and pulpy. Midseason.

Mammoni figs numerous, unusually large, maturing over a long season; pulpy and attractive to dried-fruit beetles.

Mendolaro. Described and illustrated by Vallese (1909); more common in Lecee district than Colombaro.

Leaves small, generally 5-lobed. Mamme figs rather small, oblate, deep green, partly tinged with violet. Profichi medium, turbinate; color green; interior light violet; stamens numerous.

Milco (syn. Endrich). See descriptions by Eisen (1901), Roeding (1914), Rixford (1918a), Condit (1920a, 1947) ; illustrations of tree and fruit by Condit (1920a), and of fruit (1933). According to Eisen, this variety was imported by G. N. Milco from Dalmatia. On the other hand, Rixford states that there is little doubt that it was introduced by W. B. West under the name Verdoni, and later exploited by Milco, whose name it bears. However, this is in conflict with statements by Maslin (1890, page 410) and others that Verdoni is the name under which W. B. West introduced the White Adriatic from Italy. Milco is the oldest and for several decades the most widely distributed caprifig in California; trees are still found in commercial orchards, but are now seldom propagated or planted.

Trees upright, well branched; terminal buds green; leaves medium, mostly 5-lobed; sinuses medium; base subcordate; surface somewhat glossy, graygreen in color; petioles tawny to slightly violet near insertion with blade.

Mamme crop good; figs medium, $11 / 2$ inches in diameter, spherical, mostly without neck; ribs inconspicuous; white flecks numerous, commonly tinged with violet; color green; bloom prominent; interior purple. Mamme figs are generally regarded as exceptionally resistant to frost damage.

Profichi crop fair to good; figs medium, oblique-spherical to turbinate, mostly without neck; ribs narrow, only slightly elevated; eye in center of a definite depression; surface dull green, with prominent bloom; white flecks large, scattered, fading out at maturity; interior light purple. Season late. (Plate 6.)

Roeding No. 1. See descriptions by Eisen (1901), Roeding (1903, 1914), Rixford (1918a), and Condit (1920a, 1933, 1947), with illustrations of profichi $(1920 a, 1933)$. It was introduced from Meander Valley of Turkey in 1887 by Fred Roeding, Fresno, and for many years was the most widely planted of any caprifig because of tree vigor and ease of propagation; it was later superseded by better varieties.

Tree vigorous, spreading, with green terminal buds, inclined to produce numerous hollow, polleniferous figs or "blanks"; leaves medium, 3- to 5-lobed, middle lobe broad toward apex, narrowed toward base; sinuses rather shallow ; base cordate; margins coarsely crenate throughout; surface dull.

Mamme crop good; figs small, oblate-spherical, without neck; ribs indistinct, narrow; color green, with conspicuous, small white flecks; interior purple.

Profichi crop good if well colonized by blastophagas; figs variable, small to medium, from 1 to $1 \frac{1 / 2}{2}$ inches in diameter, turbinate to spherical, with or 
without short, prominent neck; ribs present but inconspicuous; eye slightly protruding from the rounded apex; color light green; white flecks fairly large and scattered; interior purple. Season medium early. (Plate 6.)

Roeding No. 4. A variety of uncertain origin and identity; probably introduced by the Fancher Creek Nursery, Fresno, but exact records lost; see descriptions by Condit (1920a, 1947).

Tree vigorous, upright, with slender branches much like those of Roeding No. 2; bark smooth, not scaly; leaves below medium to small, 3- to 5-lobed; sinuses moderately deep and open; base truncate to somewhat decurrent.

Mamme crop generally good; figs medium, up to $1 \frac{1}{4}$ inches in diameter, spherical, without neck, or pyriform, with neck somewhat flattened; stalk short; ribs fairly prominent; eye small, with chaffy scales; white flecks prominent, scattered; color green, with rather prominent bloom; interior purple.

Profichi crop good; figs medium or larger, turbinate; eye protrudes from the slightly depressed apex; neck short or sometimes wanting, occasionally more prominent and somewhat flattened; color green, with numerous and prominent white flecks; interior deep purple. Season late.

Another caprifig commonly designated as No. 4 differs from the above in having profichi with prominent ribs producing a corrugated surface, and with prominent neck distinctly flattened. Roeding No. 4 has no particular value as a caprifig except for the late season of ripening of the profichi.

Rotondo (syn. Caprificus sphaerocarpa Gasparrini). Description of Gasparrini (1845) quoted by Vallese (1904). Profichi spherical, somewhat ribbed; stalk short; color green; pulp light violet.

Samson (syn. Markarian No. 1). See description by Condit $(1920 a, 1947)$ and illustration by him (1920a). Original California tree is on the Stanford ranch, Vina; introduced from Asia Minor by the Bulletin Company, San Francisco, 1882 ; propagated and distributed by W. H. Samson, Corning, as Capri No. 5, and described by him in 1906 as a very compact grower and productive of all three crops ; later distributed by Henry Markarian, Fresno, as Markarian No. 1; large trees commonly found in commercial fig plantings.

Tree moderately vigorous, exceptionally dense or much branched; trunks of older trees characteristically furrowed or creased; terminal buds green; leaves medium, 5-lobed, sometimes with additional basal lobes; sinuses of moderate depth; base cordate; margins crenate; surface somewhat glossy.

Mamme crop fair; figs medium, oblique-turbinate, with short neck and stalk; ribs fairly prominent; color green, with numerous and conspicuous white flecks; interior deep purple.

Profichi crop fair; figs medium to large, turbinate, with neck prominent and thick or sometimes tapering and up to $1 / 2$ inch long; ribs moderately prominent; white flecks large, and very conspicuous on immature fruit; color light green; bloom prominent; interior violet-purple; stamens generally good but sometimes rusty and unproductive of pollen. Midseason. (Plate 6.) Profichi are invariably affected by a virus which causes some of the young figs to become malformed and to drop, or to be blemished with mosaic spots in the form of a ring or crescent. See Condit (1920a, fig. 12), and Condit and Horne (1943). 
San Antonio. Described and illustrated by Vallese (1909). Leaves very small, scabrous, dark green above, shallowly 3-lobed. Profichi flask-shaped; apex rounded, with the center protruding like a nipple; neck prominent, gradually narrowing to the stalk; color pea green; interior violet.

Tardivo (syn. Gagliano del Capo). Described and illustrated by Vallese (1909) ; also described by De Rosa (1911).

Leaves large, intense green, somewhat scabrous on upper side, generally 3-lobed; sinuses shallow. Profichi of medium size; neck short; apex rounded, slightly nippled at center; color clear green, with few white flecks; interior purple.

Tit-en-Tsekourt (syn. Ain-el-Hadjel). Listed by Hanoteau and Letourneux (1872). Described and illustrated by Mauri (1939a). Name signifies "eye of the partridge," because of the rosy color of the eye scales. Recognized throughout Kabylia by its variety name.

Tree spreading, productive; leaves large, 3-lobed.

Profichi large, from $1 \frac{1}{2}$ to 2 inches in diameter; body spherical, with short neck; eye conspicuous, on account of rosy scales; color green; interior violet.

\section{Caprifigs with Interior Violet or Purple; Skin Green, Tinged with Darker Shades of Brown or Violet}

Abetroune. Described and illustrated by Mauri (1939a); named after place of origin; regarded as one of the earliest varieties at Tizi-Rached, Algeria.

Tree productive and vigorous; leaves almost entire, or sometimes 5-lobed.

Profichi large, up to 2 inches in diameter, pyriform, with medium stalk; color green, sometimes tinged with violet at maturity; eye scales green, or rose-tinted; interior violet.

Adras Violet. Described and illustrated by Mauri (1939a); found with Adras Blanc, but is later in season of maturity and has a violet interior. At Ouadhias, Algeria, it is sometimes erroneously called Beurzel, and is also confused with other varieties.

Tree generally of large size, much branched, compact, and very productive; leaves generally 5-lobed, but variable.

Profichi small, $1 \frac{1}{2}$ inches in diameter, pyriform; stalk short; color green, tinged with violet at maturity; interior violet.

Ayers. A variety found in the orchard of A. F. Ayers and of other growers near Merced, California; similar in habit of growth to trees of Roeding No. 2 , but terminal buds are violet-brown, and fruit characters are decidedly different. Leaves below medium size.

Mamme crop good; figs below medium to small in size, somewhat oblate; neck absent or very short, and often slightly flattened; ribs fairly prominent; color green, tinged with violet; white flecks conspicuous; interior very light purple.

Profichi below medium in size; neck fairly prominent, slightly flattened; stalk short; white flecks conspicuous on the green surface; apex broad, not depressed; interior purple. 
Gemini II. Described and illustrated by Vallese (1909). Leaves very small, bright green above, ordinarily deeply 7-lobed, more rarely 5- or 3-lobed. Profichi conical, elongated, oblique, ribbed, rather long-stalked; color bright green, with white flecks, becoming yellowish violet at complete maturity; interior light violet.

Mammoni and mamme crops not observed.

Grosso. Described and illustrated by Vallese (1909). Leaves of medium size, scabrous, deep green above, lighter below, asymmetrical, 5- or 3-lobed; sinuses deep and broad. Profichi very large, oblique-pyriform ; apex rounded, slightly nippled at center; color bright green, changing at maturity to pale green tinged with violet; interior violet.

Hamma. Introduced in 1901 from Algiers as a very valuable variety, found growing by a stone quarry above the Jardin d'Essai du Hamma. "It is probably from this tree that the Blastophaga was introduced into California in 1899." (Swingle, in description of P.I. No. 6,475; see also, No. 6,481, P.I. Inventory No. 10.)

Tree vigorous; leaves medium, 3- to 5-lobed; base truncate to subcordate.

Mamme crop fair at Riverside, California; figs below medium, pyriform, with prominent short neck; white flecks prominent; surface smooth, hardly at all ribbed; color green; interior violet.

Profichi crop good ; figs below medium, pyriform, with prominent neck and short stalk; color green until mature, then becoming reddish violet with conspicuous bloom; interior violet. Quality fair, but not worthy of commercial planting.

Howard (syn. Solms-Laubach No. 3). Described by Eisen (1901); received (probably at Niles, California) from Solms-Laubach, Naples, and named for L. O. Howard. A violet-brown fig with violet interior; probably never widely propagated or distributed.

Kara Mor. (Turkish name signifies "purplish black.") This variety supplies over sixty per cent of the eaprifigs of the Meander Valley, according to Condit and Baskaya (1948).

Tree large, vigorous; leaves deeply lobed, much like those of Sari Lop. Figs large, top-shaped, with neck; color purplish black ; interior purple.

Magnissalis. See account of Roeding (1914) and description by Condit $(1920 a)$; introduced from Aidin, Turkey, by G. C. Roeding in 1901, and named after S. G. Magnissalis ; now rare or nonexistent in California.

Tree vigorous, densely branched, with large leaves; terminal buds green.

Mamme crop generally good ; figs medium, spherical, mostly without neck; eye large, protruding from apex; scales green, or violet-tinted; ribs fairly prominent; color green, flushed with light violet; white flecks few, scattered; interior purple.

Profichi above medium to large, pyriform, with prominent neck; ribs narrow, very slightly elevated; eye fairly large, not depressed; color green, with delicate bloom; white flecks irregular in size, fairly conspicuous; interior purple. A green fig, but placed in this section because of the violet mamme figs.

Montesino. Described and illustrated by Vallese (1909). Leaves medium in size, generally 3 -lobed, but rarely entire or nearly so ; sinuses rather shal- 
low. Profichi oblique-pyriform, with rounded, slightly nippled apex; stalk rather long; color green, becoming violet at maturity ; interior violet.

Ricciuto (syn. Caprificus rugosa Gasparrini). Description of Gasparrini (1845) quoted by Vallese (1904). A variety common at Portici, and regarded more highly than Chiajese on account of its greater production of blastophagas.

Mamme small, spherical, rugose, somewhat flattened at the apex; color violet. Profichi large as a guinea hen's egg; ribs elevated; color green; pulp light violet.

Rock (syn. Solms-Laubach No. 2). Described by Eisen (1901). Received in California from Solms-Laubach, Naples, and named for John Rock, Niles. Rock (according to Eisen) was the "owner of the largest assortment of fig varieties collected in one place." A pyriform caprifig, with violet-colored ribs and violet interior. Probably never propagated or distributed.

Roeding No. 2. See description by Eisen (1901) as Smyrna No. 2, and by Roeding (1903, 1914), Rixford (1918a), and Condit (1920a, 1947). Introduced by Fred Roeding, Fresno, with Roeding No. 1, but is seldom found in commercial plantings.

Tree distinctive, on account of its upright habit of growth and slender twigs; bark of trunk scaly, as shown by Condit (1941a, figure 20); leaves below medium, mostly 5 -lobed; sinuses of medium depth; base cordate; surface somewhat glossy.

Mamme crop small or none; figs small, 1 inch or less in diameter, spherical, without neck; ribs narrow, mostly prominent; eye scales pinkish; color greenish violet; interior purple.

Profichi crop fair to good; figs small to medium, spherical to pyriform, with prominent neck that is often flattened; apex rounded, with eye slightly protruding; surface smooth, glossy, greenish yellow, becoming reddish violet at complete maturity; interior purple. Season later than Roeding No. 1.

Mammoni crop practically none.

Roeding No. 3. See descriptions by Eisen (1901, as Smyrna No. 3), Roeding $(1903,1914)$, and Condit $(1920 a, 1933,1947)$, with illustrations of fruit $(1920 a, 1933)$. It was introduced in 1887 by Fred Roeding, Fresno, with Roeding No. 1 and Roeding No. 2, from Meander Valley of Turkey. Cuttings were planted and numbered from one to three in the nursery row; No. 3 proved to be the earliest in season of maturity, and No. 2 the latest. Roeding No. 3 shares with Stanford the distinction of being the most valuable and highly regarded caprifig variety in California (plate 3 ).

In good soil, tree is vigorous, much branched, with short, slender twigs; distinguished from most common varieties by the brown or violet coloration of dormant fruit and terminal buds, and by the violet color of the mamme figs. Leaves below medium to small, 3- to 5-lobed; middle lobe broad above, narrowing toward base; sinuses of medium depth; base subcordate; margins crenate; surface somewhat glossy.

Mamme crop generally good, usually consisting of two types of figs, both medium in size, up to 1 or $1 \frac{1}{2}$ inches in diameter, oblate to oblique-turbinate, with or without short, thick neck; figs of one type are green or light violet in color ; ribs prominent; texture somewhat soft or "punky"; apparently not 
fully inhabited by blastophagas; susceptible to frost injury. Figs of the second type are violet-purple in color; ribs either not prominent or entirely absent; texture solid or firm; white flecks small and inconspicuous, somewhat masked by violet coloration of skin; eye depressed, in center of the broadly flattened apex; scales reddish brown; interior purple, with meat also tinged with violet.

Profichi crop very good; polleniferous or uninhabited figs inclined to stay green and remain on tree; insectiferous figs variable, from medium to large, up to 2 inches in diameter and over 2 inches in length, pyriform, with neck prominent, sometimes curved, and often distinctly flattened; apex broad, flattened, with the eye protruding from center of a slight depression; eye scales chaffy, erect at maturity ; ribs prominent, narrow; color light green, with white flecks numerous and conspicuous; bloom prominent; interior purple. Season early. (Plate 6.)

Mammoni crop small but ample.

Rosso. Described by De Rosa (1911). Profichi subspherical, almost sessile; eye scales rosy; color violet; pulp light red, somewhat edible at complete maturity.

Schwarz (syn. Solms-Laubach No. 4). Described by Eisen (1901); received in California from Solms-Laubach, Naples, and named for E. A. Schwarz. A pyriform caprifig of violet-brown skin color and violet interior. Probably not propagated or distributed.

Solms-Laubach (syn. Solms-Laubach No. 1). Described by Eisen (1901); received from Solms-Laubach, Naples, but apparently not propagated or distributed in California. Profichi oblique-turbinate, mahogany brown, with violet flush in sun; "meat yellowish white, with a few violet streaks."

\section{Caprifigs with Interior White; Skin Green}

Ak-kaba. A Turkish variety which transports well because of its thick, firm meat, according to Condit and Baskaya (1948). Figs very large, pyriform, light green ; interior white or very light pink.

Azaim (syn. Orzidane). Described and illustrated by Mauri (1939a) as a variety found at Beni-Aissi, near Fort National; sometimes confused with Adras Blane.

Leaves generally 5-lobed, with shallow sinuses. Profichi rather large, up to 2 inches in diameter, spherical, with surface almost smooth; color green; eye scales green, sometimes rose-tinted; interior white; texture firm, readily transported. Season early, same as Illoul.

Bianco (syn. Caprificus leucocarpa Gasparrini). Described and illustrated by Gasparrini (1845); description quoted by Vallese (1904). A variety little grown near Naples, as it produces few blastophagas.

Mamme about 1 inch long, smooth, turbinate; color green to violet. Profichi about twice as large as mamme; color pale green; pulp white. The "Bianco" described by De Rosa (1911) appears to be a different variety.

Colombaro. Described and illustrated by Vallese (1909); cultivated under other names near Lecee, and in many adjacent districts.

Tree vigorous; leaves of medium size, generally 3-lobed; sinuses deep. 
Mamme crop small. Profichi large, pyriform, with long neck; color green, dotted with white flecks ; interior white; cavity relatively small. Season first ten days of July. Mammoni very few.

Croisic (syns. Saint John, Cordelia, Pingo de Mel, Gillette). Described as Croisic by Solms-Laubach $(1882,1885)$, Trabut (1901), Leclerc du Sablon (1908), Rixford (1920a), and Condit (1942, 1947). Described as Saint John or Saint Johns by Wythes (1890b, 1900b), Wright (1895), Eisen (1901), Bunyard and Thomas (1904), Starnes and Monroe (1907, as Saint Jean Blanc), E. A. Bunyard (1925), O. T. (1905), Thompson (1925), and Preston (1951). Described as Cordelia by Eisen $(1896,1901)$. Described as Pingo de Mel by Coleman (1887a), Eisen (1901), Thomas (1902), Henslow (1902), Cheffins (1905), Royal Horticultural Society (1916), and Condit (1921b).

In 1882, Solms-Laubach reported observations both at Croisic and at Cherbourg, France, of an edible fig which, like the caprifig, had a zone of male flowers inside near the eye. Three years later he expressed the opinion that Croisic is simply a highly developed caprifig deprived of the blastophagas which normally inhabit caprifigs. In July, 1893, Gustav Eisen noticed in the San Francisco market some large yellow figs shipped from Cordelia, California. He examined the fruit and found "every one with a fully developed zone of male flowers, fully ripe, and with an abundant, perfectly developed pollen." Eisen concluded that this fig was possibly identical with the Croisic described by Solms-Laubach, but he placed it in a special class, the Cordelia, or Ficus carica relicta. At a meeting of the Royal Horticultural Society, July 8, 1902, Henslow cited the fig variety Pingo de Mel as an exception to the rule that all edible figs are female, since its fruit bore stamens.

According to Wythes (1890b), the Saint John, exhibited by Veitch and Sons, Chelsea, at the Temple Show in London, was a welcome addition to the list of good varieties. In 1900, Wythes expressed the opinion that Pingo de Mel and Saint John were not the same. However, George Bunyard, also O. T. and Thompson, regarded the two as identical, and recommended the variety as one of the best for forcing in pots.

Trees of the Croisic are occasionally found in California, especially in the vicinity of San Francisco Bay. They are also grown in a small way in Oregon under the name "Gillette," because cuttings were obtained from the Gillet Nursery, Nevada City, California. P.I. No. 6,952, obtained from Malta as Tin Baitri or Saint John, and Nos. 18,858 and 18,885 of the Chiswick collection, have all proved to be identical with Croisic.

Tree vigorous and productive; leaves medium to large, mostly 5-lobed; sinuses medium, narrow; hase subcordate.

Profichi medium or above, up to $13 / 4$ inches in diameter, pyriform with distinct neck; ribs prominent, with surface often somewhat corrugated ; eye fairly large, with yellowish-green scales; color greenish yellow; interior white; edible pulp insipid, lacking in sugar; staminate flowers few, generally lacking in pollen.

Mammoni crop scanty in interior valleys but fair in cool, coastal climates; figs much the same as profichi.

Elma. (Turkish name signifying "apple.") Described by Condit and Baskaya (1948). Tree large, with prominent nodal swellings; leaves dark green. 
Figs large, spherical, green, with white interior. Less productive of blastophagas than some other caprifigs.

Gemini I. Described and illustrated by Vallese (1909). Leaves of medium size; generally 5-lobed, with deep sinuses. Profichi medium, top-shaped, with broad, rounded apex; color green; interior white. Mammoni and mamme crops not observed.

Hajji Mestan. A Turkish variety, named after a person, according to Condit and Baskaya (1948). Figs contain numerous blastophagas, but shrivel easily in hot weather; for some unaccountable reason, this variety is more susceptible than other caprifigs to attacks of Lonchaea aristella Beck., the black fly.

Figs medium, pyriform, light green; interior white.

Illoul (syn. Aoriv). Described and illustrated by Mauri (1939a); name derived from place of origin; variety very common at Tizi-Rached, Fort National, where it represents fifty per cent of the caprifigs of the district; grown near Mekla under the name Aoriv.

Tree vigorous, diffusely branched, productive; leaves 3- to 5-lobed, rarely entire.

Profichi rather large, 11/2 to 2 inches in diameter, spherical; stalk thick and short; surface slightly ribbed; color greenish yellow; eye green; interior white. Season very early.

Kongur. A Turkish variety, named after a place, according to Condit and Baskaya (1948). Figs medium, top-shaped, green; interior white. Season late.

Kuyucak. A Turkish variety, named after a place, according to Condit and Baskaya (1948). Tree of medium size; leaves shallowly lobed. Figs medium, pyriform, green; interior white. Season late.

Loomis. Seedling No. 147, from the Maslin orchard at Loomis; described by Rixford (1918a) as producing one of the earliest crops in the orchard. Trees never planted commercially and now rarely found. Profichi large, with distinct neck and prominent ribs; color green; interior white.

Madel (syn. Oumadel). Described and illustrated by Mauri (1939a); named for the proprietor of the original planting, located by the railroad at Sidi-Aich; also grown in Takricts, valley of the Soummam, under the name Oumadel. Tree vigorous and productive. Profichi with white interior. Season early.

Markarian (syn. Markarian No. 2). Described and illustrated by Condit $(1920 a)$. Variety propagated and distributed by W. H. Samson, Corning, California, probably from a tree introduced from Asia Minor by the Bulletin Company of San Francisco; described by Samson (1906) as Capri No. 3; later obtained by Henry Markarian, Fresno, and grown as Markarian No. 2.

Tree with upright branches, similar in habit of growth and foliage to that of the Sari Lop (Calimyrna). Rarely found in collections of caprifigs.

Mamme crop light; figs medium or above, oblate, without neck; stalk thick and short, inclined to be flattened; ribs narrow but prominent; eye rather large, in center of a distinct, craterlike protrusion; color light green; interior white.

Profichi crop fair to good; figs large, up to 2 inches in diameter, pyriform, 
with neck often distinctly flattened; eye in center of a broad depression; ribs few but prominent; white flecks scattered, inconspicuous; color light green; interior white. Midseason.

Maslin seedling caprifigs. See accounts by Rixford (1912, 1918a). Seedlings distributed under numbers by the United States Department of Agriculture and given names as follows: No. 70, Bleasdale; No. 144, Mason; No. 147, Loomis; No. 148, Newcastle. These varieties are separately mentioned in this work, in their respective color groups. None have been planted commercially, and trees are now seldom found, or are completely lost. Many show close relationship to Sari Lop (the probable female parent), in having branches with swollen nodes, large, deeply-lobed leaves, and profichi with flattened neck.

Maslin No. 150. An unnamed Maslin seedling, of sufficient merit to warrant inclusion in a commercial planting at Orosi, California.

Tree upright, with branches somewhat swollen at the nodes; terminal buds green. Leaves large, mostly 5-lobed; sinuses rather shallow; base broadly subcordate; petiole thick, of medium length; margins shallowly crenate.

Mamme crop fair; figs large, oblique-turbinate to oblate; neck sometimes flattened; eye in center of a craterlike protrusion; ribs prominent, narrow ; color light green, with scattered white flecks ; interior white.

Profichi crop good; figs large, onion-shaped; neck prominent, somewhat flattened; ribs slightly elevated; apex broad, not depressed; color green; interior white.

Mason. Seedling No. 144, from the Maslin orchard at Loomis; described by Rixford (1918a); named after S. C. Mason, who discovered it. Figs large, green; interior white. Not grown commercially.

Medloub (syn. Bou Ankir). Briefly described by Mauri (1939a). Variety found at Sidi-Aich, but tree not in production; resembles Adras Blanc, but is green, with white interior.

Newcastle. Seedling No. 148, from the Maslin orchard at Loomis; described by Rixford (1918a). Figs large, turbinate, with flattened neck; color green; interior white.

Primaticcio. Described and illustrated by Vallese (1909). Leaves large, generally 3-lobed; sinuses deep. Profichi medium, turbinate; color deep green; interior white.

Samson caprifigs. Varieties obtained by W. H. Samson, Corning, from the Stanford ranch, Vina, and distributed under numbers in 1906. No. 1 was later identified as Stanford, and No. 5 as Samson (Markarian No. 1).

Stanford. Described and illustrated by Condit (1920a, 1933); description only (1947). This variety was mentioned by Rixford (1912) under the name Stanford as "a splendid tree, growing at the Stanford ranch at Vina. It was raised from a cutting imported by the writer during the winter of 18811882, from the Smyrna district of Asia Minor." According to A. Nadir and M. Halit (1929), Kara Ilek, the best caprifig of the Smyrna fig district, is the same as Stanford. Distributed by W. H. Samson, Corning, as Capri No. 1 Stanford and Roeding No. 3 are the best commercial varieties of caprifig grown in California. 
Tree vigorous, spreading (see plate 3 , and Condit, 1920a) ; terminal buds green; leaves above medium to large, 5 -lobed, middle lobe up to $23 / 4$ inches broad; sinuses medium to deep; base truncate to subcordate or decurrent; margins crenate on upper half of lobes, entire toward the base; surface slightly glossy. (Plate 13.)

Mamme crop good; figs medium or above, up to $1 \frac{1}{2}$ inches in diameter, oblique-turbinate, mostly with short, thick neck and short stalk; ribs present, slightly elevated; white flecks large and conspicuous; color green, with prominent bloom; eye scales light green.

Profichi crop excellent; figs above medium, pyriform, generally oblique; neck distinct, often somewhat curved; stalk up to $1 / 4$ inch long; ribs not prominent; eye scales chaffy; white flecks scattered, inconspicuous; color light green; interior white (plate 6). Midseason.

Mammoni crop small but ample.

Taranimt. Listed by Hanoteau and Letourneux (1872); described and illustrated by Mauri (1939a); figs very similar to those of the Smyrna-type Taranimt, hence the name; cultivated at Beni-Aissi, Algeria.

Leaves entire, or nearly so. Profichi large, up to 2 inches in diameter, pyriform, with short stalk; color green; interior white. Season earlier than Adras Violet.

\section{Caprifigs with Interior White; Skin Brown or Purplish}

Adras Blanc. Described and illustrated by Mauri (1939a); found in Kabylia under various names, such as "Azaim" at Ouadhias, and probably "Bouhioua" at Beni-Aissi; at Sidi-Aich it may be the same as Ameza.

Tree vigorous, very compact, productive; leaves 3 - to 5-lobed.

Profichi medium, 13/4 inches in diameter, pyriform; stalk very short; color green, tinged with violet; interior white. Season earlier than that of Adras Violet but less prolonged.

Averane. Described by Mauri (1939a). Name indicates a foreign or imported variety. Found at Beni-Aissi. In appearance of tree, foliage, and fruit it resembles Adras Blanc, but the season is later, and the profichi are violet-black outside.

Brawley. A seedling produced by Francis Heiny, Brawley, from a cross of Kadota with pollen of Ficus pseudo-carica.

Branches and twigs slender, pubescent; terminal buds dingy green or slightly violet; leaves small, entire to mostly 3-lobed; sinuses shallow; base truncate; margins finely serrate.

Mamme crop good; figs small, up to $7 / 8$ inch diameter, spherical; neck short, distinctly flattened; apex rounded, with eye slightly protruding; stalk short; ribs fairly prominent; color violet, with distinct bloom; white flecks present, but obscured by body color; interior white; stamens present. Reported to be exceptionally resistant to winter injury.

Profichi crop good; figs small or below medium, up to $1 \frac{1 / 4}{4}$ inches in diameter, turbinate, with slender neck; ribs somewhat elevated; eye slightly protruding from the rounded apex; white flecks scarce, practically absent; color green, gradually changing to reddish purple; interior white. Midseason. A good caprifig, except for its small size. 
Bsikri. P.I. No. 6,478, from Chetma oasis, near Biskra, Algeria, in 1900.

Profichi crop good at Riverside, California. Figs medium, pyriform; neck short, prominent, somewhat flattened; stalk short; ribs narrow, somewhat elevated; eye medium, protruding slightly from apex; color violet-brown at maturity; interior white; cavity small; quality fair. Season late.

Ficus palmata Forsk. This Indian form of $F$. carica, probably introduced by Dr. F. Franceschi, of Santa Barbara, has long been found in fig collections in Algeria and California, and in both places has been used for hybridizing. See Trabut (1922) and Condit (1947). No named varieties have been established. Practically evergreen in mild climates, with new growth starting in late January. The character of earliness is inherited by hybrids.

Trees variable in vigor and habit of growth; twigs pubescent, slender; terminal buds green or colored; leaves very variable, from entire or nonlobed to deeply dissected. (Plate 13.)

Mamme figs usually contain staminate flowers which mature pollen.

Profichi crop generally good, but figs are too small for use in commercial caprification. Figs mostly purple outside, and invariably white inside; stigmas of very young figs sometimes distinctly colored pink.

Ficus pseudo-carica Miq. This species, indigenous to Eritrea and Abyssinia, was introduced into California by Dr. F. Franceschi, of Santa Barbara, in 1902; sometimes designated as "Abyssinian caprifig." Like $F$. palmata, it has been used for hybridizing with $F$. carica. See Franceschi (1912), Rixford (1912, 1918a), Rixford and Heiny (1911), Trabut (1922), and Condit $(1947,1920 a)$; the last with illustration of fruit and leaves.

The tree has slender, willowy branches, with dormant buds violet; leaves small, mostly 3-lobed; sinuses medium; base truncate; texture thin, velvety; petioles very pubescent, russet in color; mosaic spots prominent, with some leaves dwarfed or malformed. (Plate 13.)

Mamme figs small, pyriform, with prominent, slender neck and long, slender stalk; color violet-purple; interior white; staminate flowers present.

Profichi small, elongated-pyriform, with slender neck and long stalk; ribs narrow; eye protruding; color brown to purplish black; interior white. (Plate 6.)

Maslin No. 91. This seedling, from the Maslin orchard at Loomis, is occasionally found in variety collections. Unlike most Maslin seedlings, the figs are purple outside rather than green; interior white. It has not been given a variety name.

Van Lennep. Listed in the 1915-1916 catalogue of Fancher Creek Nurseries, Fresno; introduced from Smyrna by D. Van Lennep of Auburn; variety probably lost. Profichi purplish brown; interior white.

\section{Miscellaneous Caprifigs; Interior Color not Determined}

Algiers No. 1 and No. 2. Listed by Eisen (1901) as forwarded by W. T. Swingle from Algeria to the United States Department of Agriculture, and then to John Rock, Niles, California.

Bardakji. Mentioned by Nadir and Halit (1929) as a variety from the Smyrna district, Turkey. 
Belamie. P.I. No. 6,487, from Algiers in 1901.

Bleasdale. Seedling No. 70, from Loomis, California; described by Rixford (1918a) as "one of the most valuable seedling capri trees of the Maslin orchard." Named for Dr. John Bleasdale, "a prolific writer on the fig." Figs green; interior color not stated. Variety never grown commercially, and probably lost.

Booung. P.I. No. 6,488, from Chetma oasis, near Biskra, Algeria, in 1901.

Bourlier. P.I. No. 6,490, from Algiers in 1901. A variety much prized by the Kabyle fig growers, who came fifteen miles or more to get figs for caprification. No description of this variety, or of Belamie and Booung, in Inventory No. 10.

Brackett (syn. Paul Meyer No. 2). Described by Eisen (1901). Variety sent by Dr. Paul Meyer from Italy to Niles, California, and named after G. B. Brackett. Tree spreading. Profichi medium, green.

Bulletin (syn. Smyrna No. 4). Briefly described by Eisen (1901). Variety included in the original importation of the Bulletin Company, San Francisco. Tree of sturdy growth. Profichi large, turbinate, greenish yellow in color.

Chiajese (syn. Caprificus oblongata Gasparrini). Description of Gasparrini (1845) quoted by Vallese (1904). A variety found commonly on the promontory of Posilipo and in the streets of Chiaja, Italy. Not much esteemed for caprification, on account of soft texture and small number of blastophagas. Season early. Profichi medium, oblong, smooth. Color green to violet.

Grande (syn. Caprificus gigantea Gasparrini). Description of Gasparrini (1845) quoted by Vallese (1904) ; illustrated by Gasparrini. Profichi turbinate, almost sessile. Color greenish violet.

Kongouz. One of four varieties in the Smyrna district of Turkey, accordding to Nadir and Halit (1929).

Maslin. Described by Eisen (1901). A seedling accidentally raised in San Francisco and named for E. W. Maslin.

Figs large; color not stated.

Meyer (syn. Paul Meyer No. 1). Described by Eisen (1901); sent by Dr. Paul Meyer from Naples to Niles, California, as a most valuable variety. Tree upright. Figs medium, yellowish green.

Mitchell. Described by Eisen (1901). Originated in a San Francisco garden, probably as a seedling, and was named for the donor. Leaves with petioles bright red. Profichi turbinate, with long neck and stalk; probably red when mature.

Mor. Listed as a late variety by Trabut (1904).

Pedunculato (syn. Caprificus pedunculata Gasparrini). Description of Gasparrini (1845) quoted by Vallese (1904). Name refers to the variable fruit stalk, which is often swollen. Found occasionally at Portici and Naples. Profichi medium, turbinate, somewhat ribbed; color green.

Rivers (syn. Italian No. 2). Described by Eisen (1901) as a variety imported by John Rock, Niles, California, from Thomas Rivers \& Son, London; supposed to be of Italian origin. Tree of strong, dense growth. Profichi turbinate, green. 
Swingle (syns. Algiers No. 3, Capri Smyrna No. 4). Described by Eisen (1901) as a variety imported by the United States Department of Agriculture from Algiers, and established on the place of George Roeding, Fresno. Blastophagas were first successfully colonized on this tree in the spring of 1899. Named for W. T. Swingle. Mamme figs large, greenish yellow.

Taylor (syn. Italian No. 1). Described by Eisen (1901). Introduced by the United States Department of Agriculture from Italy as "Troano"; named by Eisen for W. A. Taylor. Tree of spreading growth. Profichi medium, light green, with a purple tint. Mammoni large, unusually early.

Thaberkant (a black fig) and Tifouzal. Listed by Hanoteau and Letourneux (1872).

Neapolitan caprifigs. A collection of caprifig cuttings obtained in 1902 at Naples by W. T. Swingle (1905), and introduced under Plant Introduction Nos. 8,829 to 8,847 . No variety names are given, but seven of the principal kinds are described and separated by a botanical key, based mainly on leaf characters.

See P.I. Nos. 6,773 to 6,823 for record of miscellaneous caprifigs introduced in 1901 from vicinity of Tizi-Ouzou, Algeria, mostly without variety names.

The following description of caprifigs on the island of Malta is by J. Borg (1922):

A considerable proportion of seedlings, especially those originating from the white or light-colored edible varieties, produce uneatable fruits; and when they produce several crops, they are called caprifigs, and fruit may be used as such. However, the fruit of the true caprifigs is always more or less dry, becoming soft at maturity, but never fleshy or luscious as the edible figs. A "dry" caprifig is essential for the proper development of the Blastophaga, and therefore good sorts of eaprifigs are always propagated by cuttings or layers, or budded on seedlings. The two best-known caprifigs are the so-called white caprifig (duccar $a b j a d$ ) and the red caprifig (duccar atimar). The white caprifig is that most frequently met with. Its fruits are whitish green, with red scales at the orifice. The red caprifig is smaller, round, or somewhat flattened, of a uniform, rusty greenish-red color; it is "drier" than the white variety, and is preferred whenever obtainable. A late variety of green caprifig, producing long fruits, which mature their galls about three weeks later than the other sorts, is much valued for the eaprification of late or secondary crops of figs which otherwise would be lost.

\section{VARIETIES OF THE SMYRNA TYPE}

Smyrna-type figs reach full maturity only as a result of pollination of the flowers and the subsequent development of the ovules into fertile seeds. They have long been grown in Asia Minor, Greece, North Africa, and Portugal, and it is in these countries that varieties have gradually been selected for culture. The following list includes those varieties which are named and described in publications available. 


\section{Smyrna-type Figs with Skin Green or Yellow; Pulp White, Amber, or Very Light Red}

Borsamele (syn. Ingannamiele). Described by Guglielmi (1908) and Donno (1952), the latter in detail.

Leaves 3 - to 5 -lobed; terminal buds brown, according to Donno (1951a).

Brebas rarely produced. Second-crop figs medium, $13 / 4$ by $21 / 4$ inches, oblate-spherical; stalk short; eye open, scales light rose ; skin color yellowish green according to Guglielmi, bluish green according to Donno; pulp light rose when mature; "borsamele" (like a bag or pouch of honey). Much esteemed as a fresh fruit; of little use for drying.

Eisen. Seedling No. 52 from Maslin orchard, Loomis, California; described by Rixford (1918a). Cuttings distributed, but variety never established in cultivation.

Kaab el Ghazal. P.I. No. 6,461; a Damascus fig grown in Algeria before introduction into the United States in 1901. Figs medium, yellow, honey color inside. (See P.I. Inventory No. 10.)

Khazouri. Described by Minangoin (1931) from Djerba, Tunisia, as a Smyrna-type variety.

Leaves small, 5-lobed; upper sinuses deep, open; petiole short. Figs small, $11 / 2$ inches in diameter, spherical; skin glossy, light green in color; pulp amber.

Malaki. Introduced from Algeria in 1901 under P.I. No. 6,466, but originally from Damascus. (See P.I. Inventory No. 10.) Figs large, yellow, with honey-colored pulp; splitting when ripe.

Rosa. Described and illustrated by Vallese (1909); grown in a limited way in Lecce Province only.

Tree of considerable size; leaves mostly 5-lobed. First crop none; second crop consumed fresh, not good for drying on account of the delicate skin. Caprification is practiced by local growers, but it is not certain that this is necessary for the variety.

Figs large, top-shaped, flattened at apex; stalk short; color lemon yellow, tinged with green; ribs slightly elevated, branched; skin thick but tender, commonly checking and revealing the white meat; interior white; flavor sweet, very delicate.

Sari Lop (syns. Lob Injir (or Ingir), Erbeyli, Calimyrna, Aidin). Name from sari, "yellow," and lop, "delicious." See accounts by Eisen (1901, with frontispiece illustration), Roeding (1903, with color plate), Trabut (1904, 1923), Samson (1906), Mills (1914), Rixford (1918a), Borg (1922), Davis (1928), Hagan (1929), Burger and De Wet (1931), Mauri (1942), Condit (1920b, 1923, 1933, 1947), Condit and Baskaya (1948), Ozbek (1949), and Tamaro (1948, as "Esmirna"). See also, Condit (1941a, figures 2, J, 3, and 6.)

This variety has been grown in the Meander Valley of Turkey for several centuries; introduced into California at various times; first commercial planting made in 1886 by Mr. Fred Roeding and his son, George, at Fresno, but no crop secured until 1900 after the successful introduction of blastophagas. "Calimyrna" was the result of a $\$ 25.00$ prize offered by George C. 
Roeding for the best name for the variety as grown in California. Trabut and Mauri both report the variety unsuccessful in Algeria.

Trees vigorous; habit of growth upright (plate 1), with prominent nodal swellings on older framework branches (plate 4). See Condit (1933, figs. 8, $10,11 ; 1941 a$, figs. 15,16$)$. Leaves above medium to large, mostly 5-lobed; upper sinuses deep, of medium width, lower shallow; base truncate to shallowly cordate; upper margins shallowly crenate, lower entire; upper surface dull; leaves on sucker wood with much narrower lobes and deeper sinuses. (Plate 13.)

Breba crop fair in some seasons; called Yel Injur, or "wind figs," in Turkey, according to Hagan. Brebas large, pyriform, with prominent neck; color golden yellow; pulp amber, almost seedless; flavor insipid.

Second-crop figs large, up to $2 \frac{1}{2}$ inches in diameter and 2 inches from base to apex, oblate-spherical; neck thick, short, and flattened; average weight 70 grams; stalk short; ribs narrow, elevated, rather prominent; eye large, open (as illustrated by Condit, 1941a); scales chaffy, dingy straw color; surface somewhat glossy, with delicate bloom; white flecks inconspicuous, masked by yellow; color golden yellow to light lemon yellow, attractive; meat white, $1 / 8$ inch thick; pulp amber to light strawberry ; flavor rich and sweet; quality excellent, both fresh and dried; seeds numerous. According to Ozbek, the seeds of Sari Lop average 708 per gram in number. Season medium. Main defects are large eye, and tendency to split in unfavorable weather. (Plates $8 ; 11 ; 12 ; 15, C$.)

Scionto (syn. Fico Aggiunto). Described and illustrated by Vallese (1909). Cultivated in the vicinity of Brindisi. Like Dottato Bianco, it is eaten fresh and is used for drying, but requires caprification. There is no breba crop.

Leaves large, generally 5-lobed. Figs medium ; body spherical ; neck prominent; stalk very short; skin greenish yellow, with scattered white flecks; pulp white; flavor sweet, very delicate.

Teratology common in this variety, with one fruit superimposed above another, hence the term aggiunto, or "added."

Snowden. An unidentified variety found on the place of P. W. Snowden, Modesto, in 1922, and therefore named after him; other trees located at Escalon. Scions grafted in a Kadota tree at Fresno in 1924 bore fruit for many years; young trees bore large figs of excellent quality in 1953.

Tree vigorous; leaves above medium to large, mostly 3-lobed.

Breba crop none; main crop good. Figs large, up to $23 / 8$ inches in diameter and $23 / 4$ inches in length; average weight 93 grams; shape pyriform, body spherical; neck prominent, curved and somewhat flattened; stalk short; ribs elevated, fairly prominent; eye large, open; surface somewhat glossy, with delicate bloom; white flecks large, scattered, conspicuous ; color lemon yellow, attractive; meat white; pulp amber. Flavor rich, sweet; quality excellent, both fresh and dried. Worthy of more extensive trial. Figs inclined to split in unfavorable weather.

Sultanie. P.I. No. 6,465; a Damascus fig grown in Algeria before introduction into the United States in 1901. Figs medium, yellow, white inside; splitting when ripe. 


\section{Smyrna-type Figs with Skin Green or Yellow; Pulp Various Shades of Red}

Abate (syns. Arba, Paradiso of Cavolini, Panetto, Albachiara). Described and illustrated by Vallese (1909); described by Guglielmi (1908), De Rosa (1911), Tamaro (1948), and Donno (1952). Cultivated in Lecce Province especially for production of fresh fruit.

Tree vigorous in good soil; leaves usually 3-lobed, large; twigs and buds described by Donno (1951a).

Figs oblate-spherical, slightly depressed at the apex; stalk short; eye open; ribs numerous, elevated; color yellowish green; skin checking crisscross at maturity; pulp rose color, very sweet; seeds numerous.

Abiarous. Described briefly and illustrated by Trabut (1904, 1923) and by Mauri (1942); described by Mazières (1920). Sparsely planted near Sidi-Aich.

Tree vigorous, productive, with large, 5-lobed leaves. Figs globular, without neck or with a very short, inconspicuous one; size 2 inches in diameter by $2 \frac{1}{4}$ inches in length; stalk short; color bright green; pulp garnet, solid; quality good. Season more prolonged than that of Tameriout.

Aboucherchaou. (Name signifies "rough," because of the rugose character of the leaves.) See description by Trabut (1904, 1923), and Blin (1942), as Thamcingoult or Thabouhiaboult. Described and illustrated by Mauri $(1939 b, 1942)$. Sometimes called "Tabouyahboult," but this name is also used for the variety Alekake. Listed by Hanoteau and Letourneux (1872) as Abouh'archaou, and as not requiring caprification. Especially interesting because it matures about two weeks earlier than other autumn figs.

Tree vigorous, erect, productive; leaves generally 3-lobed.

Figs oblate-spherical, up to 2 inches in diameter and $11 / 2$ inches in length; ribs slightly elevated; eye large, $1 / 4$ inch across, open; scales green, changing to carmine with light margin; color green; pulp dark red; flavor sweet; quality good. Fruits too watery for drying, spoiling even on the tree.

Akca. Described and figured by Ozbek (1949). The name signifies "whitish," on account of the light color of the dried fruit, which is mixed with other varieties for the market in Izmir, Turkey.

Trees not commonly planted; leaves mostly 5-lobed. Figs large, oblate, resembling those of Sari Lop; average weight 66 grams; stalk short; eye small but open; color light green; pulp red. Used mostly fresh; number of seeds per gram, 683.

Alekake (syn. Tabouyahboult in some districts). Described and illustrated by Mauri (1939b, 1942). Name signifies "tender" or "soft," on account of the consistency of the mature fruit. Probably the variety described and illustrated by Trabut (1904) under the name Thaiadelst is the same as Alekake at Tizi-Rached. See also Blin (1942). Alekake resembles Aboucherchaou, but its leaves have more lobes, the fruits are larger and more oblate, of superior quality, and the season is 12 to 15 days later.

Tree vigorous, spreading, productive; leaves large, 3- to 5-lobed.

Figs oblate, up to $2 \frac{1}{4}$ inches in diameter and $1 \frac{1}{2}$ inches in length; stalk 
short; eye open, 1/4 inch across; scales brown when mature; color green; pulp red; texture fine; quality very good. One of the best for table use; equally good dried.

Amesas. Described and illustrated by Mauri (1942). Two different varieties are found at Mechtras under this name, which means "dull." Amesas E.A. Tree very productive; leaves 5-lobed. Figs are small, globular, and green, with rose-colored pulp that is insipid and ferments readily; quality of dried fruit poor. Amesas E.P. Tree with leaves nonlobed or shallowly 3-lobed; figs small; stalk short; pulp pale rose, of fine texture but tasteless.

Aranim-Amellal. Described and illustrated by Mauri (1939b, 1942), who reports that Aranim is masculine for Taranimt ("reed"); but the exact connection between the word and this variety of fig is not clear. Amellal means "white." See also Blin (1942). Hanoteau and Letourneux (1872) list Aranim as a variety not requiring caprification.

Tree of moderate vigor; leaves 5-lobed.

Figs medium, short-pyriform, about the same size and shape as those of Aranim-Aberkane; stalk short; skin thin, parchmentlike, closely adherent to the meat; eye closed, with greenish-white scales bordered brown; color green; pulp red; flavor sweet; quality very good. Defects are the thin skin and the tendency to split. Counts show an average of 864 seeds for split fruits and 744 for nonsplit fruits.

Bardajic (syns. Bardajik, Bardakjik). Name from two Turkish words, bardak, "pitcher," and jik, "small," the fruit resembling a water pitcher in general shape. See accounts by Eisen (1901), Roeding (1903, 1914), Rixford (1918a), Nadir and Halit (1929), Hagan (1929), Condit (1920b, 1947), and Ozbek (1949). A variety grown in coastal districts near Smyrna, where residents and visitors become familiar with the early morning cries of the peddler, "Bardajic! Bardajic!" as he calls attention to the fresh figs carried in panniers on the back of a donkey.

Tree compact, spreading; leaves large, 5-lobed, with shallow sinuses.

Figs large near the coast, smaller in the interior, pyriform, with prominent neck; stalk long, slender (short, according to Ozbek); ribs distinct; eye small; color green; white flecks scattered, small; skin thin, checking crisscross at maturity; pulp scarlet; flavor sweet. Quality excellent fresh, but not good for drying because of the dark, tough skin, and red color of pulp.

Ozbek gives the average weight of Bardajic figs as 52 grams and the number of seeds per gram as 1057. Experience with the Bardajic at Fresno, California, has been unsatisfactory, on account of splitting of the fruit on the tree.

Blowers. Described by Eisen (1901), and Rixford (1918a), as one of the varieties imported by the Bulletin Company, San Francisco, in 1882, and first planted on the place of R. B. Blowers, Woodland; never planted commercially, and probably lost. Figs medium, globose; ribs prominent; color lemon yellow; pulp pink.

Castelhano Branco (syn. Euchário Branco). See account by Mello Leotte (1901), and description with illustrations by Bobone (1932). The former 
states that the word euchário is from the archaic eucha, "chest," and caixa, "case"; i.e., "fig of the case." He also gives Euchário Preto as a synonym; but Bobone points out distinctions in size, color, and flavor. Both require caprification and produce a second crop only.

Castelhano figs are turbinate, rounded at apex; color green, obscurely tinted chestnut; pulp carmine; flavor agreeable; quality fair. Season medium. According to Mello Leotte, these figs, properly matured, are unrivaled in quality, and bring high prices in the market.

Changelge (syn. Ghengelje). Listed by Nadir and Halit (1929), also by Condit and Baskaya (1948), as a Turkish fig, well known to growers but not widely planted.

Chefaki. Described by Minangoin (1931) as a Smyrna-type fig from Hammamet, Tunisia. Leaves large, 3- to 5-lobed; petiole short. Figs without distinct neck; skin thin, glossy, pruinose, yellow in color; eye nearly closed; pulp red.

Cheker Injir (syns. Leker Injir, Sheker Injir, Seker). Described by Eisen (1901), Roeding (1903), Condit (1947), and Ozbek (1949). The name signifies "sugar fig." The variety is grown on the island of Chios; also in the southern part of the Smyrna fig district for home consumption. Of no particular value in California, either fresh or dried.

Figs medium, oblate-spherical, with short neck; color greenish yellow; ribs distinct; pulp dark strawberry in color; seeds small.

Ozbek gives the average weight of Cheker figs as 31 grams and the number of seeds per gram as 1,179. It has the smallest seeds of any of the twelve described by Ozbek.

Choer (syn. Biskra). Collected at Biskra, Algeria, by W. T. Swingle in 1900, and introduced by the United States Department of Agriculture as P.I. No. 6,480. (See P.I. Inventory No. 10.)

Tree very vigorous; branches drooping. Leaves very large, nonlobed to 3 - to 5-lobed ; upper surface dull; upper sinuses shallow and broad in 3-lobed leaf to deep and moderately broad in 5-lobed leaf ; middle lobe broad, spatulate, sometimes auricled; base subcordate; margins crenate (plate 13). Leaves practically immune to mosaic, as stated by Swingle (1928).

Figs large, up to $2 \frac{1}{4}$ inches in diameter, turbinate, with very short, thick neck and short stalk; many specimens triangular in cross section; average weight 62 grams; surface dull, with delicate bloom; eye medium to large, open; color grass green to greenish yellow ; pulp strawberry; flavor strong; quality poor. Tests in California have been unfavorable on account of poor quality of fruit and tendency to split. (Plate 14, B.)

Cueritesto (syn. Cesario). Described and illustrated by Vallese (1909). An uncommon variety producing second-crop figs only, but in great abundance; ordinarily caprified.

Leaves small, mostly 3-lobed; sinuses of medium depth. Figs below medium size, spherical, without neck; color greenish yellow; skin not very thick, rather difficult to peel; pulp light red; flavor somewhat pungent.

Djaferi. Described by Minangoin (1931) from Gabès, Tunisia, as a variety requiring caprification. Leaves small, 3-lobed, some with sinuses indis- 
tinct. Figs spherical, with very short neck; ribs present; eye closed; color light green ; pulp bright red.

Djebali. Two green figs were described under this name by Minangoin (1931). No. 1, from Gabès, Tunisia, is reported to yield well as the result of caprification. Figs small, with spherical body and long, slender neck; color light green; pulp red; seeds numerous. No. 32, from Zarzis, requires caprification. Figs with indistinct neck; skin thick, light green in color; pulp brown.

Fietta (syns. Jetta, Treccia). Described and illustrated by Guglielmi (1908), Vallese (1909), and De Rosa (1911). Cultivated in the province of Lecce.

Leaves large, 5-lobed; sinuses deep. Breba crop none. Second crop prolific; commonly caprified. Second-crop figs large, oblate-spherical, without neck; stalk short; color greenish yellow; skin checking irregularly, thin, not easily peeled; pulp light red, sweet, but somewhat acid; seeds abundant. Consumed both fresh and dried.

Gök Lop. Described by Condit and Baskaya (1948) and Ozbek (1949). Turkish name signifies "green delicious." Recommended for coastal districts of Smyrna with high relative humidity.

Figs large; stalk short; eye open; color green, with light-strawberry pulp. When dried, skin is lighter colored than that of Sari Lop, but sugar content is lower.

Ozbek gives the average weight of Gök Lop figs as 71 grams, and the number of seeds per gram as 827 .

Hilgard. Seedling No. 153 from the Maslin orchard, Loomis; named in honor of E. W. Hilgard; described by Rixford (1918a). Trees planted only for trial; variety probably lost.

Figs medium, oblate, lemon yellow ; eye open, with pink bracts; neck very short, or none; pulp red; quality excellent. Fruits almost immune from splitting.

Isly. Described by Trabut $(1901,1904)$ as a new seedling fig suitable for drying. See also Blin (1942). Tree vigorous, remarkably prolific, with large leaves. Figs large, oblate, yellowish green; eye large, open; pulp red, sweet, rich; seeds fertile.

Jadi (syn. Iadi). Described by Minangoin (1931) from Hammamet, Tunisia. Leaves medium, 5-lobed. Figs oblate-spherical, with short neck and narrow ribs; color greenish yellow; pulp red. Caprification is reported to be necessary.

Kalamata (syn. Messenia). A variety imported by the University of California from Athens, Greece, in 1930, and reported to be identical with the commercial fig of Kalamata. Panos Th. Anagnostopoulos, Athens, reports in a letter dated March 22, 1953, that the Kalamata fig is the same as Sari Lop of Turkey. See account by Condit (1924). Description is from figs produced at Riverside since 1933 .

Figs medium, spherical to obovate; neck very short and thick; ribs not prominent; eye large, open; surface somewhat glossy, with delicate bloom; white flecks large, conspicuous; skin green, unattractive, often discoloring and checking crisscross at maturity; pulp dark strawberry; flavor rich, 
sweet; quality good. Commercially inferior because of poor skin color, dark pulp, and tendency to split.

Karayaprak (syn Dülekgazi). Described by Hagan (1929), Condit and Baskaya (1948), and Ozbek (1949). Grown in some parts of the Smyrna fig district on account of its resistance to fruit diseases and insects. Figs smaller and skin coarser and thicker than that of Sari Lop; used both fresh and dried, mostly in homes.

Leaves mostly 5-lobed, but many nonlobed, unusually dark green. Figs medium, oblate; eye small; color yellowish green; pulp light strawberry.

Ozbek gives the average weight as 43 grams, and the number of seeds per gram as 839 .

Kassaba. Described by Eisen (1901), Roeding (1903, 1914), Rixford (1918a), and Condit (1947). Introduced into California in 1882 by the Bulletin Company, San Francisco, but never grown commercially.

Trees vigorous, upright; widely scattered among Sari Lop trees in the Meander Valley; also planted as a border tree at Kassaba. Leaves 3- or 5-lobed, medium, somewhat glossy above; upper sinuses shallow and narrow, lower very shallow, or none; base truncate to broadly cordate; margins serrate.

Figs large, turbinate, or sometimes oblate; neck thick, short; stalk short; ribs fairly prominent and elevated; eye medium, smaller than that of Sari Lop; surface dull; color pale green; pulp strawberry; flavor rich, sweet; quality very good. Season late. Dried figs readily distinguishable by the dark-red pulp. (Plate 15, A.)

Khadir. Described by Minangoin (1931) as a Smyrna-type fig from Dra Tamar, Tunisia. Leaves variable, some small and heart-shaped, others larger, deeply 3-lobed; petiole long. Figs small, spherical, without neck; skin of fine texture, green in color; eye closed; pulp red.

Kouffi Vert. Described by Minangoin (1931) as a Smyrna-type fig from Kalaâ Srira, Tunisia. Leaves medium, 5-lobed, lower lobes not clearly defined. Figs large, sessile; ; skin thick ; color light green, darker on ribs ; pulp dark red.

Lebi. Described and figured by Ozbek (1949). Found occasionally in the gardens of the Meander Valley. Not a popular variety, either fresh or dried, but notable because of its resistance to cold.

Leaves medium, generally 5-lobed; lobes somewhat auricled; base truncate.

Figs medium, oblate; average weight 31 grams; eye small, open; scales pink; skin yellow, finely pubescent, medium thick, easy to peel; pulp light red; flavor flat. Number of seeds per gram, 861.

Madoui. Described by Minangoin (1931) as a caprified fig from Dra Tamar, Tunisia. Leaves large, 5 -lobed ; petiole long. Figs small, oblate, without neck; eye closed; skin thick, green in color; pulp hollow at the center, bright red.

Malaki Blanc (P.I. No. 6,464). A Damascus fig, grown in Algeria before introduction into the United States in 1901. Figs medium, yellow, with red pulp; not splitting when ripe.

Mamari (P.I. No, 6,463). Same source as Malaki Blanc. Figs medium, yellow, red inside; splitting when ripe. 
Maple-Leaved. Described by Eisen (1901) and Roeding (1903). A variety imported from Turkey by G. C. Roeding, and given a local name derived from the form of the leaf. He reported it to be a fig of inferior quality, of no value for drying.

Merchini. Described by Minangoin (1931) from Dra Tamar, Tunisia. Leaves medium, 3- to 5-lobed. Figs oblate, often oblique, sessile; skin thin, greenish yellow; pulp rose-colored; seeds large.

Mota (syns. Allamoda, Moda). Described by Donno $(1951 a, 1952)$ as a variety of Lecce Province.

Tree with green terminal buds, and 3- to 5-lobed leaves. Brebas rare. Second-crop figs medium, 2 inches long by $13 / 4$ inches in diameter, top-shaped; stalk short, strongly attached to the branch; ribs numerous; eye open; color light green; white flecks scattered, numerous; pulp light red, very sweet; very good for drying. Season early.

Mouzai. Described by Minangoin (1931) from Gafsa, Tunisia. Leaves large, somewhat concave above. Figs large, spherical; skin thin, smooth, yellow in color ; pulp light red.

Panettaro (syns. Albanega, Panettiero, Abbanega). Described and figured by Vallese (1909); brief account by Guglielmi (1908); described in detail by Donno (1952) as Albanega.

Tree vigorous; leaves large, 5- to 7-lobed; terminal buds green, according to Donno (1951a). Figs large, oblate; stalk very short; eye open; color yellowish green; ribs slightly elevated; skin checking ; pulp light strawberry, filling the cavity; flavor sweet, very delicate. One of the better figs when consumed fresh. It is not much used for drying on account of its late season of maturity.

Pasulito (syn. Pasu'ella). Described by Guglielmi (1908) and De Rosa (1911). Rarely produces brebas; second crop usually caprified.

Tree robust; leaves larger than those of most other varieties, ordinarily 5-lobed. Figs spherical, with short stalk; color greenish yellow; skin checking at maturity; eye scales rose-colored; pulp red; seeds large, numerous. Usually consumed fresh.

Pazzo (syn. Paccio). Described and illustrated by Vallese (1909); described by Guglielmi (1908), De Rosa (1911), and Tamaro (1948). Widely grown in Terra d'Otranto.

Tree moderately vigorous; leaves mostly 5- to 7-lobed. Figs spherical, medium, with short stalk; eye large; scales rose-colored; skin yellowish green; pulp bright red; seeds large, very numerous. Quality mediocre when dried.

Rixford. Seedling No. 114 from the Maslin orchard, Loomis; named by W. T. Swingle in honor of G. P. Rixford. See accounts by Swingle (1909) and Rixford (1918a). Distributed as a promising variety, since at Loomis the eye of most figs became sealed with a drop of gum ; found to be unsatisfactory, on account of dark-strawberry pulp and inferior quality when dried.

Round White Smyrna. See description by Eisen (1901). An unidentified variety, imported from Turkey.

Sesso (syns. Sessune, Peloso, Pilosa, Piloso, Lungo Bianco). Described and pictured by Vallese (1909). Described by Guglielmi (1908) and De Rosa 
(1911). The variety Fara, described by Donno (1952), appears to be the same as Sesso.

Tree vigorous, with green terminal buds, according to Donno (1951a). Leaves large, generally 5-lobed. Brebas none. Second crop abundant and esteemed for drying; figs resistant to rain damage.

Second-crop figs large, oblate-spherical, flattened at the apex; stalk short; ribs numerous; eye open; color canary yellow, dotted with white flecks; skin thick, easily peeled; pulp red; flavor very sweet, delicate.

Sigilli. Described and figured by Ozbek (1949) as a variety found rarely in the Meander Valley of Turkey. Fruit consumed mostly fresh.

Figs large, oblate, with short stalk, strongly attached to the branch; average weight 58 grams; eye open; skin green, not easily peeled; pulp light red; flavor flat. Number of seeds per gram, 930 .

Souaba-el-Adjia Blanche. Described by Minangoin (1931), from Menzel Temine, Tunisia, as a variety requiring caprification.

Leaves above medium, 5-lobed; upper sinuses deep, almost closed, petiolar sinus open; petiole thick and short. Figs medium, 2 inches long by $1 \frac{1}{2}$ inches in diameter, pyriform; stalk very short; skin very thin, light green in color ; pulp slightly hollow, light red.

Stanford. See description and accounts by Rixford (1918a, 1920b), Condit (1922a, 1947), and Close (1929). Imported by the Bulletin Company, San Francisco, in 1882, and established on the Stanford ranch, Vina. Cuttings distributed by W. H. Samson, Corning, and by G. P. Rixford; named in honor of Governor Leland Stanford. Variety commonly called "Stanford Nonsplitting" because of its resistance to splitting in unfavorable weather.

Trees somewhat more vigorous and denser in growth than those of Sari Lop, as shown by Condit (1941a, fig. 16) ; leaves with deep sinuses and lyrate margins, thus readily distinguishable, even in the nursery row, from Sari Lop, the leaves of which have entire margins. Mostly regarded with disfavor by growers, on account of low tree yields, light weight, and medium size of fruit.

Figs medium, spherical; neck short, somewhat flattened; average weight 48 grams; stalk short; ribs narrow; eye medium, open; surface dull, with delicate bloom; white flecks fairly large and conspicuous; color green; pulp dark strawberry; flavor rich; eating quality good. Dried figs light in color.

Sultane Bi-longue. Described by Minangoin (1931), from Djerba, Tunisia, as a variety requiring "fécondation."

Leaves large, 3-lobed; sinuses nearly closed. Figs very much like those of Bezoult Rhadem at Kalaâ Srira, but the skin color is yellow rather than violet; pulp red. (See Besoul-el-Khadem, p. 356.)

Sultani (P.I. No. 6,462). Originally grown at Damascus, Syria; later introduced into California from Rouiba, Algeria, in 1901. (See P.I. Inventory No. 10.)

Tree slow-growing; nodal swellings on branches very conspicuous. Leaves badly mottled by mosaic; variety no longer grown. Description is from trees and fruit at Riverside.

Figs large, green; white flecks unusually large and conspicuous; surface glossy; pulp bright strawberry; quality fair. Very susceptible to splitting. 
Tabelout. Briefly described by Trabut $(1904,1923)$, and Blin (1942), as Thabelout; described and illustrated by Mauri $(1939 b, 1942)$. Name from belout, "small gland," probably on account of the small size of the fruit.

Tree rather vigorous, productive; leaves 3-lobed, often nonlobed. Figs small, short-pyriform; stalk short; eye medium; color green; pulp red; flavor subacid. Quality good fresh; too small for commercial market.

Tabelout (large-fruited). Described and illustrated by Mauri (1939b, 1942), as a variety at Tizi-Rached. Similar to Tabelout, but with larger fruits. Figs of inferior quality.

Tadefouit. Described and illustrated by Mauri $(1939 b, 1942)$. Grown at Tizi-Rached, where it is sometimes erroneously called Imlloui. Eisen (1901) lists "Thadhefouith" as a white fig from Kabylia, which does not require caprification.

Tree moderately vigorous. Leaves generally 3-lobed. Figs short-pyriform, with neck very inconspicuous; stalk short; eye medium; color green ; pulp red, sweet. Quality good, both fresh and dried.

Taharit. Described and illustrated by Mauri $(1939 b, 1942)$. One variety called Tarlit at Tamazirt, and another known as Taidelt at Sidi-Aich, are both very similar to Taharit.

Tree vigorous. Leaves 5-lobed. Figs oblate-spherical, without neck; stalk short; eye open; color yellowish green; pulp light red; flavor mild. Quality good fresh, but mediocre dried.

Takourchit. Described and illustrated by Mauri (1942). Trees found near Sidi-Aich, where this variety is sometimes called "Azigzaou." Tree moderately vigorous, erect. Leaves 3- to 5-lobed. Figs medium, globular; eye large, open; color light green; pulp red.

Tameriout (syns. Taamrouth, Thaamriout, Bougiotte, and erroneously, Imlloui). Described and illustrated by Mauri $(1939 b, 1942)$. Name from Ait Aamar, near Bougie, where the variety originated. Thaamriout, briefly described and illustrated by Mazières (1920), and by Trabut $(1904,1923)$, as very common near Tizi-Ouzou, may be the same variety. See also Blin (1942) and Montagnac (1952). The bulk of dried figs at Bougie consists of Tameriout; it is later in maturing and more sensitive to drought and heat than Taranimt. Successfully introduced into California in 1950 as P.I. No. 153,693 .

Tree vigorous, erect. Leaves 5-lobed.

Figs pyriform, with prominent neck; stalk short; eye medium; color light green; meat thin, white; pulp red, very sweet. Quality good, fresh or dried.

Taranimt (syns. Thaaranimt, Tagouaout). See description and illustration by Trabut (1904, 1923). Descriptions by Mazières (1920), Mauri (1939b, 1942), and Blin (1942). See also Montagnac (1952). Name signifies "reed," possibly because the figs are dried on reed trays in the mountains of Kabylia. It is the principal fig of Tizi-Ouzou; most of the orchards in the Sebaou Valley are planted to it, as the yield is generally better than from Tameriout; it is somewhat earlier in maturing than the latter, but more exacting in caprification. Introduced into California recently as P.I. No. 
153,694. Hanoteau and Letourneux (1872) list Thar'animt as Smyrna-type, producing brebas as well as second-crop figs.

Tree compact, vigorous, productive. Leaves generally 3-lobed.

Figs pyriform; neck not prominent; stalk over $1 / 4$ inch in length; eye medium; color green; meat medium thick; pulp red, very sweet. Quality good, both fresh and dried.

Taurisano. Described and illustrated by Vallese (1909), and Donno (1952), as a variety grown in Lecee Province, where growers maintain that it requires caprification.

Tree large. Leaves medium, generally 3-lobed, with shallow sinuses. Twigs and buds described by Donno (1951a).

Breba crop produced only in favorable seasons; figs small, top-shaped, greenish yellow ; pulp strawberry.

Second-crop figs oblate-spherical ; stalk short ; color light green ; pulp rosered. Season second week in August. Used mostly for drying in spite of tough skin, inferior flavor, and numerous seeds.

Tazarift. Described and illustrated by Mauri (1939b, 1942). Name signifies "alum," probably on account of the acid flavor of the mature fruit; cultivated at Tizi-Rached, but not well known.

Figs globular, with short neck ; stalk short; eye medium ; color green, with delicate bloom and white flecks; pulp carmine. Fresh fruit esteemed because of its distinctive flavor; dried fruit too small for market.

Três um Prato. Described and illustrated by Bobone (1932). Collected in Algarve, and believed to be of the Smyrna type. Figs medium, pyriform, with prominent neck; skin greenish yellow, smooth, sometimes checking; pulp rose-colored; flavor agreeable; quality good.

Verdescone (syns. Verdesco at Mesagne; Verdone at Taranto ; Acriesto at Carosino). Described and illustrated by Vallese (1909). Cultivated especially in the Taranto district; consumed fresh and dried. It produces few if any brebas.

Leaves medium, usually 5-lobed, with deep sinuses. Figs large, flaskshaped, with prominent neck; ribs slightly elevated; skin green, medium thick; pulp red; flavor very agreeable.

West. Seedling No. 14 from the Maslin orchard, Loomis; named by W. T. Swingle (1909) in honor of W. B. West, Stockton. See description by Rixford $(1918 a)$. Reported to bear a fair first crop; distributed as a promising variety, but discarded by growers because the fruits were inferior to Sari Lop in size and color.

Wilson. Described by Eisen (1901) and Rixford (1918a). Variety distributed by United States Department of Agriculture in 1891, and named in honor of the secretary, James Wilson. Grown only for trial, and probably lost.

Yediver. Described and figured by Ozbek (1949) as a variety occasionally grown in the Meander Valley.

Figs medium, oblate, with short stalk; average weight 45 grams; eye open; skin thin, pubescent, yellow; pulp red; flavor sweet, aromatic. Number of seeds per gram, 930 . 


\section{Smyrna-type Figs with Skin Dark (Various Shades of Violet to Black); Pulp White or Amber}

Euscaire (syn. Euscaire Preto). Introduced as P.I. No. 18,851 in 1906, with the Chiswick collection of English figs; listed but not described by Eisen (1901); requires caprification in California.

Tree upright, open; terminal buds brown. Leaves medium, glossy above; upper sinuses of medium depth and width, lower sinuses shallow; base cordate, sometimes truncate or even decurrent; margins wavy, coarsely crenate; texture harsh, thick. (Plate 13.)

Figs medium, pyriform, with a prominent neck; average weight 40 grams; stalk thick, up to $1 / 2$ inch long; ribs narrow, elevated; eye medium, open; scales violet; white flecks large, conspicuous; color black; skin checking lengthwise, as shown by Condit (1941a, fig. 8, A) ; pulp amber ; flavor rich, sweet. Quality excellent fresh, but inferior and small in size when dried. Of no commercial importance. (Plate 15, B.)

Hamriti. Described by Minangoin (1931) as a variety requiring caprification at Kalaâ Srira, Tunisia.

Leaves medium, 3- to 5-lobed; sinuses deep, sometimes closed. Figs with short, thick neck; skin thin; eye almost closed; color dark violet, with bands almost black; pulp amber.

Scancaniso (syn. Fico della Villa of Cavolini). Described and illustrated by Vallese (1909) ; probably the same variety described by Guglielmi (1908) as Scansaniso. Planted more commonly than Turco; occasionally produces a breba crop in favorable seasons; caprification generally practiced.

Leaves large, 3- to 5-lobed. Figs large, broadly turbinate; neck and stalk both short; color rosy violet; skin checking; pulp whitish. Highly esteemed for fresh consumption.

\section{Smyrna-type Figs with Skin Dark (Various Shades of Red, Brown, or Violet to Black); Pulp Various Shades of Red}

Abougandjour. Described and illustrated by Mauri (1942). Name signifies "long beak," owing to the particularly long stalk. Grown near Fort National; also common at Mechtras, Boghni, and Dra-el-Mizan, where it is appreciated for its productiveness and good keeping qualities.

Tree vigorous, compact. Leaves rather small, 3-lobed. Figs globular; neck short; size medium; stalk over $1 / 2$ inch in length; color violet-black; pulp garnet, solid.

Adjaffar. Described and illustrated by Mauri (1942). Trees well distributed in the Soummam Valley; sometimes confused with Azendjar; known as Azegoush by some growers near Sidi-Aich.

Tree vigorous, very productive. Leaves generally 5-lobed; petiole often tinged with red.

Figs globular, above medium; neck missing ; skin rather thick; color violet, with scattered white flecks; pulp red; quality good.

Aghan. Introduced from Afghanistan under P.I. No. 134,750, as a hardy fig, able to withstand zero temperatures. At Riverside it produced small, purple figs with deep-strawberry pulp that were of no particular value. 
Agouarzguilef. Described and illustrated by Mauri (1939b, 1942). Abachlaou, also found at Tizi-Rached, may be the same.

Tree vigorous, diffuse, very productive; leaves 5-lobed.

Figs medium, oblate-spherical, slightly oblique; stalk short; neck none; ribs not prominent; color black, with white flecks; pulp red, sweet. Quality good for drying, but inferior to Azendjar. Season later than Taranimt.

Agoussim. Described and illustrated by Mauri (1942). Found in the region of Sidi-Aich.

Tree moderately vigorous, diffuse, very productive. Leaves 5-lobed; petiole slender, tinged with red.

Figs medium, globular, without neck ; stalk short ; color violet-black, darker at the apex; pulp garnet, of good quality. Season sometimes earlier than that of Tameriout.

Aranim-Aberkane. Described and illustrated by Mauri $(1939 b, 1942)$. The word aberkane signifies "black"; it is listed by Trabut (1904) and Blin (1942) as a black fig.

Tree moderately vigorous, somewhat erect. Leaves 3 - to 5-lobed, with narrow and deep sinuses.

Figs medium, short-pyriform, with neck and stalk both short; skin thin, parchmentlike; eye half open; color black with white flecks; meat thin ; pulp red, sweet. Quality excellent fresh, but inferior dried on account of tough skin. Fruit inclined to split in wet weather. Split figs average 1,008 fertile seeds; sound figs, 884 .

Averane (syn. Aberakmouch at Mekla). Described and illustrated by Mauri $(1939 b, 1942)$. Name signifies "stranger," probably because of its introduction from another place into Tizi-Rached, or even into Kabylia.

Tree vigorous, compact and erect, very productive. Leaves generally 5 -lobed; petiole slender, green, tinged with carmine. Trabut $(1904,1923)$ briefly described Averane as having nonlobed leaves. See also Blin (1942).

Figs below medium, globular, without neck; stalk short; eye partly open, scales tinged with carmine; color black; pulp red, sweet. Quality good. Season fairly early.

Avouzegar. Described and illustrated by Mauri (1942). Name signifies "reddish," owing to the characteristic violet-red tint of fruit at maturity.

Tree vigorous, diffuse, very productive. Leaves 5-lobed. Figs globular, flattened at the apex, medium in size, reddish violet in color; eye small. closed; pulp red. Of fair quality, but too small after drying.

Azendjar. See brief account by Trabut (1904, 1923), and Blin (1942), as Azenjar. Described and pictured by Mauri $(1939 b, 1942)$. Hanoteau and Letourneux (1872) list Ajenjar as a common fig, bearing two crops. Name signifies "gray-green," on account of the green tint, which persists even on the mature fruit. Figs regarded by Kabyles as the best of dried figs; not acceptable in market, however, on account of black color.

Tree very vigorous, diffuse, productive; lower branches tending to droop. Leaves large, 3 - to 5 -lobed.

Figs medium, $13 / 4$ by 2 inches, short-pyriform, with neck practically none; eye medium; color black, dotted with white flecks, often shaded green toward the eye; pulp dark red, very sweet. Quality very good, both fresh and dried. 
Bardakjik Black. Described by Eisen (1901) as a black fig of Asia Minor, where it is considered one of the best for fresh consumption.

Barli. Two apparently different Smyrna-type varieties, described as Barli by Minangoin (1931). One, from Dra Tamar, Tunisia, has small, elongated figs, with reddish skin and light-red pulp. The other, from Monastir, produces figs that are oblate, ribbed, and without stalk; skin thin, light green; pulp red; seeds numerous.

Belmandil. (syn. Cara Lisa). Described by Mello Leotte (1901). Name comes from bello, "fine," and mandil (roupa), "linen," in reference to the texture of the skin. Specimens collected at Loulé, Portugal, and described by Bobone (1932) under the name Cara Lisa, were very similar, and probably identical to Belmandil.

Breba crop none; second crop requires caprification. Second-crop figs globular, without neck, smooth; stalk short; color green tinged with violet; pulp carmine; flavor sweet and agreeable; quality good.

Besoul-el-Khadem. Described by Guillochon (1913, 1927, 1929) and by Minangoin (1931) as Bezoult Rhadem from Gabès, and by Valdeyron and Crossa-Raynaud (1950) as Bezoul-el-Khadem. The last authors state that this name probably includes several different clones, having figs of similar shape and of violet color. Leaves 3 - to 5-lobed, or often nonlobed. Figs medium; skin thick, violet in color; pulp dark red, hollow at center.

Minangoin also described Bezoult Rhadem or Bou Defi from Tarzis as a dark-violet fig, with pomegranate-red pulp. Furthermore, he recorded a variety of the same name from Kalaâ Srira, producing large, pyriform figs, violet in color, with red pulp. The latter requires caprification.

Biddin-el-Brel. Described by Minangoin (1931) from Dra Tamar, Tunisia, as a Smyrna-type fig. Tree productive. Leaves small, 3-lobed, or sometimes nonlobed. Figs with long, slender neck; eye small; skin thin; color reddish violet, with thin lines nearly black; pulp red; seeds numerous.

Bou-Ang. Described by Minangoin (1931) as a variety requiring caprification at Gabès, Tunisia. Leaves large, 3-lobed; upper sinuses very deep; petiole slender. Figs with short neck; eye closed; color greenish yellow, tinged with violet; pulp red.

Bou-Harrak. Described by Minangoin (1931) from Ras-el-Djebel, Tunisia. as a Smyrna-type fig of moderate quality. Figs large, somewhat oblate, with short neck; skin thin, dark violet; pulp red.

Castelhano Preto (syns. Euchário Preto, Castelhano da Rocha). Described by Mello Leotte (1901) and Bobone (1932); the latter illustrates three different forms, as grown at Cacela and Silves in Algarve.

Figs turbinate to pyriform; stalk up to $1 / 2$ inch long; color dark violet; pulp dark chestnut, coarse, sweet; quality good.

Habtir. Described by Guillochon (1913, 1927, 1929), and Minangoin (1931), as a fig deep violet or black in color, small to medium in size; neck not distinct; eye nearly closed; pulp dark red. According to Minangoin, it requires caprification.

Kara Injir. Described by Hagan (1929) as a black fig, grown in northern and eastern Turkey. Fruit rather dry, thick-skinned, and generally poor in quality. 
Khalouli. Described by Minangoin (1931) from Djerba, Tunisia, as a variety "à féconder."

Leaves rather large, 3-lobed; sinuses deep, nearly closed. Figs spherical, small, $1 \frac{1}{2}$ inches in diameter; stalk short; skin rather thick, dark violet in color; pulp red.

Kouffi Rouge. Described by Minangoin (1931) as a variety requiring caprification at Kalaâ Srira, Tunisia.

Leaves large, 7 by 7 inches, 5 -lobed; upper sinuses very deep. Figs large, sessile, somewhat oblate; skin thin, light green, tinged with wine red at the apex; ribs violet; pulp red; seeds numerous.

Lugliatico (syns. Lugliarolo, Migliarolo). Described by Porta (1592), Semmola (1845, with figure), Gasparrini (1845, as Ficus polymorpha var. juliana), and by Savastano (1885), as a fig of medium size, purplish black in color, with rosy pulp. Pasquale (1876) described it as a spherical fig; color green, shaded with black.

Marabout (syns. Sultane du Marabout, Aseltani). Introduced in 1928 at request of University of California by United States Department of Agriculture, under P.I. No. 77,480, from E. Rolland, Tizi-Ouzou, Algeria. Correspondence with N. Mauri, Algiers, indicates that this is the same as Aseltani, a variety very little planted, having large, colored fruit, of no value for drying. This may be the one which Trabut (1904) described and pictured as Thaboukal (Taboukal) or Sultane, with a long neck like that of a water jar.

Tree in California unusually vigorous, with thick branches, forming a dense, compact top. Leaves large, 3- to 5-lobed; upper sinuses shallow, narrow, lower sinuses none, or very shallow; base shallowly cordate; margins crenate; petiole green, tinged with pink.

Figs large, up to $2 \frac{1}{4}$ inches in diameter and 3 inches in length, pyriform, with rounded apex; neck very prominent, often $3 / 4$ inch long, sometimes curved and somewhat angular; average weight 66 grams; stalk short, or often up to $1 / 2$ inch long; ribs narrow, slightly elevated, prominent on account of early coloration deeper than body; eye large, open, but ostiole closed by scales; surface glossy, with prominent bloom; white flecks small, scattered, conspicuous; color purplish black on body, shading to light green on the neck; meat white, thick; pulp strawberry, rather coarse in texture; flavor rich, sweet. Quality very good fresh. Season later than that of Sari Lop ; figs continue to mature over a long period. A promising variety for the fresh-fruit market. (Plate 14, A.) See also Condit (1941a, fig. 2, $T$ ).

Mor. Described and figured by Ozbek (1949). Name signifies "violet," on account of the violet color of the fresh and dried fruit. Trees scarce in Turkish gardens.

Figs large, oblate, with long stalk; average weight 55 grams; eye small, partly open; color light green, tinged with purple; pulp red. Number of seeds per gram, 793.

Mor Güz (literally, "violet autumn"). Described by Ozbek (1949) as a variety rarely found in the Meander Valley.

Leaves medium, 5-lobed. Figs above medium, spherical; stalk medium long ; eye small, partly open; skin thick, violet on a green background; pulp red, fibrous; flavor flat. Consumed fresh. Number of seeds per gram, 861 . 
Napoletana. Described by Donno $(1951 a, 1952)$ from Lecee Province of Italy. Branches with brick-red terminal buds and 3- to 5-lobed leaves. Growers carefully and repeatedly caprify the figs of this variety. Brebas are seldom produced. These two facts distinguish it from Napolitaine, described elsewhere.

Second-crop figs medium, obovate to pyriform; stalk up to $3 / 8$ inch in length; ribs numerous; eye open, scales yellowish or violet; color green, tinged with violet; white flecks scattered, numerous; pulp light red. Consumed mostly fresh. Season late, mid-August to October.

Passacanne. Described by De Rosa (1911). Tree robust. Leaves usually 5-lobed. Figs oblate; stalk short; eye small, scales colored carmine-violet; skin violet; pulp salmon-rose; seeds medium, scattered. Ordinarily consumed fresh.

Purple Bulletin Smyrna. Descriptions by Eisen (1901) and Roeding (1903) conflict in certain details, such as shape, neck, and stalk. Included in the fig importation from Turkey by the Bulletin Company, San Francisco, in 1883.

Figs large, oblate-pyriform, with short neck; color purplish brown, with large white flecks; pulp amber to light strawberry. Quality good fresh, but poor dried, on account of tough skin and unattractive color.

Purple Smyrna. A variety described by Eisen (1901) and Roeding (1903, 1914). Imported from the Smyrna district by G. C. Roeding, Fresno. Tree a dense grower. Figs small, globular, purplish black. Quality good fresh or dried. Of no particular value.

Rherabi (syn. Corbeau). Described by Minangoin (1931) from Ras-elDjebel, Tunisia, as a variety requiring caprification.

Leaves large, 3-lobed; sinuses of medium depth, open. Figs spherical, above medium, 17\% inches in diameter ; skin of fine texture, distinctly ribbed; stalk very short; eye closed; color black; pulp solid, red.

Salatello (syn. Salateddhu). Described by De Rosa (1911). Tree lacking in vigor, with branches short-jointed. Leaves large, 3- to 5-lobed. Figs oblate; stalk very short; color green, tinged with violet-brown; pulp carmine; seeds large, numerous; flavor insipid.

Soltanine. Described briefly by Guillochon (1913, 1927, 1929). Probably the same fig described by Minangoin (1931) under the name Soltani, from Dra Tamar, Tunisia, requiring caprification.

Leaves large, 3-lobed. Figs medium, spherical, with elongated neck; skin of fine texture, reddish violet in color; pulp dark red; quality very good.

Taklit. Described and illustrated by Mauri (1942). Name signifies "negress," on account of black color of fruit. Sparsely cultivated in the valley of the Soummam.

Tree vigorous, very productive. Leaves 5-lobed. Figs globular, small; color black; very few if any white flecks; pulp deep red; quality good.

Taroumant. Described and illustrated by Mauri (1942) from a single tree at Beni-Ourlis. Name signifies "grenade," probably from the appearance of the red pulp in fruits split after rain. Figs large, greenish violet; pulp garnet, texture coarse; quality poor.

Techich (syn. Assel). Described by Minangoin (1931) as a Smyrna-type variety from Menzel Temine, Tunisia. 
Leaves small, generally 3-lobed, with some 5-lobed or even nonlobed;

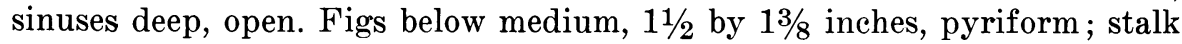
practically none; skin very thin, light brown in color; pulp red.

Turco. Described and illustrated by Vallese (1909). Trees large, with small, 5-lobed leaves; not commonly found. Figs below medium, ovoid; stalk short; color violet; pulp red.

Zafrani. Described by Minangoin (1931) from Monastir, Tunisia. Leaves medium, 3-lobed; upper sinuses deep, closed; petiole short. Figs small; neck short; skin rather thick, dark violet in color; ribs present; pulp light red. An attractive fruit, requiring caprification.

\section{Smyrna-type Figs Lacking Complete Descriptions}

Hammani. Described by Minangoin (1931) from Hammamet, Tunisia, as a variety that requires caprification. Leaves below medium, 5 -lobed; upper sinuses deep, open. Figs somewhat oblate, $1 \frac{1}{2}$ by $13 / 4$ inches; stalk very short; color light yellow.

Khlouth. Described by Minangoin (1931) from El Oudiane, Tunisia. Leaves very large, 5-lobed; sinuses deep and open; petiole long, up to 4 inches. Figs large; neck short; ribs present; skin thick, glossy, light green in color. Requires caprification.

Teen Kazzi. A Smyrna-type fig, introduced in 1927 from Beirut, Syria, under P.I. No. 72,615. No production of fruit in California.

Thaaranimt Entael Hadjar (syn. Azerou at Tizi-Ouzou). Described by Trabut (1923). Tree vigorous, with drooping branches; leaves large. Figs light green in color; neck elongated. Fruit easily harvested, because it dries on the tree; well regarded in the market.

Thamkarkor Rose. Described by Trabut $(1904,1923)$ as a small, round fig, borne so profusely as to hang like grapes on the twigs. Observed at Seddouk, where the small, dried fruits were sometimes sought by consumers. See also Blin (1942).

Zidi. Described and illustrated in color by Valdeyron and Crossa-Raynaud (1950) as a Tunisian variety producing a second crop only. Tree of large size. Leaves often very large. Figs large, violet-black; used fresh. Caprification necessary.

The following varieties, listed and very briefly described by Trabut (1904, 1923), may be of the Smyrna type: Timlouit, Thaaoust, Thaharchou, Thazgouart, and Thaarlit.

Hanoteau and Letourneux (1872) list five kinds from Kabylia, believed to require caprification: Thar'animt, El Hadj, Abouzouggar, Mezzith, and Thazaicht.

\section{VARIETIES OF THE SAN PEDRO TYPE}

San Pedro-type figs combine the fruit-setting peculiarities of both the Smyrna and the Common type on one tree in a single annual cycle. Firstcrop figs (brebas) are of the Common type, and develop parthenocarpically. Second-crop figs are of the Smyrna type, the syconia dropping unless stimulated by pollination and fertilization of the long-styled flowers. All of the 
twenty-one varieties included in the list of San Pedro-type figs bear a more or less abundant crop of brebas. Since parthenocarpic development of second-crop figs is not a fixed character, the inclusion of certain varieties or the omission of others may be questioned. An example of a perplexing variety is the King, which, without caprification, drops practically all of the main crop at Riverside, but matures a large percentage in coastal climates. Drap d'Or is included in the San Pedro group, although at Riverside a small number of second-crop figs reach maturity without the stimulus of caprification. The following varieties are divided into two groups, based on the color of skin and pulp.

\section{San Pedro-type Figs with Skin Green; Pulp Red}

Cachôpeiro Branco (probable synonyms are Lampo Branco, Vindimo Branco, Santa Catarina, Roma Branco). Described by Mello Leotte (1901) and Bobone (1932); illustrated also by the latter. Cachopo, described by Mello Leotte, may also be the same, although he reported the second crop set fruit without caprification. Brebas mature in Algarve from the middle of May to the end of June, while the second crop ripens in the middle of August.

Brebas pyriform to turbinate, with thick neck and short stalk; color greenish yellow. Second-crop figs oblate-spherical, without neck; pulp rosy chestnut; texture coarse; quality good.

Colombro (syns. Columbo, Colombra, Colummone, Colombone, Columbaro, and probably Colombo Pazzo). Described by Semmola (1845, with illustration) ; by Gasparrini (1845) as Colombro; by Savastano (1885) as Colombo; by Vallese (1909) as Colummone, with illustration of leaves; by Siniscalchi (1911) as Columbro; and by Donno (1951b) as Columbaro. According to Vallese, the names Columbo, Colombone, etc., are probably applied to different varieties with a profuse breba crop, commonly called "colummi" or "colombi." Savastano stated that caprification is indispensable for Colombo; Vallese, however, expressed doubt in the matter, since in some districts the practice of caprification is extended to all varieties, whether they require it or not. De Rosa (1911) found that Colombo Pazzo required caprification; Donno describes the two crops of Columbaro in detail, but does not mention caprification. Colombro is grown in central Lecce Province and near Cape Leuca.

The tree has light-green terminal buds and mostly 5-lobed leaves; see Donno (1951a) for account of buds and twigs.

Brebas not described by Vallese, but reported by Savastano to be small, spherical, green in color. According to Donno (1951b) the brebas are large, pyriform, light green in color; pulp light red.

Second-crop figs (after Donno) medium, 2 by 2 inches, spherical; stalk up to $3 / 8$ inch in length; eye mostly open; ribs numerous, elevated; skin color light green; pulp red. Mostly consumed fresh.

Gentile (syns. Gentilla, Figue d'Or, Fico d'Oro, Tiburtina of Pliny, Ficus carica pulchella Risso). Described by Porta (1592), Tanara (1651), Aldrovandi (1668), Miller (1768), Hanbury (1770), Christ (1812), Forsyth 
(1803), Gallesio (1817), Risso (1826), Lindley (1831), Holley (1854), Dochnahl (1855), Sauvaigo (1889, 1894), Eisen (1896, 1897, 1901), Bois (1928), Condit (1921b, 1947), Evreinoff (1947), and Tamaro (1948). Illustrated by Eisen (1901) and Condit (1921b).

According to Gallesio, the Gentile fig is the same variety recorded by Pliny as Tiburtina. Aldrovandi called it Gentilium. It was highly praised by Gallesio, who said it well deserved the name it bears, Gentile, or "delicate"; he added that he knew of no other variety which produced brebas equal to it in beauty, delicacy, and flavor. Figs of the second crop, according to Gallesio, reached a certain size, then shriveled and dropped. Sauvaigo reported that the Gentile tree bears two crops, but that figs of the second crop are not edible, since they drop before they mature. Trees are commonly found from Naples to Toscana and along the Italian Riviera. The Gentile described by Simonet is regarded by them as identical with Dottato.

According to Eisen, two cuttings of the Gentile were found at San Leandro, California, in 1852. They were planted in a nursery, and one later developed into a large tree. The original plant died, but a cutting from it, planted on the Kimball place, 1859 Hoover Street, Hayward, is still growing and producing brebas each year. Other trees were reported by Eisen at Alameda and at Knights Ferry. P.I. No. 18,899 of the Chiswick collection is listed as Gentile, but no California records have been located as to behavior of trees from that introduction. In coastal districts, the Gentile is similar in external fruit characters to the King, but is much inferior to that variety in color and texture of pulp and in eating quality. Gentile is not recommended for dooryard planting, since trees of certain other varieties bear not only brebas but also main-crop figs without caprification.

The tree is vigorous, and reaches large size, with lower branches drooping. Leaves are large, and 3-lobed. Description of brebas is after that of Eisen, and from specimens produced by the tree at Hayward.

Breba crop fair to good; fruits above medium to large; body spherical, with short, thick neck; stalk very short; ribs not prominent; eye large, protruding, open, scales rose-colored; surface glossy, with delicate bloom; white flecks prominent, numerous; color green; pulp amber to light strawberry; flavor sweet, fairly rich; seeds few ; quality good. No description of caprified second-crop figs is available.

Comparison of the fruits and fruiting habits of Gentile and White San Pedro leads to the conclusion that these two Italian varieties are very similar, and that they may be identical.

Khdari. Described and illustrated by Grasovsky and Weitz (1932) as found in all parts of Palestine, where it is grown especially for the freshfruit market. The name signifies "green."

Trees are very distinctive in shape, with dark-green leaves.

The "daffour" (breba) crop is exceptionally good; brebas large, up to 3 inches in diameter, oblate-spherical; neck missing; stalk short; eye open, with brownish scales; skin thin, green; pulp light strawberry, very juicy; flavor sweet and rich. Not used for drying.

King. The exact origin and identity of the King fig have not been determined. About 1930, cuttings from a fig tree growing near Madera, Califor- 
nia, were planted by Sisto Pedrini, Western Evergreen Company, at Los Altos and at San Francisco. The young trees produced such excellent fruit that hundreds of plants were propagated and distributed in Pacific Coast states and elsewhere by the King Fig Plantation, San Francisco. See account by Brooks and Olmo (1949). The King tree is exceptionally prolific of the breba crop, which often sets three to five or more fruits close together, somewhat like the crop of certain caprifigs. At Riverside, and in most other inland districts, the majority of second-crop figs shrivel and drop for lack of caprification, a fact which places this variety in the San Pedro group of figs. In cool, coastal sections, a fair percentage of the crop matures by parthenocarpy, as explained elsewhere by Condit (1950).

Of all the varieties fruiting in the collection at Riverside, the King is unexcelled for the production of brebas. Few home owners, however, have found the King satisfactory, because of the severe dropping of the second crop and lack of knowledge as to the cultural methods most likely to give best results with this variety. Branches of King trees should not be cut back heavily in winter, as this removes the fruit buds which normally produce a breba crop. A judicious thinning out of the older wood occasionally would seem to be the best procedure. The following description is of trees and fruit grown at Riverside since 1941.

Tree moderately vigorous. Leaves medium, 3- to 5-lobed; base subcordate; lateral sinuses broad, shallow ; upper surface somewhat glossy, rugose; margins shallowly crenate.

Brebas above medium to large, short-pyriform, often oblique, with or without short, thick neck; average weight 88 grams; stalk short; ribs present, but not prominent; white flecks variable, large and widely scattered in some, small and numerous in others; eye large, scales chaffy or strawcolored, semi-erect; color green; bloom prominent; meat thin, white; pulp strawberry ; flavor rich; quality excellent. (Plate 16, A.)

Second-crop figs uncaprified, medium, with or without short neck; color greenish yellow; pulp amber to very light strawberry; seeds few, tender, hollow. Caprified figs with stalk very short and no neck; average weight 45 grams; color dark green; pulp dark strawberry; flavor rich; quality good. (Plates $12 ; 16, B$.)

Noce. Described by De Rosa (1911). The tree has slender branches, and large, 5-lobed leaves. It produces brebas rather abundantly, but the fruit characters are not given. Second-crop caprified figs are globular; stalk very short; color green; eye scales rose; pulp red; seeds large and numerous. Matures August and September.

Pietri. P.I. No. 102,018, received from Morocco in 1933 as Pietri, and P.I. No. 101,723, from Sochi, Black Sea district, as Violet Delicate, are identical at Riverside. These are both very similar to Blanquette (P.I. No. 102,007 ), also from Morocco, but originally in a collection of varieties from Lérida Province of Spain. All three show the characteristic bearing habit of the San Pedro type.

Breba crop fair; figs medium or above, pyriform, with prominent, thick neck and short stalk; eye large; color lettuce green ; pulp strawberry ; quality fair. Very inferior to King in productiveness, size of fruit, and quality. 
Second-crop figs medium, oblate-spherical, without neck; stalk short; color green; pulp strawberry, gelatinous in texture; seeds fertile; quality fair to poor.

San Giovanni (syn. Santa Scianni). Described by De Rosa (1911) as an Italian variety, producing some brebas and requiring caprification for the second crop.

The figs are spherical to oblate; size medium, 2 inches in diameter and $15 \%$ inches in length; stalk very short; eye medium, scales rose-colored; skin color green; pulp light red; seeds large and numerous. Usually consumed fresh. Not recommended for general planting.

San Pedro (syns. San Pedro White, White San Pedro, Apple, Saint Peter). Described by West (1882), Eisen (1885, 1896, 1897, 1901), Fancher Creek Nursery catalogue, Fresno (1885-1886), Colby (1894), California Nursery catalogue, Niles, (1889-1890), Starnes $(1903,1907$, the second with Monroe, both with illustrations), Roeding (1914), and Condit (1921b, 1947). See also Condit (1941a, fig. 2, I).

The identity and synonymy of San Pedro with a European variety have not been established. According to Eisen (1901, p. 65), "F. Pohndorff, then of Niles or vicinity, imported the White San Pedro under the name of Breba from Spain and distributed it in this country in 1883 or 1884." On the other hand, Milco stated in 1884 that he had imported the San Pedro from Dalmatia about eleven years previously. It is not the same as San Piero, described by Gallesio, nor San Pietro, both of which are treated elsewhere in this monograph.

Since about 1885, San Pedro has been widely distributed in California, but nowhere has it achieved commercial importance, despite the advertisement of one California nursery that "as a table fig this one is unsurpassed, and will exclude all others on the market." It was grown and tested at the California Experiment Stations, and Colby reported analyses of the fruit grown at Fresno in 1893. The tree that grew at Parlier, Fresno County, for many years, and that was erroneously reported in the American FruitGrower, November, 1929, as the largest fig tree in America, was of this variety; not of the Adriatic, as stated (plate 5). Trees of San Pedro have been fruiting in the collection at Riverside since 1930, and the following account is based on the behavior of this variety during the intervening years.

The tree is rather open, with drooping branches; terminal buds are green. Leaves variable in size and lobing, mostly 3-or 5-lobed; surface somewhat glossy ; upper sinuses of medium depth and width, lower very shallow, broad; base shallowly subcordate to truncate; margins coarsely and shallowly crenate.

Breba crop good; figs above medium to large, turbinate, with prominent, thick neck, or sometimes spherical without neck; average weight 78 grams; stalk short; ribs fairly prominent; white flecks variable, conspicuous on some specimens, few on others; eye large, scales straw color, erect; surface glossy, with delicate bloom; color yellowish green; meat white; pulp amber, tinged with strawberry; flavor moderately rich; quality fair to good. (Plate 17, A.)

Second-crop figs medium to large, up to 2 inches in diameter and about 
the same in length, spherical or oblate, with short stalk ; neck variable, present and prominent, or missing; average weight 58 grams ; ribs broad, prominent; eye large, open, but internally closed by scales ; surface glossy ; bloom fairly heavy; white flecks large, scattered, conspicuous; skin thick, rubbery in texture; color green to yellowish green; meat white, thick; pulp strawberry ; seeds fertile, numerous; texture gelatinous ; flavor insipid, flat; quality fair to poor. Fruit inclined to split when nearing full maturity. Of little value, either fresh or dried. (Plate 17, $B$.)

San Vito (syn. Santu Vitu). Described by Donno $(1951 a, 1951 b)$ as a variety of Lecce Province. Valued mostly for its production of brebas; second crop requires eaprification.

Trees have green terminal buds, and mostly 5 -lobed leaves. Brebas medium, 2 by 2 inches, spherical, or sometimes ovoid; eye open, scales light yellow; skin color dark green; pulp light red. Second-crop figs below medium, oblate; eye open; ribs numerous; color light green; white flecks scattered, variable in size; pulp light red.

\section{San Pedro-type Figs with Skin Bronze or Violet; Pulp Amber or Red}

Buino. Described by Portale (1910) as a variety producing only a breba crop. Brebas rather large, spherical; stalk short; color dark violet; pulp watery, but agreeable in flavor. Consumed fresh.

Carvalhal. Described by Mello Leotte (1901). Name refers to a fig of the Carvalhal estate. Tree producing abundantly first and second crops, the latter being artificially caprified.

Leaves 3-lobed, with violet stipules. Brebas large, pyriform; skin violet; pulp rose-colored. Second-crop figs smaller, globose, of same color as brebas.

Castle Kennedy (syn. Kennedy). Described by Fowler (1865, 1866), Hogg (1866), K. (1873), J. S. W. (1873), Watts (1890), Barron (1891), Massey (1893), Simon-Louis (1895), Norwich (1898), Eisen (1901, after Hogg), Ward (1904), Starnes and Monroe (1907), Reboul (1908), Brotherston (1920), E. A. Bunyard (1925), Davis (1928), Burger and De Wet (1931), and Preston (1951).

A color illustration of Ficus carica kennedyensis Hort. is given in L'Illustration Horticole, vol. 13 (ser. 2, vol. 3), pl. 476. 1866. A writer in the Gardener's Chronicle, November 19, 1864, observed that Messrs. Lawson and Son were to distribute the Castle Kennedy fig, which had been exhibited in Scotland and had obtained an award from the Edinburgh Horticultural Society. An anonymous account in 1865 (Florist and Pomologist, p. 141) stated that this variety had then existed at Castle Kennedy for nearly a century; but how it came there or what was its origin were matters on which there was no reliable information. It was believed to be quite distinct from any other variety in cultivation in England. Archibald Fowler, who grew this fig at Castle Kennedy, along with Brunswick and Brown Turkey, also maintained that it was distinct from both varieties. Several reports indicate that the trees are poor producers; but on the contrary, Hogg stated, "The tree is an abundant bearer." A writer of 1873 , signed simply as "K.," re- 
ported that Castle Kennedy was worthless as a cropper ; "... it is a runaway, unfruitful variety, not worth house room." Brotherston noted that in England only one crop, presumably the first, is produced in a year. This seems to confirm the report of Burger and De Wet, that in South Africa the second crop requires caprification, a fact that places the variety in the San Pedro group.

A letter dated June 20, 1954, from Sir John Dalrymple, Earl of Stair, states that two trees of the Castle Kennedy fig are still being grown mainly for sentimental reasons at Lochinch Castle, Stranraer, Wigtownshire, Scotland. R. W. Rye, the head gardener, agrees with "K." above that this fig "is not worth house room as it is very shy in setting fruit."

Castle Kennedy was not included in the Chiswick collection that was introduced into California, nor is the name found among those tested by the Experiment Station. P.I. No. 69,017, obtained from a French nursery in 1928 as "Kennedy," has proved to be identical with Brunswick in tree and fruit. Starnes and Monroe reported in 1907 that in Georgia, Castle Kennedy, obtained from the same French nursery as the above number, resembled Dalmatian (Brunswick), and might prove to be identical with it. Judging from the various accounts of this variety, the Castle Kennedy is very similar to Brunswick, but belongs to the San Pedro rather than to the Common group of figs.

Hogg described the fruit as very large, obovate; skin thin, tender, greenish yellow on the neck, pale brown on the body; pulp pale red, soft, not highly flavored.

Chiajese. Described by Semmola (1845), Gasparrini (1845), and Duchartre (1857). This variety, treated by Gasparrini as Ficus polymorpha, is regarded by Italian growers as one requiring caprification.

The first crop is very small; brebas large, turbinate, dark-colored, mediocre in quality. Second-crop figs medium, spherical, tawny-green in color; pulp red, of mild flavor. Used fresh.

Dauphine (syns. Dauphine Violette, Grosse Violette, Ronde Violette Hâtive, Rouge de Argenteuil, Mussega Negra, Ficus carica punctulata Risso, Pagaudière, Adam). Described by Risso (1826), Barron (1868c, 1891), Lhérault (1872), Du Breuil (1876), Simon-Louis (1895), Eisen (1888, 1901), Forrer (1894), Schneider (1902), Juignet (1909), Mazières (1920), Bois (1928), Soc. Nat. d'Hort. de France (1928), A. Rivière (1928), Delplace (1933), Simonet et al. (1945), Delbard (1947), Evreinoff (1947), and by Simonet and Chopinet (1947). Illustrated in black and white by Du Breuil, Bois, Simonet, and Condit (1941a, fig. 2, $H$ ). Illustrated in color by Delbard, and by Simonet and Chopinet.

Dauphine is grown near Paris for its abundant breba crop ; it is also cultivated extensively in southern France on account of its large, attractive fruits, which carry well to distant markets. According to Simonet et al., it is known at Sollies-Pont as Boule d'Or, Bouton d'Or, and Grosse de Juillet; but the last name is also given as a synonym of Sultane. These authors also refer it to Mussega Negra (Ficus carica punctulata Risso). There are small plantings of Dauphine near Tokyo, Japan, where the brebas ripen in July.

In 1883, Dauphine was introduced into California from England by John 
Rock as Ronde Violette Hâtive, and trees were planted for trial at various experiment stations in this state and in Arizona. At the Tulare, California, station, it was reported to be one of the most promising commercial sorts under tests. P.I. No. 18,912 of the Chiswick collection was labeled Dauphine. Another one of the same collection, P.I. No. 18,873, labeled Adam, was found to be the same as Dauphine, both in tree and in fruit. A variety introduced from France by Felix Gillet, Nevada City, as Pagaudière, has also proved at Riverside to be identical with Dauphine, although Eisen described it as a reddish-yellow fig.

Trees were under trial at the. Government Date Garden, Indio, before 1926, and several growers in the Coachella Valley obtained cuttings. From one small commercial orchard, the fresh figs were sent to market under the name "Superba." No other commercial plantings have been made in California, as Dauphine can hardly compete successfully with other black figs such as Franciscana (Mission) for fresh-fruit shipping, and its quality dried is very inferior. Trees have fruited at Fresno since 1924, and at Riverside since 1931.

In California, trees of Dauphine drop all fruits of the second crop unless caprification is practiced.

Tree vigorous, upright; outer branches drooping; terminal dormant buds green, shading to brown or violet. Leaves medium to large, 3- to 5-lobed; upper surface somewhat glossy; upper sinuses of medium depth and width, lower sinuses shallow and broad; base subcordate; margins coarsely crenate. Description of fruit is from specimens at Riverside, in comparison with the account by Simonet.

Breba crop generally good ; fruit large, $21 / 2$ by $2 \frac{1}{2}$ inches, turbinate, with or without a short, broad neck; average weight 92 grams ; stalk up to $1 / 4$ inch long; ribs broad, slightly elevated, more deeply colored than body; eye large, protruding, open, scales violet; skin of firm texture, resistant; surface glossy, with white flecks numerous and conspicuous; bloom rather heavy, pruinose; color greenish violet in the shade to violet-purple on exposed side, shading to green toward the stalk; meat white, almost $1 / 4$ inch thick; pulp light strawberry; seeds large, fairly numerous. Flavor fairly rich, but lacking distinctive fig character. Quality fair to good; especially good for shipping fresh. (Plate 18, A.)

Second-crop figs much the same as brebas, except for smaller size; shape oblate-spherical; pulp gelatinous with fertile seeds; average weight 70 grams; quality poor. (Plate $18, B$.)

Drap d'Or (syn. Royal Vineyard). The identity of Drap d'Or is in doubt. If it is regarded by French confectioners as one of the best figs for crystallized and glacé fruit, as stated by Eisen, why should the variety not be described in French publications? The only descriptions found are those of Eisen (1897, 1901), Barron (1891), Starnes and Monroe (1907), and of Woodroof and Bailey (1931). A variety was grown and tested under the name Drap d'Or at the California Experiment Stations from 1891 to 1895 ; source of the trees was probably the California Nursery Company, Niles, since that nursery imported trees from England in 1883. According to Shinn (1893), Drap d'Or did well at the Tulare station, and in 1914 he included 
it in the list of varieties generally cultivated. On dooryard trees fruited in various parts of California, the breba crop has been fair to good, but the second crop is small unless caprification is practiced. P.I. No. 18,838 of the Chiswick collection, listed as Peau Dure, is probably the same variety, as the fruiting habit at Fresno and Riverside is similar to that of the trees just described. Brebas conform closely in characters to the description given by Eisen, and to his illustration.

Royal Vineyard was described and illustrated in color by Barron (1871) as a new fig of sterling merit, "one of the very finest figs yet brought into cultivation." It was named for the nursery of J. and C. Lee, Hammersmith, England, where the variety was found without a label. Later descriptions were by Hyde (1877) and Barron (1891). P.I. No. 18,849 of the Chiswick collection is labeled Royal Vineyard; it fruited at Niles, California, and was described and also illustrated by Eisen (1901).

The tree of Drap d'Or has an open habit of growth, with branches somewhat drooping; terminal buds green. Leaves medium, somewhat glossy above, light green in color, mostly 5-lobed; upper sinuses of medium depth and width, lower sinuses shallow; lower lobes sometimes auricled; base subcordate to truncate; margins coarsely crenate. The following description is from fruits grown at Riverside since 1930.

Breba crop small; fruits large, pyriform, with prominent curved neck; ribs prominent, rendering the surface more or less corrugated, much like that of Pied de Bœuf; eye somewhat depressed, with pink scales; color light coppery bronze, attractive; pulp light strawberry; flavor sweet and rich; seeds few. Eating quality excellent, but figs are too soft and perishable for fresh-fruit market.

Caprified figs of the second crop medium to large, pyriform, decidedly oblique; average weight 66 grams; neck prominent, rather thick and somewhat curved; stalk from $1 / 2$ to $1 / 4$ inch long; ribs prominent; eye open, scales pinkish ; color reddish brown to violet-brown, deeper at apex and on exposed side ; pulp strawberry; flavor rich ; quality good. Crop is small when caprification is not practiced, as a major percentage of the figs shrivel and drop when immature.

Uncaprified figs medium, pyriform, with prominent neck and long, slender stalk; surface corrugated by raised ribs; eye medium, open, scales rose red; color bronze; meat thick, white ; pulp hollow at center, light strawberry, texture dry; quality very poor. (Plates $9 ; 24, C$.)

Fracazzano Rosso (syn. Ficazzano). Second-crop figs described and illustrated by Vallese (1909); figs of both crops described by De Rosa (1911), who states that caprification is necessary. Ficazzano, described by Portale (1910), is treated by De Rosa as synonymous with Fracazzano Rosso.

Leaves large, mostly 5-lobed.

Brebas large, ovoid; color violet, shading to dark green toward the base; pulp rose-colored; seeds few and small.

Second-crop figs turbinate to obovate, above medium; neck none; stalk very short; eye medium, surrounded by a yellowish aureole, scales violet; color rosy violet, light green toward the stalk; pulp red; seeds large; flavor sweet. Normally preferred fresh. 
Lampeira (syns. Portoghese, Lampas, Figue des Confiseurs). Described and illustrated by Gallesio (1817), Gasparrini (1845, as Ficus pachycarpa var. lusitanica), Pasquale (1876), Mello Leotte (1901), Eisen (1901), Simonet et al. (1945), Tamaro (1948), and Baldini (1953); the last with illustration of leaf and brebas. It is also figured by Tamaro. According to Gallesio, this variety was very common in Tuscany, especially at Florence, and was figured as No. 17 under the name Lampas Portoghese. Eisen praised it highly by stating: "What the White San Pedro is for Andalusia in producing the luscious brebas, the Lampeira is for southern Portugal." It is probably this same variety which Bobone (1932) described and illustrated as Figo Burro, with the following synonyms: Burro, Gentio, Roma Preto, Bispo, Cachôpeiro Preto, Bacalar Preto, Lampo Preto, and Vindimo Preto. Lampeira was once introduced into California, probably as P.I. No. 18,871, and fruited at Niles, but no later records of its occurrence or behavior in this state are available. The following description is after that of Simonet.

Tree moderately vigorous. Leaves small; deeply 3-lobed.

Brebas large, about $3 \frac{1}{2}$ inches long and $21 / 2$ inches broad, pyriform, with prominent neck and medium stalk; average weight 102 grams; eye large, open, scales violet; color greenish yellow, tinged with violet on sunny side; skin glossy, rather thick; meat thin, white; pulp rosy amber, with violet shade toward the eye; seeds rather numerous. Quality excellent; appearance fine.

Second-crop figs medium or below, about 2 inches long and $11 / 2$ inches broad, pyriform, with short, thick neck; eye partly open, scales rosy; skin delicate, checking at complete maturity, green flushed with violet; pulp deep red; seeds small. Second crop negligible without caprification.

Ottato Rosso. Described and illustrated by Vallese (1909); described in detail by Donno (1952). Variety similar to Dottato Bianco in foliage and fruit; seldom produces a breba crop. Growers disagree on necessity for caprification, probably owing to confusion with two similar varieties; experiments, however, have shown that caprification is essential to crop production.

Leaves large, 3- to 5-lobed; sinuses of medium depth; buds and branches described by Donno (1951a).

Brebas long-pyriform, ribbed on lower part of body; color light chestnut on side exposed to sun; meat white, tinged with violet; pulp amber, very sweet.

Second-crop figs above medium, ovoid, rounded at apex; stalk up to $5 / 8$ inch in length ; surface smooth, with scattered white flecks; eye open; color reddish violet; pulp amber, tinged with red. One of the best for fresh consumption; good also for drying.

Petronciano (syns. Molignano, Barbanera). Described by Gasparrini (1845, as Ficus polymorpha var. melanocarpa), Duchartre (1857), Pasquale (1876), and Savastano (1885). According to the latter, the tree bears an abundant crop of brebas; the second crop is caprified. Figs medium; skin purplish black; pulp given as white by Gasparrini; as "carnea" by Savastano; apparently flesh-colored.

Pied de Bœuf. Described by La Brousse (1774), Hogg (1866), Barron (1891), and Eisen $(1888,1901)$. La Brousse gave a disparaging opinion of 
the fresh-fruit qualities of Pied de Bœuf, but found it very good dried at Antibes, France. The other descriptions leave one in doubt as to the specific crop, but it is probable that both Hogg and Barron have considered the breba crop only, as a second crop of figs is not commonly produced in England. The slight attention given to this variety by horticultural writers is likely due to the fact that second-crop figs mostly drop unless caprification is practiced. The late Leroy Nickel, of Menlo Park, California, obtained cuttings of Pied de Bœuf from England, and donated wood for the Riverside collection in 1927. Since that time it has proved to be a promising variety for freshfruit brebas and for caprified figs of the main crop. Its behavior at Riverside has been better than in the cooler climate of Los Angeles. Tree and fruit characters are very much like those of Drap d'Or, but the two are regarded in this publication as distinct varieties.

Pied de Bœuf trees are slow-growing and densely branched, with terminal buds green in color. Leaves medium, somewhat glossy above, mostly 5-lobed, the middle lobe broadly spatulate; upper sinuses of medium depth and width, lower sinuses shallow, basal sinuses narrow; base cordate; margins coarsely crenate. The following description is based on notes made of figs produced during fourteen fruiting seasons.

Breba crop fair to good ; figs oblique-pyriform ; size large, up to $21 / 4$ inches in diameter and $31 / 2$ inches in length ; average weight 79 grams; neck prominent, often curved, and up to 1 inch long; stalk slender, $1 / 2$ to 1 inch long; ribs very prominent, the surface of the fruit therefore corrugated; eye above medium, scales rose to violet-brown; skin tender, waxy or glossy in appearance, with bloom fairly prominent; white flecks scattered, more or less concealed by body coloration; color Hessian brown, shading to green or light brown on neck; meat white, tinged with pink; pulp light strawberry, slightly hollow at the center, texture rather coarse; quality good. Excellent in appearance, but not well adapted to fresh-fruit shipping on account of tender skin and ribbed surface. (Plate 23, A.)

Second-crop caprified figs oblique-pyriform, above medium to large, up to 2 inches broad and 3 inches long; neck short and thick, or up to 1 inch long; average weight 63 grams; stalk slender, often curved, up to 1 inch long, sometimes enlarged or swollen toward the apex; ribs elevated, prominent; white flecks scattered, fairly conspicuous ; eye large, open, scales violet; skin somewhat glossy, tender, checking at maturity; color chocolate brown to mahogany red, attractive; meat white; pulp dark strawberry; flavor rich and sweet; quality excellent.

Uncaprified figs light in weight; center hollow; pulp amber ; quality poor. (Plates $9 ; 14, C$ ). See also Condit (1941a, fig. $2, R$ ).

\section{VARIETIES OF THE COMMON TYPE}

Figs of the Common type develop parthenocarpically, and do not usually require the stimulus of pollination to bring the syconia to maturity. Some common figs, such as Barnissotte and Verdal, drop all or nearly all the fruit buds of the first crop but mature a good second crop. Others, such as Franciscana and Dottato, have practically complete parthenocarpic development 
in both crops. As pointed out under Brunswick, the expression of parthenocarpy is incomplete in some varieties, and is apparently affected by the environmental complex. As with the other types, the varieties will be treated under groups based on external and internal color. The following key to some of the varieties grown in the collection at Riverside is given in order to show differentiation of important characters. For comparison, see the key to French fig varieties by Simonet et al. (1945). See also Donno (1951a) for characters of twigs and buds useful in distinguishing varieties during the dormant season.

\section{Suggestive Key for Identification of Common-type Figs at Riverside, California}

Figs of second or main crop generally on wood of current season, and in axil of a leaf. Seeds, if present, infertile or hollow unless caprification has occurred.

I. Color of fruit various shades of green or yellow. (Plate 8.)

Figs striped or banded lengthwise, with green and yellow alternating.....Panachée

Figs not conspicuously striped, more or less uniformly colored.

Pulp white or amber.

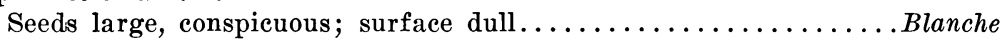

Seeds inconspicuous or undeveloped.

Stalk swollen or prominently enlarged toward body of fruit; many figs dropping when small................... Angélique

Stalk not swollen; few figs drop when small; in cool seasons or climates meat is violet-colored next to skin........... Dottato Pulp various shades of red.

Neck not present, or indistinct.

Stalk short and thick, seldom over $1 / 4$ inch long.

Size above medium to large.

Shape short-turbinate, with broad apex; terminal dormant buds brownish; lobes of leaves broad..........Genoa

Shape long-turbinate, with base gradually contracting into the semblance of a neck; terminal buds green; lobes of leaves narrow............................. Pietro

Size medium; eye scales dark to rose-colored; fruit turbinate; leaves glossy above, stiff and harsh in texture....Verdone Stalk longer, up to $1 / 2$ inch or more.

Stalk swollen or prominently enlarged; surface of fruit dull, velvety............................. Nellow Neches

Stalk not swollen.

Figs oblate; eye above medium, open, scales straw color

Figs spherical or turbinate.

Grassale

Color light green to yellow; eye scales often brightly rose-colored; white flecks inconspicuous

Color grass green; eye scales chaffy or strawcolored; white flecks scattered, more or less con-

Neck present.

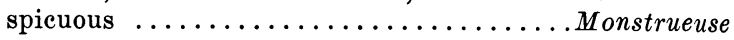

Stalk short and thick, seldom over $1 / 4$ inch long.

Eye scales brightly rose-colored; neck short......... Col de Dame

Eye scales not brightly rose-colored, at least not the surface scales; neck prominent, up to $3 / 4$ inch long, often curved 
Stalk elongated, up to $1 / 2$ inch or more in length.

Body color light green to yellow; eye scales rose-colored..Troiano

II. Color of fruit various shades of bronze, brown, chestnut, or light violet; not dark purple or black. (Plate 9.)

Pulp white or amber.

Stalk thick, often prominently swollen; size medium; color bronze

Stalk not swollen; size above medium to large.

Brunswick

Shape pyriform to turbinate, commonly oblique; color bronze, with violet tinge $\ldots \ldots \ldots \ldots \ldots \ldots \ldots \ldots \ldots \ldots \ldots$ Archipel

Pulp various shades of red.

Neck not present.

Stalk somewhat swollen or enlarged toward body of fruit.

Skin color chocolate brown; figs very small, oblate........Early Violet

Skin color green, flushed with violet; figs below medium to small,

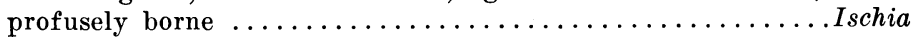

Stalk not swollen or enlarged.

Skin color reddish brown; surface marred by circular blemishes at the apex when fully mature................Gouraud Rouge

Skin color violet-gray.

Body of fig spherical; season of maturity early........Saint Jean Body of fig turbinate to obovate; season of maturity late

Partridge Eye

Neck present.

Color green, tinged with violet or light brown.

Ribs prominent, coloring more deeply than body ; midseason. Martinique

Ribs not prominent; season late.................... Verdal

Color bronze to chocolate.

Neck prominent, distinct from body; surface with elevated ribs, more or less corrugated; bloom often missing from apical zone.. Malta

Neck not prominent; body of fig gradually narrowing to the stalk without apparent constriction ......................

III. Color of fruit dark violet or purple to black. (Plate 10.)

Neck either not present, or short.

Pulp white or amber; shape turbinate to oblate......................

Pulp various shades of red.

Stalk peculiarly crooked or curved; small, immature figs coloring brown;

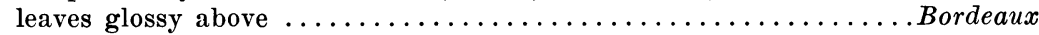

Stalk not crooked.

Surface of fruit distinctly hairy or pubescent; black color uniform over entire fruit; tree slow-growing; branches swollen at the nodes

Surface of fruit dull, only slightly pubescent; basal part of fruit

remaining green until full maturity................. Ischia Black

Neck present, more or less prominent.

Apex of mature fruit showing zone of green color lighter than body.

Green zone encircling the eye only.

Neck somewhat flattened in many specimens.

Surface of fruit glossy; texture of skin unusually firm and rubbery; season late ...................

Surface of fruit dull; bloom thick, pruinose; season medium

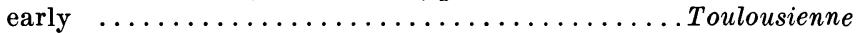

Neck round in cross section; ribs coloring earlier than body

Constantine

Green zone at apex either circular or irregular, and commonly extend-

ing onto and down one side of the body.

Figs above medium to large, pyriform; color purplish black; surface glossy $\ldots \ldots \ldots \ldots \ldots \ldots \ldots \ldots \ldots \ldots \ldots \ldots \ldots \ldots$ Barnissotte

(Key continued on next page.) 
Figs medium, oblate-spherical or turbinate; color violet, tinged with green; many figs shrivel and drop when small

Bourjassotte Grisé

Apex of fruit colored uniformly.

Figs above medium to large; eye large, open; pulp hollow at

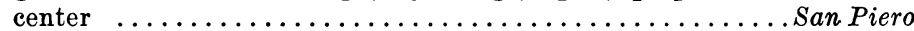

Figs medium; eye medium, partly closed; pulp solid.....Franciscana

\section{Common-type Figs with Skin Green or Yellow; Pulp Amber or White}

Albo (syns. Albicello, Albinillo, Bianchetta, Biancoletta, Biancolini, Blanca, Blanquita, Dorato, D'Oro, Gentile at Bologna, Mattano, Moscadello, Zentil). Described by Porta (1583), Gallesio (1817), Gasparrini (1845), Pasquale (1876), Roda (1881), Eisen (1901, with figure), Tamaro (1948), and Baldini (1953) ; the last with illustration of leaf, breba, and second-crop fruit.

According to Gallesio, it is one of the few varieties found along the whole coast of Italy, but not in France or Spain. Gasparrini described Fico Albo with Fico Trojano in parentheses, and also treated Biancolini as a distinct variety. Eisen regarded it as one of the best Italian figs, especially well regarded in the markets of Pavia and Milan. Tamaro described the variety as Blanca.

Tree of medium size. Leaves mostly 3-lobed; base cordate. Not fruited at Riverside, California; resembles very much the variety Angélique, described elsewhere in this monograph. Description is after that of Baldini.

Brebas almost spherical, with short, thick neck; stalk short; color canary yellow; pulp white; quality good.

Second-crop figs medium, oblate-spherical, flattened at the apex; neck none; stalk medium ; ribs indistinct; eye open, with rose-colored scales; skin yellow ; pulp amber, almost seedless, very sweet. Used mostly fresh; sometimes dried.

Angelina (syn. Argelina). Described and figured by Estelrich (1910). Tree well developed, with leaves similar to those of Bordissot Blanca (Barnissotte Blanche). Figs below medium, spherical, yellowish green; skin thick; interior white. Not a choice variety, but commonly grown in parts of Mallorea.

Blanche (syns. Blanche d'Argenteuil, Blanche Ronde, Grosse Blanche Ronde, Blanche Hâtive, Blanquo, Argentine, Blanche Fleur, Royale, Versailles, Blanquette and Madeleine of some authors, Marseilles, White Marseilles, Marseillaise White, White Naples, Pocock, Ford's Seedling, Raby Castle, White Standard, White Smyrna, Quarteria, Vigasotte Bianco). In 1700 , Tournefort described a fig variety as La Grosse Blanche Ronde. Garidel (1715) quoted this account, but expressed doubt that it was the same as the one called Blanquo Communo, grown in some parts of France. Duhamel (1755) also quoted Tournefort, and designated the variety as Figue Blanche. In his "Nouveau" work of 1809, Duhamel again quoted Tournefort, as well as Garidel, and stated that the fig known at Paris as Figue d'Argenteuil was only a subvariety of Figue Blanche of Provence, the differences between the 
two being minor, and due to climatic influences. The fig described and illustrated in color by Carbou (1865a) as Figue Blanche à Peau Verte may be the same variety.

Other accounts of this fig as Blanche, Blanche d'Argenteuil, Blanche Ronde, or Grosse Blanche Ronde are by Merlet (1667), Liger (1702), Weston (1770), Knoop (1771), La Brousse (1774), Rozier (1781-1805), Mirbel (1802-1806), Lamarck (1783-1817), Bory de Saint Vincent (1824), Noisette (1821, 1829), Couverchel (1839), Poiteau (1838-1846), Dochnahl (1855), Duchartre (1857), Forney (1863), Lhérault (1872), Simon-Louis (1895), Schneider (1902), Juignet (1909), Nomblot (1913), Mazières (1920), Leclerc (1925), Société Nationale d'Horticulture de France (1928), A. Rivière (1928), G. Rivière (1930), Delplace (1933), Delbard (1947), and Simonet et al. (1945). Figue Royale was described by Bernard (1787), Duhamel (1809), Bory de Saint Vincent (1824), and Noisette (1829), with Versailles as a synonym. On the other hand, it was described as Versailles, with or without the synonym Royale, by Couverchel (1839), Duchartre (1857), Du Breuil (1876), Hogg (1866), Soc. Pomol. de France (1887, 1947), Barron (1891), Eisen (1901), Bois (1928), Blin (1942), and Evreinoff (1947). Eisen regarded Blanche and Versailles as distinct, but later authors, such as Nomblot, Soc. Nat. d'Hort. de France (1928), and Simonet et al., treat them as the same variety. See Rolland (1914) for synonymy.

Descriptions of this variety as White Marseilles are given by Brookshaw (1812), Baxter (1820), Sawyer (1824), Lindley (1831), Rogers (1834), Holley (1854), M'Intosh (1855), Thompson (1859), Hogg (1866), G. S. (1867, 1869), Barron (1868c, 1891), Rivers (1873), Coleman (1887b), Lelong (1890), Wythes (1890a), Massey (1893), Burnette (1894), Wright (1895), Forrer (1894), Eisen (1885, 1897, 1901), Thomas (1902), Ward (1904), Starnes $(1903,1907)$, Royal Hort. Society (1916), E. A. Bunyard (1925, 1934), Cook (1925), Arnold (1926), Fruit-Grower (1936), Condit (1947), and Preston (1951). Illustrations in color are by Duhamel (1809), Brookshaw (1812), Noisette (1821), and Wright (1895). Illustrations in black and white are by Poiteau, Eisen (1901, fig. 75), Bois, Société Nationale d'Horticulture de France, Starnes, Bunyard (1934), Simonet, and Condit (1941a, fig. 2, $E$ ).

The name White Marseilles became attached to a fig that Brookshaw described and illustrated in color in 1812 of fruit gathered by himself from the original tree at the Archbishop of Canterbury's palace at Lambeth. This tree was generally believed to have been planted by Cardinal Pole during the reign of Henry the Eighth. Another account, that of Baxter (1820), stated that a fig tree at Oxford was introduced by a Mr. Pocock, hence the name Pocock's fig ; fruit exhibited on August 17, 1819, proved to be that of the White Marseilles. John Wright (1895) referred to a large tree of White Marseilles with a trunk 6 feet 9 inches in circumference 2 feet above the ground. Sawyer, in 1824, reported that the fig he named Ford's Seedling was sometimes called the Pocock, but was more properly designated White Marseilles. Various authors, including Lindley, Thompson, and Hogg, described White Marseilles, with Figue Blanche as a synonym. The description and illustration by Eisen in 1901 of Marseillaise White are regarded here 
as properly referring to Blanche. White Genoa, as pointed out by Eisen, is distinct from White Marseilles. According to Bunyard, Marseilles is a wellestablished favorite in England, thriving both indoors and on walls outside. Cape White, described by Davis (1928), Burger and De Wet (1931), and Gayner (1949), as a "well-known fig" of South Africa, appears to be very similar to, if not identical with, Blanche. In southern India the Marseilles is said by Naik (1949) to "crop well on the hills over about 5,000 feet elevation."

Blanche is extensively cultivated in Provence, mostly as a drying fig. Near Paris, where Blanche d'Argenteuil has been cultivated for many centuries, elaborate methods of culture as described by Lhérault, Juignet, and others, have been followed for the production of the first crop. A famous tree of this variety at Roscoff, France, planted by the Capuchins in 1621, has been described by Lambertye (1874), Blanchard (1878, 1879), and by Martinet and Lesourd (1924). In 1924, the branches covered an area of 600 square meters ; they were supported by 80 pillars, many of granite. The annual crop was reported to be 400 dozen figs.

The variety designated "Lemon" in most of the southeastern United States is identical with Blanche. See descriptions of Lemon by Starnes and Monroe (1907) and by Gould (1923).

At Crisfield, Maryland, and at Cape Charles, Virginia, trees of Marseilles are neither vigorous nor productive. Near Portland, Oregon, this variety ranks first among the figs tested for home and orchard planting. A Portland nurseryman, B. R. Amend, in his catalogue for the season of 1942, describes this variety as Lattarula (Italian honey fig), a name suggested by some visitors from Italy. As described elsewhere, however, the Italian variety Lattarola has red, not white, pulp.

This variety has long been grown in California, mostly under the name White Marseilles. According to Shinn (1915), White Marseilles was growing at Santa Clara and Santa Barbara before the discovery of gold. As determined by Saunders (1889), White Smyrna proved to be the same variety. It was apparently this fig which Lelong $(1890,1892)$ reported as found growing at Downey, Los Angeles County, where there was a "very large fig orchard, devoted to the Marseillaise, a small, white, sweet fruit." But Eisen (1901) mentioned that an orchard, probably the same one as above, had been dug up on account of the figs souring so badly. No other commercial plantings have been found, but dooryard trees are common, especially in southern California. It was grown and tested at the various California stations between 1893 and 1903, and an analysis of fruit grown at Fresno was recorded by Colby in 1894. According to Eisen, Versailles was once grown extensively by Felix Gillet, Nevada City; no records, however, have been found of its distribution or planting under that name.

Three varieties introduced into California in the Chiswick collection all proved to be identical with Marseilles; they are P.I. Nos. 18,864, Vigasotte Bianco; 18,866, Quarteria; and 18,904, Figue Blanche. Eisen appears to be the only author who has described the first two, and he has listed them as distinct varieties. Except for minor characters, his account of the fruit coincides closely with that of Blanche given here. 
Trees of Blanche are slow-growing, fairly dense, with green terminal buds. Leaves medium, 3- to 5-lobed; surface glossy above; upper sinuses of medium depth, narrow, lower sinuses shallow ; base subcordate, sometimes auricled; margins crenate; mature blades often affected by necrotic spots (plate 13). The following description of fruit is from specimens grown at Riverside since 1930.

Breba crop fair; figs medium or above, up to 2 inches in length and $17 / 8$ inches in diameter, turbinate, with broad, rounded apex; neck thick and short, or absent; stalk slightly curved, $1 / 4$ inch long; ribs few, inconspicuous ; eye medium, open, scales chaffy, erect at maturity; flecks very small and inconspicuous, green rather than white; bloom delicate; color light green; pulp and meat white; seeds large, conspicuous; quality fair to good.

Second-crop figs much the same as brebas, except for smaller size; average weight 30 grams ; shape spherical to oblate, mostly without neck; stalk up to $1 / 2$ inch long. Flavor fairly rich and sweet; quality fair as a fresh fruit, of light weight and poor quality when dried; susceptible to fruit spoilage. (Plates $8 ; 26, A$.)

Caprification has little effect upon size and color, either of skin or pulp. Figs produced at Portland, Oregon, and in coastal districts of California, are usually larger in size and more oblate in shape than those just described. Near Paris the second crop of Blanche matures in warm seasons only.

Brindisino. Described by Guglielmi (1908) as an oval, yellowish fig with amber pulp, very sweet; consumed more fresh than dried.

Castellana. A variety under this name was received from Málaga, Spain, in 1925 , as P.I. No. 62,778. The second-crop figs are below medium in size, pyriform, yellowish green in color; pulp amber; quality poor. (Plate 8.)

Citrato. Described by Guglielmi (1908) as a medium-sized fig of citronyellow color, hence the name. Pulp white, with numerous seeds. Consumed fresh.

Colombo Bianco (syn. Colummo Bianco). Described by Semmola (1845), Vallese (1909), De Rosa (1911), and Ferrari (1912). Illustrated by Semmola and by Vallese; regarded by Semmola as corresponding to Portoghese of Gallesio, but later writers fail to mention this similarity. Semmola stated that the figs sometimes drop prematurely, or reach only partial maturity; and De Rosa expressed doubt whether caprification is necessary. Vallese described Colummo Bianco as very similar to Colummone (Colombro) in fruit, but different in leaf characters.

Tree vigorous, attaining large size. Leaves large, asymmetrical, mostly 5-lobed. Description of fruit is after Vallese and De Rosa.

Brebas large, 3 inches broad by $3 \frac{1}{2}$ inches in length, elongated-turbinate, broad at apex; eye large; skin thick, checking at maturity, greenish yellow in color; pulp creamy white.

Second-crop figs smaller, $21 / 4$ by $23 / 4$ inches, nearly spherical; stalk short; color greenish yellow, with many white flecks; pulp white, or sometimes light rose-colored ; flavor sweet, delicate. Variety important, not only for its excellent breba crop, but also for the main crop. Used both fresh and dried. According to Ferrari, brebas are used as fresh fruit at Cosenza, and not exported. 
Dorée Nobis (or Norbus). Briefly described by Barron (1891), Shinn (1892, 1893, 1903), Forrer (1894), and Starnes (1903, as Golden Narbus, with illustrations). Described and figured by Eisen (1901) as a medium, pyriform fig, greenish yellow in color, with amber pulp; very similar to Dorée, but differing in color of pulp; spelling of name doubtful. Introduced in the Chiswick collection as P.I. No. 18,892.

Dottato (syns. Abruzzes, Adottato, Binello, Dattero (?), Datteresi, Dottato Bianco, Grascello, Trifero, Medot, Gentile, Napoletani, Ottato, Uttato, Vottato, Kadota, Clarkadota, Endrich, White Endich, White Pacific, Ficus carica binella Risso). Described by Porta (1592), La Quintinie (1692), Tournefort (1700), Liger (1702), Gallesio (1817), Risso (1826), Gasparrini (1845, as Ficus dottata), Duchartre (1857), Pasquale (1876), Roda (1881), Savastano (1885), Eisen (1888, 1897, 1901), Stubenrauch (1903), Mingioli (1904), Pellicano (1907), Starnes and Monroe (1907), Guglielmi (1908), Vallese (1909), Portale (1910), De Rosa (1911), Ferrari (1912), Siniscalchi (1911), Clark (1920), Borg (1922), Condit (1920c, 1921c, 1923, 1927, 1933, 1947), Anagnostopoulos (1937), Mauri (1942), Simonet et al. (1945), Tamaro (1948), Donno (1951a, 1951b), Casella (1952), and Baldini (1953). Illustrated in color by Clark; in black and white by Eisen, Vallese, Condit, Mauri, Tamaro, Simonet et al., Baldini, and Casella. (See last for synonyms.)

Dottato is probably the most important single fig variety grown. It constitutes a large percentage of the 70,000 tons of dried figs produced annually in Italy. In California the amount of dried figs of this variety totals over 3,000 tons, while 7,500 tons of fresh figs are canned; there are also many carloads of fresh fruit sent each season to local and distant markets, and dooryard trees are numerous.

According to Gallesio and some other Italian writers, Dottato is of ancient origin, having been praised by Pliny as an excellent fig for drying. This and a few other varieties may, therefore, have been perpetuated for some twenty centuries as single clones by propagation from cuttings. Porta described it as Ottato, a name which is still used around Naples. Gallesio reported that it is called Dottati at Sarzana, Binellino at Spezia and Chiavari, Binelli and Fichi di Napoli at Genoa, Gentile at Voltri, Napoletani at Finali, Fichi di Calabria and Dattaresi in western Liguria. According to Vallese, it is known as Napoletano at Corigliano d'Otranto, Lumincella at Francavilla, and Biancolella or Nardeleo at Oria and near Brindisi. The name Binelli is applied to Dottato by Risso because two fruits are often found joined together at the peduncle. Under his account of Dottato, Gallesio quoted the Latin description of Tournefort, who gave the common name as Medot, a synonym also used by La Quintinie and Liger. The latter stated that Medot is not raised much in France, as it is only mediocre in quality. Simonet et al. described Gentile, grown at Cap de Antibes, where it is called Figue des Abruzzes, and added that this variety appears to be the Dottato of Italy. Fracatsani, introduced in 1901 under P.I. No. 6,114 as one of the finest table figs grown on the island of Corfu, appeared to be identical with Dottato in the collection of varieties at Chico, California.

Trifero is described by Barron (1891) and Eisen (1901). The following P.I. numbers were labeled Trifero: 18,855 , in the Chiswick collection from 
England ; 86,802, from Nikita, Yalta, Crimea ; and 102,021, from Marrakech, Morocco. In variety trials all three of these introductions proved to be identical with Dottato.

Dottato is grown commercially in all of the fig districts south of Naples, as well as in Sicily. Siniscalchi calls it the variety par excellence, and states that it is rightly known as the "golden fig." According to Ferrari, it is the one best adapted to local conditions, both along the coast, as at Agropoli, and in the foothill valleys, such as at Cosenza. Both Guglielmi and Pellicano give it first rank among the figs of southern Italy, and De Rosa classes it highly for production of dried figs, as it has few seeds, sweet pulp, and delicate, although relatively thick, skin. It has been introduced into Greece, where Anagnostopoulos reports that trees produced and matured fruit well.

The exact time of the first introduction of Dottato into California is not known. Italian settlers in the foothill districts of the San Joaquin Valley undoubtedly introduced cuttings of this and other varieties for planting; large trees are still to be found on ranches established before the middle of the past century. White Endich is the name applied to a fig introduced into the Stockton district before 1870 and named for Mr. Endich of that city; later it was found to be identical with Dottato. The history of the Kadota fig and its rise to popularity has been related by Condit $(1920 c, 1927)$. Cuttings distributed by Van Deman (1890) of the United States Department of Agriculture under the name Dottato, were grown by the nursery firm, Twogood and Cutter, of Riverside, about 1889. The fruit exhibited in Los Angeles in 1893 attracted considerable attention, and created a demand for trees. In 1898, Stephen H. Taft, of Sawtelle, obtained cuttings and labeled the variety Kadota.

The name White Pacific was given to a fig propagated by W. R. Strong and Company, Sacramento, and described in their catalogue in 1883. It was found on the place of a Mr. White at Penryn, hence the name; but according to Milco (1884), trees of the same kind were "scattered now almost every place over the State," especially around Stockton. Lelong (1890) reported it from San Diego. Clarkadota was the appellation coined in 1920 by a development company at Stockton, and purported to represent trees of a superior strain. Both White Pacific and Clarkadota have proved to be identical with Dottato when trees are grown side by side in the same orchard. P.I. No. 58,643 was introduced from Padua, Italy, as Dottato. It was grown and tested at the California stations, and was reported to be the best white fig fruited at Pomona in 1903, going through fog and rain without souring. Woodard (1938) reported that in Georgia the Kadota was the sweetest fig under test, and of superior quality, but that trees were more subject to cold injury than those of Celeste (Malta). In 1948, a few Kadota trees were found near Diamond Springs, Virginia.

Dottato is variously reported as a one-crop or a two-crop variety, the number of crops depending upon the locality where grown. For example, at Riverside and in the coastal districts of southern California, the trees seldom mature perfect brebas; at Fresno, where the day and night temperatures of spring and early summer are much higher, a good breba crop is produced. 
Trees are generally vigorous, developing naturally into a compact, rounded head (plate 1) ; terminal, dormant buds are green, as described by Donno $(1951 a)$. Leaves medium, dull to somewhat glossy above, variable, with nonlobed, 3-lobed, and 5-lobed leaves on the same tree, as shown by Condit (1927) ; upper and lower sinuses mostly rather shallow ; base cordate; margins serrate to coarsely crenate.

Breba crop none, or fair; fruit medium to large, pyriform, often somewhat oblique; average weight 52 grams; neck thick, up to $7 / 8$ inch long, sometimes curved; stalk variable, from short to $1 / 2$ inch long; ribs present, moderately elevated, but mostly inconspicuous; eye medium to large, open, with thick, chaffy scales; surface fairly glossy; bloom delicate; white flecks few, but large and conspicuous; color green to yellowish green; meat thin, tinged with violet; pulp amber. Flavor rich and sweet; quality excellent; seeds few, hardly noticeable. (Plates $7 ; 20, A$.)

Second-crop figs variable from early to late part of season and under different climatic conditions; size from below to above medium, or even large ( $13 / 4$ inches in diameter by $2 \frac{1}{4}$ inches in length); weight ranges from 30 to 80 grams; shape spherical to obovate, with or without short, thick neck; stalk variable, short and thick, or sometimes up to $1 / 2$ inch long; ribs fairly prominent in larger specimens, or practically absent in smaller fruit as used for canning; eye medium, apparently open, but closed within the orifice, often sealed with drop of gum; scales straw color; surface glossy, with delicate bloom; skin rather thick, rubbery in texture, resistant to injury in handling; color green in cool climates to golden yellow in hot interior valleys ; meat white, or often tinted violet in coastal climates, as pointed out by Condit (1950); pulp amber; seeds few, small, seed coat hardly or not at all sclerified. Flavor sweet, but lacking distinctive character; quality excellent, especially for preserving and canning; skin of dried fruit somewhat thick and tough. (Plates $12 ; 20, B$.)

Caprified figs larger, grass green; pulp strawberry; seeds fertile. Good for drying. (Plates $8 ; 11$.)

Early White (syn. Jaune Hâtive.) Described by Lindley (1831); his account was apparently copied by Hogg (1866) ; also described by Eisen $(1888,1901)$. Figs small, turbinate-spherical, pale yellow; pulp amber, not highly flavored.

Edeisi (syn. Blati). Described by Grasovsky and Weitz (1932) as a variety grown in the Jerusalem subdistrict. Figs medium, spherical, flattened at the apex; neck and stalk both short; color light green; pulp amber; quality fair.

Florentine. Described by Gould (1923) as a local variety found at Alexandria, Louisiana, and labeled Florentine; no mention, however, was made of this fig in the 1935 edition of Gould's publication. Fruit medium to large, pale green; pulp amber.

Fracazzano (syn. Fracazzano Bianco). Described by Guglielmi (1908), Vallese (1909, with illustrations), De Rosa (1911), Tamaro (1948), and Donno (1951b). According to Vallese, this variety is grown throughout Lecce Province for its two crops of fruit, the second maturing into early October if the weather continues favorable. De Rosa reports that caprifica- 
tion is practiced, but Vallese maintains that the reason growers put caprifigs in the trees is that caprified figs mature about fourteen days earlier than those that are uncaprified.

Leaves of medium size, 3- to 5-lobed; terminal buds green, as described by Donno (1951a).

Brebas medium, turbinate, the body gradually narrowing toward the base into a short neck; stalk short; color yellowish green; white flecks scattered; skin checking at maturity; pulp amber, sweet; quality good.

Second-crop figs globular, slightly depressed at the apex; stalk short; ribs few, extending from base to apex; eye rather small, with rosy scales; skin thick; color greenish yellow; white flecks present; pulp creamy white, very sweet; seeds few, rather small.

Hdadi. Described by Grasovsky and Weitz (1932) as a subvariety of Sfari, growing in northern Palestine, and resembling Byadi in color and size. Figs medium, green; eye closed, scales straw-colored; pulp amber; flavor sweet, good; seeds few.

Hdeidarmal. Described by Grasovsky and Weitz (1932) as an uncommon variety of Palestine, also known as Droubi. Figs medium, spherical, green; eye open; pulp brownish amber; flavor insipid.

Jaune de Toulouse. Described by Eisen (1901) as a very handsome fig, large, oblong; skin and pulp yellow.

Kahramani. An Egyptian fig, described by Badie and Ghamrawi (1931). Tree of medium size; leaves deeply lobed. Bears two crops, the first of which is most important. Appears in the markets earlier than Sultani.

Figs medium, oblate-spherical; stalk short; skin thin, glabrous; color yellow; pulp amber, seedless, very sweet.

Kargigna. See short description by Forrer (1894) as Rargigna. Briefly described by Eisen (1901) as a variety introduced into California by G. N. Milco from Dalmatia. Figs medium or below, turbinate, light green; pulp amber. Quality mediocre; good only for the table.

Magdalen. Described by Eisen (1897, 1901), with illustration of leaf and fruit; also, in the 1901 catalogue of Barren Hill Nursery, Nevada City, California, as a French fig, far superior to the Ischias and the Celeste (Malta).

Starnes and Monroe (1907) reported a test of "Magdalena," received from California, but trees had not fruited up to that time. The variety is here considered distinct from Madeleine, which Eisen gives as a synonym.

Figs described as small, turbinate-spherical, with long, slender stalk; ribs prominent; color greenish yellow; pulp amber.

Minuto Bianco. Described by Ferrari (1912) as a small, elongatedturbinate fig, with short stalk; skin covered with a fine pubescence; color greenish yellow; pulp amber. Used both fresh and dry.

Mshaki. Briefly described by Grasovsky and Weitz (1932) as a variety grown at Jenin, Palestine. It produces large, light-green fruits, with honeycolored pulp, sweet and good in flavor.

Ojo de Perdiz (syns. Ull de Perdiu, Martinenca Blanca). Described and illustrated by Estelrich (1910) as a variety commonly grown at Manacor and other towns on the island of Mallorea. 
The tree has a rounded head, and large, 3-lobed leaves.

Figs are large, spherical, or somewhat elongated; eye wide open, scales rosy; color light green; pulp amber; flavor mild. Resistant to spoilage in humid weather. Well regarded for use as cattle feed and for drying.

Pallaro. Briefly described by Gasparrini (1845) as grown at Portici, Italy. Brebas drop; second-crop figs large, globular; color greenish yellow; pulp amber; flavor mediocre. Listed, but not described, by Savastano (1885).

Pelo de Buey. Described by Estelrich (1910) as a fairly common variety on the island of Mallorca. Figs are medium, dark green, with white pulp; used for cattle feed.

Poppa (syn. Coppa). Described by Guglielmi (1908), Vallese (1909), and Donno (1952); leaves and fruit illustrated by Vallese. The tree produces only a second crop, which matures from mid-August to late September. According to Vallese, some growers practice caprification for this variety, while others maintain that it is not necessary. Donno, on the other hand, states that all growers caprify Poppa figs.

Leaves are medium, generally 3 -lobed.

Figs large, oblique-turbinate, depressed at the apex; stalk very short; ribs slightly elevated; skin checking crisscross at maturity; color greenish yellow; pulp dark amber; seeds few. Consumed mostly in the fresh state.

Raby Castle. According to two accounts in 1878 (see The Garden, 14:584 and 16:316) the name Raby Castle was given to a fig found on an estate of the same name in England; the tree bore "two or three crops in the season more readily than Brown Turkey." Hogg (1866) regarded it as synonymous with White Marseilles (Blanche). The above accounts, however, also state that "those who have seen the two together would never confound them." Raby Castle was tested by John Rock at Niles, and by the California stations at Paso Robles, Jackson, and Tulare, but apparently was found to be an inferior variety.

Eisen (1901) described and figured it as medium, spherical, with prominent ribs; skin light green; pulp coarse, amber; quality poor. Not worthy of cultivation.

Reine (syn. Verdale in L'Ariège and the Haute-Garonne). Described by Ounous (1863) as productive of two crops; one of the most profitable varieties for shipping fresh. Figs medium, oblate-spherical, yellowish green; pulp white. Identity not certain; apparently different from Verdal and Verte, both of which have strawberry-red pulp.

Schifo. Described by Portale (1910) as an Italian variety, producing medium figs, with very short stalk; color pale yellow; pulp amber; seeds large, numerous.

Seirolles (syns. Seirola, Seyroles, Sirore, Ficus carica seirola Risso). Described by Bernard (1787), Duhamel (1809), Risso (1826), Noisette (1829), Couverchel (1839), Du Breuil (1876), Sauvaigo (1889), Eisen (1888, 1901), and Simonet et al. (1945, with figure). This variety, grown in southern France both for fresh fruit and for drying, has apparently not been tested in the United States. The following account is after that of Simonet.

Breba crop none. Second-crop figs medium to small, $1 \frac{1}{2}$ inches long by $11 / 4$ inches broad, pyriform to turbinate; average weight 17.5 grams; neck 
and ribs fairly prominent; stalk short; eye small, closed, scales yellow ; skin firm, with delicate bloom; color greenish yellow; pulp amber; seeds few. Quality good; excellent for drying. Season late September.

Tossico. Briefly described by Ferrari (1912) as an Italian fig, greenish yellow in color, with amber pulp; matures in September.

Urjal (syns. Capa Rôta, Branco). Described by Mello Leotte (1901) as Urjal, a corruption of the word argel, signifying "soft"; i.e., fig of the soft skin. Described and illustrated by Bobone (1932) as Capa Rôta, with synonyms as above.

This Portuguese variety has two crops.

Breba crop small ; fruits large, pyriform, green ; pulp amber. Second-crop figs below medium, turbinate, without neck; stalk medium; pulp coarse in texture, amber; quality fair.

Verdeccio (syns. Verdecchio, Verdichio, probably Verdino di Brianza). Described by Tanara (1651), Gallesio (1817), Gasparrini (1845, as Ficus hypoleuca), Duchartre (1857), and Eisen $(1888,1901)$. Figured by Gallesio and by Eisen. In 1651, Tanara listed Verdecchio as a variety resistant to cold and good for drying. In 1668, Aldrovandi included Verdecchij in a list of several Italian figs of that period. Gallesio described it as a variety highly esteemed at Bologna and in some parts of Lombardy. Eisen does not give the source of the material which he described and illustrated. Apparently the variety has not attracted favorable attention in Italy, and is not represented in any collection in California.

Second-crop figs below medium, pyriform, according to Gallesio, spherical, without neck, according to Eisen; color yellowish green; pulp amber. Season late.

Verdillo (syns. Verdolino and Verdoso), described and figured by Tamaro (1948), appears to be very similar to Verdeccio.

Yaffawi (syns. Bourtawi, Shourtawi, Shheimi). Described by Grasovsky and Weitz (1932). Tree prolific, bearing regularly. Figs large, slightly elongated; neck and stalk medium; eye almost closed, scales light green; color green, with ribs dark green; pulp amber; seeds many.

Zonto. Described by Guglielmi (1908) as a variety grown in Lecce Province, Italy, bearing spherical figs, with very short stalk; color yellow; pulp amber; generally consumed fresh.

\section{Common-type Figs with Skin Green or Yellow; Pulp Various Shades of Red}

Abakor (syn. Abakour Amellal). According to Hanoteau and Letourneux (1872), the Kabyles retain the Arabic name bakour, "early," for this variety, because of its abundant crop of brebas. Listed by Eisen (1901) as Abakour Amellal, probably from P.I. No. 6,469; described and illustrated by Mauri (1939b); see also Montagnac (1952).

Trees vigorous, producing two crops. Leaves 5-lobed.

Figs medium, globular; stalk short; ribs present; eye open; skin green; pulp rose-colored; quality mediocre. Brebas consumed fresh; second-crop figs generally dried. 
Aberdin. Described by Risso (1826) as Ficus carica aberdina. Figs above medium, spherical; stalk short; skin color green; pulp red; honeylike drop often exuding from the eye.

Agresto. Described by De Rosa (1911). Tree with slender branches, and medium, 5-lobed leaves; breba crop small. Figs oblate, with slender stalk; eye large, with rose-colored scales; skin green; pulp light red, sweet.

Ajlouni. Described by Grasovsky and Weitz (1932) as a very popular variety, one of the best in Samaria; probably introduced to Ramallah from Smyrna. Figs small, pyriform, with medium neck and stalk; color green; eye almost closed; pulp pinkish; flavor good; seeds many.

Amudi. Described by Grasovsky and Weitz (1932) as a variety grown at Nazareth. Figs medium, spherical, with long stalk; skin green; pulp red; quality fair.

Angélique (syns. Melette, Petite Figue Grisé, Coucourelle Blanche, Madeleine, Early Lemon, Figue d'Or). See Rolland (1914) for synonymy. There are many descriptions of this variety. The most noteworthy ones follow. Merlet (1667), La Quintinie (1692), Liger (1702), Tournefort (1719), Duhamel $(1768,1809)$, Weston (1770), La Brousse (1774), Rozier (1787), Le Berryais (1789), Mirbel (1802), Noisette (1821, 1829), Bory de Saint Vincent (1824), Lindley (1831), Couverchel (1839), M'Intosh (1855), Dochnahl (1855), Forney (1863), Hogg (1866), G. S. (1867), Barron (1868b), Du Breuil (1876), Hyde (1877), Coleman (1887b), Watts (1890), Massey (1893), Burnette (1894), Eisen (1901), Starnes (1903), Starnes and Monroe (1907), Evreinoff (1947), and Condit (1947). The color illustration by Duhamel (1809) shows a small, green fig with short, thick neck; the one by Barron shows a spherical fig, badly split at the apex; it is also figured by Starnes, and by Condit (1941a, fig. $2, D)$.

Confusion has existed as to the identity of this variety, as well as its synonyms. La Quintinie (translation by Evelyn) referred to "the little grey fig, almost of a tawny color, called Melette in Gascony." Tournefort described it as Melette or Coucourelle, of small size and tawny color. Duhamel (1768) quoted Tournefort, then described the fruit as very large, of a yellow color. Bernard (1787) disagreed with Duhamel, and believed the description of Tournefort characterized the variety Coucourelle Brune better than Angélique. Practically all later writers describe the color as yellow. Mirbel called it Angélique or Melette, and stated that it was cultivated in nearly all parts of France. Figue d'Or, P.I. No. 18,880, and Madeleine, P.I. No. 18,890 , both of the Chiswick collection, proved to be identical at Riverside. In view of the descriptions reviewed and of the specimens of Madeleine fruiting at Riverside, we are inclined to agree with Hogg, with G. S., and with Barron, rather than Eisen, that Madeleine is synonymous with Angélique. The Madeleine listed by some authors as a synonym of Blanche (Versailles) is different from the variety treated here. New French, described by Earle (1900), and by Price and White (1902), and listed as promising by Reimer (1910), is probably identical with Angélique.

Angélique is found in California only in collections. The tree is moderately vigorous, bearing two crops. The leaves are variously described as "more entire than any other," and "longer than broad, and often have only 
three lobes." Leaves of Riverside trees are medium, mostly 3-lobed; upper surface dull; upper sinuses rather shallow and narrow; base subcordate to truncate; margins coarsely crenate.

Breba crop fair to small; fruits medium, up to 2 inches in diameter, turbinate-spherical; neck very short and indistinct; stalk $1 / 4$ inch long, swollen toward the apex; ribs present, narrow; eye large, open, scales chaffy, bordered with pink, often brightly colored; surface waxy or glossy; color lemon yellow, with white flecks few and inconspicuous; pulp light strawberry, hollow at the center. (Plate 21, C.)

Second-crop figs very similar in appearance to the brebas, but smaller in size; average weight 32 grams; shape oblate-spherical, without neck; stalk up to $3 / 4$ inch long, often curved, and prominently swollen at the apex; fruit of beautiful appearance on account of the waxy surface, bright yellow color, and rosy eye scales; pulp light strawberry to almost amber, hollow, as shown by Condit (1941, fig. 11, C) ; flavor insipid ; quality poor. Very susceptible to insect infestation through the open eye, and to subsequent spoilage. (Plates $8 ; 14, D$.)

Figs incompletely parthenocarpic, many fruits dropping when small; caprified specimens much the same as uncaprified ones in size and color, but with pulp bright strawberry in color.

Angélique Jaune (syn. Vendôme). See description and illustration by Eisen (1901) from figs produced at Niles, California. Original tree from Thomas Rivers and Son, London. Reported to be a most valuable fig, distinet from Angélique, with large, pyriform fruit, greenish yellow in color ; pulp deep red. This is probably the same variety described by Langley (1728) and Ballon (1692) as Angélique or Incarnadine.

Arneo Bianco (syns. Verneo Bianco, Inverneo, Invernale, Invernengo, Invernizzo, Natalino, Tardo). Described and illustrated by Vallese (1909) as an unusually late fig, continuing to mature into October or even December in favorable seasons ; also described by Pellicano (1907), Guglielmi (1908), Portale (1910), and De Rosa (1911).

Tree large. Leaves generally 5-lobed. Figs medium, obovate; stalk very short; neck absent; skin pale yellow, with scattered white flecks; eye scales intensely rose-colored; pulp red. Consumed fresh.

Assel bou Tchiche. Described by Guillochon (1913, 1927, 1929) and by Minangoin (1931). Leaves medium, deeply 3-lobed. Figs spherical, medium in size; neck indistinct; eye open; color greenish yellow; pulp light red.

Assouani (syn. Abiad Assuan). Described by Badie and Ghamrawi (1931). Trees medium. Leaves deeply 5-lobed. Two crops. Figs oblong or pyriform; stalk short; ribs protruding; skin thin, yellowish green, firmly adhering to the meat; pulp light red; seeds few. Second crop continues maturing until January at Qena and Assuan.

Badalhouce. Described and figured by Bobone (1932). Breba erop especially good; fruits large, pyriform, greenish yellow; pulp carmine; texture fine; quality very good. Second-crop figs not described.

Barnissotte Blanche (syns. Barnissotte White, Bourjassotte Blanche, Bernissou Blane, Brogiotto Bianco, Burjassotte Branco, Bordissotte (or Bordissot) Blanca, Bourgassotte, Bourgeassotte, Olho de Passarinho, Regalo, 
Rainha, Ficus carica meridionalis Risso). Described by La Brousse (1774), Bernard (1787), Duhamel (1809), Gallesio (1817), Risso (1826), Bory de Saint Vincent (1824), Noisette (1829), Couverchel (1839), Hogg (1866), Pasquale (1876), Du Breuil (1876), Sauvaigo (1889, 1894), Eisen (1888, 1901), Barron (1891), Mello Leotte (1901), Mingioli (1904), Trabut (1904), Starnes and Monroe (1907), Estelrich (1910), Mazières (1920), Borg (1922), Sánchez (1922), Priego y Jaramillo (1922), Leclerc (1925), Bois (1928), Bobone (1932), Blin (1942), Simonet et al. (1945), Evreinoff (1947), and Baldini (1953). Illustrations by Eisen, Starnes, Estelrich, Bobone, Simonet, and Baldini.

In 1817, Gallesio reported Brogiotto Bianco to be the king of figs, and believed it to be a variety brought from Syria to Genoa sometime during the Crusades. He described the tree as a giant among fruit trees, some measuring over two meters in trunk circumference. The variety is widely distributed in Mediterranean countries. Estelrich reported that on Mallorca there are orchards planted exclusively to Bordissot Blanca. Bobone collected specimens of fruit from three different districts of Algarve, and described it as Burjassotte Branco with three synonyms. Borg stated that it is the only white fig not requiring caprification on Malta. Although Bourjassotte Blanche is mentioned by Shinn (1915) as one of the varieties cultivated in California, the existence of authentic trees is not known.

The tree bears a few brebas in some seasons only; the second crop is very prolific, maturing over a long season. Leaves large, 3- to 5-lobed. Description of fruit is after Simonet.

Second-crop figs medium, $21 / 4$ inches long and broad, turbinate, somewhat flattened at the apex; average weight 60 grams; neck prominent, short and thick; stalk short ; ribs present, but not marked; eye large, open, often splitting at maturity, scales red; skin rather firm, uniformly yellowish green, with light bloom; meat white; pulp red. Quality excellent fresh; also good for drying.

Bayoudi (syn. Adsi Abiad). Described by Guillochon (1913, 1927, 1929), and by Badie and Ghamrawi (1931), as a variety of the Common type bearing figs medium in size, oblate, with green skin and rose-colored pulp.

Minangoin (1931) described three Tunisian varieties with similar names, all three apparently requiring caprification. No. 5, Baioudi, from Gabès, produces medium, oblate fruits, green in color, with red pulp. No. 17, Bioudi, from Gafsa, has small, oblate figs, light green in color, with light-red pulp. No. 56, El-Baioudi, from Menzel Temine, is reported to bear above medium, spherical fruits, with thick skin, green in color, and red pulp. Valdeyron and Crossa-Raynaud (1950) report that the above names probably refer to several clones having fruits with light-colored skin.

Berdauda (syns. Grosse Berdoua, Verdaou). Deseribed by Du Breuil (1876), Sauvaigo (1889), and Eisen $(1888,1901)$. A large, turbinate fig, greenish yellow in color, with red pulp, grown in Provence, France.

Blancassa. Described by Sauvaigo (1889) and Eisen (1901) ; Ficus carica albida Risso given as synonym. Two crops. Brebas subglobular, green, with yellow flush; pulp pale rose. Second-crop figs subpyriform, greenish yellow; pulp red. 
Bontard. Two apparently different varieties are described by Eisen (1901) under this name; no record is given of the source or the locality where the first was grown; it was a fig below medium in size, with yellowish-green skin and pink pulp. The second account refers to the Bontard received from the Royal Horticultural Society in the Chiswick collection, first established at Niles, and later at Chico, Fresno, and Riverside, under P.I. No. 18,836. Description follows, from trees fruiting at Riverside since 1930.

Tree not vigorous, fairly dense ; terminal buds green. Leaves below medium to small, mostly 3-lobed; upper surface glossy; upper sinus shallow, rather narrow; base subcordate to truncate; margins dentate.

Brebas few, medium or above, variable in size and shape, commonly oblique-pyriform; neck prominent, sometimes curved; stalk short; eye medium, open, with straw-colored scales; white flecks numerous, fairly conspicuous; color light green; pulp light strawberry; flavor mild; quality fair to poor.

Second-crop figs medium, turbinate; neck thick, slightly flattened in some specimens; average weight 34 grams; ribs present, but not conspicuous, of same color as body; eye large, open, attracting beetles; surface dull, with delicate bloom; white flecks inconspicuous; color yellowish green; pulp very light strawberry to amber, somewhat hollow; flavor mild. Quality poor; fruit very subject to spoilage; a worthless variety here.

Caprified figs larger, with dark-strawberry pulp. (Plate 20,C.)

Borghino. Described and figured by Baldini (1953) from the Firenze district of Italy.

Tree moderately vigorous, producing one crop only; terminal buds light green. Leaves mostly 7-lobed, with deep sinuses; petiolar sinus narrow. Figs spherical, with short neck and medium stalk; eye open, surrounded by a brown ring; color light green ; pulp red, fairly sweet; seeds numerous.

Bouin (syns. Bovin, Ficus carica bovina Risso). Described by Risso (1826), Sauvaigo (1889), and Eisen (1901).

Tree with thick branches. Leaves mostly 3-lobed. Figs above medium, elongated, broadest toward the apex; skin and meat strongly adhering to the pulp; color greenish yellow; eye projecting, surrounded by a red iris; pulp bright red, of agreeable flavor.

Boukrati. Described by Grasovsky and Weitz (1932) as a variety grown only in northern Palestine. Figs medium, green; neck and stalk short; eye slightly open, with pinkish scales; pulp red. Good for fresh fruit.

Bourdissotte Blanche. Described by Hogg (1866); his description closely followed by Eisen $(1888,1901)$. Reported to be a good French drying fig, distinct from Bourjassotte Blanche. Figs small, spherical-turbinate; color greenish yellow; pulp pale rose; flavor rich.

Boutana. Described by Hogg (1866), Barron (1891), and Eisen (1901, after these two). Fruit medium, oblique-oblate; ribs distinct; stalk short; skin downy, green, without bloom; pulp dark rose; flavor flat.

Brianzola (syns. Passin, Passet). Described by Gallesio (1817), Roda (1881), Eisen (1901), and Tamaro (1948). The following account is after those of Gallesio and Tamaro, both of whom reported Brianzola to be one of the better figs of Lombardy. 
Figs small, gourd-shaped; color green; pulp red. Fresh fruit resistant to handling and transport. Fruit shrivels on the tree, a fact which accounts for the local name, "Passin" (raisin) ; also dries well in the sun, and is stored for winter use.

Buttafarro. Described by Guglielmi (1908) as a medium fig with thin, smooth skin, yellowish green in color; pulp red; mostly consumed fresh; cultivated especially in the vicinity of Squinzano.

Byadi (syn. Fallahi). Name signifies "white." Described by Grasovsky and Weitz (1932).

Trees small in size, not very prolific. Leaves deeply lobed. Figs medium, spherical; neck and stalk short; eye open, scales brown; skin color light green; pulp light pink; flavor sweet; seeds few and small. Mainly used for drying.

Cabroliana (syn. Douqueiretta). Second crop only described by Sauvaigo (1889) and Eisen (1901). Figs pyriform, 15/8 inches in diameter, $21 / 2$ inches long; color greenish yellow; pulp red. Grown at Nice and in Provence.

Caiana Blanca (syn. Ficus carica candoleana Risso, according to Sauvaigo). Described by Sauvaigo (1889) as a pyriform fig with light-green skin and red pulp.

Carabaseta. Described and figured by Estelrich (1910) as one of the best drying figs of Mallorea, receiving a gold medal at the exposition in Manacor, 1896 ; see also account of Priego y Jaramillo (1922), and of Condit (1925). P.I. No. 86,169, introduced from Lérida Province in Spain in 1928 as Carabesseta, proved to be a striped fig very similar to Panachée.

Tree of medium size, with 3-lobed leaves. Figs medium, conical, clear green; pulp light red, very sweet. Highly flavored fresh, and of especially good quality dried.

Caravanchina (syns. Caravanchina Bianca, Ficus carica collina Risso). Specific name collina implies "fig of the hills." Described by Risso (1826), Sauvaigo (1889), and Eisen (1901).

Tree with long branches, producing two crops. Leaves 3- to 5-lobed; blade sometimes prolonged to a point at the petiole.

Brebas above medium, pyriform, with elongated neck; eye prominent, with reddish scales; meat streaked with violet; pulp light red.

Second-crop figs turbinate, $1 \frac{1}{2}$ inches in diameter, greenish yellow ; pulp red.

Carlina. Described and figured by Estelrich (1910) as originating at Algaida from a tree growing in a dry wall.

Tree of moderate size. Leaves mostly 3-lobed. Figs medium; skin firm, light green in color ; pulp light red. Very good for drying and for cattle feed.

Cheihk-Ali. Described by Minangoin (1931) from Gabès, Tunisia. Leaves large, often nonlobed. Figs oblate, sessile, ribbed; eye wide open; color green, pruinose; pulp red.

Cimeirenca Blanca. Described by Risso (1826) as Ficus carica cemenelea, or fig of Amiez, France.

Tree small, very prolific; branches spreading into the shape of a parasol. Leaves small, glossy, 3-lobed, or often entire. Figs medium, turbinate, with long stalk; eye rosy; skin thick, light green; pulp red. Flavor very agreeable. 
Clauet. Described by Estelrich (1910) as a late Mallorcan variety, with 3 -lobed, deeply cleft leaves. Figs small, oblong, yellowish green in color; eye open; pulp red. Well regarded for its quality.

Col de Dame (syns. Col di Signora, Col de Señora Blanca, Col di Signora Bianca, Col des Dames, Col de Dame Blane, Cuello de Dama Blanca, Figue des Dames, Pera, Fraga, Ficus carica domina Risso, Lucrezia, according to Eisen). Described by Risso (1826), Ounous (1863), Hogg (1866), Hyde (1877), Anon. (1878), Soc. Pomol. de France (1887, 1947), Sauvaigo (1889, 1894), Barron (1891), Colby (1894), Wright (1894), Eisen (1888, 1901), Wythes (1902), Starnes and Monroe (1907), Estelrich (1910), Priego y Jaramillo (1922), Sánchez (1922), E. A. Bunyard (1925), Condit (1925), Davis (1928), Bois (1928), Blin (1942), Simonet et al. (1945), Delbard (1947), and Evreinoff (1947). Color plate by Anon. (1878) shows a yellow fig with red eye scales; both Estelrich and Simonet give an outline drawing of the fruit. See also Condit (1941a, fig. 2, O).

In his account of Figue des Dames, Risso refers to previous descriptions by Garidel, Bernard, and Duhamel ; the first two, however, made no mention of Col de Dame, but describe Trompe-Cassaire (Verte), a distinct variety. Since Risso described this fig as Figue des Dames in 1826, and a similar name is used by Simonet in 1945, the variety is designated in this publication as Col de Dame. It is widely distributed in southern France, and especially in Spain where, as Mazières (1920) stated, it probably originated. On Mallorca the figs, both fresh and dried, are used for hog feed, and at Palma the fresh fruit is common in the markets. It has long been grown for drying at Fraga, and at Barcelona the fresh figs are used for preserves.

Col de Señora Blanca was imported from England in 1883 by John Rock, of Niles, California; in 1894, it came in as P.I. No. 18,891 of the Chiswick collection, also obtained from England. Fraga, P.I. No. 96,439, originally from Lérida, Spain, proved to be identical to Col di Signora Bianca. P.I. No. 69,011, received from a French nursery in 1926 as Col de Dame, was found at Riverside to be a different variety, having small, green fruit, small eye, and dark-strawberry pulp. It is very similar to Verte, and may be identical with that variety. At Fresno, Col de Dame is inferior to Adriatic (Verdone) for drying, on account of poorer production of the tree, smaller size of fruit, and darker color of pulp. At Riverside the figs are subject to spoilage, owing to insect infestation and splitting.

The tree is vigorous, upright in habit, with dingy-green terminal buds. Leaves medium, glossy above, rather stiff and harsh in texture, 3 - to 5-lobed; upper sinuses fairly deep, margins of lobes often overlapping, lower sinuses shallow; base subcordate to truncate; margins coarsely crenate. The following description is from fruit produced at Riverside since 1930, and at Los Angeles and Fresno in 1953.

Brebas none, or very rare. Second-crop figs variable in size, from small to medium, up to $2 \frac{1}{4}$ inches long and 2 inches in diameter, short-pyriform to spherical, or even oblate-turbinate; average weight 41 grams; neck prominent, thick; stalk short; ribs fairly broad, slightly elevated, but hardly prominent; eye rather large and partly open, scales commonly brightly colored, contrasting strongly with the yellow skin; surface dull, with faint 
bloom ; white flecks large, conspicuous ; color yellowish green to lemon yellow; skin sometimes checking at maturity, as shown by Condit (1941a, fig. 8, $C$ ); pulp strawberry, almost seedless. Flavor sweet, but insipid; quality fair; season late.

Caprified figs above medium, green; pulp dark red; seeds fertile. (Plates $12 ; 20, D$.)

Cordelière (syns. Servantine, Coucourela, Coucourelle, Coucourelle Grisé, Ficus carica tournefortiana Risso). See Rolland (1914) for synonymy. In 1700, Tournefort described Figue Cordelière or Servantine, and quoted the description given by Cupani four years earlier. The latter did not use the same variety names, but reported that it was commonly known as Ficazzini Vera. Later authorities, who apparently described the same variety, are: Garidel (1715), La Brousse (1774), Bernard (1787), Rozier (1805), Duhamel (1809), Lamarck (1817), Risso (1826), Lhérault (1872), Sauvaigo (1889, 1894), Eisen (1901), Estelrich (1910, probably), Rolet (1916), and Leclerc (1925). This fig was described by Duhamel as Servantine, showing illustrations in color; also by Risso as Ficus carica cotignana, commonly known as Observantine. Simonet et al. (1945) consider Cordelière and Cotignana as identical, and give other local names, such as Célestine. However, the last name is regarded by Société Pomologique de France $(1887,1947)$ also by Eisen-as properly belonging to still another French fig of ashy-gray color. See accounts of Observantine and Célestine. Apparently Cordelière has not been grown in California, at least under that name.

The tree of Cordelière produces two crops, of which the first is the most highly regarded. Leaves are 5-lobed, with the middle lobe unusually long.

Brebas are larger and more elongated than figs of the main crop; quality good.

Second-crop figs spherical, small, 1 inch in diameter, according to Bernard, about $1 \frac{1}{2}$ inches long and $1 \frac{1}{4}$ inches in diameter, according to Risso; ribs elevated; stalk short; color yellowish green; pulp delicate rose. Figs often plunged into boiling water to facilitate drying. Season early.

Cotignacenque (syns. Cotignac, Potignacenque). Described by Bernard (1787), Duhamel (1809), Bory de Saint Vincent (1824), Noisette (1829), Couverchel (1839), and Eisen (1901). A French fig, common at Hyères.

Tree good in dry soil. Leaves 3-lobed. Figs oblong, about 2 inches long and 1 inch in width; stalk long; eye rose-colored; skin smooth, greenish yellow; pulp red. Quality good, both fresh and dried. Figs dry readily on tree before dropping.

Cótio (syn. Malaguenho Branco). Described by Mello Leotte (1901) and Bobone (1932) - the latter with illustrations-as the most important commercial variety of Algarve. The orchards of Lameira are composed almost wholly of Cótio trees. At Cacela, it is known as Malaguenho Bravo.

Breba crop none. Second-crop figs medium, turbinate; neck short and thick or none; stalk short; color green; pulp carmine; texture coarse. Quality good, especially for drying.

Damascene. Described and figured by Christ (1812) as a golden-yellow fig with red pulp. 
Dame Blanche. Described and figured by Simonet et al. (1945) from specimens collected at Sollies-Pont.

Tree bears one crop only. Leaves small, 5-lobed.

Figs small, oval-pyriform, without neck; average weight 17.5 grams; ribs not very apparent; stalk up to $1 / 2$ inch long; eye medium, circled by rosy, projecting scales; skin velvety, checking at maturity, uniformly greenish yellow; pulp red; texture fine; seeds small, not very numerous; quality mediocre.

Darji. Described by Minangoin (1931) from Menzel Temine, Tunisia. Leaves medium, mostly 5-lobed; upper sinuses deep, almost closed, lower sinuses less prominent. Figs medium, 11/2 inches in diameter, practically spherical; eye open; skin rather thick, light green in color; pulp light red.

Datte. Described by Gallesio (1817), Gasparrini (1845, as Ficus deliciosa var. castanea), Audibert Frères (1854), Hogg (1866), G. S. (1869), Du Breuil (1876), Pasquale (1876), Roda (1881), Barron (1891), Eisen (1888, 1901), Starnes and Monroe (1907), and by Tamaro (1948, with figure). Gallesio reported the following local names in Italy: Fico Madama Rosso at Milan, F. Genovese at Pavia and Laggo Maggiore, F. della Madonna at Bergamo, F. Rossetto at Voghera, F. Larde at Alessandria, and F. Averengo and F. Datto at Torino.

Datte is reported to be common in northern Italy, where the brebas are especially esteemed; in southern districts, second-crop figs are better than brebas. It was introduced into the United States in the Chiswick collection as P.I. No. 18,845, and fruited in Georgia and California, but trees are now found only in collections.

The tree is of slow growth, with many small, slender twigs; terminal buds green. Leaves medium, glossy above, 3- to 5-lobed; upper sinuses of medium depth and width, lower sinuses shallow; base subcordate to truncate; margins very shallowly crenate. Description is from fruit produced at Riverside since 1931.

Breba crop small or none; fruit medium or above, oblique-pyriform, with prominent, often curved neck; stalk short; color green, tinged with violet from the underlying violet meat; pulp dark strawberry; flavor good.

Second-crop figs medium, up to $21 / 2$ inches long and $1 \frac{1}{2}$ inches in diameter, oblique-pyriform, but irregular in shape and size; average weight 28 grams ; neck up to $1 / 2$ inch long, sometimes curved; stalk thick and short, or slender and over $1 / 2$ inch long; ribs slightly elevated, hardly prominent; surface dull, with light bloom; white flecks large, scattered, conspicuous; eye medium, open, scales straw color; skin light green, discolored by brown spots at maturity ; meat white; pulp light strawberry, fairly sweet and rich, but dry in texture; quality poor. A considerable percentage of the crop drops when figs are small, indicating lack of caprification.

Caprified specimens with dark-green skin; eye scales bright rose color; fruits inclined to split at apex; pulp of a rich strawberry color, subacid, but of agreeable flavor. Much improved by caprification.

Variety generally poor, both fresh and dried, and not worthy of further culture in California. (Plate 22, D.) See also Condit (1941a, fig. 2, $U$ ). 
Daurada. Described by Risso (1826, as Ficus carica lutea), Sauvaigo (1889), and Eisen (1901), as a small, globular fig, broad at the apex; color greenish yellow; pulp red. Grown near Nice, France.

Domestica. Briefly described by Sauvaigo (1889) and Eisen (1901) as a pyriform fig, with greenish-yellow skin and red pulp.

D'Or de Laura. Description by Eisen $(1888,1901)$, after that of Hogg (1866). Figs below medium, oblong; ribs obscure; eye closed; color yellowish green; pulp opaline, sweet; quality excellent.

Dorée (syns. Figue d'Or, Goutte d'Or). Described by Merlet (1667), Ballon (1692), Liger (1702), Langley (1728), Société Pomologique de France $(1887,1947)$, Eisen $(1888,1901)$, Starnes and Monroe (1907), Juignet (1909), Simonet et al. (1945), and Delbard (1947). Illustrated in black and white by Starnes and Monroe and by Simonet. Illustrated in color by Delbard.

Dorée is a French fig, reported by Merlet and other early writers to be subject to splitting or cracking of the skin, and therefore good only for hog feed; the checked skin also suggested to them the torn robe of a beggar; in general, however, it is described as a handsome fig of excellent quality. Starnes found in Georgia that Dorée appeared to be the same as Magnolia (Brunswick), a report which casts doubt on the identity of the specimens grown. It is doubtful, moreover, whether the true Dorée has ever fruited in California, although P.I. No. 18,897 of the Chiswick collection was labeled as that variety; no trees are now known to occur in collections of varieties. P.I. No. 102,013, introduced from Morocco in 1933 as Goutte d'Or, was found to be the same as Dottato at Riverside.

Tree of Dorée produces two crops. Leaves medium to small, 3- to 5-lobed. Description is after Simonet, from fruit grown at Bagnols-sur-Ceze.

Brebas large, elongated-pyriform, somewhat oblique; length $31 / 4$ inches, diameter $21 / 4$ inches; average weight 85 grams; neck not distinct, merging gradually with the body; stalk conical, swollen toward the junction with the fruit, about $1 / 2$ inch long; ribs not very well marked; eye in a slight depression, large, half open; scales erect, yellow to rose-colored; skin delicate, yellowish green, becoming golden yellow slightly tinged with rose on the exposed side; pulp salmon; texture fine; seeds few ; quality fair.

Second-crop figs smaller, globular, or short-pyriform; stalk swollen; ribs none; color same as brebas; pulp light rose. Quality good; excellent for drying.

Douqueira Blanca. Described by Sauvaigo (1889) and Eisen (1901) as a fig resembling Douqueira Negra (Perroquine), except in color, which is yellowish green; pulp bright red; excellent as a fresh fruit.

Du Roi. Described by G. S. (1869), Barron (1891), Colby (1894), Shinn (1893, 1903), Forrer (1894), Eisen (1897, 1901), Price and White (1902, with figure), Starnes (1903), Starnes and Monroe (1907, with figure), Woodroof and Bailey (1931), and Blin (1942).

Du Roi is a good example of a variety which was once tested and received high praise, but failed to become established. Very few accounts of it are found in horticultural publications of England. However, it was included in the Chiswick collection from that country as P.I. No. 18,843 , and tested 
widely by the California Experiment Stations. Shinn reported in 1893 and 1903 that Du Roi was considered the highest-flavored fig grown, especially in the foothills of the San Joaquin Valley ; trees suffered severe winter injury at the Tulare Experiment Station. Eisen regarded it as one of the very best figs, and stated: "It cannot be too highly recommended, and will no doubt become one of the most extensively grown figs in California and Arizona." His illustration shows four specimens that are pyriform and of medium size. Colby gave a short description of figs grown at Tulare, and analysis of the fresh fruit. Price could not have had the true Du Roi, for he represented the Texas-grown fruits as small and dark purple. Starnes described specimens from three different sources in Georgia, and illustrated one; the trees were found to be extremely productive, with fruit continuing to mature until frost. In spite of its early promise, Du Roi has apparently been lost completely from collections of fig varieties in Georgia and California. Description is from that of Eisen; apparently only one crop.

Figs above medium, round-pyriform, oblique, with swollen cheeks; ribs few, slightly elevated; neck short, variable; eye large, with amber scales; color pale bluish green; pulp amber, streaked with rose; texture fine; seeds many, minute. Quality excellent, both fresh and dried.

Barron (1891) described it as "small, roundish, pale yellow."

Fl Bitri. Described by Guillochon (1913, 1927, 1929) and Hodgson (1931), from Tunisia, as an interesting variety from the standpoint of production and quality. Also described by Minangoin (1931), from Gabès.

The tree bears two crops. Figs large, green to yellowish in color, sessile; neck none; eye open; pulp red; seeds few.

El Khadri. Described by Guillochon (1913, 1927, 1929) and by Minangoin (1931) as Khedri. Figs with short, thick neck and prominent ribs; color green, as the name indicates; pulp red; seeds numerous.

Fyrogue (syn. D'Eyrogue). Described by Hogg (1866) and Eisen (1888, 1901) as a French fig, below medium in size, oblate, pale yellow in color; pulp light red, not particularly rich in flavor.

Fourrassa. Described by Sauvaigo (1889) and Eisen (1901) as one of the largest of autumn figs, oblong, greenish yellow; pulp red; quality mediocre.

Fqeisi. Described by Grasovsky and Weitz (1932) as a midseason fig of northern Palestine, medium in size, spherical, greenish yellow in color ; pulp red; seeds few.

Gambalunga (syn. Coscialunga). Described by Savastano (1885) as a medium fig, canary yellow in color, with red pulp.

Gennes (syns. Aubicon, Figue Fièvre). Described by Merlet (1667), Liger (1702), Bradley (1757), Trabut (1904), and Blin (1942). First crop small ; second crop good. According to Trabut, the figs are pyriform, with very small eye, gray color, and pale-rose pulp. Langley (1728) described Genoa, called by the French, Figue de Gennes or La Figue Fièvre, as a long, brownishpurple fig.

Genoa (syns. Genoa White, White Genoa). Described by Miller (1768), Forsyth (1803), Lindley (1831), Rogers (1834), Holley (1854), M'Intosh (1855), Dochnahl (1855), White (1868), Hogg (1866), G. S. (1869), Massey (1893), Eisen (1885, 1897, 1901), Davis (1928), Burger and De Wet (1931), 
and Condit (1947). Illustrated by Eisen, who stated that the identity of this variety and the origin of its name had not been established. It is not identical with Marseilles White, as given by Rogers and by some other authors. Although long grown in England, the Genoa has not been favored so highly as certain other varieties, partly because the trees are such light producers. Davis reports that this variety is grown in all parts of the Union of South Africa, where it "rejoices in eleven other names, amongst them White Marseilles." He regards the fruit as good both for eating fresh and for drying.

In 1853, W. B. West, of Stockton, California, imported several varieties, including White Genoa, from Hovey \& Co., Boston; and in 1883, the California Nursery Company, Niles, obtained it from England. The variety was tested at the California Experiment Stations, but did not prove to be outstanding, either in tree production or in fruit quality. Genoa has not been planted commercially in California, and is not recommended for dooryard planting in the interior valleys. However, in coastal districts, some growers report excellent results with it. At San Simeon, for example, the tree produces two crops in favorable seasons; the first matures after the middle of August, and following a short intermission, the second crop continues until frost. At San Jose the tree bears well, but fruit is of poor quality, and is inclined to spoil on account of the large eye and hollow center. Both P.I. No. 101,712, introduced in 1933 as Arabaly, and P.I. No. 101,719, introduced as Neapolitan, from Sochi, North Caucasus, proved to be identical with Genoa at Riverside.

Trees are of moderate vigor, with spreading branches; terminal buds tawny to light brown, an unusual character for a green-fruited variety. Leaves medium to large, 3- to 5-lobed; upper surface dull; upper sinuses of medium depth and width, lower sinuses shallow and broad; base broadly subcordate, sometimes auricled; margins shallowly crenate. Description is from fruits produced at Riverside and Menlo Park.

Breba crop small; fruits large, 21/4 inches in diameter by $2 \frac{1}{2}$ inches in length, or in coastal districts more elongated, up to $3 \frac{1}{2}$ inches; average weight 80 grams ; shape oblique-pyriform, with short neck, or sometimes with longer, curved neck; stalk very short; ribs rather prominent, elevated; eye medium, open, scales chaffy or light rose; white flecks more or less concealed by yellowish-green skin color; skin smooth; bloom inconspicuous ; pulp light strawberry, hollow at center; flavor sweet, but not rich; seeds few, small; quality fair. (Plate 22, A.)

Second-crop figs medium or above, up to 2 inches in diameter and 21/4 inches in length, somewhat oblique, turbinate; average weight 60 grams; apex broad and flattened; neck very short, or absent; stalk short and thick, or sometimes curved, and up to $3 / 8$ inch long; ribs elevated, mostly prominent; surface dull; bloom hardly perceptible; color greenish yellow, blemished by circular, brown spots at maturity ; skin thin, tender, peeling readily; pulp amber, tinged with strawberry, hollow at center; texture gelatinous; flavor mild; quality poor; seeds practically none. Very susceptible to spoilage. (Plate 22, B.)

Caprified specimens with green skin color, dark-strawberry pulp, and large, fertile seeds; inclined to split at maturity. Quality fair as fresh fruit, but poor when dried. 
Glati. Described by Grasovsky and Weitz (1932) as a variety grown in the Safad subdistrict of Palestine. Figs small, spherical, green, with open eye and yellow scales; pulp distinctive, on account of its purplish-red color. Leaves are unusually thick.

Gorgone. Described by Risso (1826) as Ficus carica gorgonea, but this name is not found in later publications. Figs medium, oblong, narrowed toward the long stalk; color greenish yellow; eye large, with a raised border; pulp light red.

Gota de Mel (syn. Gota de Goma). Names signify "honey-drop" and "gum-drop"; figs when ripening exude a sugary syrup from the eye. This variety, received at Riverside in 1926 from Lérida, Spain, is distinct from Fraga (Col de Dame) and others in the collection; no description under the above names has been found.

Tree moderately vigorous, with branches swollen at the nodes; terminal buds green. Leaves medium, somewhat glossy above, mostly 3-lobed; upper sinuses shallow; base subcordate to truncate; margins crenate. Description is from figs produced at Riverside, Los Angeles, and Fresno.

Breba crop small; fruits elongated-pyriform, with neck over 1 inch long; stalk $1 / 4$ inch long; ribs fairly prominent; eye medium, open; color green; pulp light strawberry; flavor rich; eating quality good. Of no commercial value, on account of light crop and elongated shape.

Second-crop figs medium to large, up to $2 \frac{1}{4}$ inches long and 2 inches broad, pyriform, with thick, prominent neck that is often curved; average weight 40 grams; stalk thick, up to $1 / 4$ inch long, constricted at its insertion with the thick neck; ribs prominent, well elevated; eye medium, open; surface dull; white flecks large, scattered; color green; skin checking at maturity, as shown by Condit (1941a, fig. 8, E); pulp light strawberry; flavor rather strong; quality fair.

Caprified figs similar in size and shape, but with dark-red pulp. Variety of no particular value, on account of discoloration of skin at maturity and susceptibility to splitting and insect infestation. (Plate 22, C.) See also Condit (1941a, fig. 2, Q.)

Gounti. Described by Minangoin (1931) from Dra Tamar, Tunisia. Leaves large, mostly 3-lobed. Figs spherical, with short neck; skin of fine texture, green in color, without ribs; pulp solid, rose color; seeds numerous.

Another variety, also designated as Gounti, is described by Minangoin from Kalaâ Srira. Leaves small, 3- to 5-lobed. Figs large, with indistinct neck; eye open; skin color light green ; pulp pomegranate red.

A third variety is described by Minangoin as Gounti, from Hammamet; it is reported to require caprification. Figs small, pyriform ; skin thin, glossy, golden yellow in color.

Grassale. Barron (1891) described this variety as bearing small, pyriform figs. Eisen (1901) regarded Grassale as a synonym of Figue de Grasse or Matarassa, the fruit of which is described as very large. P.I. No. 18,883 of the Chiswick collection was received in California as Grassale, and fruited in several collections. At the Tulare Experiment Station of the University, it was reported as a failure in 1890. The following description is from trees growing at Riverside since 1928. 
Trees small, lacking in vigor; terminal buds green. Leaves medium, somewhat glossy above, mostly 5-lobed; both upper and lower sinuses moderately deep and broad; basal sinus sometimes broadly subcordate, but often narrow, or almost closed; margins crenate.

Breba crop none. Second-crop figs oblate-spherical, below medium to small; average weight 25 grams; neck absent, or when present, short and somewhat flattened; ribs fairly conspicuous; eye medium, open; color green, becoming spotted with brown at maturity, unattractive; pulp light strawberry, or dark red when caprified; quality poor. Very susceptible to spoilage. (Plate 17, D.)

Grasse (syns. Figue de Grasse, Matarassa, Figue Grisé, Ficus carica grassensis Risso, Grassenque; the last according to Du Breuil and Eisen). Described by Bernard (1787), Duhamel (1809), Risso (1826), Noisette (1829), Couverchel (1839), Duchartre (1857), Hogg (1866), Du Breuil (1876), Sauvaigo (1889), and Eisen $(1888,1901)$. Bernard recorded this variety in 1787 as Figue de Grasse, and all other authors followed this nomenclature until 1889, when Sauvaigo called it Matarassa. The account by Duhamel followed very closely that of Bernard, as in fact did several others, mostly without giving credit. Figue Castex (Grasse) described by Ounous (1863) may be the same variety. With the exception of Hogg, British authors ignore the variety, at least under the name Grasse. However, P.I. No. 18,850 was received in California with the Chiswick collection under the label Grasse, and fruited in various collections. At Riverside, this introduction proved to be a violet-fruited variety, identical with Bourjassotte Grisé. The following description is after that of Eisen, who reported it to be highly recommended for rich bottom lands.

Tree is vigorous, with 3-lobed leaves.

Figs very large, 8 to 9 inches in circumference by 3 inches in length, turbinate, with flattened apex; neck short; ribs distinct; stalk very short; eye open; skin thin, light yellow, with delicate bloom; pulp very dark red. A handsome fig, of medium quality when fresh, but better when dried.

Grosse Jaune (syns. Aubico Blanco, Aubique Blanche, Tapa Cartin, Ficus carica monstrosa Risso). Described by La Quintinie (1692) as La Grosse Jaune; others who give this name preference are Tournefort (1700), Garidel (1715), La Brousse (1774), Rozier (1805), Duhamel (1809), Lamarck (1817), Bory de Saint Vincent (1824), Noisette (1829), Couverchel (1839), Leclerc (1925), and Evreinoff (1947). The following authors used the designation Aubique Blanche: Bernard (1787), Duchartre (1857), Du Breuil (1876), and Bois (1928). Sauvaigo $(1889,1894)$ is followed by Eisen (1901) and by Simonet $e t$ al. (1945) in listing and describing this fig as Tapa Cartin, without any explanation as to the meaning of the name. Estelrich (1910) and Priego y Jaramillo (1922) described it as Albacor Blanca. Risso (1826) treated it as Ficus carica monstrosa, or "figue à fruit monstrueux," because some of the figs exhibited monstrosities, reported by Sauvaigo and by Penzig (1922) as the proliferation or superimposition of a secondary fruit at the apex of a primary one. Both Estelrich and Simonet figure a single fruit. Lamarck presumed that "this is the one which Miller named, La Grosse Blanche de Gênes, his variety No. 4." 
The tree has 5-lobed leaves, and produces one crop only in southern France. The following description is taken from that of Simonet.

Second-crop figs pyriform, medium in size, $2 \frac{1}{2}$ inches long by $13 / 4$ inches broad; neck prominent, rather slender, up to $3 / 8$ inch in length; stalk medium; ribs present; eye medium, closed, scales red; color green to golden yellow; meat white; pulp bright red; seeds small, numerous; quality good. Season late September.

Harraki (syn. Bou-Harraq). Described by Minangoin (1931) from Hammamet, Tunisia. Leaves medium, thick, very rough, 5-lobed; upper sinuses deep, open. Figs medium, 11/8 by 2 inches, oblate; stalk practically missing; eye open; color citron yellow; pulp light red.

Ischia Yellow (syn. Cyprus). Described by Miller (1768); his account is closely followed by most of the same authors listed for Ischia Brown, with the exception of Eisen. Ischia Yellow is one of the Ischia figs, the identity of which has not been determined; and the variety has apparently been discarded. The fruit was reported to be large, pyramidal, yellow in color; pulp dark red.

Kaffi. Described by Minangoin (1931) from Kalaâ Srira, Tunisia. Leaves medium, glossy above, 5-lobed; sinuses deep and broad. Figs with short, thick neck; ribs present; eye open ; skin thin, light green in color ; pulp red.

Kommathri. Described by Badie and Ghamrawi (1931) as a one-crop variety, grown chiefly near Alexandria.

Tree vigorous, with erect branches. Leaves 5-lobed. Figs large, pyriform; stalk medium; ribs distinct; skin easily peeled, yellowish green; white flecks prominent; pulp dark red.

Krawi (syn. Krati at Nazareth). Described by Grasovsky and Weitz (1932) as a very good drying fig.

Trees large, producing up to 180 kilos (nearly 400 pounds) per tree. Figs small to medium, turbinate; neck medium; stalk long; eye small, with lightbrown scales; skin smooth, light green; pulp red, not juicy; flavor fair.

Lattarola. Described by Guglielmi (1908) as an Italian variety, much cultivated at San Vito d'Otranto, both for fresh fruit and for drying; briefly described by Ferrari (1912). The name refers to the abundance of latex or "milk" in various parts of the plant.

Figs medium, oblate; skin thick, checking; color clear yellow; pulp red, very sweet; seeds numerous.

Limoncello. Described by De Rosa (1911), with a footnote stating that in some districts it is known as Fico Ottato ; however, Dottato is treated elsewhere in his publication as a distinct variety.

Tree vigorous. Leaves large, 3 - to 5 -lobed. Figs ovoid, $23 / 4$ inches long; stalk short; skin greenish yellow, with scattered white flecks; eye small, scales yellowish; pulp red; flavor sweet; seeds large, numerous. Mostly consumed fresh; dried product mediocre.

Lipari (syns. Petite Blanche Ronde, Liparensis, Blanquetto, Esquillarello, Verte Petite, Bouton du Guêtre). Described by Cupani (1696), Tournefort (1700), Garidel (1715), La Brousse (1774), Rozier (1805), Bernard (1787), Duhamel (1809), Lamarck (1817), Bory de Saint Vincent (1824), Couverchel (1839), Noisette (1829), Dochnahl (1855), Hogg (1866), Société Pomo- 
logique de France (1887), Barron (1891), and Eisen (1888, 1901). This variety, first described by Cupani as Ficus liparensis, is regarded by various authors as bearing the smallest fruit of any fig commonly grown in France. Blanquetto, which Duhamel gave as a name used in Provence, should not be confused with Blanche or Blanquette, a larger fig cultivated near Paris. The description by Lamarck is almost identical with that of Rozier; he added that the body of the fruit resembles that of a mushroom. The name Bouton du Guêtre, or "button of the gaiter," is also indicative of the shape of the fruit. Hogg-followed by Eisen (1901) - is one of the few English authors who give an account of Lipari. If it was ever introduced into California it certainly did not become established under this name, and no records are available of any plantings.

Brebas apparently none. Second-crop figs very small, $1 / 2$ inch to nearly $3 / 4$ inch in diameter, oblate, ribbed; eye open; color green; bloom thin; pulp pale rose; texture dry, coarse. Flavor sweet and quality good in a warm climate, according to Eisen; but Hogg reported it "not at all well flavored."

Lucano. Described and figured by Baldini (1953) from the Firenze district of Italy.

Tree vigorous, erect; terminal buds brown; one crop only.

Leaves mostly 3-lobed, the middle lobe spatulate, narrow; lateral sinuses deep ; base truncate; margin crenate.

Figs pyriform, with short neck; stalk also short; eye open, with yellowish bracts; color citron yellow; pulp of fine texture, hollow, almost seedless, brown in color; flavor sweet and agreeable. Fruits consumed fresh, but also suitable for drying.

Marquês (syn. Ponte da Quarteria). Described and illustrated by Bobone (1932) ; known as Marquês at Lagos, and as Ponte da Quarteria at Loulé. Second-crop figs medium, oblate-spherical, yellowish green; pulp red; texture coarse; flavor agreeable; quality fair.

Marseillaise (syns. Athènes, Figue de Marseilles, Petite Marseillaise, Ficus carica massiliensis Risso). Described by Tournefort (1700), Garidel (1715), La Brousse (1774), Bernard (1787), Rozier (1805), Mirbel (1806), Duhamel (1809, with illustration), Bory de Saint Vincent (1824), Lamarck (1817), Risso (1826), Duchartre (1857), Hogg (1866), Du Breuil (1876), Soc. Pomol. de France (1887), Sauvaigo (1889, 1894), Eisen $(1888,1901)$, Trabut (1904), Rolet (1916), Mazières (1920), Sánchez (1922), Bois (1928), Blin (1942), Simonet et al. (1945, with illustrations), and Evreinoff (1947). The descriptions of this variety by Tournefort, and by several later authors, definitely refer to the interior of this fig as rosy or red, a character which differentiates it from Marseillaise White, described by Eisen (1901). Sauvaigo treated it as Marseillaise or Figue d'Athènes, and that is regarded here as the correct synonymy. See Rolland (1914) for synonyms. It is properly described by Hogg, but apparently was ignored by other English authors.

Marseillaise, though small, is reported to be one of the best figs for drying in Provence. It has probably been introduced into California; if so, records are lacking as to its distribution. P.I. No. 102,017, received at Riverside in 1933 from Moroceo as Marseillaise, may be that variety; however, it produced small, brownish, and worthless figs, identical with Grassale, P.I. No. 18,883. 
The tree bears only one crop, maturing in September. Leaves are small, 3 - to 5-lobed. The following description is after that of Simonet, from fruit grown at Sollies-Pont.

Figs small, $13 / 8$ inches long and about the same in diameter, turbinate to subglobular, with indistinct neck; average weight 22.5 grams; ribs numerous, rather prominent; stalk up to $1 / 2$ inch long; eye medium, surrounded by a red aureole; scales rose, flat; skin checking at maturity, uniformly greenish yellow; pulp strawberry; flavor sweet; quality good.

Martigiano. Described and figured by Baldini (1953) as an Italian variety, producing one crop only in the district of Carmignano near Firenze.

Trees unusually vigorous; terminal buds green. Leaves 3-lobed, or almost nonlobed; sinuses very shallow and narrow; base cordate; margin crenate. Figs spherical, without neck; stalk short; eye small, open, with rosy seales; skin checking at maturity, light green in color; pulp red; seeds few. Consumed fresh.

Mastroleone (syn. Mastruglione). Described by Guglielmi (1908) as grown principally in the area of San Vito dei Normanni, Italy. Figs oval; skin green; pulp red, very sweet. First-crop figs sold fresh; those of the second crop, maturing in September, are mostly dried.

Meloncella (syn. Melonceddha). Described by Guglielmi (1908) and Vallese (1909), the latter with illustrations of leaves and fruit. According to Vallese, this variety is widely grown in Lecee Province, both for fresh fruit and for drying.

Tree large. Leaves both 3- and 5-lobed. Figs pyriform, with neck gradually narrowing from body to the short stalk; ribs slightly elevated; color greenish yellow; pulp light rose.

Meou (syns. Figue Mielleuse, Ficus carica mellifera Risso). Described by Risso (1826), Sauvaigo (1889), Eisen (1901), and Simonet et al. (1945). $F$. carica mellifera was described by Risso as a fig with luscious fruit, the one of all varieties which in drying conserves its sweetness without change. Sauvaigo recorded the same variety as Figo de Meou, apparently a Provençal term. The following description is a complex of accounts from the sources listed above.

Tree is upright, with 3-lobed leaves. There are two crops.

Brebas large, 2 to $2 \frac{1}{4}$ inches in diameter, turbinate; skin thin, checking, greenish yellow; eye protruding; meat violet; pulp red, very sweet and syrupy.

Second-crop figs globular, up to 2 inches in diameter; stalk short; color pistachio green; pulp light red. Good for drying, but inferior when fresh.

Monaco (syns. Monaco Bianco, Fico della Lunigiana). Described by Gallesio (1817), Gasparrini (1845, as Ficus deliciosa var. latifolia), Audibert Frères (1854), Hogg (1866), Pasquale (1876), Barron (1891), Eisen (1888, 1897, 1901), Wythes (1902), Wright (1894), Forrer (1894), Stubenrauch (1903), Bunyard and Thomas (1904), Starnes and Monroe (1907), De Rosa (1911), and Tamaro (1948). Illustrated by. Eisen (1901) and by Tamaro. According to Gallesio, this variety originated in the district of Lunigiana, where the fruit was highly esteemed. It was grown at Genoa and other places in northern Italy, but apparently has not been much distributed in 
France. Hogg reported Monaco as a coarse fig, inclined to split, and not a first-rate variety. On the other hand, Wythes classed it as superior to Brown Turkey in flavor, but not so reliable in production.

Monaco Bianco was introduced into California in the Chiswick collection as P.I. No. 18,853, and fruited at Niles, where Eisen found it to be a very good, juicy fig, splendid for the table. If it was grown at Chico, no record is available as to its behavior. At various California stations, reports were conflicting, as the following quotations show: "Quality is fair to good, and the bearing capacity is large" (Tulare); "The best large fig at the station" (Pomona); "One of the most useful figs at the station" (Jackson); "Former recommendation ... considerably modified; more than half the crop soured on the tree in 1896" (Pomona). The variety has since disappeared, and no trees are known to exist in collections.

In Italy the tree is large, with shallowly lobed leaves; it produces two crops. The following description is from various accounts.

Brebas abundant, especially along the coast, oblong, with prominent neck and very short stalk; skin green, with white flecks; meat streaked with violet, as in Dottato; pulp rose-colored, of fine texture; quality excellent.

Second-crop figs (according to Eisen) large, $21 / 2$ inches by 2 inches, turbinate, rounded at the apex; neck very short; ribs narrow, slightly elevated on the body, but not on the neck; eye wide open, with large, tawny scales; skin dark green, paler on the sunny side; bloom thin; pulp red; quality good. Consumed mostly fresh, according to De Rosa.

Monstrueuse (syn. Grosse Monstrueuse de Lipari). Described by Barron (1868c, 1870, 1891), Hogg (1871, with figure), and Eisen (1888, 1901). Illustrated by Barron (1870) from fruits produced at Chiswick; he reported it as Grosse Monstrueuse de Lipari, a French variety, comparatively unknown in England. P.I. No. 18,846 of the Chiswick collection has fruited in several test orchards under the name of Monstrueuse. Doubt has existed as to the identity of this variety, which, according to Barron, has a light-brown or chestnut-colored skin in England, while California specimens are green in color. This discrepancy can be explained by the fact that Barron's account is of the brebas only, which in California have a general green color but are commonly flushed with violet from the underlying colored meat. P.I. No. 18,878 , labeled Dr. Hogg's Clare, is the same as Monstrueuse. In England it is essentially a "first-bearing" kind, and rarely yields a second crop.

Cuttings from five different gardens in Washington, D.C., have produced fruit identical with that of Monstrueuse in test plots in California, demonstrating the fact that this variety is being successfully grown in the eastern United States. At Riverside, California, the breba crop is exceptionally good. Second-crop figs are larger and better in the coastal district of Los Angeles than at Riverside, as pointed out by Condit (1950). Apparently Monstrueuse was not tested at the early California Experiment Stations, and only recently have its good qualities recommended it for trial as a dooryard fruit.

The tree is vigorous, with broad, dense top; terminal buds are green. Leaves medium to large, somewhat glossy above, 3- to 5-lobed, the former predominating; upper sinuses shallow; base cordate; margins crenate.

Brebas above medium to large, oblique-pyriform, mostly with distinct, 
thick neck; average weight 47 grams; stalk thick, up to $1 / 2$ inch long; eye medium, open, scales straw color, or tinged with pink; white flecks scattered, prominent; color green, tinged with violet from the underlying meat; pulp dark strawberry, with a characteristic fig flavor; quality good. (Plate 19, A.)

Second-crop figs medium or above, up to $2 \frac{1}{2}$ inches long and 2 inches in diameter, turbinate, without neck, or with short, thick neck; average weight 40 grams; stalk up to $5 / 8$ inch long; white flecks large and scattered; ribs narrow, very slightly raised, showing partly as thin lines of dark green; eye medium, open, scales tawny, erect; color grass green; pulp very light strawberry, solid, or slightly hollow at center; flavor sweet, rich; quality good.

Caprified figs somewhat larger, inclined to split at apex; pulp dark strawberry; seeds numerous. (Plate $19, B$.)

Moresca (syn. Gentilla Roussa). Described by Sauvaigo (1889) and Eisen (1901) as a variety producing two crops near Nice. Brebas large, obliquepyriform, with long neck; eye scales red ; color gray; pulp pale red. Secondcrop figs not described.

Moscatel Branco (syn. Pingo de Mel). Described and illustrated by Bobone (1932) as a Portuguese variety, not grown commercially, but widely distributed in Algarve. The name Pingo de Mel, "honey-drop," is sometimes given because of the honeylike gum which.exudes from the eye. The trees generally produce two crops.

Breba crop small; fruits pyriform, with short, thick neck and short stalk; color yellowish green; pulp red, with traces of violet.

Second crop heavy; figs pyriform to spherical; skin smooth, somewhat puberulent; color dark green; pulp red; texture fine; quality very good.

Mussega (syns. Cougourdana, Figue Reine, Ficus carica linneana Risso). Described by Risso (1826), Du Breuil (1876), Sauvaigo (1889), and Eisen (1901). Grown in southern France, at Nice, Aix, and Saint-Rémy.

Leaves are large, commonly 3-lobed. Descriptions apply only to figs of the second crop. These are of medium size, pyriform, with slender neck; skin thin, light green; eye with red scales; pulp bright red; flavor agreeable.

Mwazi (Northern). Described by Grasovsky and Weitz (1932) as a variety distinct from the Mwazi grown in southern Palestine. Figs large, elongatedpyriform, with prominent neck and medium stalk; eye somewhat open, with purplish scales; skin thin, glossy, green; pulp light red, containing many large seeds; texture dry; flavor flat.

Neimi. Described by Grasovsky and Weitz (1932. as an Egyptian variety, known in the northern part of that country as Shuhmani. Figs small, greenish yellow; neck long; stalk short; eye small, open, scales brownish; pulp light strawberry; seeds many, small.

Noursi. Described by Grasovsky and Weitz (1932) as a globular fig; size medium ; color green ; eye open, scales yellowish ; pulp red; seeds many, small. It is grown in the Safed Subdistrict of Egypt.

Pajajero. Described by Escribano y Pérez (1884) as grown in Murcia, Spain, for its second crop; used for eating fresh as well as for drying. P.I. No. 58,663, introduced from Málaga in 1927 as Blanquilla, proved to be the same as Pajajero at Riverside. See also short account by Condit (1925).

Tree is of medium size. Leaves rather small, shallowly lobed. Figs globular, 
below medium to small, up to $1 \frac{1 / 4}{4}$ inches long; stalk short and thick; skin color greenish yellow; pulp rose-colored, juicy and sweet.

Panachée (syns. Figa Turca, Maravilla, Princessa, Rayonne, Courgette Rayée, Jaspée, Limone, Bourjassotte Panachée, Père Hilarion, Striped, Tiger, Zigarella, Col di Signora Panachée, Variegato, Fracazzano Rigato, Bracotedesco, Ficus carica radiata Risso, Ficus pachycarpa var. fasciata Gasparrini). Described by Risso (1826), Gasparrini (1845), Audibert Frères (1854), Hogg (1866), Pasquale (1876), Barron (1869b, 1891), Soc. Pomol. de France $(1887,1947)$, Eisen $(1888,1901)$, Sauvaigo (1889), Colby (1894), Cusin (1900), Trabut (1904), Starnes and Monroe (1907), Vallese (1909), Roeding (1914), Borg (1922), Condit (1921b, 1928b, 1947), Davis (1928), Blin (1942), and Simonet et al. (1945). Illustrated in color by Barron $(1869 b)$ and Condit $(1941 a)$. Illustrated in black and white by Vallese, Condit (1928b, 1941a, fig. 8, $D$ ), and Simonet.

In Dendrologia Naturalis, published in 1668, Ulisse Aldrovandi described and illustrated a fig designated as "ficus virgata fructu," or virgate fruit, marked with alternating bands of yellow and green. A translation (courtesy of Mrs. P. H. Timberlake) of an interesting speculation as to its origin follows: "Whether or not there is any truth in what Palladius stated in Martius, title 10, to wit, that the bicolored fig sprouts from two branches (the white and the dark kind) which have been twisted together and tightly bound, so that the buds are forced to mix their juices, and combine by this means the distinct peculiarities of both, it is at least not certain that they have ever grown together naturally."

It was probably this same fig which Risso described as Ficus carica radiata, and Gasparrini as Fico Limone.

According to Condit (1928b), the origin of this sectorial chimera has not been learned. Barron (1869b) described it as a sport from the better-known Col di Signora Bianca, one of the finest Italian varieties.

Borg reported that this variegated fig, "Tina ta Spanja," grown at Marsascala in Malta, is said to be of Spanish origin, and needs caprification. P.I. No. 86,169, obtained from Lérida, Spain, in 1928, has proved at Riverside to be identical with Panachée, and to belong to the Common type of figs. Individual trees are found in widely separated localities of California, but there is little if any interest in extending its culture.

The tree is moderately vigorous and upright in habit of growth; bark of young twigs commonly tawny or brown, and striped with yellow; terminal buds green. Leaves not variegated, above medium to large, mostly 5-lobed; upper sinuses of medium depth, rather narrow, lower sinuses shallow, basal sinuses narrow, or in some almost closed; upper and basal lobes often auricled; margins coarsely crenate; surface dull. The following description of fruit is from specimens produced at Riverside since 1930.

Brebas none. Second-crop figs medium, up to $21 / 4$ inches in length and 2 inches in diameter; average weight 40 grams; shape pyriform, with neck prominent, and somewhat flattened in some specimens; stalk to $3 / 8$ inch long; ribs practically absent; surface glossy, with a delicate bloom; white flecks inconspicuous; eye medium or above, open, scales variable, from chaffy to light violet; color light yellow, with alternate bands of green, the latter 
fading out at complete maturity ; meat thick, white; pulp strawberry, mealy in texture; quality mediocre to poor. (Plates $8 ; 26, D$.)

Caprified figs are somewhat larger, with pulp blood-red in color. Splitting of fruit bad, even when uncaprified, as shown in color illustration by Barron.

Passanudo. Described and illustrated by Bobone (1932). Second-crop figs medium, turbinate or oblate; stalk very short; skin yellowish green, smooth, dull, commonly checking when mature; pulp carmine, coarse, of agreeable flavor; quality good.

Pecciolo Bianco. Described and figured by Baldini (1953) from Firenze, Italy.

Tree of medium size, with open head and green terminal buds. Leaves mostly 5-lobed; upper lobes spatulate, lower lobes triangular; base shallowly cordate. Figs pyriform, with short, slender neck; stalk $5 / 8$ inch in length; eye closed, scales rosy ; color light yellow ; pulp red, flavor moderately sweet; seeds many. Highly regarded for table use.

Pennese. Described by Pasquale (1876) as a light-green to yellow fig, topshaped, with red pulp. Further listed only by Savastano (1885).

Pero. Described by De Rosa (1911). Leaves large, mostly 3-lobed. Breba crop only occasionally produced. Second-crop figs medium, pyriform; stalk long; eye large, with salmon-yellow scales; color green; white flecks numerous; pulp red; seeds numerous, large. Used mostly fresh.

Perticone. Described and illustrated by Baldini (1953) from Firenze, Italy.

Tree vigorous, with light-green terminal buds. Leaves mostly 5 -lobed, the lobes spatulate and obtuse; upper sinuses deep, moderately open; base cordate; margin crenate.

Brebas long-pyriform, with indistinct neck; stalk thick, inserted obliquely on the receptacle; eye large, open; color dark green, flushed with brown toward the apex; light flecks numerous, prominent; pulp solid, light red; seeds numerous.

Second-crop figs spherical, without neck; stalk thick, short; eye large, open; ribs indistinct; color light green; light flecks numerous; pulp light red; seeds numerous. Consumed fresh and dried; also used for processing into marmalade.

Peters White. Local name for an unidentified variety described by Eisen from Atwater, California. Tree bears two crops of medium-sized green figs, with pink pulp.

Pissalutto (syns. Pissalutto Bianco, Pitalusse, Pittalusse Blanche, Poussouluda, Sarnese Bianco). Described by Gallesio (1817), Semmola (1845), Pasquale (1876), Du Breuil (1876), Savastano (1885, probably), Sauvaigo (1889, 1894), Eisen $(1888,1901)$, Trabut (1904), Mingioli (1904), Mazières (1920), Blin (1942), Simonet et al. (1945), and Tamaro (1948). According to Gallesio, Pissalutto is the same variety listed by Pliny and Columella as "ficus liviana," one of the best figs of the Roman Era, an identification which Eisen considered highly doubtful. Sarnese, described by Gasparrini (1845) and Savastano (1885), is probably the same variety. The fruit is figured by Semmola, Eisen, and Simonet. Pissalutto is commonly grown in Liguria, and is especially well liked at Sarzana, where it is called Binello; it is also re- 
ported to do well in Tuscany, Corsica, and Sardinia; according to Gasparrini, it was caprified at Naples. In southern France it is grown under the name, Pittalusse Blanche.

This variety has not been properly tested in California. P.I. Nos. 77,481 and 113,651 represented cuttings obtained from Italy as Pissalutto, but the fruit produced at Riverside did not conform to the descriptions given by Italian authors. Pitalouse, described and illustrated by Price and White in Texas, was a brown fig, and apparently a different variety from the one now under consideration. Pissalutto is a one-crop fig, very few if any brebas being produced.

The tree is reported by Gallesio to be moderately vigorous, but not so large as that of Dottato. Leaves are large and 5-lobed, with the terminal lobe considerably longer than the lateral ones. The following description is taken from that of Simonet.

Second-crop figs medium, pyriform, with prominent, slender neck, up to one inch in length; average weight 35 grams; stalk slender, often over $1 / 2$ inch long; eye small, partly open, scales numerous, brick red; skin deli cately pruinose, checking at complete maturity; color greenish yellow to golden yellow ; meat white; pulp of fine texture, red. Quality good, especially fresh. Stands shipment well on account of the firm skin.

Pounchuda. Described by Risso (1826) as Ficus carica acuta; later described by Sauvaigo (1889) and Eisen (1901) as a variety productive of two crops. Figs of the second crop are of medium size, oblong, with long stalk, pistachio green to yellowish in color; pulp red, honeylike in flavor.

Processotto. Described and illustrated by Vallese (1909), from Lecce Province in Italy. Leaves large, generally 5-lobed. Second-crop figs medium, turbinate, with broad apex and short, thick neck; stalk very short; skin checking, but readily peeled; color greenish yellow; pulp red.

Quarai. Described from Ras-el-Djebel, Tunisia, by Minangoin (1931). Leaves medium, 5-lobed; upper sinuses deep, nearly closed; petiole thick, short; terminal bud thick, green. Figs large, $2 \frac{1}{2}$ by 2 inches, pyriform; stalk short; eye open; skin thick, light green in color; pulp hollow, light red.

Ravignon. Reported by Colby (1894) as a large fig, pyriform, greenish yellow in color, with brown spots; pulp pale strawberry. Produced at the Tulare Experiment Station in California.

Rebanquio. Described and figured by Bobone (1932) as a pyriform, green fig, with red pulp of good quality.

Redd-el-Gouch. Described by Minangoin (1931) from Gafsa, Tunisia. Leaves large, 3-lobed; petiolar sinus wide open. Figs small; eye wide open; skin thick, green in color; pulp red, somewhat hollow.

Rizzello (syn. Rizzeddhu). Described by Vallese (1909), with illustrations of leaves and fruit; also described by De Rosa (1911). Widely cultivated in the vicinity of Gallipoli, Lecce Province.

Leaves are large, asymmetrical, mostly 5-lobed. Breba crop none. Secondcrop figs below medium, oblate-spherical ; stalk very short; neck practically absent; eye large, scales rose-colored; white flecks conspicuous ; color greenish yellow; pulp light red; seeds large and numerous. Some consumed fresh, but mostly dried. 
Rondella Blanca (syn. Hélène). Described by Risso (1826) as Ficus carica helena, and referred to as Rondella Blanca by Eisen (1901). Risso stated that the variety was not much cultivated, as the fruits were very subject to spoilage from insect infestation.

The tree produces two crops. Figs spherical, on a long stalk; eye large, rose-colored; skin tender, greenish yellow; pulp red, sweet.

Rougette. Described by Hogg (1866) and Eisen (1888, 1901, after Hogg). Figs below medium, obovate, smooth; eye closed; color coppery yellow on body to yellow on stalk; pulp red; quality mediocre.

Salerne (syn. Ficus carica salernitana Risso). Deseribed by Bernard (1787), Duhamel (1809), Bory de Saint Vincent (1824), Risso (1826), Noisette (1829), Couverchel (1839), and Eisen (1901). The identity of this variety is somewhat confused. In their accounts of Salerne, Bernard, Duhamel, and Risso all referred to the Latin description of Tournefort. The latter, however, gave the common name as La Grosse Blanche Ronde, which is synonymous with Blanche. Bernard and Duhamel also reported that the fruits of Salerne were subject to spoilage on account of the open eye, through which rain water penetrated. Eisen referred to the open eye, but added that the fruit was "not subject to dropping, or injury by rain."

Authors generally agree that Salerne trees bear no breba crop. Secondcrop figs are described as above medium, globular, with short stalk; skin color pistachio green; pulp red, flavor agreeable. Very good for drying. Season early.

San Pietro. Described by Trabut (1904), Blin (1942), Société Pomologique de France (1947), and Condit (1947). Illustrated in color by Condit (1941a). In 1901, the United States Department of Agriculture introduced a variety of fig under P.I. No. 5,919 and the name San Pietro. It came from Lesina (Hvar) Island, Dalmatia, and was reported to be an early-season fig of exceptionally large size. Trees at Chico, California, when seen in August, 1916, were producing medium-sized figs, green in color, with amber pulp. In 1926, euttings of San Pietro were obtained from the late Leroy Nickel, of Menlo Park. These were grown first at Fresno, and since 1932, in the collection of varieties at Riverside. It was such a satisfactory variety at Menlo Park that "it almost stopped the quest for a better fig" (according to the gardener, Theodore Woolley), producing two crops of excellent figs, both under glass and out of doors. The account by Trabut, and especially that of the Société Pomologique de France, leave little doubt that the San Pietro described by them is the same as the one now under trial in California, which is treated herewith. However, if the variety does have merit, as the second account states, it seems strange that other French and Italian horticulturists have not included it in their publications.

The tree at Riverside is only moderately vigorous; terminal buds are green to dingy brown. Leaves medium, glossy above, variable, some 3-lobed with shallow sinuses and broad lobes, others 5-lobed with deep sinuses and long, narrow lobes, both upper and basal lobes commonly auricled; base cordate; margins very shallowly crenate. (Plate 13.)

Breba crop fair; figs large, up to 2 inches in diameter and $23 / 4$ inches in length, oblique-pyriform, with prominent neck; stalk short; eye medium, 
open; white flecks large, scattered; surface dull; ribs few, only slightly elevated; color light green; meat thin, tinged with violet; pulp dark strawberry; flavor rich, sweet; quality good.

Second-crop figs large, up to $2 \frac{1}{4}$ inches broad and 3 inches long, turbinate, mostly without neck, or neck present and gradually narrowed from body to stalk; average weight 73 grams; stalk short; ribs branched, slightly elevated; apex broad, flattened; eye above medium, open, scales chaffy or pink, with scarious margins; white flecks few, large, widely spaced ; color yellowish green; pulp light strawberry, hollow; flavor fairly rich. Quality mediocre; dried color poor.

Caprified specimens have dark-strawberry, solid pulp, with large seeds; average weight 88 grams. Recommended for trial in coastal sections of California only. (Plate 25, A.)

Scaranzone. Described by Guglielmi (1908) as found in the vicinity of Squinzano, Italy. Figs large, spherical; skin smooth, thick; color yellowish ; pulp red, moderately sweet. Consumed fresh.

Sfari. Described and illustrated by Grasovsky and Weitz (1932) as the best drying fig of the Safad Subdistrict; also grown near Nazareth. The name signifies "yellow."

Figs medium, pyriform, with long neck; eye open, scales pink; color yellow; pulp light red.

Quality good, especially when dried.

Sharrawi. Described by Grasovsky and Weitz (1932) as a variety grown near Nablus, Palestine. Figs medium, pyriform; eye almost closed; skin thin, greenish yellow; pulp light red; flavor subacid; seeds small.

Shtawi. Described by Grasovsky and Weitz (1932) as a very late fig, grown in Samaria and Galilee. Figs pyriform; neck medium; stalk long; eye almost closed, scales light yellow; color green; pulp red; seeds few, small.

Sicile (syn. Ficus carica siciliana Risso). Described by Risso (1826), Sauvaigo (1889), and Eisen (1901), as a Sicilian variety, introduced into France and grown near Nice. The description by Eisen of first-crop figs follows closely that of previous authors.

Figs large, pyriform, the body abruptly narrowed to form the neck; stalk rather long; eye large; skin checking, yellowish green in color ; meat violet; pulp pale red.

Signorella (syn. Cerva). Described by Ferrari (1912) as a Sicilian variety, having a light-green skin color and red pulp of a somewhat bitter flavor.

Slati. Described by Grasovsky and Weitz (1932) as a very early variety, grown in Samaria. Figs small, spherical; stalk long; skin thin; color green; pulp pale red; seeds numerous.

Sucrada (syn. Ficus carica saccharata Risso, or "sugar fig"). Described by Risso (1826), Sauvaigo (1889), and Eisen (1901), as a variety grown in a small way in the Alpes Maritimes, producing two crops.

Brebas pyriform, greenish yellow, tinged with brown on the ribs. Secondcrop figs pyriform; stalk long; eye rose-colored; skin glossy, light green to yellow; pulp pale red. Flavor very sweet, therefore subject to attacks by birds. 
Sulomo. Described by De Rosa (1911), but not recommended for further planting in Italy. Brebas scarce. Second-crop figs subspherical, 2 inches by $13 / 4$ inches; stalk short; eye rather large, scales yellow; skin green; pulp amber, tinged with rose; seeds numerous.

Sydawi. Described by Grasovsky and Weitz (1932) as a variety found in Acre and Nazareth subdistricts only; probably introduced from Sidon or Syria. Figs small, spherical, without neck; stalk fairly long; eye open, scales bright red; skin thick, green in color; pulp red; seeds few.

Tbani (syns. Tlabi, Jalboushi, Umm-et-Tabat, De'at-el-Arab). Described by Grasovsky and Weitz (1932). Figs large, elongated; neck and stalk short; eye slightly open, scales yellowish; color greenish yellow, darker green on the ribs; pulp red. Flavor sweet and good. Season August.

Tordo. Described by Guglielmi (1908). The name signifies a variety subject to attack by birds-especially the "tordo," or thrush-because of the sweetness of the pulp. Second-crop figs large, oblate, with short stalk; skin thick, glossy ; color deep green; pulp red; seeds numerous, large. Consumed mostly fresh near San Vito, Lecce Province.

Toscana (syn. Florentina). Description by Sauvaigo (1889), translated by Eisen (1901); a French variety, producing two crops. Brebas large, oblique-pyriform; eye prominent; color greenish yellow; pulp amber, streaked with violet, highly flavored. Second-crop figs not'described.

Troiano (syns. Trojano, Campanella). Described by Porta (1583, 1592), Gallesio (1817), Semmola (1845), Gasparrini (1845, as Ficus leucocarpa), Duchartre (1857), Pasquale (1876), Savastano (1885), Eisen (1901), Pellicano (1907), Guglielmi (1908), Vallese (1909), Ferrari (1912), Condit (1947), and Tamaro (1948, with figure). Illustrations of leaves and fruit are given by Semmola; also by Vallese, who regarded Campanella as a synonym. Porta, and later Gallesio, considered Troiano to be the same variety listed by Pliny under the name Livia. In the vicinity of Naples this variety is extensively cultivated, and is highly esteemed for its production of fruit over a long season in late summer and fall. Albo, which some authors consider the same as Troiano, produces two crops, and is treated in this monograph as distinct. A variety found growing on Smith Island, near Crisfield, Maryland, and grown in the Califormia collection under the name Smith Island Lemon, has proved to be practically identical with Troiano.

According to Eisen (1901, p. 65), the "Trojano" was introduced into California by W. B. West in 1878, but "did not prove satisfactory in Stockton, and was never distributed." It was grown and tested at the California Experiment Stations from 1890 to 1903, and at Pomona was found to be valuable and worth planting in that district. Van Deman (1890) reported that cuttings of Trojano had been distributed from Washington, D.C. P.I. No. 40,499, forwarded from Naples in 1915 by Dr. Gustav Eisen as "Troiaro," was recommended by him for planting in southern California. The fruits were reported not to be affected adversely by fall rains, and to be possessed of advantages not found in any other variety ripening at the same time. Three trees have been located in California and identified as Troiano; one at Ontario, another at Redwood City, and a third at Vacaville. A variety imported from Italy prior to 1940 by a San Francisco nursery under the 
name Verdoni, has also proved to be the same as Troiano. It can be recommended for home planting, especially in coastal districts; but can hardly compete with Dottato for canning purposes, on account of its strawberry pulp, which will color the syrup in which it is processed. The figs are too small for a commercial dried product. The following description is based on the behavior of trees fruiting at Riverside since 1935, and at Fresno in 1953.

Tree vigorous; terminal buds greenish violet. Leaves medium, somewhat glossy above, mostly 3 -lobed; upper sinuses shallow ; base cordate; margins crenate.

Breba crop none. Second-crop figs below medium to small, up to $11 / 2$ inches in diameter, spherical to turbinate; average weight 35 grams; neck mostly absent, or when present, very short and thick; stalk up to $3 / 4$ inch long, often curved; ribs narrow, elevated, fairly prominent; eye large, open, scales rose pink; white flecks inconspicuous; surface dull, with delicate bloom; skin prominently checked crisscross at maturity ; color yellow, sometimes faintly tinged with brown on the exposed side; meat white; pulp strawberry; quality fair to good. (Plates $8 ; 12 ; 26, E$.)

Caprified specimens larger, average weight 41 grams; color green; pulp dark strawberry; seeds fertile.

Unnequi. Described by Grasovsky and Weitz (1932) as a popular variety in Palestine, used for drying. Figs medium, spherical to oblique-pyriform; stalk long, distinctively enlarged or swollen near body of the fruit; neck none; eye open, scales brown; skin green; pulp light strawberry, sweet; seeds numerous; quality fair.

Verdale Blanche (syns. Verdala Blanca, Verdal White, Ficus carica variabilis Risso). Described by Risso (1826), Eisen (1901), and Simonet et al. (1945), as a variety grown in Provence. Figs small, pyriform, with long neck; skin light green; pulp blood red.

Verdeal. Described by Mello Leotte (1901) and Bobone (1932), the latter with illustrations. A Portuguese variety, producing a good second crop in August. Figs medium, short-pyriform to oblate, with or without short, thick neck; stalk short; color dark green; pulp carmine; quality fairly good.

Verdino. Described and illustrated by Baldini (1953) from Firenze, Italy, producing one crop only.

Tree vigorous; terminal buds green. Leaves mostly 3-lobed; sinuses shallow, narrow ; base cordate ; margins almost entire. Figs pyriform, with short, slender neck; eye small, open, with rosy scales; stalk short; skin checking at maturity, dark green in color; pulp red. Consumed mostly fresh.

Verdone (syns. Grosse Verte, Nebian, Adriatic, White Adriatic, Fico di Fragola, Strawberry). Deseribed as Verdone by Gallesio (1817), Gasparrini (1845), and West (1882). Described as Grosse Verte by Audibert Frères (1854) and Barron (1867, 1868a, with outline drawing). Described as Nebian by Hogg (1866), Wright (1894), and E. A. Bunyard (1925). Described as Adriatic by Eisen (1885, 1887, 1888, 1897, 1901), Massey (1893), Forrer (1894), Colby (1894), Earle (1900), Wythes (1902), Starnes (1903), Starnes and Monroe (1907, with figure), Mills (1914), Roeding (1914), Potts (1917), Roberts (1917), Condit (1920d, 1921c, 1923, 1933, 1947), 
Davis (1928), Burger and De Wet (1931), Grasovsky and Weitz (1932), and by Woodroof and Bailey (1931). See account and color plate of Adriatic by Lelong (1890) and by Taylor (1898); trees are figured by Condit (1933).

In 1727, Richard Bradley reported that he had introduced the Verdone fig into England from Italy. Almost a hundred years later, Gallesio published a good account of this variety, then extensively grown in the vicinity of Rome. Gasparrini briefly described it, giving credit to Gallesio for his earlier account ; but other Italian writers apparently ignore it. Verde Gentil, described by Tamaro (1948) may be the same variety. The name Verdone ("greenfinch") was given on account of the green color of the skin. With the exception of Audibert Frères, who called it Grosse Verte, French authors omit reference to this variety. The origin and significance of the name Nebian, used by Hogg, have not been determined. Bunyard stated that Nebian is much grown in California for drying, under the name Adriatic. Davis, also Burger and De Wet, report that in South Africa the White Adriatic is a very consistent bearer of figs, good for jam and for drying. Grasovsky and Weitz state that it produces good crops of high-quality fruit in Palestine. Barron (1868a) described Grosse Verte as "one of the largest, handsomest, and richest-flavored varieties in cultivation-well suited for pot culture." Starnes found White Adriatic an excellent variety in Georgia.

The following notes on the Verdone (White Adriatic) in California are taken from the account by Eisen (1901, p. 70). The first importation was made by W. B. West from an English nursery, via Panama, in 1865. Later, Dr. Sposati, of Stockton, is said to have received the same variety from his native home in Italy under the name Fico di Fragola, or "strawberry fig." G. N. Milco found ten-year-old trees growing on the Captain Gray ranch at Atwater, recognized their value, and labeled them "Adriatic," as stated by Milco (1885). Milco "did much toward making the variety known, but also much toward keeping the growers in the dark as regards its true nature. Since 1884 the variety has been extensively cultivated in California and distributed to many of the southern states, especially Florida. It is a fine variety in some localities, but in others worthless." See also discussion by Mileo and others (1887), on varieties.

The Chiswick collection from England included Nebian as P.I. No. 18,863 and Grosse Verte as P.I. No. 18,876. These two proved to be identical in the plantings at Niles and Chico. At the California Experiment Stations, from 1893 to 1901, trees of the Verdone (Adriatic) grew vigorously, but at Tulare they were very susceptible to frost damage, and the second-crop figs soured badly. (See report of Forrer, 1894.) However, commercial plantings, made in both the Sacramento and San Joaquin valleys, proved the adaptability of the variety to climatic and soil conditions, and for several decades it was the largest producer of dried figs in California. The bearing acreage of Verdone trees in 1953 was 6,921, and in 1952-1953 there were 7,699 tons of dried figs shipped to the trade. In comparison, the Sari Lop (Calimyrna) acreage was 10,267 , and 9,505 tons were marketed as dried fruit.

Trees of the Verdone planted in dooryards are not so satisfactory for production of figs for home use as are certain other kinds, on account of the lack of a first crop and the susceptibility of the fruit to spoilage. In the 
vicinity of Los Angeles, however, good results have been secured by heavy pruning of trees and the resultant production of a crop which matures late in the season. The influence of climate upon fruit characters is especially marked in this variety. Condit (1950) states that "figs picked at Merced, in the interior valley, on September 24, 1949, for example, showed a pulp light strawberry in color, and a meat thin and white. Figs of the same variety, picked three days later at Mission San Jose, where the climate is cool, showed the pulp to be blood red and the meat tinged with violet."

The following account of Verdone is based on observations of commercial plantings and of individual trees over a long period, and of trees fruiting in the collection of varieties at Riverside since 1932.

Trees vigorous, densely branched, with broad, spreading crown. (Plate 2.) (See also Condit, $1941 a$, fig. 15.) Terminal buds green. As already pointed out (Condit, 1947, p. 103), leaves of Verdone trees appear a week or ten days before those of Sari Lop and may, therefore, be seriously injured by late frosts, while leaves of the latter escape injury. Leaves medium, decidedly glossy above, stiff in texture, mostly 5-lobed; upper sinuses deep, moderately broad, lower sinuses fairly shallow; base broadly subcordate to truncate; middle lobe spatulate, with upper margins coarsely crenate, lower margins entire; leaf mosaic fairly conspicuous, with occasional twigs having badly distorted and dwarfed leaves, as shown by Condit and Horne (1933). (See also plate 13.)

Breba crop very small, or none (crop of 1953 was unusually heavy as the result of frost damage to terminal buds and the resultant pushing out of lateral fruit buds); figs medium or above, oblique-pyriform, mostly with prominent neck, up to $3 / 4$ inch long; stalk thick, sometimes swollen, up to $1 / 4$ inch long; ribs narrow, inconspicuous; white flecks fairly numerous and prominent; eye medium, scales greenish, with scarious margins; skin thin, colored greenish violet by the underlying dark-violet meat; pulp dark strawberry; flavor rich; quality good. (Plates $7 ; 16, D$. .)

Second crop good; figs in hot, interior valleys are medium, turbinate, with or without short, thick neck; average weight 50 grams; stalk up to $3 / 4$ inch long, often somewhat curved; ribs slightly elevated, but hardly prominent; eye medium, open, scales chaffy, straw to flesh color, or sometimes pink; surface dull, with delicate bloom; white flecks large, prominent, widely scattered; color green to greenish yellow; meat thin, white; pulp light strawberry, somewhat hollow at the center. Flavor fairly rich, of a characteristic fig type. Quality good, especially for drying. In cool climates figs are large, grass green outside; pulp blood red; quality excellent. (Plates 8; $16, C$.

Caprified figs are medium or above, deep green; pulp solid, dark red; flavor peculiarly acid. As many as 1,600 fertile seeds in a single fruit. (Plate 11.)

Verte (syns. Coeur, De Cour, De Cuers, Verdalle, Verdale, Des Dames, Figue d'Espagne, Trompe-Chasseur, Trompe-Cassaire, Ischia Green, Figue d'Hiver, Ficus carica aulica Risso). Described as Verte by Merlet (1667), La Quintinie (1692), Tournefort (1700), Liger (1702), Garidel (1715), Langley (1728), La Brousse (1774), Rozier (1805), Duhamel (1809), Christ 
(1812), Lamarck (1817), Bory de Saint Vincent (1824), Couverchel (1839), and Leclere (1925). Described as De Cour or De Cuers by Bernard (1787), Risso (1826), Du Breuil (1876), and Eisen (1901). Described as Verdale by La Brousse (1774), Hogg (1866), and Société Pomologique de France (1947, probably). Described as Trompe-Chasseur or TrompeCassaire by Sauvaigo (1889) and Simonet et al. (1945). Described as Ischia Green by Miller (1768), Hanbury (1770), Forsyth (1803), Brookshaw (1812), Green (1824), Lindley (1831), Burnette (1894), Earle (1900), Leclere (1925), Stansel and Wyche (1932), and Condit (1947). See Rolland (1914) for synonymy. The fruits are illustrated in color by Duhamel and by Brookshaw.

Merlet described Figue Verte (also called Verdalle or Figue d'Espagne) as bearing few brebas, but many second-crop figs, some of which remain on the tree over winter and mature in the spring, hence the name, Figue d'Hiver. Garidel stated that it was also called Trompe-Cassaire because of its resemblance to Bourjassotte, which also hangs on the tree during winter. Eisen reported that this green fig appears unripe even when mature; therefore, it is called Trompe-Chasseur, "hunter's deception." Couverchel listed it as Figue Verte des Dames or De Guers, but did not explain the significance of the latter name, which may be a corruption of De Cuers. The suggestion of Rozier, that Verte might be the same as Ischia Green of Miller, is accepted as correct after comparison of descriptions by the various authors cited. Contrary to the reports of some horticulturists, such as Hogg, Eisen, Starnes, and Gould, Ischia Green and Ischia White are regarded here as distinct varieties. Sauvaigo referred Verte to Ficus carica falaciosa of Risso, but this Latin terminology has not been found in the 1826 edition of Risso, who described Figue de Cour under F. carica aulica. Langley treated Verte as a green fig, called in France, Figue Verte and in Italy, Verdone. The latter, however, is regarded in this monograph as distinct.

Verte is reported to be one of the better figs of Provence, especially at Grasse and Toulon. English writers, beginning with Miller, state that the skin is thin, green, and when fully ripe, is stained by the meat to a brownish cast; also, that the interior purple color will stain linen or paper. As early as 1832, the William Kenrick Nursery, Newton, Massachusetts, offered for sale trees of Green Ischia at one dollar each. In 1894, Ischia Green was included in the Chiswick collection as P.I. No. 18,856. It has long been grown in the southern United States, but on account of confusion with Ischia White, reports on its behavior must be carefully evaluated. However, the variety has certainly not been nearly so well regarded or extensively planted as have Brown Turkey, Celeste (Malta), or Brunswick. A small commercial planting is on the place of Stoughton Sterling, Crisfield, Maryland. Two trees have been located in California dooryards; one in the yard of C. W. Gates, 128 Fey Drive, Burlingame; the other on the place of John Kruttschnitt, San Mateo. Ischia Green has been received and tested at Riverside with material from the following localities: Crisfield, Maryland; Sherman, Angleton, and San Antonio, Texas.

The fruit is late in maturing, but of good quality. The very light production of brebas, the small size of the main-crop figs, and its late season of 
maturity, are factors sufficient to prevent much extension of Verte, at least in California. A variety labeled Calvert, briefly described by Close (1933), was received in 1929 from the Angleton, Texas, station, numbered 8,370. This has proved to be identical with Verte at Riverside, and both are very similar to Col de Dame.

Branches of the tree have terminal buds, green in color. Leaves below medium, glossy above, nonlobed to 3-lobed; upper sinuses shallow; base broadly subcordate to truncate; margins coarsely crenate. Description is from figs produced at Riverside since 1942, and at Fresno in the season of 1953.

Brebas few, or rarely produced, as reported by Simonet; figs medium, pyriform, with prominent neck and short stalk; eye small, scales straw color; white flecks small, numerous, conspicuous ; color green ; bloom delicate; meat thin, violet; pulp strawberry.

Second-crop figs small, turbinate, without neck, or pyriform, with prominent, somewhat flattened neck; average weight 40 grams; stalk up to $1 / 4$ inch long; eye small, fairly well closed, scales tawny; ribs narrow, fairly well elevated; white flecks scattered, conspicuous; color grass green; meat white; pulp dark strawberry; quality good. Season late.

Caprified figs have much the same characters, but the pulp is blood red in color. (Plate 17, C.)

Vescovo. Described and figured by Vallese (1909) as a variety grown in the district of Francavilla, Italy.

Leaves are of medium size, mostly 5-lobed. Second-crop figs turbinate, without neck; stalk short; ribs inconspicuous ; skin of fine texture, readily peeled; color greenish yellow; bloom delicate; pulp light rose; flavor not very sweet, somewhat acid.

Violada Blanca (syn. Violeta of Genoa). Described and figured by Tamaro (1948) as a tree of large size and extraordinary vigor, with 3-lobed leaves. Brebas do not mature.

Figs large, short-pyriform, with thick neck; skin thin, checking lengthwise; color green; pulp wine red. Used principally fresh, but also dried.

Yellow Neches. This variety was received in 1929 from Station No. 3, Angleton, Texas, under number 8,374. See references to it by Close (1929) and by Stansel and Wyche (1932). Its exact identity has not been determined. Apparently, it is an Old World fig that was introduced in early colonial days, since a tree of the same variety was found growing at Jamestown, Virginia, in October, 1940. Other trees have been found in four different localities of California. A considerable percentage of the second crop at Riverside drops while immature, apparently from lack of caprification. The name "Neches" probably refers to the swollen stalk, which is more prominent than in any other variety of the California collection. (See Condit, $1941 a$, fig. $4, B$.) It has nothing to recommend it for home planting, as there are many varieties superior in productiveness of tree and in quality of fruit.

The tree is moderately vigorous, densely branched; nodal swellings rather prominent; terminal, dormant buds green. Leaves small, dull on upper surface, mostly 3-lobed; upper sinuses rather shallow; base cordate; margins coarsely crenate. 
Breba crop small ; figs small, 11/4 inches in length and diameter, turbinate, with or without distinct neck; stalk up to $1 / 2$ inch long, and much swollen; ribs few, but well elevated; eye medium, open, scales pink; color green; pulp strawberry; quality fair. (Plate $23, C$.)

Second-crop figs much the same as brebas, spherical to turbinate, generally without neck; average weight 12 grams; stalk prominently swollen, up to 1 inch long; ribs narrow, inconspicuous; white flecks indistinct, seattered; eye medium, scales rose pink ; surface dull, with faint bloom, somewhat puberulent; color green to light yellow; meat white; pulp strawberry, practically seedless; flavor insipid; quality poor. (Plate $23, D$.)

Caprified figs larger, with dark-strawberry pulp and subacid flavor.

Zamozujica. Introduced in 1901 from Lesina (Hvar) Island, Dalmatia, as P.I. No. 5,921, and reported to be a good fig, with unusually tender skin; dried figs shipped in quantity to Trieste. Trees at Chico, California, were studied in August, 1916, and found to produce medium fruits, similar to the Pajajero, or so-called "bird fig," of the Vacaville district. Variety established at Riverside in 1941 from cuttings received from Angleton, Texas.

Second-crop figs below medium to small, pyriform, with prominent, short neck; eye medium, with rose-colored scales; skin color green; pulp strawberry; quality poor.

Zimitza. Described by Colby (1894) and Eisen (1901). According to the latter, it was introduced into California from Dalmatia; the tree grew well, and produced late in the season; possibly identical with Natalino (Arneo Bianco).

Figs medium or below, turbinate, with long stalk; neck none; eye closed; color olive green; pulp amber, with a tinge of red, hollow.

\section{Common-type Figs with Skin Green or Yellow; Pulp Color not Designated}

Agulla. Described and illustrated by Estelrich (1910) as a variety bearing fruit similar to that of Alicantina. Figs small, green, resistant to rain damage; readily dried.

Alicantina (syns. Blancassa, Blanca Clara, Cantina, Blanqueta). Described by Estelrich (1910), Sánchez (1922), and Priego y Jaramillo (1922).

Tree upright, with 5-lobed leaves; widely planted on the island of Mallorca. Figs spherical, medium; stalk slender; color green. Highly regarded, both fresh and dried. Resistant to spoilage in wet weather.

Biter Abiod. Described by Guillochon (1913, 1927, 1929) and Minangoin (1931) as a variety producing two crops. Listed by Hodgson (1931) and Valdeyron and Crossa-Raynaud (1950) as good for brebas, which are early, very large, pyriform, and green in color.

Second-crop figs (according to Minangoin) large, oblate, sessile; eye wide open; skin very thin, green. Valdeyron states that the second crop sometimes requires caprification.

Bontalette. Listed by Eisen $(1888,1901)$ as a "white" fig, used for drying at Brignoles, France. 
Caseta. Described and figured by Estelrich (1910). A variety similar to Parejal, but fruit smaller, greener in color, and less pulpy. For drying, it is reported superior to Alicantina, and even more resistant to rain damage. At Pollensa, where it probably originated, it is highly regarded, and the dried fruit is the first of any variety to appear in markets.

Castagnola. Described by Sauvaigo (1889) and Eisen (1901) as a mediumsized fig, globular, bright green in color. Grown near Savoy, France.

Cervone. Listed by Gasparrini (1845), under Ficus deliciosa var. maxima, as a turbinate fig, yellow in color.

Cistallino. Described by Ferrari (1912) as an Italian variety of medium size, spherical; skin green, glossy; tree prolific; season early; not much grown.

Comadre. Regarded by Eisen (1901) as the best white drying fig of southern Portugal. The term "comadre," however, commonly designates a grade of dried figs, and not any distinct variety.

Dois à Fôlha. Described and illustrated by Bobone (1932) as a common Portuguese fig, so named because two figs appear in the axil of each leaf. Figs are globular, with short stalk and greenish-yellow skin.

Du Japon. Described by Simonet et al. (1945) as a variety that closely resembles Dalmatia and Blanche Navello. Two crops are produced. Brebas large to very large, elongated-pyriform. Second-crop figs medium, pyriform, greenish yellow in color; quality mediocre.

El Nouchi. Described by Guillochon $(1913,1927,1929)$ as a small, spherical fig of yellow color, rather good in flavor, maturing in August.

Espagnole (syn. D'Espagne). Described by Duchartre (1857), Sauvaigo (1894), and Eisen (1888, 1901), as a very good, light-green fig, cultivated at Aix, France.

This may be the same as Verte, described elsewhere.

Fettouai. Described by Guillochon $(1913,1927,1929)$ as a fig of medium size, globular, yellow in color, maturing in August.

Gajico. A variety listed by Pellicano (1907) as a caprified, yellow fig, of little importance.

Graissane. See Rolland (1914) for synonymy. Described by Garidel (1715), La Brousse (1774), Rozier (1805), Lamarck (1817), Duhamel (1809), Noisette (1829), and Eisen (1901). According to Garidel, trees of Graissane are found throughout Provence; but this is contradicted by Duhamel. The latter briefly describes the fruit as spherical, flattened at the apex; skin light-colored; flavor insipid.

Hospitalière. Briefly described by Duchartre (1857), Du Breuil (1876), and Eisen (1888, 1901), as a greenish-yellow fig of Salon, France; good for drying.

Jorba. Described and illustrated by Estelrich (1910) as bearing fruit similar to that of Alicantina. Figs of small size, green in color, easily dried.

Levant (syn. Turque). Described briefly by Duhamel $(1755,1809)$; his account followed by Couverchel (1839) and Eisen (1901). A variety seldom cultivated in France; leaves deeply lobed; figs large, yellow.

Llimonenca. Described and figured by Estelrich (1910) as a small, lemoncolored fig, spherical in shape, late in maturing; used mostly for cattle feed. 
New French. Described by Earle (1900) as a small, spherical, lightcolored fig, of medium quality. (May be identical with Angélique-see p. 382.)

Parejal (syns. Julia in Ibiza, Parechal in Valencia). Described and figured by Estelrich (1910); see also account by Priego y Jaramillo (1922).

Tree attains considerable size. Leaves 3-lobed. Breba crop small, of little value. Second-crop figs medium to large, conical; stalk medium, coriaceous; skin checking at maturity; color dark green; color of pulp not specified. Used for drying and for cattle feed.

Subvarieties are Parejalina and Parejal Rayada, or Pintada.

Pelosa. Described by Estelrich (1910) as a variety occasionally found in Mallorcan villages. Called "Pelosa" because of the pubescent skin. Secondcrop figs medium, conical, yellowish green ; flavor mild. Used for cattle feed. Crop matures by mid-September.

Pilosella. Described by Ferrari (1912) as a green fig, with short, thick stalk; skin pubescent; matures in September.

Précoce (syn. Petite Blanche). A variety briefly described by La Quintinie (1692), Cupani (1696), Liger (1702), and Tournefort (1719), as producing medium-sized, green fruit, of mediocre quality. According to Liger, it was not much esteemed in France, and probably was not distributed.

Ragusa (syn. Ragusaine). Described briefly by Duchartre (1857), Du Breuil (1876), and Eisen (1888, 1901), as a light-green fig of fair quality, introduced from Dalmatia into France. Introduced into California by G. N. Milco, under the name Dalmatian. It was tested at the California Experiment Stations, and was found at Tulare to resemble "the Smyrna of California, and the Brunswick, except that it is more flattened and one-sided in shape."

Reginella. Described by Guglielmi (1908) as a variety maturing an abundant fall crop in Lecee Province, Italy. Figs large, oval, greenish yellow in color. Consumed fresh.

Serra. Described and illustrated by Estelrich (1910) as a variety grown near Pollensa, Mallorea, mainly for hog feed. Figs below medium, turbinate, without neck; stalk short; color greenish yellow; pulp of good flavor.

Sextius. Listed by Du Breuil $(1876)$ and Eisen $(1888,1901)$ as a yellow fig of good quality, grown near Aix, France.

Sultani. Described by Grasovsky and Weitz (1932) as a large, round, green fig of good quality, grown in Jenin, Palestine.

Tassiret. Briefly described by Guillochon $(1913,1927,1929)$ as a belowmedium, yellowish fig, maturing in August in Tunisia.

Tiboulenque (syn. Tibourenque). Listed by Duchartre (1857), Du Breuil (1876), and Eisen $(1888,1901)$, as a "white" fig of France, very good both fresh and dried. No fruit characters given.

Tira (syns. Hortella, Filera). Described and figured by Estelrich (1910) as a Mallorean variety, similar in fruit characters to Alicantina. Secondcrop figs medium, spherical, yellow in color; quality excellent for drying.

Vacal. Described and figured by Estelrich (1910) as a Mallorcan fig of minor importance. Figs medium, oblate-spherical, without neck; eye large; color light green; white flecks numerous, small. Used for cattle feed and for drying. 


\section{Common-type Figs with Skin Dark (Various Shades of Red, Brown, or Violet to Black); Pulp White or Amber}

Abboudi (syns. Ghorabi, Ghozi). Described by Badie and Ghamrawi (1931) as an Egyptian variety, bearing two crops that mature a fortnight earlier than other kinds. Figs medium, oblate, ribbed; stalk short; skin thin, purplish black; pulp yellowish white.

Albanera. See description by Porta (1592). Ferrari (1912) gives it as a Sicilian fig, not commonly grown; fruits spherical, black; pulp amber.

Arbal. The only description found is that of Eisen (1901). Included in the Chiswick collection from England as P.I. No. 18,861. Not fruited at Riverside; the following description is after Eisen.

Figs medium, pyriform; ribs many, but indistinct; eye small, open; skin olive green, flushed with violet; pulp amber; a fine, highly flavored fig, of poor appearance.

Archipel (syns. De l'Archipel, Osborn, Osborn's Prolific, Hardy Prolific, Figue Grisé, Ronde Noire?). In 1854, Audibert Frères described a variety of fig under the name Archipel, having a single crop of reddish-brown fruits with pale-yellow pulp, maturing in September. Other French authors apparently ignored the variety designated as Archipel. Hogg (1866) and Eisen (1888) described it as De l'Archipel. The later account by Eisen (1901) is based on fruit produced by the Archipel that was introduced from England in the Chiswick collection, and established at Niles, California, as P.I. No. 18,835. This description, and that of Barron (1891), fit closely the fruit characters of the variety known as Osborn's Prolific. Furthermore, in the collection of varieties at Riverside, Archipel, obtained from Angleton, Texas, as P.I. No. 18,835 , has proved to be identical with Osborn. P.I. No. 18,879 of the Chiswick collection, labeled Hardy Prolific, was also identical with Archipel. The name Archipel is, therefore, given priority. P.I. Nos. 60,493 and 69,014, introduced from France as Figue Grisé, are both the same as Archipel at Riverside. The same is true of Rolandine No. 102,020, from Moroceo.

Osborn's Prolific is described by S. (1878), Moore (1879), Coleman (1887b), Barron (1891), Massey (1893), Wythes (1893), Eisen (1901), Starnes and Monroe (1907), Royal Hort. Society (1916), E. A. Bunyard (1925), Cook (1925), Davis (1928), Condit (1947), and Preston (1951). According to Bunyard, this variety was introduced into England in 18781879 by Messrs. Osborn, of Fulham, and was designated Osborn's Prolific on account of the productiveness of the trees. Eisen refers to an account by Hogg, but no mention of the Osborn is found in the 1866 edition of The Fruit Manual by that author. Barron and Wythes both regarded the variety as identical with Brown Turkey.

The fact that English nurseries have been confused over these two varieties is indicated by experiences with recent introductions into California. Cuttings received in 1929 as Brown Turkey produced fruit in 1933 identical with Archipel (Osborn). On the other hand, Brown Turkey, introduced under P.I. Nos. 93,275 and 95,598 , bore fruit in both cases typical of that 
variety and entirely distinct from Archipel. The variety Ronde Noire has proved in California tests to be identical with Osborn in some plots, and different in others. The description and illustration of Ronde Noire by Eisen (1901) fit the Archipel closely, even though he stated that it is very distinct from that variety. In the collection of figs maintained by the late Leroy Nickel at Menlo Park, the Ronde Noire and Osborn were identical. Neveralla, listed in the 1942 catalogue of Willamette Fig Gardens, Portland, Oregon, by B. R. Amend, has proved at Riverside to be identical with Archipel.

Various French growers imported Osborn from England, and issued reports on its behavior. Among these are the following: Anon. (1882), Carrière (1881, 1884), B. Rivière (1907), and Reboul (1908).

Archipel (Osborn) was tested at the Amador, Tulare, and Paso Robles Experiment Stations in California between 1889 and 1896, and was reported to produce high-quality figs in abundance. Individual trees have been found in the foothills of Merced and Mariposa counties, in various localities near San Francisco Bay, and in southern California.

Trees are upright in habit of growth; terminal dormant buds are green in color. Leaves above medium, 3- to 5-lobed, the basal lobe sometimes auricled; upper sinuses of medium depth and width, lower sinuses shallow, basal sinus sometimes narrow and almost closed, but generally open, forming a cordate base; margins coarsely crenate; surface somewhat glossy. The following description is from fruit produced at Riverside since 1930.

Breba crop good. Figs above medium, pyriform, somewhat oblique; neck prominent, often elongated; stalk short; ribs not prominent, mostly evident as dark-colored bands; eye medium, open, scales reddish brown; skin cracking or checking at full maturity; color bronze, tinged with violet; bloom delicate; meat white; pulp cottony white, tinged with pink; texture spongy or mealy; flavor somewhat strong; quality fair. Of doubtful value, on account of unattractive color and poor flavor.

Second-crop figs variable in size, from 2 to $21 / 2$ inches long and $11 / 2$ to 2 inches in diameter; average weight 58 grams; shape pyriform to turbinate, commonly oblique; neck thick, up to $3 / 4$ inch long; stalk variable; ribs very slightly elevated, coloring more deeply than body; eye medium, open, scales light brown, scarious on margins; surface dull; bloom delicate; white flecks large, scattered, not prominent; color bronze, with violet tinge; pulp amber, almost seedless; texture mealy, inclined to be somewhat dry; flavor insipid; quality poor. (Plates $9 ; 27, D$.)

Caprified specimens of larger size; external color darker violet; pulp strawberry, seedy. Figs practically worthless in interior valleys, either dried or fresh; very much subject to spoilage. In cool, coastal climates, fruit sizes are larger, and figs are of good to excellent quality for fresh consumption.

Barbillone. Described by Eisen (1901), Schneider (1902), Juignet (1909), Nomblot (1913), Mazières (1920), A. Rivière (1928), Société Nationale d'Horticulture de France (1928), Delplace (1933), Delbard (1947), and Evreinoff (1947). Illustrated in color by Delbard. Origin uncertain, but reported to be a bud sport of Blanche, and named for the grower at Argenteuil who found it.

Tree productive of brebas; second crop small. 
Brebas medium to large, variable in shape, but commonly pyriform; ribs distinct; stalk short; eye large, with protruding scales; skin thin, easily peeled, greenish violet in color; pulp amber, tinged with red. Quality very good, superior to that of Blanche for fresh fruit.

Second-crop figs medium ; neck lacking ; eye small, open, with dark-colored scales ; skin thin, violet-black; pulp amber, coarse, juicy.

Beall. Described by Brooks and Olmo (1946) and by Condit (1947). A chance seedling, found by W. A. Beall in the Santa Clara Valley, California, and transplanted by him to Fresno, where it fruited in 1922. Characters suggest Archipel (Osborn) as the female parent; variety reported well worthy of planting in desert valleys and in coastal climates for the production of fresh fruit.

Tree moderately vigorous, bearing two crops; terminal buds violet-brown.

Leaves medium or larger, dull to slightly glossy above, mostly 5-lobed; upper and lower sinuses of medium depth and width; basal lobes often auricled; base cordate, the sinus generally narrow; margins crenate. Fruit descriptions are from Riverside, California, specimens.

Brebas large, up to 3 inches long by $21 / 4$ inches in diameter, pyriform, with prominent, thick neck; average weight 71 grams; stalk thick, up to $1 / 4$ inch long; eye medium, open; white flecks scattered, fairly conspicuous; color brown to purplish black, shading to green on the neck; pulp white; flavor fairly rich; quality good. (Plate 18, C.)

Second-crop figs medium to large, oblate to turbinate, with or without a short, thick neck; average weight 66 grams; stalk short and thick; ribs elevated, more deeply colored than body; eye medium, open, with violet scales; surface somewhat glossy, with distinct bloom; white flecks large, conspicuous; color claret-brown to coppery black, lighter toward the stalk'; skin checking at maturity; pulp amber, hollow at center; flavor fairly sweet and rich. (Plates $10 ; 18, D$.)

Caprified figs with light-strawberry pulp and large, fertile seeds; dried figs of poor color and quality.

Brunswick (syns., after Hogg and Eisen: Bayswater, Boughton, Black Naples, Brown Hamburgh, Clare, Clémentine, De Saint Jean, Hanover, Madonna, Large White Turkey. Also Magnolia, Dalmatian). Described by Duhamel (1755), Miller (1768), Hanbury (1770), Brookshaw (1812), Anon. (1828), George Lindley (1831), John Lindley (1841), Rogers (1834), Morren (1852), Holley (1854), M'Intosh (1855), Thompson (1859), Hogg (1866), White (1868), Barron (1868c,1891), James Anderson (1874), Hyde (1877), West (1882), Massey (1893), Burnette (1894), Wright (1895), Forrer (1894), Eisen (1885, 1897, 1901), Earle (1900), Price and White (1902), Starnes (1903), Starnes and Monroe (1907), Van Velzer (1909), Hume (1915), Potts (1917), Gould (1919), Cook (1925), Mowry and Weber (1925), Davis (1928), Traub and Fraps (1928), E. A. Bunyard (1925, 1934), Stansel and Wyche (1932), Condit (1921b, 1922b, 1941b, 1947), Arnold (1926), Fruit-Grower (1936), Woodard (1938, 1940), Delbard (1947), and Preston (1951). Illustrations of the fruit in color are by Brookshaw, Anon. (1828), John Lindley, Morren, and James Anderson. Illustrations in black and white are by Potts. Price. Traub, E. A. Bunyard, and 
Condit (1941a, fig. 2, $L$ ). Leaves are figured by Eisen, Price, Van Velzer, Gould, Traub, and by Woodroof and Bailey.

Brunswick is another variety about which considerable confusion has existed. Much of this arises from the fact that most English descriptions and illustrations deal with the first-crop fruit, which horticulturists in the United States have found so different from figs of the main crop. Furthermore, as Eisen stated in 1901, this variety is erroneously known in California and parts of the South as Brown Turkey; in fact, price quotations of fresh figs in the Los $\Lambda$ ngeles markets still refer to Brunswick when the actual variety on sale is San Piero (Brown Turkey). ${ }^{7}$ This variety has apparently been widely distributed in fig-growing countries, and various names have been attached to it. Cuttings of the following numbers have fruited at Riverside, and all were found to be identical with Brunswick.

Baidi-P.I. No. 80,294, from Palestine.

Belle Dame-P.I. No. 69,010, from France.

Belle Dame Blanche-P.I. No. 86,790, from Yalta, Crimea.

Blanche d'Argenteuil-P.I. No. 92,304, from France.

Brunswick-P.I. No. 93,276, from England.

Col di Signora-P.I. No. 102,099, from Morocco.

Dalmatia-P.I. No. 102,010, from Moroceo.

Dor-P.I. No. 101,715, from the Caucasus.

Kennedy-P.I. No. 69,017, from France.

Kennedy-P.I. No. 102,015, from Moroceo.

Khurtmani-P.I. No. 80,297, from Palestine.

Magnolia, from Texas; cuttings from local trees at Greenwich, Connecticut; also, from the vicinity of Washington, D.C.

Reference to descriptions of some of these varieties found elsewhere in this report will show that the names are not synonyms of Brunswick; therefore, the material was sent incorrectly identified. Castle Kennedy is similar to Brunswick, but is generally regarded as a distinct variety.

According to Rogers, the Brunswick "was introduced in the early days of Miller under the name of Madonna, which ought never to have been changed; but on the accession of George I, it was named as above." Lindley used the name Brunswick in preference to Madonna because it was the better known of the two. The name "Magnolia" appeared in a publication by Thomas Affleck in 1854 as a synonym of Jaune, a French fig. Sometime previously, a tree peddler had gone through parts of Texas offering magnolia trees for sale; when planted, it was found that the trees produced figs rather than magnolia leaves and flowers, hence the name of the variety. Van Velzer stated that Brunswick had many pet names, among them Magnolia, Hanover, and Madonna. He added: "Those who still contend that the Magnolia is a new variety, distinct from the Brunswick, can discover their error by studying the leaves, bark, wood, and fruit, which have characteristies and habits that distinguish it from all others. Some nurserymen profit from this misconception by buying cuttings of Brunswick trees at a much lower price than is asked for Magnolia wood, and selling them afterward as the same stock."

${ }^{7}$ For further comments regarding confusion in this synonymy, see descriptions of Brown Turkey (page 428) and San Piero (page 467). 
Audibert Frères (1854) described Figue Clémentine, a variety designated as Aubergine at Avignon. Both Thompson and Hogg regarded Clémentine as synonymous with Brunswick. In Japan, some growers have confused Brunswick with White Genoa; it was once a popular variety, but has been superseded by Dauphine.

In Texas, the Brunswick (Magnolia) is grown extensively as a preserving fig. It is commonly found as a dooryard tree in the southeastern United States, and at Washington, D.C., there are prolific specimens growing along the south wall of the Naval Observatory (plate 2). The variety is not so popular, however, as Brown Turkey, because of the tendency of the fruits to split and spoil. In Northampton and Accomac counties, Virginia, Brunswick fig trees are common, and are locally known under the name "Silver Leaf," though the significance of the name is not clear. In California, trees of this variety are dwarf in habit of growth unless watered copiously. Small commercial plantings have failed to be profitable, as the production of canning figs per acre is considerably less than that of Dottato. As pointed out by Chandler (1934), the Brunswick is incompletely parthenocarpic in California, as fruit buds are forming and dropping prematurely all summer. In Texas, this fruit drop is almost or quite negligible on vigorous trees. George Lindley regarded the Brunswick as one of the most useful of the hardy figs in England, especially on walls with a southern exposure. It is not recommended for forcing under glass in comparison with Brown Turkey, as the immature figs are inclined to drop.

Trees, at least in California, are slow-growing, spreading, with fairly thick twigs; the terminal buds are green. Leaves, as described by Miller, are more narrowly lobed than those of most other varieties; such leaves, especially characteristic of heavily pruned trees with vigorous branches, are 5-lobed, with deep sinuses, the basal lobes auricled; margins of lobes coarsely and irregularly crenate; base cordate; leaves from fruiting branches somewhat glossy above, 3- to 5-lobed, with lobes broader and base truncate (plate 13). The following description is of fruits produced at Riverside and at Fresno.

Breba crop generally very small; brebas large, up to $33 / 4$ inches long and $13 / 4$ inches in diameter, pyriform, decidedly oblique; neck a continuation of the body, or hardly distinguishable from it; stalk thick, often swollen, up to $1 / 2$ inch long; ribs few, indistinct; eye medium, wide open, scales pinkish; surface mostly dull, somewhat glossy at the apex; white flecks fairly numerous, but hardly conspicuous, becoming masked as fruit matures ; color reddish brown, with a tinge of violet in the sun, much lighter brown to greenish on the shaded side and on the neck; meat white; pulp amber, with a tinge of pink, hollow, texture mealy; flavor flat, lacking character; quality fair. (Plate 21, A.)

Second-crop figs medium, oblique-turbinate; average weight 42 grams; neck absent; stalk thick, up to $1 / 4$ inch long, often prominently swollen, as shown by Condit (1941a, figs. $4, A$ and $9, B$ ); ribs inconspicuous, commonly colored more deeply than body; eye medium, open, scales violet-brown; white flecks numerous and conspicuous, irregular in size and shape; skin checking at maturity; color bronze; pulp amber, tinged with strawberry, hollow at 
center; seeds small, or rudimentary, the fruits therefore commonly referred to as "seedless"; flavor sweet, fairly rich. Quality good fresh; excellent for preserving; inferior for drying. (Plate 21, B.)

Caprified figs strikingly different from uncaprified ones, larger in size; average weight 67 grams; color bronze, shaded with violet, especially on ribs; pulp deep strawberry, solid; seeds numerous; flavor sweet and rich.

Chiattarella. Described by Ferrari (1912) as an Italian fig, globular in shape, black in color, with honeylike pulp.

Datil (syns. Agradable Blanco, Amable). Described by Tamaro (1948) as a variety extensively grown in Italy, productive of one crop only.

Figs medium, bell-shaped; skin delicate, checking at maturity; color light yellow, tinged with red at maturity; pulp white, very sweet. Used mostly dried.

Goureau. Described by Ounous (1863) as a French variety, producing two crops. Figs large, greenish black, with white pulp. They stand transport well.

Grosse Superfine. Described and illustrated in color by Herineq (1850) as a new kind obtained at La Saussaye, near Paris. Figs large, pyriform, ribbed; color green, shaded with violet; pulp yellowish, sweet.

Jorest. Described by Eisen (1901) as a very productive and handsome French fig of exquisite quality; fruit medium, oblong-turbinate; skin red; pulp white.

Leon. Described in the 1911 catalogue of Glen Saint Mary Nursery, Florida, and by Close (1929), as a seedling on the place of J. W. Coles, Tallahassee; not widely distributed. Figs reported to be large, turbinate, green, with brownish tint; pulp amber.

Marinera. Briefly described by Ferrari (1912) as a medium-sized fig, very little grown at Cosenza, Italy. Figs similar to those of Reggitana (skin black, pulp amber), but the stalk is not so short.

Marsaoui. Described by Minangoin (1931) from Ras-el-Djebel, Tunisia. Leaves small, 3-lobed. Figs ovoid, with short neck; eye somewhat open; skin thin, violet, with greenish stripes; pulp white; seeds fairly numerous, scattered.

Marzelli. Described by Eisen (1901) as a violet-purple fig with white opaline pulp; grown in Italy.

Matelassa (syn. Matelassiera). Description by Eisen (1901), after that of Sauvaigo (1889), as a variety grown in Nice and Provence. Brebas large, lopsided; skin dark red; pulp yellow. One of the few figs with dark skin and light pulp.

Mwazi (syns. Khurtmani, Eseli). Described and illustrated by Grasovsky and Weitz (1932) as one of the best figs for fresh use grown in southern Palestine.

Trees are large, but not very prolific; breba crop good. Second-crop figs large, pyriform, with prominent neck; stalk short; eye open, scales purple; skin thin, glossy, greenish, with purple ribs; pulp amber; flavor sweet and delicious.

P.I. No. 80,297 , introduced into California as Khurtmani, proved to be identical with Brunswick. 
Osborn Prolific (Rust). Two or three decades ago, the Edward H. Rust Nurseries, Pasadena, California, obtained some fig cuttings from a tree peddler who said that the variety was originally from England. The nursery propagated the material, and eventually distributed it under the name Osborn Prolific. Trees have been located in a few dooryards at Arcadia, San Gabriel, and Pasadena, and scions have fruited at Riverside since 1950. Brebas are seldom produced. The main crop, however, ripens over a long season, and is highly regarded for fresh-fruit consumption.

Leaves above medium, mostly 5-lobed; upper sinuses of medium depth, lower sinuses shallow, basal sinuses broad; base sometimes truncate, usually cordate; upper margins coarsely serrate, lower margins entire.

Second-crop figs above medium, pyriform, with body 2 inches long by $13 / 4$ inches in diameter; average weight 40 grams; neck thick and short, or often slender, and up to 1 inch long, decidedly flattened, also curved; stalk slender, up to 1 inch long, allowing the fruit to hang with the apex downward; ribs narrow, slightly raised; eye medium or above, open; white flecks few, elongated, inconspicuous ; surface somewhat glossy, skin checking crisscross at complete maturity; bloom delicate; color bronze to violet-brown; meat white; pulp amber, or light strawberry, somewhat hollow; flavor sweet and rich; seeds medium; quality fair. (Plate 28, B.)

Reggitana. Described by Ferrari (1912) as a variety from Reggio, Calabria, hence the name. Figs rather elongated; color black; pulp amber.

Roja (syn. Rojal). Described and illustrated by Estelrich (1910) as a variety which produces brebas in abundance near Algaida, Mallorca; these appear in quantity in the markets of Palma. Also described by Priego y Jaramillo (1922). Figs of the main crop are resistant to rain damage, and are highly regarded for their quality ; the variety is therefore cultivated in all the Balearic Islands.

Brebas large, egg-shaped; stalk thick; skin color reddish brown; pulp amber.

Second-crop figs much the same, maturing in August and September.

Two subvarieties are given. The first, Roja d'en Bardina, rarely produces brebas. The second, Roja de Son Suau, produces no brebas, while the maincrop figs are of a darker red color than are those of Roja.

Russello. Described by Pasquale (1876, with figure) and Pellicano (1907) as a late-season Italian fig, of medium size, pyriform, yellowish brown in color; pulp amber.

Scavello (syn. Nero). Described by Ferrari (1912) as a variety widely grown in Italy, especially at altitudes up to 2,100 feet. Breba crop good. Second-crop figs turbinate, reddish violet; pulp amber. Consumed both fresh and dried. Season late.

\section{Common-type Figs with Skin Dark (Various Shades of Red, Brown, or Violet to Black); Pulp Various Shades of Red}

Adam. Described by Eisen (1888, 1901), Barron (1891), Davis (1928), and by Burger and De Wet (1931). P.I. No. 18,873, introduced from England as Adam, proved to be identical with Dauphine; P.I. No. 102,003, from 
Morocco, also labeled Adam, produced small green figs of no value. Apparently this is a French variety, the original name having been lost; said to be desirable on account of its good first crop.

Brebas above medium, turbinate, with medium neck; eye large; skin dull green, with violet flush; pulp amber-white.

Second-crop figs medium, ribbed; color yellowish brown; pulp dull amber to red. Useful for dessert in South Africa.

Albacor de Grá and Albacor Comun. Described and figured by Estelrich (1910) as black, oblong figs with red pulp; subvarieties of Albacor. The second is well regarded on account of its abundant main crop, good for drying.

Amarouna (syn. Ficus carica amara Risso). Second crop only described by Risso (1826), Sauvaigo (1889), and Eisen (1901). Figs medium, pyriform; skin reddish brown, checking at maturity; eye prominent; pulp red, of a bitter taste; seeds many.

Asqalawi-Asmar. Described by Grasovsky and Weitz (1932) as a mediumsized black fig, distinguished by a bright-red circle around the open eye; pulp pink, rather dry; seeds few.

Aubane. Described by Risso (1826) as Ficus carica aubana. A variety grown rarely in southern France. Figs medium, pyriform; skin rather thick and tough, checking crisscross ; color light green, tinged with reddish violet; pulp light red.

Azaich. Described and illustrated by Mauri (1939b, 1942). Crop matures sooner than that of the Smyrna-type Averane, which is an advantage under some conditions of culture and climate. Listed by Hanoteau and Letourneux (1872) and Eisen (1901) as a common fig, bearing two crops.

Tree rather vigorous and productive; leaves generally 5-lobed; petiole usually tinged with earmine.

Figs pyriform, somewhat oblique; neck thick and prominent; stalk short; eye medium, with rosy scales; color black; pulp red. Quality good, both fresh and dried.

Bacorinho. Deseribed and figured by Bobone (1932) as commonly grown at Loulé, Portugal. Figs turbinate; stalk short; skin green, with obscure violet tint; pulp carmine, coarse; quality good.

Bargemon. Described by Bernard (1787), Noisette (1829), Couverchel (1839), Eisen (1901), and Leclerc (1925). Figs small, oblong to subglobular; skin pale violet, on a yellow background; pulp red. Quality excellent, both fresh and dry. Season late.

Barnissenca (syns. Bernissenca, Bernard, Bernissenque, Barnissenquo, Martinenca, probably Vernisingue or Vernissenque, Ficus carica bernardi Risso). Described by Bernard (1787), Duhamel (1809), Risso (1826), Noisette (1829), Couverchel (1839), Escribano y Pérez (1884), Sauvaigo (1889), Eisen (1888, 1901), Estelrich (1910), Sánchez (1922), Priego y Jaramillo (1922), and Simonet et al. (1945). See the account of Sarreigne in this monograph, regarding the confusion of that variety with Barnissenca. The latter is a fig of Provence, reported to do best in a moist, rich soil, and apt to drop its fruit when grown on drier ground. Risso gives the season of maturity as September to December. Sauvaigo emphasizes this by 
stating that Barnissenca is one of the varieties in which late figs of the second crop may remain on the tree during the winter, maturing in the spring. As pointed out under the description of Sarreigne, the variety Barnissenca is properly referred to as Ficus carica bernardi of Risso, and not to $F$. carica garideli, as given by Sauvaigo, and later by both Eisen and Simonet. Martinenca is described and figured by Estelrich, with Bernissenque as a synonym; on account of its quality and resistance to bad drying weather in the fall, growers on the Balearic Islands call it the "queen of black figs."

Vernisingue has been described by Merlet (1667), Ballon (1692), Liger (1702), Langley (1728), Bradley (1757), Hanbury (1770), Christ (1812), Audibert Frères (1854), Hogg (1866), Soc. Pomol. de France (1887, 1947), Eisen (1888, 1901), and by Starnes and Monroe (1907, with illustration).

Merlet called it Vernisingue, a name which Liger stated was very plainly invented. The spelling Vernissenque was adopted by both Hogg and Eisen. The latest account, that of Société Pomologique de France, lists it as Vernissangue, with Vernissenque as a synonym, and agrees with most early authors that the external color of the fig is ashy violet or violet-brown. Eisen, however, followed Hogg in describing the skin as perfectly black, without a trace of lighter color. All of this leads to the conclusion that the identity of Vernissenque is very much in doubt. The evidence seems to point to the conclusion that it is the same as Barnissenca, in spite of the fact that Eisen (1901) reported it to be "a distinct and well-characterized fig, superior in flavor to the small, round Verdal, which it somewhat resembles."

The tree of Barnissenca bears a second crop only. No records of its occurrence in California have been found. Description of fruit is compiled from accounts of various authors.

Figs medium or below, about $1 \frac{1}{4}$ by $1 \frac{1}{2}$ inches, oblique-spherical; skin thin, adhering to the pulp; color violet-brown; pulp bright red; texture watery; quality mediocre.

Barnissotte (syns. Bellegarde, Bernissou Negra, Bourjassotte Noire, Bouriageotte, Brogiotto Fiorentino, Brogiotto Nero, Précoce Noire, Burjassotte Preto, Grosse Bourjassotte, Grosso Figo, Monacello, Ficus polymorpha var. depressa Gasparrini, F. carica barnissota Risso). Described by Tanara (1651), Merlet (1667), Cupani (1696), Garidel (1715), Tournefort (1719), La Brousse (1774), Bernard (1787), Rozier (1805), Duhamel (1809), Gallesio (1817), Bory de Saint Vincent (1824), Risso (1826), Noisette (1829), Couverchel (1839), Semmola (1845), Dochnahl (1855), Duchartre (1857), Hogg (1866), Du Breuil (1876), Roda (1881), Soc. Pomol. de France (1887, 1947), Barron (1891), Eisen (1888, 1897, 1901), Sauvaigo (1889, 1894), Massey (1893), Mello Leotte (1901), Starnes and Monroe (1907), Tschaen (1908), Estelrich (1910), Nomblot (1913), Rolet (1916), Mazières (1920), Borg (1922), Sánchez (1922), Priego y Jaramillo (1922), Leclerc (1925), Bois (1928), Bobone (1932), Simonet et al. (1945), Simonet and Chopinet (1947), Condit (1947), Delbard (1947), Evreinoff (1947), and Baldini (1953). Color illustration by Duhamel; also by Simonet (1947). Figured in black and white by Semmola, Estelrich, Starnes and Monroe, and Baldini. 
Barnissotte is widely grown in Italy, in southern France, and in parts of Spain and Portugal; it is the same variety described by Pliny and other Roman writers as "Fico Africano," according to Gallesio, who regarded it as one of the best figs, exquisite in quality. P.I. No. 18,889 , of the Chiswick collection, labeled Negro Largo, bore fruit identical with that of Barnissotte. In 1926, this variety (Barnissotte) was introduced into California from southern France as P.I. No. 69,009 , but has been planted only in variety collections. The description and illustration of Brogiotto Nero by Baldini apparently represent a variety somewhat different from Barnissotte.

The tree of Barnissotte is vigorous, with brown terminal buds. Leaves medium to large, glossy above, mostly 5 -lobed; middle lobe elongated, broadly spatulate, sometimes auricled; upper sinuses deep in some, of medium depth in others, lower sinuses shallow; base cordate; margins coarsely crenate. Fruit description is from specimens at Los Angeles and Riverside.

Brebas rare, above medium to large, pyriform, purplish black; pulp strawberry.

Second-crop figs medium to large, but variable in size and shape, from $11 / 2$ to $23 / 4$ inches in length, and from $1 \frac{1}{2}$ to 2 inches in diameter; shape turbinate-pyriform, sometimes oblique, with broad apex; average weight 50 grams; neck variable, either prominent and somewhat flattened, thick, and short, or indistinguishable from body; stalk thick, short, loosely attached, allowing many figs to drop when not quite ripe; ribs elevated, narrow, prominent on account of deeper coloration; eye medium, open, scales erect, chaffy ; surface somewhat glossy, with distinct, pruinose bloom; white flecks large and conspicuous, as shown by Condit (1941a, fig. 9, $A$ ); color purplish black on apex and body, lighter toward the stalk, some specimens with green color persisting in irregular patches on body and apex; meat white; pulp light strawberry; flavor fairly sweet and rich. Quality good to excellent, especially in coastal climates. (Plates $10 ; 27, A$.)

Caprified figs larger, subject to spoilage by splitting, souring, and endosepsis; pulp dark strawberry to blood red.

Bec de Perdrix. Described by Hogg $(1866)$ and Eisen $(1888,1901)$ as a good drying fig of Spain and southern France, of medium size, pyriform, with purple skin and dark-red pulp.

Becuelle (syn. Bucuelle). Described by Simonet et al. (1945) as given below. Found under the name Coucourelle à Plascassier, but differing from the variety described by Eisen (1901) under Coucourelle Gavotte.

Tree bears two crops. Brebas small, elongated-pyriform; neck prominent; skin reddish violet; pulp of fine texture, solid, red; flavor sweet; quality very good. Second-crop figs similar, with sizes somewhat smaller. Good for drying.

Bellona (syns. Bellone, Belloune, Ficus carica bellona Risso). See Rolland (1914) for synonymy. Described by Bernard (1787), Duhamel (1809), Bory de Saint Vincent (1824), Risso (1826), Couverchel (1839), Hogg (1866), Sauvaigo (1889), Colby (1894), Eisen (1901, after Sauvaigo), Rolet (1916), Mazières (1920), Leclerc (1925), Bois (1928), Simonet et al. (1945), Simonet and Chopinet (1947), and Evreinoff (1947). 
Tree with drooping branches; producing two crops; leaves large, deeply 3- to 5-lobed. Extensively grown in Provence, where it is reported by Sauvaigo to be the queen of figs; excellent both fresh and dried. Description of fruit is after Simonet, from specimens secured at Antibes.

Brebas rare, or none, medium, pyriform; neck well marked, often curved; ribs prominent; color violet-gray; pulp red.

Second crop abundant; figs broadly oblique-pyriform, flattened at the apex; ribs elevated; eye small, closed, scales erect, violet; skin purplish black, checking at maturity; pulp red, with numerous small seeds; quality excellent.

Betada. Described by Hogg (1866) as a small, spherical, black fig, with rose-colored pulp of rich flavor.

Bidh-el-Djemel. Described by Guillochon (1913, 1927, 1929), and by Minangoin (1931); the latter as Biddin-el-Djemel, from Menzel Temine, Tunisia. Leaves small, 3-lobed. Figs below medium; eye open; skin very thin, violet in color ; pulp hollow, of wine-red color.

Biter Akhal. Described by Minangoin (1931) from Ras-el-Djebel, Tunisia, as producing two crops in a year. Leaves below medium, 5-lobed. Figs oblate, $11 / 4$ inches in length and 2 inches in diameter; stalk very short; eye wide open; skin of fine texture, wine red in color; pulp light red.

Blavette. Described by Bernard (1787), Duhamel (1809), Bory de Saint Vincent (1824), Noisette (1829), and Couverchel (1839). Eisen (1901) listed Blavette as a synonym of Cotignana, but earlier authors make no mention of such a synonymy.

The figs of Blavette are oblong, violet in color, with deep-red pulp, and are very much subject to dropping. This fault apparently accounts for the lack of interest in the variety.

Bocarde. Described by Eisen $(1888,1901)$ as a French fig, medium in size, dark brown in color, with bright-red pulp; quality very good.

Bondance Précoce. Described and illustrated by Eisen (1901) as a pyriform fig, below medium, brown in color, with light-red pulp of fine quality.

Bordeaux (syns. Angélique Black or A. Noire, Petite Figue Violette, Albicougris, according to Eisen, Figue de Bordeaux, Violette, Violette de Bordeaux, Figue Poire, Petite Aubique, Figuo Aubiquoun, Negronne). In 1692, a description by La Quintinie (translated by Evelyn) referred to the Angélique fig as "of a violet color and long but not very big, the pulp red and reasonably good." Both Cupani (1696) and Tournefort (1700) described Angélique as a violet fig. Yet most later authors, from Duhamel (1768) on, refer to this variety as bearing yellow fruit. It seems proper, therefore, to denote the former as Angélique Black, leaving the name Angélique for the variety described elsewhere in this monograph. Eisen (1901) gave a short account (after Barron, 1891) of Angélique Noire, a dark fig with bright-red pulp.

It is probably this variety with dark fruit which was described as Figue de Bordeaux, Violette, or Violette de Bordeaux by Liger (1702), Merlet (1740), Duhamel (1768), Weston (1770), La Brousse (1774), Le Berryais (1789), Mirbel (1802), Noisette (1821), Bory de Saint Vincent (1824), George Lindley (1831), Couverchel (1839), Thompson (1859), Forney 
(1863), Hogg (1866), Du Breuil (1876), Barron (1891), Eisen (1888, 1901), Price and White (1902), Leclerc (1925), and E. A. Bunyard (1925). Negronne was described by Garidel (1715), Rozier (1805), Lamarck (1817), Bernard (1787), Duhamel (1768, 1809), Bory de Saint Vincent (1824), Noisette (1829), Couverchel (1839), Eisen (1901), and E. A. Bunyard (1925).

Barron (1891) regarded Negronne to be the same as Violette de Bordeaux. Eisen believed that the two were not identical, but very similar, except for the smaller leaves of the latter. Bunyard (1925) agreed with Eisen, and stated that Violette de Bordeaux resembled Negronne, but was a distinct variety. In regard to the stalk of Negronne, Eisen reported, "stalk and part of neck bent over and rising in a curve upward, where the fig hangs down." This unique character is difficult to describe, but Eisen's statement confirms the opinion that Violette de Bordeaux of our collection is the same as Negronne of early authors. As grown at Riverside, however, Bordeaux does not show the green color persisting on the neck or base of the mature fruit, which Duhamel (1768) found characteristic of the variety in France. Variety No. 26 of Duhamel (1809), described as Figue Poire, Figue de Bordeaux, and Petite Aubique (Figuo Aubiquoun in Provence), is here considered to be the same as Angélique (Black) of Cupani and Tournefort. Duhamel described Negronne under his No. 33, and referred to the previous accounts of Garidel and Bernard. Under Bordeaux, Eisen stated: "A distinction must be made between the Petite Aubique and the Aubique, the former being identical with our Bordeaux, the latter with Black San Pedro, which is synonymous with Grosse Violette de Bordeaux." (See p. 467.)

In 1715, Garidel reported that Negronne was found in nearly all the vineyards and fields near Aix. Duhamel and later authors, including Leclerc, assert that Figue de Bordeaux is grown in the vicinity of Paris, where it produces two crops in warm seasons. According to Eisen, Bordeaux is common around Bordeaux and Nagronne, in southern France. Lindley said it was then cultivated throughout France. Bunyard regarded the tree of Negronne as very prolific in England, and the fruit to be of excellent quality. Fruits of Bordeaux are illustrated by Duhamel (1768), Noisette (1821, in color), Du Breuil (1876), Rozier (1805), Wright (1894, in color), Eisen (1901), and by Price and White (1902). See also: The Garden, 41:333 (1892).

Negronne was introduced into California from England as P.I. No. 18,839 of the Chiswick collection. At Niles, Chico, and Fresno it proved to be identical with Violette de Bordeaux, which was obtained in 1921 from the collection of Leroy Nickel at Menlo Park. Grosse Violette de Bordeaux, introduced as No. 18,844 of the Chiswick collection, produced fruit indistinguishable from that of Violette de Bordeaux, confirming the opinion of Barron (1891) that they were the same, but contradicting that of Eisen, mentioned above. No records have been found of tests of this variety at the California Experiment Stations. A tree, located at Santa Barbara in 1932, was identified as Bordeaux, and other trees are occasionally found in dooryards. Price and White found the tree of Bordeaux to be vigorous and prolific in Texas, but the fruit was insipid and the quality poor. Cuttings 
of a tree growing at 597 Columbia Road, N.W., Washington, D.C., have produced fruit in California identical with that of Bordeaux. At Portland, Oregon, Negronne produces two crops of black figs, good in quality.

Bordeaux is similar to Ischia Black, but differs from it in leaf and fruit characters. Leaves of Ischia Black are small, nonlobed or 3-lobed, surface dull; those of Bordeaux are medium, 3- to 5-lobed, deeply cleft, surface glossy. Duhamel described the leaves of Violette as smaller than those of Blanche, and divided deeply into five parts or lobes, with the borders markedly dentate. Figs of Ischia Black do not have the peculiar thick and crooked stalk that is characteristic of the Bordeaux fruit stalk. The small, immature fruits of both varieties show a distinctive early coloration of a reddish-brown hue, in contrast to fruits of Franciscana (Mission), which change to a black color just before reaching full size and maturity. The following description is from trees which have fruited at Riverside since 1930, and at Fresno in the season of 1953 .

Tree rather dwarf in comparison with trees of Franciscana or Dottato; terminal buds violet-purple to brown in color. Leaves with upper surface glossy ; base truncate to shallowly cordate; middle lobe narrowed toward its base, lateral lobes broad; margins coarsely serrate.

Breba crop fair to good ; figs medium, up to $2 \frac{1}{2}$ inches long and $13 / 4$ inches in diameter, pyriform, with thick, gently tapering neck; average weight 36 grams; stalk variable, often thick or swollen toward body of the fruit, not straight, but commonly curved or bent at an angle, as mentioned above, up to $3 / 4$ inch long, sometimes cracked or split on one side, the crack extending from stalk into the neck; ribs prominent, well elevated; eye medium, scales same color as body, which is purplish black; meat white, tinged with violet; pulp strawberry, rich; quality very good. (Plate $25, D$.)

Second-crop figs small to medium, up to $13 / 4$ inches long and $11 / 2$ inches in diameter, spherical, or pyriform to obovate, often oblique; average weight 27 grams; neck missing, or when present, short and thick; stalk up to $5 / 8$ inch long, peculiarly curved, as in brebas as shown by Condit (1941a, fig. $4, E$ ), purplish in color; eye medium, open, scales purple; color purplish black on both body and neck; bloom commonly on basal half of fruit, but not on body or apex, characterized by Eisen (1901) as "a distinct and fine blue bloom, confined to the neck, ending sharply halfway to the equatorial"; white flecks large, scattered, eventually masked by dark body color; skin somewhat glossy, purplish black when fully mature; meat white; pulp strawberry, fairly rich in flavor. (Plates $10 ; 25, E$.)

Caprified specimens much the same, somewhat larger in size; pulp dark strawberry, subacid in flavor; seeds numerous.

This variety is.inferior to Franciscana (Mission) for commercial planting, on account of smaller size of fruit; good for home planting, as tree is dwarf and prolific in fruit production.

Bouche-barrique (syn. Tapa Cartin Negra, Ficus carica clausa Risso). Described by Risso (1826); listed by Sauvaigo (1889) and Eisen (1901). Second-crop figs medium, oblong, gradually narrowed toward the stalk; skin glossy, black; pulp red; flavor agreeable. 
Bourdissotte Noire. Described by Hogg (1866) ; description closely followed by Eisen $(1888,1901)$. Reported to be a Spanish variety, distinct from Black Bourjassotte. Figs medium, turbinate; neck and stalk short; color purple; pulp "flesh-colored"; flavor sweet, but not rich.

Bourjassotte Grisé (syn. Grizzly Bourjassotte). Described by Audibert Frères (1854), Hogg (1866), Barron (1868d, 1869a, 1891), Moore (1871), Pearson (1872), Rivers (1873), Luckhurst (1880), Wright (1895), Eisen (1901), Wythes (1902), Bunyard and Thomas (1904), E. A. Bunyard (1925, 1934), O. T. (1905), Starnes and Monroe (1907), Royal Hort. Society (1916), Cook (1925), Arnold (1926), and Preston (1951). Illustrated in color by Wright. Illustrated in black and white by Moore, O. T., Starnes and Monroe, T. (1907), and Condit (1941a, fig. 2, K).

Pearson stated in 1872 that Bourjassotte Grisé was a new name for an old variety, grown for many years at Clumber, England, under the name Blanche. According to Rivers, the Bourjassotte figs were so named because they came from Burjasot, a village in Spain, near Valencia. Barron (1891) reported Bourjassotte Grisé as "the most constantly good fig" he had grown. It has long been highly regarded in England, especially for forcing.

The variety was introduced into California as P.I. No. 18,847 , from the Chiswick collection. Outside of collections, two trees of this variety have been located in California; one is in front of the Court House Annex, Santa Ana; the other is in the garden of Mr. Robert Gallegos, Mission San Jose. At both of these places and at Riverside, the production of brebas is very light, and dropping of green, immature figs of the second crop is heavy ; apparently, this is an example of partial or incomplete parthenocarpy.

Tree fairly dense, vigorous; terminal buds violet. Leaves medium, mostly 3-lobed; upper surface glossy; upper sinuses of medium depth and width; base subcordate; margins coarsely crenate. The following description is taken from fruit borne by trees at Riverside, Los Angeles, and Fresno.

Brebas few, many not maturing properly, medium, turbinate, with broad, flattened, or somewhat depressed apex; color greenish bronze, or violet; white flecks conspicuous; pulp dark strawberry; quality fair.

Second-crop figs medium, $1 \frac{1}{2}$ to 2 inches in length, and about the same in diameter, pyriform to oblate-turbinate, with short, thick neck; average weight 38 grams; stalk short; ribs slightly elevated, hardly prominent; eye medium, open, scales tinged with violet; white flecks numerous, conspicuous; color greenish violet, darker at the apex, many specimens showing a green zone persisting around the eye and on the sides; pruinose bloom well marked; pulp strawberry; quality fair. (Plates $10 ; 11 ; 12 ; 25, B$.)

Caprified specimens with external color violet-brown; pulp blood red; flavor subacid, rather strong.

Briasca (syn. Brayasque). Described by Sauvaigo (1889), Eisen (1901), and Simonet et al. (1945). Illustrated by the last two authors in black and white. The account is after that of Simonet, from specimens at Villefranche.

Leaves medium, 3- to 5-lobed. Brebas pyriform, medium in size, $21 / 4$ inches long and 13/4 inches in diameter; average weight 35 grams; neck short, gradually narrowing to the medium stalk; ribs not very prominent; eye promi- 
nent, somewhat open, with violet scales; skin glossy, slightly pubescent, reddish violet, lighter toward the stalk; pulp red, sweet; seeds rather numerous; quality good. Second crop not observed.

Briasca Doussa (syns. Bouffros, Ficus carica dulcissima Risso). Described by Bernard (1787), Duhamel (1809, with color illustration), Risso (1826), Noisette (1829), Couverchel (1839), Sauvaigo (1889), Eisen (1901), and Simonet et al. (1945). Fruit reported to mature early, and not much inclined to drop prematurely; therefore trees are commonly planted near Draguignan. Two crops, June and September. Description is after that of Risso.

Leaves 3-lobed. Figs similar to those of Ficus carica nigra, or Negrette, but with longer stalk, more oblate shape, and redder pulp. Size small; shape oblong, with rounded apex; skin glossy, violet-black; pulp amber in the spring crop, reddish in figs of autumn; quality mediocre.

Brignolenque. Described by La Brousse (1774) as a variety grown at Saint-Esprit, France. Figs very large, black, with red pulp; quality good, both fresh and dried.

Brown Turkey (syns., according to Hogg: Ashridge Forcing, Blue, Common Blue, Blue Burgundy, Brown Italian, Brown Naples, Long Naples, Early Howick, Italian Large Blue, Lee's Perpetual, Murrey, Small Blue, Fleur Rouge, Walton). Described by numerous authors, beginning with Miller (1768). Others are as follows: Hanbury (1770), Brookshaw (1812), George Lindley (1831), Rogers (1834), M'Intosh (1855), Dochnahl (1860), Thompson (1859), Hogg (1866), White (1868), G. S. (1869), Barron (1868c, 1891), Hyde (1877), Coleman (1880, 1887b), Eisen (1885, 1888, 1901, probably confused), Wythes (1890a, 1900a), W. I. (1893), Wright (1895), Burnette (1894), Price and White (1902), Starnes (1903), Starnes and Monroe (1907), Ward (1904), McHatton (1909), Reimer (1910), Royal Hort. Society (1916), Potts (1917), Gould (1919), Hume (1915), Cook (1925), Mowry and Weber (1925), E. A. Bunyard (1925, 1934), Arnold (1926), Fruit-Grower (1936), Ashley (1940), Woodard (1940), Beckett (1941), Anon. (1944), Condit (1947), and Preston (1951). Illustrated in color by Brookshaw, Hyde, and Coleman. Illustrated in black and white by Wythes (1900a), Price and White, Anon. (The Garden, 63 : 427, 1903), Bunyard (1934), and Beckett.

According to a writer in the Gardener's Chronicle, March 25, 1843, French growers have called this fig La Perpétuelle, a name corrupted in England to Lee's Perpetual. Sources of other such names have not been found. It should be emphasized also that the name "Brown Turkey" has been commonly used for two distinct varieties; one, the English Brown Turkey, and the other, California Brown Turkey. The latter is properly referred to as "San Piero."

John Rogers (1834) stated: "Miller in the fourth edition of his Dictionary just mentions the 'long purple fig,' though Whitmill (an eminent gardener of his day, and to whom Miller owed much for his early knowledge of gardening ), in his list or book, published in 1726, calls it 'Whitmill's Early Purple'; but which was neither more nor less than the 'long purple' of Miller. This little bit of vanity in Whitmill-to gain a sale for his trees, or a little celebrity to his name- - has been too much practiced by many who were by nature his juniors, and professionally by far his inferiors." 
The Brown Turkey that was described by Miller to be "so well known as to need no description" is undoubtedly a European variety, introduced into England and given a local name without reference to origin. The synonyms, Brown Naples, Long Naples, and Italian, indicate that it came from Italy, but it has not yet been identified with any variety from that country. For more than two centuries, however, this fig has stood at the head of the list of English varieties for general cultivation, both outdoors and under glass. Coleman reported in 1880: "For forcing we have nothing to surpass, if we have anything to equal it, as it is early, handsome, very prolific, not liable to drop, and of first-rate quality." An anonymous writer in 1852 (see "Literature Cited") described a tree at Worthing, trained in the form of a wheel, its branches forming twelve spokes, with the over-all height fourteen feet, and the circumference thirty feet. In 1883, J. Clarke told of a single tree of Brown Turkey covering a wall space of twenty yards "literally crowded with magnificent and well-formed fruit." W. I. (1893) referred to fine trees growing on the chalk cliffs of England, where the sea spray dashed over them. More recently, E. A. Bunyard wrote: "This is the variety most commonly grown; more are planted, I imagine, than of all the other varieties put together, owing to its hardiness and productivity."

According to Eisen, the Brown Turkey was brought to California from Boston by W. B. West in 1853, and from England by John Rock in 1883. It has doubtless been introduced many other times by various nurseries. Early reports of the California Agricultural Experiment Station include Brown Turkey among the varieties being tested at the substations. Apparently, it failed to compete successfully with other varieties, and until recently no trees were to be found, even in collections. Introductions have been made from England under P.I. Nos. 81,676, 93,275, and 95,598. At Riverside, however, trees from these importations, as well as those obtained from the southern United States, are so badly affected by the mosaic caused by Ficivir caricae Condit and Horne, that normal fruit has seldom been produced. (See plate 13, showing effect of mosaic on leaves.) On the other hand, trees growing in the southern and eastern states are not at all or very little affected by mosaic. They are of a dwarf habit of growth, and hardy, commonly bearing two crops. The Brown Turkey ranks with Celeste (Malta) as the most popular dooryard fig from Texas east to Florida and north to Maryland. The Everbearing fig of Texas, described by Close (1935), is very similar to, if not identical with, Brown Turkey, although treated as a distinct variety by various nurseries. Harrison, briefly described by Close (1933), and Delta, or New Delta, described by two anonymous writers in 1943 and 1944 (see "Literature Cited"), are also very similar to Brown Turkey.

Descriptions of fruit by Eisen and some other authors are not clear, as they are probably confused with similar varieties. Confusion also exists in some descriptions, as indicated by the two synonyms, Large Blue and Small Blue, with reference to size of fruit. The following description is from specimens grown at Riverside and Fresno, and as compiled from various English accounts.

Leaves small, mostly 3-lobed; upper surface dull; upper sinuses shallow and narrow; base subcordate; margins crenate. 
Brebas few, medium, oblique-pyriform, with thick neck that is often curved; stalk up to $1 / 2$ inch long, sometimes swollen toward the body of the fruit; ribs prominent, producing a somewhat corrugated surface; eye medium, open, scales violet-brown; color mahogany brown, tinged with violet; meat white, with violet tinge; pulp strawberry; flavor fairly rich; quality fair. (Plate 21, D.)

Second-crop figs medium or below, turbinate or oblate, mostly without neck; average weight 28 grams; stalk up to $5 / 8$ inch long, often thick and swollen at the apex; ribs present, fairly prominent, more deeply colored than body; eye medium, open, with violet-brown scales; white flecks large, conspicuous, scattered; color auburn to burnt umber; pulp amber to light strawberry, practically seedless; flavor sweet, but not rich; quality fair. (Plate $15, E$.)

Caprified figs violet-brown, bloom prominent; average weight 36 grams; pulp strawberry; quality only fair. Second crop matures over a long season.

Rogers (1834) stated that if Lee's Perpetual-bearing fig is "cultivated as it should be-that is, in pots, under glass-it yields fruit nearly all the year round."

Brugeotte. Described by Merlet (1667) as a large, violet fig with red pulp, produced abundantly in autumn; this description was followed closely by Ballon (1692), Liger (1702), Langley (1728), and Bradley (1757). In 1727, Bradley included Brugeotte in the list of fig varieties he had introduced from Italy into England.

Caiana (syns. Bertolina, Ficus carica caiana Risso, $F$. carica browni Risso; the last according to Sauvaigo). Described by Risso (1826), Sauvaigo (1889), and Eisen (1901).

Figs small, turbinate; skin thin, reddish violet, with distinct bloom ; pulp pale red, rather watery, and of bitter flavor. Grown at Nice and in Provence.

Calabresa. First crop only described by Sauvaigo (1889) and Eisen (1901). Brebas large, about 3 inches long and 21/2 inches in diameter, pyriform; color bright green, tinged with brown; meat violet; pulp red. Grown near Nice.

Calderona (syn. Paretjal Negra). Described and figured by Estelrich (1910).

Tree of medium size; leaves mostly 3 -lobed. Breba crop none. Second-crop figs similar to and often confused with "Bordissot" and Martinenca; size medium; shape oblate-spherical, with very short, thick neck; color black; pulp dark red. Used for drying, but not extensively cultivated on Mallorea.

Caravanchina Negra (syns. Caravanquin Negra, Ficus carica obovata Risso). Described by Risso (1826), Sauvaigo (1889), and Eisen (1901).

Tree with long, spreading branches; leaves medium, 3- to 5-lobed. Figs small, oblong; skin thin, glossy, somewhat ribbed; color violet-black; eye surrounded by a reddish iris; pulp dull red; flavor agreeable. According to Risso, it is necessary to plunge the dried fruit into boiling water in order to preserve it.

Cascitello. Described by Guglielmi (1908) and De Rosa (1911) as Cascitello; described by Vallese (1909) and Donno (1951a) as Nero. De Rosa states in a footnote that he prefers the name Cascitello over Nero, as the 
latter is a general one, commonly used for other varieties. De Rosa gives the following synonyms: Casciteddha, Cascella, Cascetta, and Banegra. Vallese and Donno give additional synonyms: Colummo, Colombo, San Pietro, Sampiero, Schiavone, Niuro, Canibianco, Mario, Mariu, and Napulitano. Two of these, San Pietro and San Piero (Sampiero), are described elsewhere in this monograph as distinct varieties. As pointed out by Donno, Cascitello (synonym Colummo) should not be confused with Colummone or Colombo Pazzo (Colombro).

Trees widely planted in Lecee Province, producing two crops ; leaves generally 3-lobed; terminal buds brick red, as described by Donno (1951a).

Breba crop generally abundant, although scarce in some years; fruits turbinate, broad at apex; stalk short, often swollen; skin greenish violet, checking somewhat at maturity; pulp rose-colored, very sweet; seeds few, hollow.

Second-crop figs of two sorts; the caprified, designated as Schiavoni, and the uncaprified, designated as Canibianchi. Schiavoni medium, oblate, depressed at the apex; stalk short; eye rather large, with scales violet; skin checking rather prominently at maturity, readily peeled; color violet-black; pulp coral red; seeds fertile. Canibianchi smaller, sometimes not even half the size of the Schiavoni, much lighter in color of skin and pulp; flavor sweet; seeds few. Fruit of Cascitello is mostly consumed fresh, especially the Canibianchi; the Schiavoni are preferred for drying.

Castagnolo. Deseribed and figured by Baldini (1953) as an Italian variety, producing one crop only.

Branches with brown terminal buds. Leaves mostly 5-lobed; lobes spatulate; sinuses deep and wide open; base cordate; margins crenate.

Figs oblate, without neck; stalk short; eye closed; color violet-brown; bloom pruinose; pulp red, sweet; seeds numerous. Production light. Crop matures middle of September; of little importance.

Castanhal. Described and illustrated by Bobone (1932) as a variety very similar in fruit characters to Sopa e Vinho. Breba crop none. Second-crop figs at $\Lambda$ lenquer medium, turbinate, green, tinged with violet; pulp carmine; quality good.

Catalan (syn. Ficus carica gallica, according to Sauvaigo). Described briefly by Risso (1826), Pasquale (1876), Sauvaigo (1889), Eisen (1901), Pellicano (1907), and Portale (1910).

Figs oblate-spherical, violet-black in color; pulp red. Grown at Nice and along the Riviera, but of minor importance; consumed mostly fresh.

Célestine (syns. Beaucaire, Figue Grisé, Grisette). Described by Langley (1728), Hogg (1866), Soc. Pomol. de France (1887, 1947), Eisen (1888, 1901), Starnes and Monroe (1907, with figure), Simonet et al. (1945), Evreinoff (1947), and Delbard (1947). (See account under Cordelière of confusion regarding this and other variety names.) A French fig, not reported in California collections.

Tree spreading, of moderate vigor, very productive; fresh fruit excellent.

Brebas large, pyriform, violet-gray; pulp rose, sweet; quality good.

Second-crop figs smaller, more elongated; color ashy gray; pulp red ; flavor very agreeable. Season early. 
Cernica. Described by Eisen $(1888,1901)$ as a black Dalmatian fig of medium size, introduced into California by G. N. Milco; resembles Barnissotte. Colby (1894) gave an analysis of the fruit grown at Fresno, and described it as a medium, spherical fig of purple color, with blood-red pulp.

Chetoui. Described by Minangoin (1931) from Dra Tamar, Tunisia. Leaves large, 3-lobed; petiole long. Fruit large; body spherical, elongated into a distinct neck; skin thin, black; pulp rose-colored.

Cimeirenca. Sauvaigo (1889), followed by Eisen (1901), described this as a violet-black fig, similar in other characters to Cimeirenca Blanca.

Claveu (syns. Clou, Ficus carica clavicularis Risso). Described by Risso (1826), Sauvaigo (1889), and Eisen (1901). Name derived from the elongated form of the fruit ("club-shaped").

Tree produces two crops. Leaves 3 - to 5 -lobed; sinuses deep; blade prolonged to a point on the long petiole.

Brebas large, elongated-pyriform; eye protruding; skin thin, uniformly dark brown to black; pulp carmine. Second-crop figs smaller, turbinate.

Col de Dame Noir (syns. Col di Signora Nero, or Negra, Col de Señora Negra, Cuello de Dama Negra, probably Fico del Giammico of Guglielmi, Bouankirk.) Deseribed by Audibert Frères (1854), Hogg (1866), G. S. (1869), Eisen $(1888,1901)$, Starnes and Monroe (1907), Guglielmi (1908), Estelrich (1910), Priego y Jaramillo (1922), Mauri (1939b), Simonet et al. (1945), Delbard (1947), and Montagnac (1952). Illustration of fruit by Eisen; of tree, leaves, and fruit by Mauri. In Spain, this black fig is not so common or so highly regarded as Col de Dame, although the fruit is said by Estelrich to be resistant to spoilage in wet weather. In France, it is a late variety of excellent quality; Eisen reported it as extensively cultivated near Roussillon, and as superior to Col di Signora Bianca. Simonet reported that the tree bears only one crop and questioned the statement of Eisen regarding a first crop. According to Mauri, the name Bouankirk signifies "long neck." The Kabyles also designate the variety by the names D'Abouch Takli, "breast of a negress," and Abgait. It is widely grown in North Africa, but on account of thickness of skin it is not dried commercially.

Col de Señora Negra was introduced into California from England by John Rock in 1883; it was not included in the Chiswick collection. P.I. No. 6,467 , listed as Baalie, has proved to be the same variety at Riverside. The following description is taken from that of Simonet.

Leaves large, 3- to 5-lobed; margins undulate. Figs medium; average weight 45 grams; body subglobular to oval; neck elongated-cylindrical, thick; ribs prominent, elevated; stalk very short; eye small, with dark-red scales; skin fine, but fairly resistant, checking crisscross at full maturity; color dark violet, greenish toward the stalk; meat white; pulp deep red, luscious; quality excellent. Season late.

Colombo Nero (syn. Colummaro Nero). Described and illustrated by Vallese (1909); description only by De Rosa (1911).

Tree bears two crops. Leaves small, asymmetrical, mostly 5-lobed.

Brebas elongated-pyriform, rounded at the apex; eye projecting, with rose-colored scales; color violet.

Second-crop figs medium, ovoid, narrowed toward the base; stalk very 
short; eye large, scales violet; skin yellowish green near the stalk, gradually becoming bluish violet on body and apex, especially on side exposed to the sun; pulp light red; seeds few.

Constantine. Described by Colby (1894), Forrer (1894), and Eisen (1901, with illustration). Introduced into California by John Rock in 1883, and in the Chiswick collection of 1894 as P.I. No. 18,874 ; now found only in collections. Description is from a tree fruiting at Riverside since 1930.

Tree fairly dense; terminal buds greenish brown. Leaves medium, glossy above, mostly 3-lobed; upper sinuses of medium depth and width; base cordate to truncate; margins shallowly crenate.

Brebas none, or very few. Second-crop figs small to medium, up to $13 / 4$ inches in length and diameter, turbinate, with short, thick neck; average weight 26 grams; stalk short and thick; ribs slightly elevated, coloring earlier than body; surface dull, with prominent bloom; eye large, open, surrounded by a more or less distinct zone of greenish color, scales violet; white flecks small, scattered; skin firm, violet-purple, checking slightly at maturity ; pulp strawberry; texture dry and mealy; seeds few.

Caprified specimens with dark-red pulp. Quality good, but fruits small and of comparatively little value, either fresh or dried. (Plates $10 ; 15, F$.)

Cótigo (syn. Cótio Tinto). Described and figured by Bobone (1932), who stated that Mello Leotte (1901) regarded this variety as a mutation of Cótio, producing colored rather than green figs. Second-crop figs green, with violet spots; stalk medium; pulp carmine; texture coarse; quality good.

Coucourelle Brune. Described by Tournefort (1700), Bernard (1787), Duhamel (1809), Bory de Saint Vincent (1824), Noisette (1829), Duchartre (1857), Hogg (1866), Couverchel (1839), Barron (1891), and Eisen (1888, 1901). The designation of this variety by Eisen as Ficus carica fusca Risso, has not been found. Illustration in color by Duhamel. The description by Tournefort seemed to Bernard to fit Coucourelle Brune better than Angélique, as explained under that variety. According to Couverchel, trees are common in Provence, where the fruits play an important role in supplying food for the country people. The description is after that of Eisen.

Brebas very early ; size $11 / 2$ by $13 / 4$ inches.

Second-crop figs below medium, spherical; stalk variable, short to moderately long; color brown; bloom prominent; pulp dark red; flavor insipid; quality fair.

Coucourelle Gavotte (syns. Coucourelle Noire, Ficus carica labillardiera Risso). Described by Risso (1826), Hogg (1866), Barron (1891), and Eisen $(1888,1901)$. Risso described this variety as Labillardière, and referred to the previous accounts of Tournefort, Bernard, and Duhamel; however, these last three accounts seem to belong properly to Coucourelle Brune, and not to Coucourelle Gavotte. Eisen follows closely the description of Hogg. The account by Barron is confusing, since the color of Coucourelle Brune is given as dark purple, and that of Coucourelle Gavotte as dark brown. This is just the opposite of the accounts by Risso and the others.

According to Eisen, the tree bears two crops, and his description probably refers to figs of the second crop.

Figs below medium, spherical, with dark, longitudinal lines; neck none; 
eye open; color black on sunny side, pale bronze on shaded side; pulp blood red; flavor rich.

Cravé. Described by Simon-Louis Frères (1895) and by Eisen (1901) as a variety of Italy and France. Figs medium to small, violet-black in color; pulp dark red; flavor insipid. According to Barron (1891), Cravé (Rivers) resembles Violette de Bordeaux.

Cumpini (syn. Del Capo). Described and illustrated by Vallese (1909).

Leaves mostly 5-lobed. Figs medium, ovoid; stalk short; ribs slightly raised, deeply colored; skin of a chestnut-rose color toward the stalk, but black on body; bloom light, pruinose; pulp red.

Cuore (syns. Rubado, Roubauda Blanca, Arbauda, Corazón, Ficus carica richardia Risso). Described by Gallesio (1817), Risso (1826), Sauvaigo (1889), Eisen (1901, with illustration), Simonet et al. (1945), and Tamaro (1948). According to Gallesio, the name Cuore was given to this variety because the fruit is somewhat heart-shaped. It was designated richardia by Risso in honor of Professor Richard, of Paris. The variety is much prized as a table fig in Italy, especially in Umbria, Sabina, and in the vicinity of Rome; the Genoese know it as Rubado. Gallesio stated that it was not found in Provence or in Spain ; but Eisen reported its culture in Provence, as well as in northern Italy. Rubado has been reported under trial by both the California and the Texas Experiment Stations, but its proper identity has not been established. According to Van Deman (1890), cuttings of Rubado were distributed from Washington, D.C.

The tree reaches moderate size, with small, 3- to 5-lobed leaves; first crop very light, or none.

Second-crop figs (according to Eisen) above medium to large, $23 / 4$ inches long by 2 inches in diameter, oblong to turbinate, gradually tapering toward the short stalk; skin thick, checking crisscross, adherent to the meat; color green, tinged brown in the sun, and ashy gray in the shade; eye reddish, with gum exuding at maturity; pulp red, sweet, rather sharp or caustic to the taste, and not so delicately flavored as Pissalutto or Dottato. Skin is tough in texture when dried. Season late.

Curigo. Described and illustrated by Bobone (1932). Pata de Cavalo, collected at Coimbra, is similar to Curigo; the two differ somewhat in intensity of color, external and internal.

Figs pyriform to turbinate, with short, thick neck; stalk medium; skin green, with many violet spots ; pulp carmine to chestnut-rose ; texture coarse ; quality good.

Dame Noire. Described and figured by Simonet et al. (1945) from specimens grown at Sollies-Pont.

One crop only ; leaves medium. Figs small, subglobular, slightly narrowed toward the stalk, which is up to $1 \frac{1 / 2}{2}$ inches in length; average weight 20 grams; eye in a slight depression, with rosy scales; skin pubescent, checking at maturity, uniformly reddish violet in color; pulp light red; quality mediocre.

Datte Quotidienne. In his account of 1888, Eisen regarded Quotidienne as synonymous with Datte; but in 1901, he classified these two as distinct 
varieties. One of the common names he gives for Datte Quotidienne is Constant Date; he reported it as a very fine fig for drying, especially at Salon and Eyquières, France. The only other account found is that by Audibert Frères in 1854; they describe it as a one-crop variety, with elongated fruit, green skin color, and dark-red pulp. P.I. No. 18,860 of the Chiswick collection, when fruited in California, produced pyriform figs, purplish black in color. This leads to the conclusion that the material under P.I. No. 18,860 was not true to the variety, and that the account by Eisen should be accepted as authentic, although, unfortunately, he did not give the source of the specimens described.

Figs medium to large, pyriform, without neck, or with neck very short and thick; eye closed, depressed, small; color green to violet-brown on ribs and exposed side; bloom prominent around the stem end, but terminating abruptly at the equatorial line; pulp rose-colored.

Dattero (syns. Donicale of Pistoia, Bezzoso of Lunigiana, Cortese of Liguria, Coasea of Riviera di Ponente, Vezzoso at Piacentino-all according to Gallesio; Rolandine, Rolandine Blanche, Briasca of Grasse, Blanchette, Ficus carica rolandina Risso, Ficus polymorpha var. elegans Gasparrini). Described by Gallesio (1817), Gasparrini (1845), Roda (1881), and Mingioli (1904), as Dattero. Described by Risso (1826), Sauvaigo (1889, 1894), Eisen (1901), Trabut (1904), Bois (1928), Blin (1942), Simonet et al. (1945, with illustration of fruit), and Evreinoff (1947), as Rolandine or Rolandina. Described by Baldini (1953) as Donicale, with Verdiccio Gentile as a synonym. Illustration of leaf and fruit by Baldini.

According to Eisen, Dattero is the same as Dottato. The accounts of Dattero by Gallesio, and of Rolandine by Eisen, Risso, Sauvaigo, and Simonet, however, agree that this is a one-crop variety, and that the skin color of the figs is green, tinged with rose. On the other hand, Dottato trees bear two crops, and the figs are yellowish green in color. Dattero is, therefore, treated here as a distinct variety, and Rolandine as identical with it. Authorities also agree that it is an excellent fig, especially for drying, along the Italian Riviera and in southern France. It seems not to have been tested in California, at least under the names listed. P.I. No. 102,020, introduced from Morocco as Rolandine in 1933 and fruited at Riverside, proved to be identical with Archipel (Osborn's Prolific) - a different fig from the variety under consideration here. The following account is based on those of Simonet et al. and Baldini.

Leaves mostly 5-lobed; base shallowly cordate.

Breba crop none. Second-crop figs medium, up to 2 inches long and $11 / 2$ inches in diameter; average weight 32 grams; shape obovate to pyriform; neck not prominent, or entirely missing; stalk short; ribs not much in evidence; eye small, closed, scales pink; skin checking at maturity ; color yellowish green, tinged with violet; pulp light rose, somewhat hollow; seeds small, few. Quality very good, especially for drying.

Djebali. Described by Minangoin (1931) from Gafsa, Tunisia. Leaves large, 3-lobed; petiole long and slender. Figs with prominent neck; eye wide open; color violet; pulp light red. 
Djerbi. Described by Minangoin (1931) from Hammamet, Tunisia. Leaves small, 3-lobed, or sometimes almost nonlobed; sinuses hardly prominent. Figs oblate-spherical, sessile; eye open; color dark violet; pulp brown; seeds numerous.

Doctor Hogg Black. According to Eisen (1901), this variety was found by Hogg near Toulouse, France. It bore figs almost black, with red pulp. (See note under Franciscana.)

D'Or Bifère. Described by Barron (1891) and Eisen (1901, after Barron) as a small, ovate fig; color greenish yellow, suffused with brown; pulp blood red, rich and juicy.

D'Or de Baume. Described by Hogg (1866) and Eisen (1888, 1901, after Hogg). Figs medium, oblong; ribs distinct; stalk short; eye open; color hazel-brown; pulp rosy to amber; quality excellent.

Early Violet. Described by Thompson (1859), Hogg (1866), G. S. (1869), Coleman (1887b), Massey (1893), Wythes (1890a, 1893), Shinn (1893), Wright (1895), Hansen (1894), Eisen (1897, 1901), Price and White (1902), and by Starnes and Monroe (1907). Illustrated by Price, Eisen, and by Starnes and Monroe. In his account of Early Violet, Thompson referred to the description of Thomas Rivers, who probably introduced the variety into England and gave it a name. It was reported to be especially good for forcing in pots, as the tree ripened three crops in a season. Hogg stated: "Though small and in the estimation of some, an insignificant variety, this is among figs what the Red Masculine is among apricots, and the Red Nutmeg among peaches-a nicely flavoured, very early, and remarkably prolific fig."

The California Nursery Company, Niles, listed and described Early Violet in its catalogue for 1889-1890. During the next few years, it was tested at the California Experiment Stations and found to be early, but with fruit too small for commercial planting. Cuttings were obtained from Crisfield, Maryland, in 1940, and from the Custis estate near Cape Charles, Virginia, in 1943, and grafted in the variety orchard at Riverside. Very few, if any, brebas have been produced, and second-crop figs are smaller than those of any other variety in the collection. Many figs shrivel and drop when small.

Leaves small, thin, dull on upper surface; lobes mostly three; upper sinuses shallow; base subcordate to truncate; margins crenate. Badly affected by mosaic, which dwarfs both leaves and fruit. Description of fruit is compiled from various sources, and from specimens grown at Riverside.

Brebas none. Second-crop figs small to very small, 1 inch long by $1 \frac{1}{4}$ inches in diameter; average weight 9.2 grams; shape turbinate to oblatespherical; stalk slender, up to $3 / 4$ inch long, somewhat enlarged toward body of fruit; ribs prominent, more darkly colored than body; eye large, open, scales rose; bloom delicate; color chocolate-brown; pulp strawberry; seeds small; quality fair. Susceptible to spoilage. Reported by Eisen as preferable to the Ischias and Celeste; trees now very rare in the southern United States, in comparison with the latter variety. (Plate $27, E$.)

Eva. Name applied locally in the Union of South Africa to a variety producing small to medium fruits, purplish brown in color; pulp pinkish amber, slightly hollow. It resembles Common Brown, Kaapse Bruin (Cape Brown), and Black Sugar in the subtropical orchard of the Western Province Fruit 
Research Station, Stellenbosch, according to Dr. Daniel du Preez, in a letter dated February 23, 1953.

Ferguson. Described by Close (1929) as a variety grown by a nursery at New Braunfels, Texas. At Riverside, California, the Ferguson has produced second-crop figs only. These are medium to small in size, pyriform, with prominent neck; stalk short; color purplish black, with green zone often persisting at apex; pulp light strawberry; quality only fair.

Figue Fleur. A variety received in 1933 from Marrakech, Morocco (but originally from Lérida, Spain), under P.I. No. 102,012.

Breba crop small; figs small, pyriform, purple; pulp dark strawberry.

Second-crop figs small in size, pyriform, purplish black in color; bloom prominent on body, absent in a circular area at the apex, as shown in plate 12 ; pulp strawberry. Season early.

Ford (syn. Ford Seedling). Described and illustrated by Eisen (1901) as a different variety from the one listed by Hogg, who regarded it as identical with Marseillaise.

Figs large, pyriform, greenish violet; pulp red, coarse in texture. Source of specimens not given.

Franche Paillard (syns. Abondance, Franque Pagarde). Described by La Brousse (1774), Duchartre (1857), Soc. Pomol. de France (1887, 1947), Eisen $(1888,1901)$, Colby (1894), Forrer (1894); the last two as Abondance Précoce.

Tree vigorous ; first crop light, but second crop very abundant. Description is from Société Pomologique de France (1947).

Brebas medium, elongated, dark brown in color; pulp deep red; quality very good.

Second-crop figs medium, pyriform; color violet-brown in the sun to greenish violet in the shade; pulp red, very juicy; quality good.

Franciscana (syns. Mission, California Black, Negra, Brebal, Douro Vebra, Biberaeo, Reculver, Gouraud Noir, Gourreau du Languedoc, probably Noire d'Espagne, Gourreau Noir). Described by Carbou (1865b), Hogg (1866), West (1882), Escribano y Pérez (1884), Barron (1891), Lelong (1892), Shinn (1893), Colby (1894), Eisen (1885, 1897, 1901), Wythes (1902), Starnes (1903), Starnes and Monroe (1907), Bunyard and Thomas (1904), Dean (1904), Roeding (1914), Mills (1914, 1918), W. S. Anderson (1924), Condit (1921a, 1921c, 1923, 1925, 1933, 1947), E. A. Bunyard (1925), and Blin (1942).

Illustration of tree by Eisen (1901) and Condit (1921a, 1933); fruit figured by Condit (1921a). For color plates see Carbou (1865b) and Associated Grower (Fresno), November, 1922.

The Franciscana (Mission) fig was introduced at San Diego about 1768 from mission stations in Baja California, and until the middle of the past century was practically the only variety grown in the early settlements. In 1882 , West reported that it was too well known to need description, and added that it was the only black fig of his acquaintance that was of any value for drying. Eisen, in 1885, stated that this variety was not good for drying, but in later publications described it as a fig which dried well. In his bulletin of 1901 we read: "The general belief that the Mission is a distinct California 
fig is erroneous. We can no more lay exclusive claim to this fig than can Mexico and Chile. It was undoubtedly brought from Spain or Portugal at a very early date after the conquest."

About 1909, Eisen identified the "Mission" as Franciscana, of Spain, but the exact reference to his publication has not been located. In 1925, Condit wrote, after personal observations in Spain: "The Franciscana is a black fig commonly grown at Estepona, over sixty miles below Málaga, on the coast. Dried figs of this variety seen at Motril appeared to be identical to the California Mission." It seems to be the same variety that Escribano y Pérez described in 1884 as Higuera Negra, of Murcia Province, where it was much esteemed both for fresh fruit and for drying. The following two introductions from Málaga into California have proved to be identical with the Franciscana: P.I. No. 58,664 as Negra, and P.I. No. 62,777 as Brebal.

Three varieties imported from England with the Chiswick collection, P.I. No. 18,875 as Biberaeo, No. 18,896 as Gouraud Noir, and No. 18,868 as Reculver, also produce fruit like that of the Franciscana. The first two are described by Eisen as distinct varieties, but the characters listed by him coincide almost exactly with those of the Franciscana. According to E. A. Bunyard (1925), the name Reculver comes from Reculver, Kent, England, where this fig was introduced by the Romans. Dean, in 1904, described Reculver as a prolific fig tree with small, purple fruits.

Another introduction of the Chiswick collection, P.I. No. 18,867, labeled Douro Vebra, bore fruit very similar to the Franciscana. According to Barron (1891), Douro Vebra is the same as Biberaeo. In the original notebook of John Rock, Niles, dated 1895, there are outline drawings and notes of California Black, Biberaeo, and Reculver. Under the short description of Reculver there appears this line in the handwriting of Gustav Eisen: "Leaves mottled, as on Mission." This unpublished note, we might point out here, is probably the first observation made on the occurrence of a leaf mosaic on the fig in California.

Although it appears strange that Eisen should not have considered the above three kinds to be the same as Franciscana, they are being treated here as identical with that variety.

The Franciscana fig has long been grown in the eastern and southern United States. Trees have been observed on the original Arlington estate of the Custis family near Cape Charles, Virginia, and on a neighboring farm; also at the Virginia Truck Experiment Station, Norfolk, and at the Hampton Institute. The probable reasons for the lack in popularity of the variety in these districts are the susceptibility of trees to frost damage, and their light productivity. W. S. Anderson reported in 1924 that in south Mississippi, "the Black Mission was injured more than any other variety by the cold, and produced very few fruits." On the other hand, the fruit was of the highest quality, "standing up better when left on the tree during the rainy season than any other variety in the test." Woodard (1940) showed that in Georgia, the Mission was much inferior to Celeste in fruit production. Wythes (1902) reported Gouraud Noir, or Dr. Hogg's black fig, to be a fineflavored fruit, and excellent for pot culture in England.

Franciscana trees are widely distributed in California, both as individual 
trees and in commercial plantings. Immense specimens are found, especially in the foothills of the interior valleys (plate 5). The one figured by Condit in 1919 near Corning, with a trunk circumference of $131 / 2$ feet, has disappeared; but there are others just as large, or larger. Another and older tree, still growing on the William Curtner place near Mission San Jose, is reported to have been planted about 1800. Mills (1918) tells of other large specimens. During seasons with unusually low temperatures, trees of this variety are more subject to injury than are trees of other commercial kinds, as pointed out by Shinn (1892) and Hodgson (1934). On account of the productive capacity of the trees, resistance of the fruit to spoilage, and excellent quality both fresh and dried, the Franciscana has long enjoyed an excellent reputation. The main objection to it commercially is the black skin color, which practically prohibits use of the dried fruit in fig paste.

The tree is a vigorous grower, with branches rather slender (plate 4), the larger often drooping to the ground and taking root at the tip ; terminal buds are violet-brown. Leaves large, averaging $75 / 8$ inches broad and 8 inches in length; lobes mostly 5 , but sometimes 3 , or on vigorous wood with each basal lobe auricled; upper surface somewhat glossy. Mosaic spots common and conspicuous on leaves and fruit, but seldom sufficiently serious to cause alarm on the part of growers.

Breba crop good in most seasons; fruits large, up to 2 inches in diameter and 3 inches in length, pyriform, with prominent, thick neck, often $1 / 2$ inch long; average weight 56 grams; stalk short and thick; ribs fairly prominent, slightly raised, generally coloring earlier than body; eye medium, scales purple; surface glossy, with pruinose bloom; white flecks prominent, scattered; skin checking lengthwise at full maturity; color black; meat thin, white, or slightly colored; pulp light strawberry, solid ; flavor rich, decidedly characteristic of the fig. Quality excellent. Widely used fresh for local and distant markets, and frequently dried. (Plate 19, D.)

Second-crop figs variable in size and shape, larger and longer in cool coastal climates than in the interior, as reported by Condit (1950); average weight near Los Angeles 41 grams, at Riverside 25 grams; size medium; shape pyriform, with thick neck, or often without neck; body $1 \frac{1 / 2}{2}$ to $13 / 4$ inches in length; stalk short, thick; ribs narrow, only slightly elevated; eye small to medium, fairly well closed, scales violet; surface dull, with conspicuous bloom; flecks of white at first prominent, as shown by Condit (1941a, fig. 9, $F$ ), becoming obscured by body color; skin checking at complete maturity; color black over entire surface; pulp amber to light strawberry; flavor distinctive, rich. Quality excellent, both fresh and dried.

Caprified figs somewhat larger; average weight 56 grams; pulp dark strawberry; seeds large, fertile. These figs are not regarded favorably, however, by dried-fig packers because of greater loss by spoilage. (Plates 10; $11 ; 19$, C.)

Frette (syns. Rouge de La Frette, Violette de La Frette). Described by Lhérault (1872), Simon-Louis Frères (1895), Eisen (1888, 1901), and Delplace (1933), as a variety grown at La Frette, near Paris.

Tree very productive; two crops. Figs large, pyriform, with reddishbrown skin and rose-colored pulp; season late. 
Galluccio (syns. Gaddhuzzo, Nocciuola, Quagghia, Quaglia, Russuliddu). Described by Guglielmi (1908) as Fico della Quaglia; designated also as Fico Galluccio and Fico Nocciuola. Vallese (1909) describes and illustrates Fico Quagghia and lists Gaddhuzzo, but does not give an account of it. De Rosa (1911) treats the variety as Galluccio, with Gaddhuzzo as a synonym, and in a footnote refers to the above authors.

Trees are not commonly found in Italy. Leaves are large, 3- to 5-lobed.

Breba crop small, with fruits elongated. Second-crop figs small, pyriform; skin thick, smooth; color violet; bloom conspicuous, pruinose; eye medium, with pale-violet scales; pulp pomegranate red in color; seeds large; flavor very sweet. Usually consumed fresh, but also used dried.

Ghzali (syns. Ghozlani in Beisan, Zarraki in Tulkarm, Mulleisi or Ebeidi in Jerusalem). Described by Grasovsky and Weitz (1932) as a mediumsized fig, pyriform, with short neck and long stalk; distinctive on account of its bronze background with purplish ribs ; eye wide open, scales purplish; pulp light red; flavor good; seeds numerous.

Gouraud Rouge. Described by G. S. (1869), Barron (1891), Eisen (1901), and Wythes (1902). Introduced into California as P.I. No. 18,869 of the Chiswick collection ; fruited first at Niles, later at Chico, Fresno, and Riverside; illustrated in color by Condit (1941a).

Tree slow-growing, rather densely branched; terminal buds green; blade of leaf broader than long; petiole half as long as blade; lobes 3 to 5 . Description of fruits is from those produced at Riverside.

Breba crop fair; fruits medium, up to $23 / 4$ inches long and $13 / 4$ inches in diameter, oblique-pyriform, with prominent neck that is often curved and up to 1 inch long; stalk about $1 / 4$ inch long, sometimes swollen toward the apex; ribs slightly elevated; eye medium, open, scales brick red; surface dull, with light bloom; white flecks scattered, but becoming obscured by body color; skin chocolate to burnt umber; meat fairly thin, of a delicate violet color; pulp light strawberry, almost seedless; flavor fairly sweet and rich; quality fair.

Second-crop figs medium, turbinate, flattened at apex, mostly without a short neck; average weight 34 grams; stalk up to $3 / 4$ inch long; ribs inconspicuous, very slightly elevated; eye medium, open, scales violet-brown; white flecks inconspicuous, concealed by dark body color; skin tender, developing dark, circular blotches at full maturity, as shown in plate 9 ; color an unusual rich reddish brown, attractive; meat white; pulp strawberry; flavor mild; quality fair. Very subject to spoilage; worthless for drying. (Plates $9 ; 24, D$.)

Caprified specimens with deep-strawberry pulp and subacid taste; quality poor.

Granato. Dèscribed briefly by Gasparrini (1845) and Savastano (1885) as a little-known variety.

The first crop drops. Second-crop figs are spherical, black, with red pulp of good quality.

Grosse Marseilles. Described by Barron (1891) and Eisen (1901, after Barron) as a fig of medium size, pyriform; skin greenish yellow, shaded brown; pulp dull red; of second quality. 
Guiliana. Described by Eisen (1901) as a small, spherical, violet-gray fig, with salmon-colored pulp. Spelling of name in doubt. Noted as a sweet fig, but of very poor appearance.

Hâtive d'Argenteuil. A variety received from southern France in 1928, under P.I. No. 69,016 . Not identified with any other variety in the collection at Riverside.

Breba crop none. Second-crop figs small, oblique-spherical, with short, thick neck; color violet; bloom commonly absent from circular zone at apex, as illustrated for Figue Fleur in plate 12; pulp strawberry; quality good. Fruits commonly dry without spoilage. (Plate 10.)

Hmadi. Described by Grasovsky and Weitz (1932) as a small Palestinian fig, spherical, with a short, curved neck and medium stalk; color yellowish green; ribs purplish; eye open, with bright-red or purple scales; pulp red; flavor subacid. Very much relished by the fellaheen.

Hmari. Described and illustrated by Grasovsky and Weitz (1932) as one of the earliest figs to ripen in Palestine. It is especially well liked as a breakfast fruit, and is also highly regarded for shipping fresh.

Figs medium, spherical to turbinate; skin thin, smooth, green, with purple blotches; eye closed, surrounded by a purple ring, scales purple; pulp light red; flavor good, subacid; seeds abundant.

Horaigaki. A Japanese variety, producing one crop, from September to November. P.I. No. 122,756, introduced into California in 1940 and labeled Horaigaki, was reported to be a seedling developed by Dr. Tanikawa, Okitsu, Japan, from a cross of Hâtive d'Argenteuil by Roeding No. 2. Fruited at Riverside, 1945 to 1949 , but was discarded.

Figs above medium, pyriform, with thick neck; ribs prominent; eye above medium ; color violet-purple ; meat violet; pulp strawberry ; quality fair only.

Hunt. A seedling fig developed by B. W. Hunt, Eatonton, Georgia, before 1929 , as the result of crossing Ischia Green (Verte) with pollen sent from a caprifig in California. In this seedling there was realized the objective of producing a fig having a long stalk which would allow the fruit to hang downward, so that water from rain or dew would drain away from the eye. The tree bears a light breba crop and a heavy main crop, and in Georgia the figs are parthenocarpic. In California the tree drops its fruit badly; the variety is therefore incompletely parthenocarpic. Found only in collections.

Tree vigorous, with upright branches; terminal buds green. Leaves medium to large, moderately glossy, 3- to 5-lobed; upper sinuses of medium depth and width, lower sinuses shallow; base subcordate; margins coarsely crenate. Description is from fruit grown at Riverside and Los Angeles.

Breba crop small; fruits small to medium, elongated, oblique-pyriform; neck distinct, but merging gradually into the body ; stalk up to $1 / 2$ inch long; color green, shading to brown toward the apex; pulp strawberry, somewhat dry and mealy in texture; quality poor.

Second-crop figs small to below medium, up to $17 / 8$ inches long by $11 / 4$ inches broad, pyriform, with a distinct, short neck; average weight 20 grams ; stalk variable, but generally slender, up to $3 / 4$ inch long; ribs fairly prominent; eye small, scales chaffy, erect; surface dull, with distinct bloom; white flecks scattered, prominent, becoming masked by the bronze body color; 
pulp amber, tinged with strawberry; seeds practically none; flavor rich and sweet; quality fair to good. Similar to Celeste (Malta), but of larger size. (Plate 27, B.)

Caprified specimens much the same, except for dark-strawberry pulp and fertile seeds ; average weight 30 grams.

Imperial (syns. Imperiau; Ficus carica imperialis Risso; Brogiotto, according to Gasparrini). Described by Porta (1592), Risso (1826), Gasparrini (1845), Sauvaigo (1889), and Eisen (1901), as a rather large fig, commonly grown near Grasse, France. According to Eisen, the tree bears two crops, the brebas being medium in size and poor in quality.

Second-crop figs medium, oblique-turbinate, with elongated neck; color greenish, tinged with reddish violet; eye scales bright red; pulp pale red; quality only fair.

Invernengo Rosso. Described by Guglielmi (1908) as an Italian variety, grown especially at Surbo, in Lecee Province. The figs are elongated-oval, reddish brown in color of skin; pulp red, with numerous fertile seeds, a fact which suggests that this may be a variety of the Smyrna type. Consumed exclusively as fresh fruit. Matures from middle of September to December.

\section{The Ischia Figs}

Rogers (1834) stated that all the Ischia figs introduced by Miller from an Italian island of that name were of first quality. Barron (1868e) reported that Miller probably lost or destroyed the original labels of Italian figs, and then substituted such names as Ischia or Genoa in their places. In the 1759 edition of his Gardener's Dictionary, Miller briefly described the Brown or Chestnut-colored Ischia, the Green Ischia, the Yellow Ischia, and the Small Brown Ischia, but not the White Ischia. Several later writers treat White Ischia and Green Ischia as synonymous, but in this monograph the two are treated separately, the latter as Verte. White Ischia will be described simply as Ischia, others of the group as Ischia Black, Ischia Brown, and Ischia Yellow. The last is briefly mentioned under "skin green or yellow." The synonym Nerii, which sometimes appears with Ischia White, apparently refers to the Italian nero or "black" ; if used at all, therefore, it should appear with Ischia Black.

Ischia (syns. White Ischia, Singleton, Brocket Hall). Described by Royal Horticultural Society catalogues of 1831 and 1842, M'Intosh (1855), Hogg (1866), Barron (1868c, 1891), Wright (1894), Wythes (1890a, 1893), Eisen (1885, 1888, 1897, 1901), Forrer (1894), S. H. B. (1896), Price and White (1902), Starnes (1903), Starnes and Monroe (1907), Royal Hort. Society (1916), Gould (1919), Hume (1915), Bunyard and Thomas (1904), E. A. Bunyard (1925, 1934), Mowry and Weber (1925), Cook (1925), Arnold (1926), Condit (1921b, as Lipari ; 1947), R. A. (1937), and Preston (1951). Illustrated by Eisen, Price, Starnes, and Condit (1941a, fig. 2, B).

As explained above, the exact identity of this variety is uncertain, the name White Ischia having been applied after its introduction into England, where it proved to be especially good for pot culture and for forcing. Barron (1868c) thus gave his opinion of it: "The little White Ischia is very fickle 
in respect to quality; the fruits of today are excellent, of three days hence watery and tasteless; the tree bears fruit as profusely as a gooseberry bush." Accounts of the variety in the southern United States are somewhat uncertain, because of the possible confusion of the White and Green Ischia. Starnes found Ischia White "decidedly the first choice" for Georgia, where the fruit shriveled and dried naturally on the tree in good seasons. In 1948, a tree of this variety was found growing at Grosse Coate, near Easton, Maryland.

According to Eisen, Ischia was introduced into California in 1853 by W. B. West, from a nursery in Boston, and in 1883 the California Nursery Company, Niles, received it from England. It was also brought in as P.I. No. 18,886 of the Chiswick collection. Large trees are commonly found in the Sierra Nevada foothills, and before 1922 there was a small orchard of at least eighty-four trees near McFarland in Kern County. One of the largest trees of this variety is on the place of Mrs. Nettie Sullivan, Grabner P.O., Fresno County, near the upper end of Millerton Lake; it is reported to have been planted by Wilburn Winchell in 1851. In Merced County an Ischia tree is growing in a dooryard at Plainsburg.

Although trees were grown at the early California Experiment Stations, the variety failed to receive favorable attention on account of the small size of the fruit. In good weather the figs dry partly on the tree and drop with little spoilage; they are also good for homemade preserves and pickles.

The tree has a dense habit of growth, with numerous small, short twigs; terminal buds are olive green in color. Leaves small, glossy above, mostly 3-lobed; upper sinuses shallow and narrow ; base truncate, sometimes decurrent; margins crenate (plate 13). Description of figs is from specimens grown at Riverside.

Breba crop small or none; fruits below medium, spherical, with very short neck; stalk short and thick; eye rather large, open; color of skin green, tinged with violet; pulp light strawberry; quality poor.

Figs of second crop borne profusely; size small, averaging 18 grams in weight, up to $1 \frac{1 / 2}{2}$ inches in diameter by $1 \frac{1}{4}$ inches from base to apex; shape oblate to spherical, with or without short neck; stalk short and thick, or up to $1 / 2$ inch long, sometimes swollen toward the apex ; ribs narrow, prominent; eye medium, open, scales pink; surface dull, with faint bloom; white flecks seattered and inconspicuous, as shown by Condit (1941a, fig. 9, $H$ ) ; skin checking crisscross, discolored or blemished by circular brown spots at complete maturity ; color green, flushed with violet; meat white, thin; pulp very light strawberry; flavor sweet; quality fair. (Plates $9 ; 15, D$.)

Caprified specimens slightly larger and heavier; pulp deep strawberry; flavor somewhat acid.

Ischia Black (syns. Blue Ischia, Early Forcing, Nero). Described by Miller (1768), Hanbury (1770), Forsyth (1803), Brookshaw (1812), Green (1824), George Lindley (1831), Rogers (1834), Holley (1854), Dochnahl (1855), M'Intosh (1855), Hogg (1866), Thompson (1859), Eisen (1885, $1888,1901)$, Coleman (1887b), Wythes (1890a, 1893), Barron (1891), Massey (1893), Burnette (1894), Starnes (1903), Starnes and Monroe (1907), Bunyard and Thomas (1904), E. A. Bunyard (1925, 1934), Hume (1915), 
Gould (1919), Mowry and Weber (1925), Cook (1925), Condit (1947), and Preston (1951). Illustrated in color by Brookshaw (1812) and Condit $(1941 a)$; in black and white by Eisen (1901) .

Ischia Black was apparently introduced into England from the island of Ischia by Philip Miller, who described it as a black fig of high flavor, especially attractive to birds. Later English authors add little to Miller's brief description. Wythes did not grow many trees, as he found the fruit to be of poorer quality than that of Ischia. E. A. Bunyard (1934), however, added this note to his account: "A variety for the epicure when flavor is valued."

Ischia Black was obtained by the California Nursery Company from England in 1893, and about the same time it arrived with the Chiswick collection as P.I. No. 18,894. Trees have fruited in collections at Niles, Chico, Fresno, and Riverside, and at various state experiment stations. Individual trees of this variety are also commonly found in orchards of the Franciscana fig, and occasionally in dooryards. As Eisen commented in 1901, Ischia Black "is a common variety, but one which could easily be dispensed with." The fruits are smaller, but otherwise comparable, fresh and dried, to those of Franciscana.

The tree is vigorous, upright in habit, with branches inclined to droop; terminal buds are reddish brown. Leaves similar to those of Ischia, medium to small; upper surface glossy, rugose; mostly 3-lobed, but often nonlobed; upper sinuses moderately deep and broad; base subcordate to truncate; margins coarsely crenate (plate 13). Description of fruit is from specimens maturing at Riverside and Fresno.

Breba crop fair; fruits medium or above, up to $2 \frac{1}{4}$ inches long and $13 / 4$ inches in diameter, oblique-pyriform, with a short, thick neck; stalk often $1 / 2$ inch long or more, somewhat swollen toward body of the fig ; ribs narrow, slightly elevated; eye medium, open, scales purple; color purplish black; bloom conspicuous; meat thin, white, with a violet tinge; pulp strawberry; flavor fairly sweet and rich.

Second-crop figs small to medium, oblique-pyriform to turbinate, with or without a short neck; average weight 30 grams; stalk up to $1 / 2$ inch long; surface dull, bloom fairly heavy; white flecks scattered, finally masked by black body color; pulp strawberry; quality good.

Caprified specimens similar in external characters to the uncaprified ones; pulp dark strawberry; seeds fertile, prominent. (Plate 27, C.)

Ischia Brown (syns. Brown Ischia, Chestnut-colored Ischia). Described by Miller (1768), Hanbury (1770), Forsyth (1803), Green (1824), George Lindley (1831), Rogers (1834), Holley (1854), Dochnahl (1855), Thompson (1859), Hogg (1866), Eisen (1888, 1901), Coleman (1887b), and Wright (1894). In his Gardener's Dictionary of 1759, Miller described Small Brown Ischia as a variety bearing small figs, with leaves less divided than any of the other sorts. He also described the Brown or Chestnut-colored fig as "the largest yet seen." It is possible that the first description properly referred to the White Ischia, the fruit of which has a violet flush when fully mature. Hogg and later English authors treat only Brown Ischia, and ignore the prefix, "small." 
A variety, under the name Brown Ischia, was tested at the Tulare station, where the fruit was found to be of excellent quality. A few growers later reported experience with it, but in at least one case the variety was confused with Brunswick. If any trees are now growing in California, their location is not known to us. The following description is after that of Hogg and Eisen.

The tree an excellent producer, especially in pots for forcing.

Figs medium, turbinate-spherical; eye very large; color light brown or chestnut; pulp violet, sweet and of good flavor.

Jasper (syn. À Bois Jaspé). The only descriptions found are those of Barron (1891), Eisen (1888, 1901), and of Starnes and Monroe (1907). P.I. No. 18,848 of the Chiswick collection, labeled À Bois Jaspé, produced fruit purplish brown in color. The variety has probably been lost from California collections. Description is after that of Eisen.

Figs medium to large, pyriform; stalk short; color greenish yellow, tinged with bronze; pulp pale rose in color; quality fair.

Jerusalem (syns. Figue Goutte, Gerusalem). Described by Audibert Frères (1854), Duchartre (1857), Ounous (1863), Hogg (1866), G. S. (1869), La Brousse (1774), Soc. Pomol. de France (1887, 1947), Eisen (1888, 1901), Starnes and Monroe (1907, with illustration), and Delbard (1947). Audibert Frères in 1854 reported, "les fruits avortent presque tous." This statement regarding the Jerusalem fig in France holds also for its behavior at Riverside, California ; for here, too, it drops its fruit badly. Hogg also remarked that the tree is a very poor bearer. The main disagreement in the above descriptions concerns fruit color, which Hogg and Eisen give as black, while Audibert Frères and La Brousse term the color brown. On the other hand, Société Pomologique de France and Delbard give the skin color as light or yellowish.

Jerusalem was introduced into California with the Chiswick collection as P.I. No. 18,862, and has fruited in various plots. In Georgia the tree was productive, with fruit quality fair to good; color was described as "yellow, with dirty, brownish-black blotches." The following description is from fruits produced at Fresno and Riverside since 1926.

Tree rather dense, spreading, with outer branches drooping; terminal buds green. Leaves medium, glossy above, mostly 5-lobed; upper sinuses of medium depth and width; base subcordate to truncate; lower lobes often auricled; margins crenate. Susceptible to mosaic injury. (Plate 13.)

Breba crop none. Main crop drops badly unless caprification is practiced; figs medium, up to $17 / 8$ inches in diameter and $1 \frac{1}{2}$ inches in length, oblatespherical, mostly without neck; average weight 39 grams; stalk short and thick; ribs fairly prominent; eye medium to large, open, with violet scales ; white flecks scattered, rather conspicuous; surface dull, with light bloom; color green, shaded with brown or violet; meat white, sometimes tinged with violet; pulp strawberry.

Caprified specimens darker-colored on outside and of a deeper strawberry inside than when uncaprified; quality good to very good; skin color unattractive.

A variety of no particular value. 
Kahili. Described by Minangoin (1931) from Gafsa, Tunisia. Leaves small, deeply. 3-lobed; petiolar sinus very prominent; petiole long and slender. Figs small, oblate-spherical; eye wide open; color violet; pulp light red.

Kharroubi. Name signifies "carob," as the figs have the color and sweetness of earob pods. Described and illustrated by Grasovsky and Weitz (1932) as one of the sweetest and best black figs of southern Palestine.

Trees are large and prolific. Figs medium, spherical; neck and stalk both short ; eye open, scales pink; skin thin, purplish black ; pulp light strawberry; seeds many; season late. Figs susceptible to rain damage.

Kus. Described and figured by Ozbek (1949) as only occasionally found in gardens at Odemish, near Izmir, Turkey. Name signifies "bird." Figs consumed fresh, ripening over a long season in summer. Variety probably of the Common type.

Leaves mostly 3-lobed. Figs medium, pyriform, with prominent neck; stalk slender; average weight 23 grams ; eye protruding, partly open; white flecks large; color violet; pulp light red, moderately sweet, somewhat aromatic.

Lardaro (syns. Lardaio, and probably Ladaro). Described and figured by Gasparrini (1845) as Fico Lardaro, with the botanical name Ficus pachycarpa. Other descriptions are by Porta (1592), Duchartre (1857), Pasquale (1876, with figure), Savastano (1885), and Eisen $(1888,1901)$. According to Eisen, this is the most common fig near Naples, where trees produce abundant crops. Savastano reported that caprification is practiced for Lardaro. P.I. No. 86,809, received from Yalta, Crimea, as Lardaro, proved at Riverside to be a medium-sized Smyrna-type fig of a green, unattractive color. It is uncertain whether Lardaro is a Common-type or a Smyrna-type variety. The following description is after that of Eisen.

Tree moderately vigorous, with spreading branches. Leaves large, 3-lobed.

Brebas none. Second-crop figs above medium to large, up to 3 inches long and $13 / 4$ inches broad, pyriform, with long, tapering neck; stalk very short; ribs prominent, raised, rough and irregular; eye flat, small but open; color green on body and neck, with ribs dingy violet-brown; pulp pale rose, hollow, coarse; flavor agreeable.

Levenssana. Described by Risso (1826) as Ficus carica smithii, and by Sauvaigo (1889) as Levenssana; description of Eisen (1901) is a literal translation of that of Sauvaigo. Variety originated at Levens, near Nice.

Figs medium, oblate-spherical; skin hard, glossy, adhering to the pulp; color pistachio green on lower half and brownish violet toward the apex; eye red; pulp bright red.

Longue d'Août. Described and illustrated by Simonet et al. $(1945,1947)$ as a two-crop variety, grown at Sollies-Pont.

Brebas above medium, up to 5 inches long and $13 / 4$ inches in diameter, elongated-pyriform, very oblique; neck long and curved; stalk of medium length; surface corrugated by numerous, prominent ribs; eye slightly protruding, open, scales brownish; color of skin golden yellow, with brown tinge on the sunny side; pulp light red; flavor insipid.

Second-crop figs medium, 21/4 inches long, pyriform, somewhat ribbed; neck short, or none; stalk up to $3 / 4$ inch in length; eye closed; skin green, flushed with violet-brown; pulp rose-colored; quality mediocre. 
McFadden. A seedling fig, described by Rixford (1918b) and Close (1929) as one of the progeny of a cross, Agen by Meyer Capri No. 2. First fruited on the place of A. J. McFadden, Santa Ana. At Riverside, the tree has produced small figs, without neck, violet to purplish black, with strawberry pulp.

Madeline. Variety received in 1923 from a grower at San Jose, California. Produced medium-sized figs, dark violet in color, with strawberry pulp. The Madeline described by Earle (1900) is probably Blanche (Madeleine). Identity of Madeline not determined. (Plates 9, 11, 12.)

Madère (syns. Figue de Madère, Figue Noire). Described by Merlet (1667), Ballon (1692), Liger (1702), and Langley (1728), as a large French fig, elongated, reddish brown to black, with light-red pulp. Madère is probably identical with some other variety, such as San Piero.

Malmaison (syn. Bifère de la Malmaison). Described by Audibert Frères (1854), Hogg (1866), Barron (1891), and Eisen (1888, 1901). Hogg reported for Bifère de la Malmaison: "Skin of a pale hazel-brown covered with a thin, grey bloom. Flesh . . agreeably flavoured but not rich."

Eisen followed closely the account of Barron, which stated that the fruit is below medium; skin pale brown, streaked with purple, with light bloom; pulp red, very rich.

Audibert Frères regarded the variety highly, especially for its production of a first crop, and predicted a good future for it when transportation facilities improved. Their description showed a fig of large size, brown to reddish black, with a light-rose pulp.

Malta (syns. Small Brown, Celeste, Celestial, Sugar, Blue Celeste, Celeste Violette). Described as Malta by Miller (1768), Hanbury (1770), Forsyth (1803), Brookshaw (1812, with color plate), Green (1824), George Lindley (1831), Holley (1854), M'Intosh (1855), Dochnahl (1855), and by Bunyard and Thomas (1904). Described as Celeste by Affleck (1850, 1852, 1854), White (1868), Massey (1893), Burnette (1894), Eisen (1885, 1897, 1901*), ${ }^{8}$ Earle (1900), Price and White (1902*), Starnes (1903*), Starnes and Monroe (1907), Anon. (1908), Van Velzer (1909*), Reimer (1910*), Potts (1917), Gould (1919*), Hume (1915*), W. S. Anderson (1924-1928), Mowry and Weber (1925), Woodroof and Bailey (1931*), Stansel and Wyche (1932), Woodard (1938, 1940), Ashley (1940), and Condit (1941a*, $\left.1947^{*}\right)$.

The identity of the Celeste fig, so widely grown in the southern United States, has long been in doubt. White (1868) suggested that it might prove to be the Malta described by previous authors. Others seem to have overlooked this suggestion, but a close comparison of descriptions of Malta and Celeste leaves no doubt of their identity. English writers reiterate the statement of Miller, that Malta shrivels on the tree and becomes a fine sweetmeat. Stansel and Wyche report that in Texas, Celeste will dry on the tree to some extent without souring. Bunyard and Thomas state that Malta "is in all respects like Brown Turkey except in the shape of the fruits, which are shorter and of peg-top shape." Figue d'Automne or Celeste, listed by Ballon

\footnotetext{
${ }^{8}$ Where asterisks appear in citations, illustrations of the tree or fruit of this variety are given by authors.
} 
(1692), and Liger (1702), as bearing fruit which may remain on the tree during the winter and mature in the spring, is apparently a different variety.

As early as 1850, Thomas Affleck reported that of the twenty-odd sorts of figs in his orchard at Washington, Mississippi, the Celeste or Celestial was the general favorite. Source of the first importation of Celeste and the significance of the name have not been learned. In its catalogue of 1828 , Bartram's Botanic Garden, Philadelphia, offered "Coelestial" fig trees at fifty cents each. For a century or more it has been the leading variety in Louisiana and Mississippi ; Earle (1897) reported that nine-tenths of all figs grown in these two states were Celeste. In Georgia, Woodard showed that this variety ranked with Brunswick and Brown Turkey in high production and resistance to winter injury.

Although Malta is a common fig, trees do drop a considerable percentage of their crop under some circumstances. W. S. Anderson found in Mississippi in 1924, that many fruits set, but when not more than one-half inch in diameter they usually shriveled and fell off; the trees bore better crops in dooryards than under orchard conditions, either with clean culture or in permanent sod. Canning companies at St. Martinsville, Elizabeth, and Jeanerette, Louisiana, harvest Malta (Celeste) figs from dooryard trees, and handle considerable quantities as preserves under various brands. In the garden of the restored governor's mansion, at Williamsburg, Virginia, there is a planting of fig trees consisting mostly of this variety.

Malta (Celeste) was introduced into California from eastern nurseries between 1860 and 1870 , but on account of the small size of the fruit has never attracted attention commercially. Individual trees are occasionally found in yards, but most homeowners prefer varieties which either produce two crops, or a single crop of larger fruit. Trees are hardy, partly on account of prolonged spring dormancy. According to Stansel and Wyche, they were not injured in Texas by a temperature of $11^{\circ} \mathrm{F}$. in 1930 .

In the southern United States it is generally considered to be a vigorous grower, but in California trees are slow-growing and dwarf in habit as compared with trees of most commercial varieties. Terminal buds are green. Leaves below medium, glossy, 3- to 5-lobed; upper sinuses moderately deep and broad, lower sinuses shallow; base subcordate; margins crenate.

Breba crop small, or mostly none; in Texas a few brebas occasionally mature in May, the individual figs being larger than those of the main crop.

Second-crop figs at Riverside, California, small, up to $13 / 4$ inches long and $11 / 4$ inches in diameter, pyriform, with neck tapering gradually from body to stalk; average weight 14 grams; stalk slender, up to $3 / 4$ inch long; ribs broad, slightly elevated; eye medium, partly open, but not readily admitting dried-fruit beetles; scales chaffy, erect at maturity; surface dull, with conspicuous bloom often absent from a sharply defined apical zone; white flecks scattered, fairly conspicuous, but becoming masked by mature body color; skin checking crisscross at maturity; color violet-bronze to chocolate brown; pulp strawberry; flavor sweet and rich; seeds small, hardly noticeable; quality good. Figs drop and dry without spoiling. (Plates $9 ; 25, C$.)

Caprified figs are larger, spherical-turbinate; pronounced violet tint outside and dark strawberry inside; flavor subacid; seeds numerous. 
Mappafero (syn. Fico Potentino). Described and illustrated by Vallese (1909); description in detail by Donno (1951b). Widely planted in Lecee Province.

Terminal buds brick red, as described by Donno (1951a); leaves mostly 3-lobed.

Brebas large, $31 / 4$ inches long by $21 / 2$ inches broad, pyriform ; ribs present; skin checking irregularly; color green, tinged with reddish violet; pulp light red.

Second-crop figs medium, oblate-spherical, broad or flattened at the apex, rounded toward the short stalk; color yellowish green, tinged with violet on the sunny side; white flecks elongated; pulp light red; flavor sweet, agreeable. Consumed both fresh and dried.

Marseillaise Black (syns. Black Marseilles, Marseillaise Negra, Black Provence, Ficus carica phoceana Risso, according to Sauvaigo). Described by Sawyer (1824), Hogg (1866), G. S. (1869), Sauvaigo (1889), Barron (1891), Eisen (1901), Starnes (1903), and Starnes and Monroe (1907, with illustration). The following account is after that of Eisen, which differs somewhat from the short one given by Hogg.

Figs medium, pyriform, with distinct neck; stalk long, about one-third the length of the fig; ribs distinct, especially on neck and body ; eye medium, closed, scales large, red; skin waxy, with thin bloom; color black; pulp red. Quality good in Provence and at Nice.

Marseillaise Long (syns. Grosse Blanche Longue, Blanche Longue). Described by Cupani (1696), Tournefort (1700), Liger (1702), Garidel (1715), Bernard (1787), Rozier (1805), Duhamel (1809), Bory de Saint Vincent (1824), Noisette (1829), Couverchel (1839), Duchartre (1857), Forney (1863), Eisen (1901), Trabut (1904), and Blin (1942). According to Rozier, Grosse Blanche Longue is similar to Blanche Ronde (Blanche); the main difference is in the shape and color, the former having oblong rather than globular fruits and brown, not green, color of skin. Couverchel and later authors list it as Longue Marseillaise. It is grown mostly in southern France. Trabut stated that it was introduced into Algeria previous to 1904, and grown both for fresh and dried fruit. So far as known, it has not been tested in California. Both Garidel and Couverchel regarded the brebas as much inferior in quality to figs of the second crop. The former stated that the figs are sometimes spoiled by foggy weather, hence are called "Figues Neblados." The following description is after that of Trabut.

Figs pyriform, $2 \frac{1}{4}$ inches long by $13 / 4$ inches in diameter; stalk rather long; ribs elevated; eye with projecting scales, surrounded by a brown zone; skin delicate, adhering to meat, checking crisscross at maturity; white flecks present; color dull gray, tinged with violet-brown; pulp red, sweet; seeds small, numerous.

Martinique (syn. Black Martinique). Described by Ounous (1863), and by Eisen (1888, 1901, after Hogg, 1866). Introduced into California with the Chiswick collection as P.I. No. 18,884, and fruited at Niles, Chico, Fresno, and Riverside.

The tree is rather densely branched; terminal buds are brown. Leaves medium, somewhat glossy above, 3- to 5-lobed; upper sinuses moderately 
deep, rather narrow, lower sinuses shallow; base subcordate. Description is from figs produced at Riverside since 1931.

Brebas very few, or none. Second-crop figs below medium to small, up to $11 / 2$ inches in length and the same in diameter; shape turbinate-spherical to pyriform, sometimes oblique; average weight 23 grams; neck distinct, generally somewhat flattened; stalk short; ribs prominent, conspicuous on account of deeper coloration than body; eye medium, open, surrounded by a zone of lighter color, scales tinged with violet; surface dull, with fairly heavy bloom; white flecks scattered, of medium size and prominence; color purplish black, with neck remaining green; pulp light strawberry, solid; flavor rich and sweet. Quality good as a fresh fruit; external color poor when dried. See Condit (1941a, fig. 2, $G$ ).

Caprified specimens, when mature, show checked skin and dark-strawberry pulp; flavor subacid. (Plate $28, D$.)

Martinique White. Described by Eisen (1901) as a small fig, pyriform, with short neck and prominent, swollen cheeks; ribs distinct, few; eye open, large; color yellowish green, with ribs flushed violet; pulp red, well flavored. "A most excellent fig for canning."

Maure. Described by Risso (1826) as Ficus carica caffra. Figs nearly spherical ; skin thick, glossy ; color black ; bloom pruinose ; ribs narrow ; pulp light red; seeds numerous.

Meirana (syn. Ficus carica meirana Risso, according to Sauvaigo). Description by Eisen (1901), after that of Sauvaigo (1889), as a variety grown at Levens, France, producing two crops. Brebas very large, brownish black; pulp red. Second-crop figs black; pulp rose-colored.

Melagrano (syns. Franciscana, San France, Fico Unico, Fico di Spagna, Fico Robado, Ficus carica franciscana Risso, $F$. polymorpha var. haematocarpa Gasparrini). Described by Gallesio (1817), Risso (1826), Gasparrini (1845), Duchartre (1857), Pasquale (1876), Roda (1881), Sauvaigo (1889), Eisen (1901), Trabut (1904), Simonet et al. (1945), and Tamaro (1948, as Granado). Gallesio reported that Melagrano was not being grown in central Italy, but that trees were common near Genoa and in certain other localities. In southern France it was known as "Fico di San Francesco." The name Fico di Spagna is due to the fact that a variety of Valencia, Spain, was apparently identical. Trabut reported that Franciscana, or Figue d'Espagne, common in Oran, was sometimes confused with Verdale.

According to Gallesio, the tree has spreading branches and 3-lobed leaves.

Breba crop none. Second-crop figs medium, 2 to $2 \frac{1}{2}$ inches in diameter, turbinate; skin checking crisscross at maturity; color greenish violet; pulp blood red, like that of a pomegranate; good both fresh and dried. In wet weather, figs split wide open and spoil.

Melinga (syn. Figue Melingue). Described by Merlet (1667) ; his account almost exactly followed by Ballon (1692), Liger (1702), Langley (1728), and Bradley (1757).

Figs reported to be rather small, elongated; violet outside and red inside; quality excellent. Fruits tend to drop when nearly mature.

Melouba. Described by Minangoin (1931) from Gafsa, Tunisia. Leaves medium, 3-lobed; sinuses deep; petiolar sinus none. Figs medium; eye open; 
color violet, with ribs darker; pulp hollow, light rose in color; quality very good.

Mentonasca (syn. Mentone). Described by Sauvaigo (1889) and Eisen (1901) as a variety grown near Mentone and Nice, producing figs above medium in size, pyriform; skin thin, dark violet in color; pulp red.

Merengiana (syns. Marangiano, Melanciano, Melanzana, Parmigiano, Dottato Nero or Rosso, Ficus carica melitensis Risso). Described by Risso (1826), Sauvaigo (1889), Eisen (1901), Guglielmi (1908), Vallese (1909, with illustrations of leaves and fruit), and De Rosa (1911). F. carica melitensis, or Figue de Malta, described by Risso, was recorded by Sauvaigo as Merengiano. The name Melanciano implies "black," while Melanzana suggests resemblance of the color of this fig to that of an eggplant. According to Vallese, this variety is known in some districts as Dottato Rosso. Merengiana is grown to a limited extent only in southern Italy, while in France it is found along the Riviera. A variety grown by Italian residents of Washington, D.C., and called by them Eggplant or Melanzana, has fruited at Riverside, California, and proved to be the same as Franciscana.

Leaves of the tree are generally 3-lobed. Description of fruit is after that of Vallese.

Breba crop borne only in favorable years; fruit large, obconical, with rounded apex; color green, tinged with purple on exposed side; pulp pale rose, sweet.

Second-crop figs oblate-spherical (as shown in fig. 75 of Vallese); stalk short; color violet; bloom pruinose; skin readily peeled from meat; pulp light red; flavor sweet, pleasing. Consumed fresh; not much adapted to drying, as it is subject to spoilage in some seasons.

Merioun (syns. Fico Fetifero, Fico dall'Osso, Ficus carica nucleata Risso). Described by Gallesio (1817), Risso (1826), Sauvaigo (1889), Eisen (1901), and Simonet et al. (1945). This variety was described by Gallesio as Fico Fetifero, or "fetus-bearing fig," because the body of many of the fruits bore at the apex a crumpled and irregular second fruit, with scales at the base. In Piedmont it was known as Fico dall'Osso, "bony fig," on account of the hardness of the secondary fig, analogous to nut fruits, commonly called "fruit stones." This monstrosity is similar to the fruit of Caprificus gigantea (Grande), illustrated by Gasparrini in 1845, and to some of the teratological forms of figs discussed by Penzig (1922). According to Eisen, Tapa Cartin (Grosse Jaune) develops a similar monstrosity at the apex of the fruit. Gallesio reported that in spite of its malformed fruit, Merioun vied with other varieties in Piedmont, and was found along the slopes of the coastal Alps, especially at Saluzzo. Eisen, on the other hand, stated that it is a curious but not a valuable fig, and is rare in Provence.

The tree bears two crops. Description of fruit follows that of Eisen.

Brebas up to 3 inches in diameter, bell-shaped, flattened at the apex, some fruits contracted at the middle; upper part violet, lower part greenish yellow; pulp red, sweet, agreeable, but dry and hard around the eye.

Second-crop figs smaller, but similar in most characters.

Merlinga. Described briefly by Sauvaigo (1889), Eisen (1901), and Simonet et al. (1945), as grown near Nice. Figs generally borne in pairs, below 
medium, turbinate, with long, slender neck; color dark brown to violet on the neck; pulp red.

Messina. Described by Portale (1910) as Fico Messinese. A violet-colored fig, with short stalk; pulp red.

Mignonne (syn. Minion). Described by Merlet (1667), Ballon (1692), Liger (1702), Langley (1728), Hanbury (1770), and George Lindley (1831). The account of Mignonne by Merlet is more or less closely followed by the other authors. Figs small, violet-brown; pulp red, highly flavored; quality excellent.

Minuto Nero. Described by Ferrari (1912) as similar to Minuto Bianco, but black in color. Figs small, turbinate; pulp red; quality good.

Monaie. Described by Société Pomologique de France (1887, 1947) and Eisen $(1888,1901)$. Tree is of large size, producing one crop in September. Figs above medium, oblong-spherical; skin thick, bronze in color, prominently striped with violet; pulp red; quality good.

Moscatel Preto (syn. Bêbera). Described and illustrated by Bobone (1932). Known as Moscatel Preto at Coimbra, and Bêbera at Cacela and on the island of Madeira.

The tree produces two crops. Mello Leotte (1901), on the other hand, described Bêbera as a variety which does not produce a first crop, and the second crop as requiring caprification.

Brebas oblique-pyriform, sometimes much elongated; neck thick; stalk short; color violet-black; pulp dark carmine, streaked with violet; flavor sweet and agreeable.

Second-crop figs pyriform, elongated specimens unusual in having the internal cavity narrowed at the base rather than rounded; stalk short; color green toward the stalk, violet on the body; surface smooth, puberulent; pulp carmine; texture fine; quality good.

Mouissonne (syns. Mouissonne Noire, Bouissonne, Moissoa, Figue Violette, Ficus carica movissona Risso). Described by Garidel (1715), La Brousse (1774), Bernard (1787), Rozier (1805), Lamarck (1817), Duhamel (1755, 1809), Bory de Saint Vincent (1824), Risso (1826), Noisette (1829), Couverchel (1839), Audibert Frères (1854), Duchartre (1857), Hogg (1866), Du Breuil (1876), Soc. Pomol. de France (1887, 1947), Sauvaigo (1889, 1894), Eisen (1888, 1901), Colby (1894), Starnes and Monroe (1907), Rolet (1916), Mazières (1920), Leclerc (1925), Bois (1928), Simonet et al. (1945, 1947), Evreinoff (1947), and Delbard (1947). See Rolland (1914) for synonymy. Illustrated in color by Duhamel; in black and white by Eisen, Starnes and Monroe, and by Simonet.

Mouissonne is a French variety, grown in the Department of the Var, especially at Hyères, Nice, and Grasse. The only description by an author in England is that of Hogg, and the account by Eisen appears to have been compiled. Colby gives a brief description and an analysis of "Missonne," from fruits grown at Fresno, California. According to Eisen, Bouissonne was once introduced from France by Felix Gillet, of Nevada City; no trees are now known to occur in California collections.

The following description is from that of Simonet et al. (1945). Leaves are of medium size, deeply 3 - to 5-lobed. 
Brebas few, medium, pyriform; neck short; average weight 50 grams ; ribs not prominent; stalk short; eye small, with violet scales ; color violet, merging into green toward the stalk; skin checking lengthwise at maturity; pulp red, of sweet flavor and fine texture; seeds numerous, small; quality good.

Second crop abundant; figs medium, pyriform to turbinate; neck short, or none; average weight 40 grams; ribs not much in evidence; stalk short; eye in a slight depression, small, with violet scales; skin delicate, checking crisscross at maturity; color dark violet; bloom prominent, pruinose; pulp dark red; seeds small. Quality good for fresh-fruit shipments.

Mourenao (syns. Bagassa, Ficus carica mourenao Risso). Described by Bernard (1787), Duhamel (1809), Risso (1826), Noisette (1829), Couverchel (1839), Sauvaigo (1889), and Eisen (1901). See Rolland (1914) for synonymy. Illustrated in color by Duhamel. According to Risso, Mourenao is known as Bagassa in the vicinity of Villefranche. Most descriptions follow closely that of Risso.

The figs are small, globular; skin thick, checking crisscross, violet-black in color ; the pulp is white, according to Bernard and Duhamel, red, according to Risso and Eisen; quality mediocre.

Museau de Lièvre. Described and illustrated by Starnes and Monroe (1907) as a French fig of medium size, oblique-turbinate, with prominent ribs, violet-brown skin, and light-rose pulp; a shy producer. The application of the name, "rabbit's nose," is not clear.

Nain. Briefly described by Merlet (1667) as a violet fig with red pulp; same account given by Ballon (1692), Langley (1728), and Bradley (1757). Knoop (1771), however, reported that Dodonaeus, Lobel, Dalechamp, and other ancient authors mentioned Figuier Nain; but later writers were of the opinion that this dwarf fig was simply a tree, poorly nourished, as if grown in a pot.

Napolitaine (syns. Napolitano, Neapolitan). Described by Audibert Frères (1854), Duchartre (1857), Du Breuil (1876), Soc. Pomol. de France (1887, 1947), Eisen (1888, 1901), Trabut (1904), Mazières (1920), Sánchez (1922), and Blin (1942). This is probably the same as Napolitano, described and figured by Pasquale (1876), and distributed in France under the name Napolitaine. Eisen (1888) ventured the opinion that it was identical with Troiano, so widely grown and highly regarded at Naples. Troiano, however, produces no first crop, or only a scanty one, while Napolitaine is described as productive of two crops in southern France.

The tree is said to be vigorous, and very productive. The following description is after that of Société Pomologique de France.

Brebas large, elongated-oval; color green, suffused with violet-bronze; pulp red; quality fair.

Second-crop figs medium, turbinate; skin color same as brebas; pulp red, sweet; quality very good.

Negrette (syns. Negretta, Rock Fig, Ficus carica nigra Risso). Described by Risso (1826, probably), Sauvaigo (1889), Eisen $(1888,1901)$, and Simonet et al. (1945); the last with an outline drawing of the fruit. Negrette is confused with Negronne. Risso described a variety as $\boldsymbol{F}$. carica nigra, or "black fig," and referred to previous descriptions by Garidel, Bernard, and 
Duhamel, all three of whom called it Negronne. Sauvaigo, Eisen, and Simonet describe Negrette as the variety treated by Risso. Negronne is regarded here as synonymous with Bordeaux. The name Rock Fig is listed by Eisen on account of the ability of Negrette to thrive in rocky places. The following description is after that of Simonet.

Leaves small to medium, entire, or 3-lobed.

Brebas few, small; average weight 25 grams; shape turbinate to pyriform; neck none, or very short; stalk short; eye small, closed, somewhat depressed, scales violet; ribs well marked; color dark violet, with pruinose bloom; pulp red; seeds numerous; quality mediocre.

Second-crop figs much the same in fruit characters as the brebas. Sauvaigo and Eisen give the pulp as "pale yellow."

Nerolello. Described by Pasquale (1876) and Savastano (1885) as an Italian fig, medium, with long stalk; color reddish violet; pulp red. Fruit sometimes proliferated. Good for drying.

Noir Moutier. Briefly described by Eisen $(1888,1901)$ as a very rich table fig of the Loire, France, introduced into California by Felix Gillet, of Nevada City. It was found at the Pomona Experiment Station in 1897, that Noir Moutier was a large, brown fig, not yet affected by fig souring. Eisen gave the color as yellow, with red stripes. A variety labeled Noir Moutier was secured in 1927 from a grower near Pomona, who regarded it as desirable for brebas but inferior for the second crop. Trees have fruited at Fresno and Riverside. The following description is from specimens studied at Riverside since 1933.

Tree vigorous, with outer branches drooping; terminal buds green.

Breba crop fair; fruits below medium to small, turbinate to pyriform, with short, thick neck; stalk short; eye medium; ribs fairly prominent, narrow; white flecks scattered, inconspicuous; bloom delicate; color bronze, tinged with violet; meat thin, violet; pulp strawberry; texture rather dry; flavor moderately rich; quality fair.

Second-crop figs drop badly when small, but some mature without caprification; size medium; average weight 28 grams; shape spherical, without neck, or on vigorous wood with neck prominent and flattened; eye large, open, scales tinged with violet; surface somewhat glossy, with prominent bloom; white flecks large, scattered, conspicuous; color greenish violet to mahogany; pulp strawberry; quality poor.

Caprified figs somewhat larger, greenish violet in color; pulp dark strawberry; average weight 36 grams. Flavor rich and sweet, but figs are small, and of no particular value. (Plate $17, E$.)

Noral. Described by Escribano y Pérez (1884) as a Spanish variety, producing two crops.

Brebas large, of mediocre quality. Second-crop figs turbinate, $1 \frac{1}{2}$ inches long; stalk thick, short; color light green in the shade, tinged with reddish brown on the sunny side; skin checking crisscross at maturity; pulp light red. Quality good fresh; very good for drying.

Nourchi (syns. Matmata, El Hamma). Described by Minangoin (1931) from Gabès, Tunisia. Leaves medium, variable in shape and lobing, some nonlobed. Figs pyriform; stalk short; eye open; color greenish violet; pulp red; seeds few. 
Observantine (syns. Cotignana, Observantière Grisé, Ficus carica cotignana Risso). Described by Bernard (1787), Risso (1826), Sauvaigo (1889), Eisen (1901), Blin (1942), and Simonet et al. $(1945,1947)$; the last with illustration of first- and second-crop figs. See Rolland (1914) for synonymy; also, the discussion under Cordelière elsewhere in this monograph of the confusion regarding that and other variety names. A French fig, cultivated at Sollies-Pont for shipping, notwithstanding delicacy of the fruit for transport; reported by Sauvaigo to withstand the winters near Paris. Not found in California.

Tree large, upright, producing two crops; leaves 3- to 5-lobed, with long, pubescent petiole. Description after that of Sauvaigo.

Brebas large, up to $3 \frac{1}{4}$ inches in length, elongated-pyriform, broad at the apex, abruptly constricted toward the base; stalk long; skin thick, tender, checking at maturity; color green, tinged with pale lilac; pulp light red, very sweet. Much in demand as fresh fruit.

Second-crop figs smaller, lighter in color, oblong; eye surrounded by a rose-colored aureole; pulp red; quality fair. Superior for drying.

Fil de Perdrix (Eye of the Partridge, Pheasant Eye). Described by La Brousse (1774), Hogg (1866), G. S. (1869), Barron (1868c, 1891), and Eisen $(1888,1901)$. Before 1866, this French variety was introduced into England, where it fruited and received the comments of various horticulturists. Barron reported it to be similar to Ischia White in that the tree "fruited as profusely as a gooseberry bush"; the fruit had a large, prominent eye, and was of second quality. G. S. found the figs to be "without any peculiar beauty, such as one would expect from the name."

P.I. No. 18,842 of the Chiswick collection was labeled Eil de Perdrix. Scions of this variety, obtained from the Angleton, Texas, station, produced fruit in 1944 at Riverside. The following short description is from notes taken at Chico and Riverside in comparison with the account of Hogg.

Second-crop figs below medium to small, short-turbinate to oblate; neck short and thick, or none; stalk short; ribs only slightly elevated; eye medium to large, open, scales violet; surface dull; color chestnut brown to mahogany; pulp light strawberry; flavor insipid; quality fair to poor.

Caprified figs larger, with deep-strawberry pulp, rich in flavor; quality good, but figs of no particular value.

Ome (syns. Figo d'Ome; Ficus carica richeta Risso, according to Eisen). Described by Sauvaigo (1889), whose brief account is translated by Eisen (1901). Figs medium, up to 2 inches in diameter; eye red, with green iris; skin black; pulp bright red. Grown at Nice and along the Riviera.

Paradiso. Described by Cupani (1696), Gallesio (1817), Gasparrini (1845), Duchartre (1857), Pasquale (1876), Savastano (1885), Vallese (1909), Ferrari (1912), and by Tamaro (1948) as Paraíso (probably). Illustrations of leaves and fruit by Vallese. The short Latin description of this variety by Gallesio is under the heading Ficus carica bifera; he regarded the first-crop figs as better than the second. Gasparrini used the term Ficus deliciosa, with the common name Fico Paradiso; he stated that it was the belief of growers that second-crop figs required caprification.

Paradiso is a Neapolitan variety, disseminated near Genoa as Albero d'Oro. 
Trees were rare along the Riviera, according to Gallesio, but some were grown in Provence. Savastano noted that trees of Paradiso were grown primarily for production of the first crop. In his account, Vallese reported that it was well distributed in Lecce Province, but he did not give descriptive notes of the first crop.

The leaves are of medium size, generally 5-lobed.

Brebas (according to Gallesio) medium, elongated; skin green, with white flecks; meat violet, like that of Dottato; pulp light rose, delicate; flavor exquisite.

Second-crop figs (according to Vallese) turbinate, slightly oblique; ribs present on lower half of the body; stalk rather short; skin greenish yellow, shaded with violet on the ribs, especially on the sunny side; pulp wine red, very sweet. Fruit produced over a long season, from August and September to December and January. Marketed only fresh.

Pardo. Described and illustrated by Bobone (1932) from specimens collected at Loulé. Second-crop figs oblate-spherical; skin green, streaked with violet, smooth, dull; pulp carmine, coarse, soft; flavor fairly agreeable; quality mediocre.

Partridge Eye. A variety labeled Partridge Eye was introduced in 1925 from Granada, Spain, under P.I. No. 62,780. Trees, fruiting at Riverside since 1926, have produced figs different from the varieties described as Eil de Perdrix and Ojo de Perdiz. There is no breba crop, and the second crop is late in maturing.

The tree is vigorous, with spreading top; terminal buds are green.

Figs medium, obovate, with or without a short neck; average weight 30 grams; stalk up to $1 / 2$ inch long; eye small, but sufficiently open to admit dried-fruit beetles; surface somewhat glossy, with delicate bloom; color greenish violet; pulp light strawberry; texture dry, somewhat mushy; quality fair. At Los Angeles, most of the fruits shrivel and drop without reaching perfect maturity.

Caprified figs larger, with dark-strawberry pulp ; not improved by caprification. $\Lambda$ worthless fig in California. (Plate 28, A.)

Pastilière (syns. Pastidière, Pastellière, Hirta, Hirta du Japon, del Giappone, Japanese, Ficus hirta). Pastilière is described by G. S. (1869), Colby (1894), Forrer (1894), Trabut (1904), Eisen (1897, 1901), Condit (1921b, 1947), and Braunton (1936). Hirta is described by Barron (1891), Eisen (1888, 1901), Shinn (1893, 1903, 1915), Colby (1894), Forrer (1894), SimonLouis Frères (1895), Price and White (1902), Starnes (1903), Starnes and Monroe (1907, with figure), and Blin (1942).

The origin and identity of the variety Pastilière are somewhat in doubt. Eisen (1888) listed it as coming from Italy, but in his later publication he omitted any reference to its origin. It is illustrated and described in Eisen's bulletin of 1901, with the following comment: "If the writer could plant only one blue variety, it would certainly be this fig. The fine form of the tree, its abundant cropping, and the superior quality of the fruit should make this fig a favorite all over the Pacific Coast."

Pastilière was grown and tested at the California Experiment Stations from 1891 to 1903, with reports such as the following: At Jackson, the best 
black fig; at Paso Robles, a very desirable variety; at Tulare, ranked first with Hirta du Japon so far as bearing was concerned; at Pomona, Hirta du Japon was a heavy producer in 1892 , but in 1895 was utterly worthless, as the figs soured and rotted on the tree. In 1894, Hansen reported Pastilière as the best black fig at the Foothill station. P.I. No. 18,888 of the Chiswick collection was labeled Pastilière. According to notes taken at Chico in September, 1921, fruits of this introduction were small, purplish black, and of no particular value, either fresh or dried. A commercial planting of Pastilière, consisting of about eighty trees, was maintained for several years at the Point Loma homestead, San Diego. The crops of fresh figs during the fiveyear period, 1921 to 1925 , varied from 3,900 to 8,580 pounds, obtained from the single crop ripening in August. Another small planting was made at Vacaville, but there the variety was found to be inferior to Mission (Franciscana).

According to Simon-Louis Frères (1895), Hirta is a Japanese variety, introduced into France by M. de Siebold. Barron described it in 1891 as one of Rivers Brothers' introductions. Trabut (1904) stated that it had been brought only recently into Algeria. In California, it was described by Eisen in 1888 as "a fruit covered with a downy fuzz." In 1901, he described it as a purple fig, with "skin smooth, but not waxy ; not downy, even when magnified," and added that there was reported to be another Hirta with downy fruit, also from Japan. Colby (1894) gave analyses of the fruit from Tulare County. Shinn $(1903,1915)$ stated that Hirta du Japon is a dark-purple fig, of high quality for home gardens. Hirta du Japon, obtained in 1920 from J. C. Shinn, Niles, has proved to be identical with Pastilière in variety tests. It was included in the Chiswick collection from England as P.I. No. 18,857.

Various accounts report that the tree of Pastilière is of slow, compact growth, so that it might be called a dwarf tree. G. S. (1869) stated that both tree and leaves were ill-shaped, and that most of the fruit dropped off, imperfect. At Riverside, two trees of Pastilière and one of Hirta, all planted in 1928, have been decidedly dwarf in habit of growth. Furthermore, both trunk and branches show prominent nodal swellings characteristic of this and of certain other varieties. (Plate 5.)

Terminal buds are plump, short, and green in color, tinged with brown. Leaves below medium to small, mostly 3-lobed, but many nonlobed; upper sinuses shallow, basal sinuses shallow and broad; base sometimes truncate; surface slightly glossy; margins coarsely serrate. The following description is based mainly on fruit produced by Pastilière trees obtained in 1920 from the California Nursery Company, Niles.

Brebas none, or rare. Second crop abundant. Figs medium, 11/2 to $21 / 2$ inches in length and about the same in diameter, turbinate or oblate; weight of individual fruits from 27 to 55 grams; neck absent, or when present, short and thick; stalk purple, thick, sometimes prominently enlarged toward the apex, up to 1 inch in length, loosely attached to the twig, so that figs seldom dry on the tree, but drop when mature; ribs narrow, slightly raised, conspicuous on the immature fruit because of earlier coloration than body; eye large, open, scales purple, with scarious margins; surface dull, with very conspicuous, pruinose bloom, thickly studded with prominent, harsh hairs 
(hence the variety name Hirta); white flecks large, conspicuous at first, but finally obscured by body coloration; skin fairly tender, checking crisscross at maturity; color purplish black; meat white; pulp gelatinous in texture, light strawberry in color, hollow at the center; flavor insipid, watery. Seed coats not at all developed, or only partially so ; pulp is therefore almost seedless. Quality at Riverside fair to poor. See Condit (1941a, fig. 2, $C$ ). (Plates $10 ; 28, E$.)

Caprified figs somewhat larger, with dark-strawberry pulp and large, fertile seeds.

A fig of no value for drying and of little value for fresh fruit, on account of variable sizes, loose stalk, prominent spicules on the skin, and insipid flavor.

Peau Dure (syns. Dure Peau, Peldure, Peau d'Âne). Described by La Brousse (1774), Audibert Frères (1854), Hogg (1866), Soc. Pomol. de France (1887, 1947), Barron (1891), Eisen (1901), Starnes and Monroe (1907, with illustration), and E. A. Bunyard (1925). The synonym Verte Brune is ascribed to this variety by some authors, but is treated in this monograph as a distinct kind. According to La Brousse, the name Peau Dure referred to the close adherence of the firm skin to the meat; he added that the fresh figs sold in French markets at prices sometimes double those of other varieties.

The identity of Peau Dure in California collections is in doubt. P.I. No. 18,838 of the Chiswick collection proved to be the same as Drap d'Or and Royal Vineyard, which belong to the San Pedro class, as described elsewhere. The Peau Dure of French authors apparently bears two crops. The latest account, that of Société Pomologique de France (1947), is followed here.

The tree is described as medium in size, vigorous, and very productive.

Brebas medium, pyriform; skin glossy, firm; color brown, flushed with olive green; pulp reddish, slightly acid in flavor; quality very good.

Second-crop figs smaller, rounded at the apex, the body abruptly narrowed into a long neck; skin firm; color olive, tinged with violet in the sun. Resistant to rain damage; excellent for drying.

Pecciolo Nero. Described and figured by Baldini (1953) from Firenze, Italy; producing one crop only.

Tree with spreading branches; terminal buds light rose in color. Leaves mostly 5-lobed; middle lobe spatulate, obtuse, basal lobes often fused with the middle ones; base shallowly cordate; upper sinuses deep and open.

Figs pyriform, with short, slender neck; stalk slender, recurved; eye small, closed, obscurely violet; skin checking at maturity, almost black; pulp solid (probably red). Consumed fresh, and sometimes dried. More highly regarded than Pecciolo Bianco.

Peconjudo (syns. Pédonculée; Peconjude Grisé; Peconjano ; Pecouliano; Ficus carica longicaudata Risso, according to Eisen). Described by Risso (1826), Duchartre (1857), Du Breuil (1876), Eisen (1888, 1901), Sauvaigo (1889), and Simonet et al. (1945). This variety is not represented in California collections, and apparently has not been grown in England. The following description is adapted from that of Simonet, who gives Fayence as the locality in France where it is grown. 
The tree produces no brebas. Leaves are small, and deeply 3-lobed.

Second-crop figs medium to small, up to $1 \frac{1}{2}$ inches in diameter and $13 / 4$ inches in length; shape pyriform, with neck absent, or not prominent; average weight 25 grams ; stalk long ; ribs not much in evidence; eye small, closed, scales rose-colored; skin firm; color yellowish green, slightly tinged with blue or burnt umber; pulp red; quality good; seeds small, numerous.

Pedral. Described and figured by Bobone (1932) as a Portuguese variety, bearing two crops. Brebas turbinate to oblong, yellowish green, with violet spots. Second-crop figs oblate-spherical; stalk short; pulp carmine, coarse; quality fair.

Penna (syn. Fico Rescio at Mesagne). Described and illustrated by Vallese (1909) ; collected at Torre Penna on the Adriatic coast, north of Brindisi.

Leaves 3- to 5-lobed. Crops two, but brebas not available for description.

Figs globular, without neck; ribs slightly elevated; skin tender, with scattered white flecks, checking at maturity; color green toward the stalk, violet on the body, especially on exposed side and on ribs; pulp rose-colored; flavor sweet, subacid.

Pentolello. Described by Savastano (1885) as a variety grown at Sorrento, Italy, producing abundant crops. Figs medium, turbinate; skin black, checking at maturity; pulp rose-colored. Good for table use.

Perouas (syns. Velue, Peloua, Ficus carica pilosa Risso). Described by Bernard (1787), Duhamel (1809), Bory de Saint Vincent (1824), Risso (1826), Noisette (1829), Couverchel (1839), Dochnahl (1855), Sauvaigo (1889), Eisen (1901), and by Starnes and Monroe (1907). Eisen listed the names Cortice Crasso, Setosa, and Velvet as synonyms, but did not give their origin or meaning; he stated that the spelling, Perouas, was "probably an error for Pelouas." However, the earliest reference found to this variety, that of Bernard (1787), gave it as Perouas, signifying "hairy," on account of the prominent pubescence. No record has been found of any introduction of Perouas into the United States, and the description by Eisen is evidently taken from French authors. In fact, the account by Duhamel (1809) is almost identical with that of Bernard.

The tree is reported to be productive, and not particular as to soil conditions. Leaves are 5-lobed.

Figs are above medium, pyriform; skin tender, pubescent; color violetbrown; pulp pale rose. Consumed fresh.

Perroquine (syns. Perruquière, Violette Perruquine, Argusela, Douqueira, Douqueira Negra, Peroquina, Monginenco ["in the vicinity of Grasse"], Ficus carica nicaeensis Risso). Described by Bernard (1787), Duhamel (1809), Risso (1826), Noisette (1829), Couverchel (1839), Duchartre (1857), Hogg (1866), Sauvaigo (1889), Eisen (1888, 1901), Trabut (1904), and Simonet et al. (1945). Illustrated by Duhamel in color ; by Eisen and Simonet in black and white. Douqueira Negra and Perroquine are treated as distinct varieties by Eisen, but are regarded as synonymous by Simonet. According to Sauvaigo and Risso, Douqueira originated near Nice (hence the name $F$. carica nicaeensis), where it was regarded as one of the oldest and best-known figs of the district.

The tree produces two crops, of which the first is the most important. 
Leaves are of medium size, 3- to 5-lobed. Description is after that of Simonet, from specimens grown at Villefranche-sur-Mer.

Brebas medium, 21/2 inches long by $1 \frac{1}{2}$ inches in diameter ; average weight 35 grams ; shape elongated-pyriform; neck gradually tapering from body of fig to the stalk; ribs present, extending from stalk to apex; eye in a slight depression, closed, with violet scales; surface finely pubescent, with pruinose bloom; color reddish violet, with lighter shade toward the stalk and on side not exposed to the sun; skin adhering to the violet meat; pulp red, solid, not very juicy; seeds small, rather numerous ; quality fair to good.

Second-crop figs much smaller than brebas, pyriform; color uniformly violet-black, pruinose; skin not checking at maturity; pulp red. Quality only fair fresh, but good when dried.

Pissalutto Nero (syns. Pissalutto Negro, Pittalusse Noire, Sarnese Nero, Suffren, Ficus carica suffrenia Risso). Described by Gallesio (1817), Risso (1826), Semmola (1845), Eisen (1901), and Simonet et al. (1945). According to Gallesio, this variety is grown near Genoa, but is inferior to Pissalutto Bianco. The following description is from that of Simonet, taken from trees growing near Antibes, France, yielding one crop only in late September.

Second-crop figs medium, pyriform, with prominent, slender neck; stalk long, readily detached from the twig; eye small, open, scales pink; ribs slightly elevated; color dark violet, shading to green toward the stalk; pulp red; seeds small, numerous; quality good.

Poona. Described briefly and illustrated in color by Naik (1949), as the most prolific variety on the plains of India. Figs medium, oblique-pyriform, light purple; pulp rosy, sweet and well-flavored.

Poulette. Described by Audibert Frères (1854), Duchartre (1857), Hogg (1866), Du Breuil (1876), Soc. Pomol. de France (1887, 1947), Eisen (1888, 1901), Barron (1891), and Wright (1894). Poulette is a French fig, reported by $\mathrm{Du}$ Breuil to be cultivated at Tarascon and Salon, producing two crops. British authors describe second-crop figs as handsome, and of excellent quality. It was introduced into California in the Chiswick collection as P.I. No. 18,841; at Chico, both in tree and fruit, it was similar to No. 18,842, Eil de Perdrix. In 1940, trees in the variety collection at Angleton, Texas, produced bronze figs, with large, open eyes. Poulette has been fruiting at Riverside since 1931, and the following account is based on its behavior there.

The tree is upright, and rather open in habit of growth; terminal buds are green in color. Leaves medium, somewhat glossy above, mostly 5-lobed; upper sinuses rather deep and narrow, lower sinuses of medium depth; middle lobe broad, spatulate, often auricled, especially on leaves of sucker wood; basal lobes sometimes auricled; base subcordate; margins coarsely crenate.

Breba crop none. Second crop fair to good; figs variable in size, from small to above medium, up to 2 inches in diameter and $13 / 4$ inches in length; shape mostly oblate to short-turbinate, with neck generally absent, or sometimes short and thick; stalk short, or in some specimens $1 / 2$ inch long; ribs present, but not prominent; eye medium to large, open, scales violet; surface dull, with delicate bloom; white flecks large, scattered; color bronze to greenish violet; meat white; pulp light strawberry; seeds small, only partially sclerified; quality fair to poor. (Plates $9 ; 27, F$.)

Caprified figs are larger; color purplish black, tinged with green; pulp 
dark strawberry; quality fair to good. Mature fruits tend to split badly at the apex.

A variety of no importance in California, either fresh or dried, on account of small size, poor color, and mediocre quality.

Praecox (Ficus carica praecox Risso). Under this name Risso (1826) described a variety bearing two crops. Second-crop figs were small, spherical to oblong, black in color, with red pulp; brebas were larger, long-stalked, with large eye. Some specimens showed malformations.

Précoce de Barcelona. Described by Starnes and Monroe (1907, with figure), Reboul (1908), and by Grasovsky and Weitz (1932). The origin and identity of this variety have not been revealed. The Georgia material tested by Starnes and Monroe was obtained from Nabonnand and Co., Alpes Maritimes, France. In 1928, rooted cuttings of Précoce de Barcelona were introduced by the United States Department of Agriculture from the same nursery, under P.I. No. 69,019. It has been fruiting at Riverside since 1931; notes taken during the intervening years show the characters given below.

Tree fairly vigorous; terminal buds violet-brown. Leaves medium, somewhat glossy, mostly 5-lobed; upper sinuses of medium depth and width, lower sinuses shallow; basal lobes commonly auricled; basal sinus cordate, often narrow; margins coarsely crenate.

Breba crop small to fair; figs medium, turbinate, with short, thick neck; stalk up to $1 / 4$ inch long, swollen toward the body of fruit; eye large, open; color purplish black; pulp light strawberry. Season early, figs commonly beginning to ripen two weeks ahead of Franciscana.

Second-crop figs small, $1 \frac{1}{2}$ inches in length and diameter; average weight 25 grams; shape spherical, with neck mostly absent; stalk up to $1 / 2$ inch long, often showing a peculiar split or crack, extending into the base of the fruit; surface glossy, black, with conspicuous pruinose bloom; skin checking at maturity; pulp light strawberry; flavor rich, distinct, much like that of Franciscana; quality fair to good. See Condit (1941a, fig. 2, A).

Caprified figs are much the same, except for the darker strawberry pulp and fertile seeds. The statement of Starnes and Monroe, "but for its small size would be promising," may well be repeated here.

Pregussata (syn. Pergussata). Described by George Lindley (1831), Holley (1854), M'Intosh (1855), Thompson (1859), Hogg (1866), White (1868), Eisen (1888; 1901, with illustration), Watts (1890), Starnes (1903), and by Starnes and Monroe (1907). According to Lindley, this most beautiful and excellent fig was sent to England from the Ionian Islands, and was listed as No. 57 in the catalogue of the Royal Horticultural Society. Although described by Hogg as producing luscious figs, it was not included in the Chiswick collection that was sent to the United States. Eisen, in 1888, used the spelling Pregussata for the variety name, but in his bulletin of 1901 he gave it as Pergussata. All other authors list it as Pregussata. The description by Hogg was copied by Eisen, who stated that "this is probably the true Pergussata, received from England under that name." No later account of the variety in California has been found. Starnes reported that Pregussata was worthless in Georgia, because trees never matured a crop in that state.

Second-crop figs are described as medium, oblate, dark brown, tinged with purple; pulp dark red; flavor sweet and rich. 
Preston (syn. Preston Prolific). Described by Anon. (1949) as a promising seedling fig, first fruited in 1943 at Preston, Victoria, Australia, by R. N. Jones. Figs are medium to large, oblate, without neck ; stalk very short ; color bronze; pulp amber, tinged with red. Satisfactory for jam.

Qeisi (syn. Mrari). Described by Grasovsky and Weitz (1932) as a Palestinian variety, bearing poor crops of small, dark-purple figs, with long, thick stalk, short neck, and light-red pulp; quality inferior.

Ramsey. Described by Gould (1923) and Close (1929) as a seedling fig, grown in 1908 by the nursery of F. T. Ramsey and Son, Austin, Texas, and introduced to the trade in 1915. The 1925 catalogue of the Austin Nursery stated that Ramsey is a seedling which "resembles Magnolia, but does not crack open." California tests of Ramsey, obtained from various sources, lead to the conclusion that it is very similar to, if not identical with, Brown Turkey of England and the southeastern United States. The Pacific Rural Press, September 19, 1925, reported it as a "new seedless fig" of fine flavor, at Burbank, California.

Recousse Noire. Described by Audibert Frères (1854), Hogg (1866), Du Breuil (1876), and Eisen (1888, 1901, after Hogg). This variety was included in the Chiswick collection as P.I. No. 18,881, and was grown at Niles and Chico; at the latter place, on September 14, 1921, the crop was practically all on the ground, and the dried figs were of a dirty-brown color. At Menlo Park, Recousse Noire proved to be a large, black fig, disappointing in quality.

Fruits produced at Riverside, California, since 1937 have furnished the data that follow.

The tree has slender, somewhat drooping branches. The terminal buds are brown.

Breba crop none. Second-crop figs medium, pyriform, with short, thick neck; stalk medium; ribs narrow, not prominent; eye medium, open; color purplish black, shading to green on the neck; pulp strawberry; flavor rich. Quality good fresh, but dried figs are not black in color. Variety discarded as not equal to Franciscana in quality.

According to Eisen, Recousse Violette is similar to Recousse Noire, but with deep-red pulp.

Regina (syn. Reina). Described by Gallesio (1817), Gasparrini (1845, as Ficus pachycarpa var. nobilis), Pasquale (1876), Roda (1881), and Tamaro (1948, with figure), but apparently ignored by other authors. It was highly praised by Gallesio, who stated that the markets in Rome were well supplied with its fruits in September.

Breba crop none. Second-crop figs large, pyriform; skin color light violet, with delicate bloom; pulp pomegranate red; quality good.

Rei. Described by Bobone (1932) from specimens obtained in various districts of Portugal. It is also known as Figo de Torres.

Brebas oblong-turbinate, $3 \frac{1}{2}$ inches long by $2 \frac{1}{2}$ inches in diameter; skin smooth, glossy, checking; color green, spotted with violet; pulp carmine; flavor agreeable.

Second-crop figs medium, turbinate; skin rugose, checking at maturity; color greenish violet; pulp light red, of fine texture; quality very good. 
Rocarde. Described by La Brousse (1774), Shinn (1893), Forrer (1894), and Eisen (1901, spelled Rocardi). This variety was grown at the California Experiment Stations from 1890 to 1903. Shinn reported as follows: "Two figs, as grown at the Stations, appear much alike; they are the De Constantine and Rocarde. The skin is black and green striped; the flesh is coarse, though rich; the seeds are large; and the type appears to be like the old Mission fig. The green color forms a blotch at the calyx, and then runs in narrowing bands toward the stem. The trees appear to grow somewhat differently."

At Tulare the tree bore excellent crops, but the quality of fruit was distinctly second-rate. The following description is after that of Eisen.

Figs small, pyriform, with very short stalk; eye small, sunken; skin smooth, with indistinct ribs; color violet-purple; bloom delicate; pulp light red, solid.

Rondeletta. Described briefly by Sauvaigo (1889) and Eisen (1901) as a globular fig, with skin green, shaded brown; pulp red. Grown near Nice, France.

Rondella Negra. Described briefly by Sauvaigo (1889) and Eisen (1901) as a fig below medium in size, turbinate, with a long neck; eye reddish violet; skin purplish black; pulp red. Grown in the vicinity of Mentone, France.

Ronde Rouge. Described by Barron (1891) and Eisen (1901, after Barron) as a medium fig, with dull, tawny-red skin and red pulp.

Rosa. Described by Guglielmi (1908) as a variety from Surbo, Italy, maturing one crop in August. It is obviously different from the Smyrna-type fig described by Vallese. Figs are large, oblate, violet in color ; pulp red. Consumed fresh.

Rose Blanche (syn. La Rousse). Described by Garidel (1715), Bernard (1787), Rozier (1805), Duhamel (1809), Couverchel (1839), Duchartre (1857), Du Breuil (1876), Colby (1894), and Eisen (1888, 1901). In his account, Bernard quated the original Latin description by Garidel, and designated the variety as Rose Blanche rather than Figuo Roso. Rozier also quoted Garidel, but used the common name La Rousse without specifying its significance. Like Rose Noire, this variety is commonly grown in southern France. In 1893, Colby received for analysis figs labeled Rose Blanche from Fred Roeding, Fresno, California; they were of a dark-purple color, which leaves doubt as to their identity.

Various accounts give second-crop figs as very large, spherical, flattened at the apex; stalk long; color greenish brown; pulp red. Good for drying.

Rose Noire (syns. Cuou de Muelo, Rolandine Noire, Ficus carica rosa nigra Risso). Described by Garidel (1715), La Brousse (1774), Bernard (1787), Lamarck (1817), Risso (1826), Duhamel (1809), Noisette (1829), Couverchel (1839), Eisen (1901), and Simonet et al. (1945). See Rolland (1914) for synonymy of Cuou de Muelo. Illustrated in color by Duhamel; in black and white by Eisen and by Simonet. The original description by Garidel stated that growers knew this variety as Cuou de Muelo, a Provençal name, apparently referring to the distinctive neck of the fruit. Bernard and all later writers refer to it as Rose Noire. It is ranked as one of the better figs of Provence. The following account is after that of Simonet. 
Leaves medium, deeply 5-lobed. Breba crop none. Second-crop figs pyriform, medium in size, up to $21 / 4$ inches long and $13 / 4$ inches in diameter; average weight 40 grams; neck not especially prominent; stalk short; ribs not much in evidence; eye slightly protruding, small, closed, scales violet; skin thin, checking lengthwise at maturity; color bronze, tinged with violet; bloom pruinose ; pulp amber to light rose; seeds small, not numerous ; quality very good.

Rose Peyronne. Described by Hogg (1866) and Eisen (1888, 1901). According to Hogg, this variety "is distinct from Brunswick, with which it is made synonymous in the Horticultural Society's catalogue and in the first edition of this work." (The Fruit Manual.)

Figs medium, obovate; stalk up to $1 / 4$ inch long; color pale brown; bloom delicate; skin checks crisscross at maturity; pulp pale salmon in color; flavor rich and sweet.

Roussale. Briefly described by La Brousse (1774) as a spherical fig, red outside and pale red inside.

Roussana. Described briefly by Sauvaigo (1889) and Eisen (1901) as cultivated near Nice, France. Second-crop figs medium, reddish violet in color, with red pulp.

Roxo de Valinhos. Described briefly by Clemente et al. (1953). Reported to have been obtained from Italy several years ago, and now it constitutes 98 per cent of the production of fresh figs in the vicinity of São Paulo, Brazil. Similar to, and possibly identical with, San Piero.

Second-crop figs large, pyriform; stalk short; eye large, open; color purplish black; pulp rosy, with hollow center; quality good.

Royal (syns. Obispo, Trojano di Napoli, Tassa Brown, Geraci Black). In 1932, fig scions labeled Obispo were received from Millard Sharpe, Vacaville, California, and grafted into a Dottato tree. Fruit produced since 1933 has proved to be very similar to that of Dauphine, but both crops of Obispo set and mature without caprification, while the second crop of the former requires it. This same variety was imported from Italy in 1933 by Pasquale Caloia, Los Angeles, under the designation Trojano di Napoli. It has been propagated and distributed by Armstrong Nurseries, Ontario, under the name Trojano, as a black fig with amber pulp.

This variety has apparently also been introduced by various Italian residents of the District of Columbia. Through the courtesy of H. R. Fulton, recently retired from the United States Department of Agriculture, Beltsville, Maryland, cuttings have been received from six different sources in the District. In 1947, Fulton wrote as follows about the tree on the property of Mr. Gerald Tassa, 631 Maryland Avenue, S.W., Washington: "The three varieties from Mr. Tassa were said by him to have been brought from Italy in 1894 by his elder brother. We have on file here a color painting made in 1910 of the 'Tassa Brown,' furnished by Amato Tassa from the original home address in Washington. This bears the name 'Royal Black,' and it is the name that the first members of the family applied to the variety." The true identity of the variety has not been learned, but at Mr. Fulton's suggestion, it is here designated as Royal.

Breba crop fair; figs above medium, turbinate, with or without short, 
thick neck; stalk often prominently swollen; surface glossy, with conspicuous white flecks ; eye above medium ; upper half of body purplish black, lower half green, with violet ribs; pulp strawberry, coarse.

Second-crop figs above medium, oblate-spherical to turbinate; neck mostly absent; average weight 56 grams; ribs prominent, on account of earlier coloration than body; eye above medium; color Dusky Slate Violet (Ridgway, 1912); pulp light strawberry to almost amber; texture gelatinous; flavor sweet, fairly rich; quality fair. (Plate $26, B$.)

Caprified figs with dark-strawberry pulp; otherwise, much the same as uncaprified fruit.

Rubado Negro (syns. Roubauda Negra, Ficus carica serotina Risso). The description by Risso (1826) did not list any common name for this variety. Sauvaigo (1889) gave the name as Roubauda Negra, and Eisen (1901) as Rubado Negro. It may be the same one which Porta (1583) referred to as serotina, a late fig with hard skin. No later accounts can be found. The term serotina signifies "late"; the three authors agree that this variety produces a crop late in the season-October and November-in southern France and northern Italy.

Second-crop figs are above medium, $2 \frac{1}{4}$ inches in diameter, turbinate; eye with reddish-brown iris; skin firm or hard, dark brown to black in color; pulp red.

Saint-Esprit. Described by Garidel (1715), Rozier (1805), Duhamel (1809), Lamarck (1817), Risso (1826, as Ficus carica spiritus-sancti), Noisette (1829), Couverchel (1839), Duchartre (1857), Du Breuil (1876), and Eisen $(1888,1901)$. This variety is reported as commonly grown in the vicinity of Pont Saint-Esprit, France, hence the name.

The tree bears two crops of figs that are inferior in quality. Second-crop figs large, pyriform; stalk long; skin checking, adherent to the meat, dark violet in color; pulp light red; flavor insipid.

Saint Jean (syns. Grisé de Saint Jean, Saint Jean Gris, Grisé, Grisé Savantine Bifère, Grisé Madeleine, Grosse Grisé Bifère, Ficus carica grisea Risso). Described by Liger (1702), Knoop (1771), La Brousse (1774), Risso (1826), Barron (1891), Colby (1894), Eisen (1888, 1901), Stubenrauch (1903), Starnes and Monroe (1907), and Condit (1947). Figured in black and white by Eisen and Starnes; shown in color by Condit (1941a). See comments (next page) on the name Grisé. According to La Brousse, Figue Grisé matures the first crop in June at Saint-Jean, although he did not specify the exact location of this French town. The fruits of Saint Jean, as grown in California, are of medium size or above in the first crop, and small to below medium in the second crop. The variety described under the same name by Eisen as having very large figs may be a different one. Saint Jean is listed by Simonet et al. (1945) as a synonym of Cotignana, which is described in this monograph under Observantine.

The following accessions to California plots of fig varieties have proved to be identical in tree growth and fruit production: P.I. No. 18,865, Grisé Savantine Bifère, in the Chiswick collection from England; No. 69,015, Grisé de Saint Jean, from a French nursery in 1926; No. 86,806, Grisé Madeleine, from Yalta, Crimea, in 1931; also No. 102,011, Saint Jean, and No. 
102,014, Grosse Grisé Bifère, both from Marrakech, Morocco, but reported to be originally in a collection of figs from Lérida. In 1895, notes made by John Rock at Niles on Grosse Grisé and Grisé Savantine, showed that these two were the same. The variety was grown and tested by the California Experiment Stations, and found to be especially good at Pomona, because the figs did not sour while on the tree. One distinctive characteristic of second-crop fruit, as mentioned by Eisen, is the very sharp demarcation which separates the body surface, with its heavy bloom, from the apex, which is devoid of bloom. This peculiarity is illustrated in plate 12, showing Figue Fleur. The variety is found in California only in collections, although it is well worthy of culture in dooryards for its excellent fruit.

The tree of Saint Jean is only moderately vigorous, partly because of its extreme susceptibility to leaf mosaic (plate 13); it produces two crops. The leaves are medium to small, light green, 3- to 5-lobed; upper surface dull to somewhat glossy; upper sinuses shallow, of medium width, lower sinuses shallow; base deeply subcordate, often auricled; margins coarsely crenate. Description is from figs produced at Riverside since 1932, and at Fresno in the season of 1953 .

Breba crop fair; fruits medium, up to $23 / 8$ inches long and 2 inches in diameter, oblique-turbinate to pyriform; average weight 42 grams; neck variable, sometimes prominent and flattened to thick and short, or absent; stalk thick, up to $1 / 4$ inch long; ribs present, but inconspicuous; eye rather large, open, scales violet, erect at maturity; white flecks small, masked by body color; color delicate grayish bronze; bloom fairly prominent; skin checking irregularly at maturity ; meat white; pulp light strawberry; flavor rich and sweet; quality excellent; seeds medium, tender. (Plate 23, $B$.)

Second-crop figs smaller than brebas, but much the same in other characters; average weight 31 grams; neck, if present, very short and thick; bloom conspicuous on body, but absent from apex in many specimens; color a delicate violet-gray, attractive; pulp strawberry; flavor excellent.

Caprified figs somewhat darker in skin color; pulp deeper strawberry; seeds numerous, fertile. An excellent fig for fresh-fruit consumption, and usually dries without much spoilage. Too small for commercial use. (Plates $9,23, E$.)

A variety with the common name Grisé was described by Risso (1826) as Ficus carica grisea, but later authors apparently ignored the description, or at least failed to refer to it. Eisen (1901) reported that the name Figue Grisé is a synonym for three different varieties: Beaucaire, Cotignana, and Matarassa. (For synonymy, see list at end of description section.) The fruit of Grisé de Saint Jean as grown in California compares so favorably with the description of Grisé by Risso that in this monograph these two are regarded as synonymous, and are described under the name Saint Jean. Figue Grisé, described by Merlet (1667), La Quintinie (1692), and a few other early authors, might properly be referred to as Saint Jean rather than Angélique.

Saint Ursule d'Avignon. Described by Hogg (1866), and Eisen (1888, 1901, after Hogg), as a fig below medium, oblong, without neck; color bronze; pulp pale red; flavor rich. 
Salada (syn. Ficus carica purpureo-violacea Risso, according to Eisen). Described by Sauvaigo (1889) and Eisen (1901) as a French variety, bearing two crops at Nice and along the Riviera.

Second-crop figs pyriform, with the body abruptly narrowed into a neck; size above medium; skin color light purplish black; pulp red.

Sang de Lièvre. Described by Soc. Pomol. de France (1887, 1947), Eisen $(1888,1901)$, and by Starnes and Monroe (1907, with figure of fruit). The name means, literally, "blood of the hare," apparently referring to the deepred color of the pulp. The following account is taken from that of Société Pomologique de France.

Tree produces two crops.

Brebas oblique-turbinate; color bright green; pulp blood red, sweet, of good quality.

Second-crop figs above medium, pyriform; color green, flushed with bronze; white or tawny flecks scattered; pulp dark red; quality very good. Season September to October.

San Piero. Described as San Piero by Gallesio (1817), with the following synonyms: Corbo at Pescia, Piombinese at Pisa, Nero at Massa and Sardegna, Rubicone in Lunigiana, Arbicone at Genoa, Minna di Schiavo in Sicily, Fallugiana at Abruzzes, Aubique Noire in Provence, and Breva Negra in Spain. See also Rolland (1914) for synonymy.

This variety is described as Corbo by Porta (1592); as Grosse Violette Longue by La Quintinie (1692), Ballon (1692), Garidel (1715), Tournefort (1719), Merlet (1740), Knoop (1771), La Brousse (1774), Mirbel (1802), Rozier (1805), Lamarck (1817), and Bory de Saint Vincent (1824); as Genoa Black by Langley (1728), Miller (1768), Hanbury (1770), Forsyth (1803), Green (1824), George Lindley (1831), Rogers (1834), Hogg (1866), White (1868), Massey (1893), and Wright (1894); as San Piero or Sampiero by Tanara (1651), Gasparrini (1845, under Ficus polymorpha var. bifera), Semmola (1845), Pasquale (1876), Roda (1881), Savastano (1885), Condit (1944, 1947), and Baldini (1953); as Aubique, Aubique Noire, Aulique, Abicou or Abicou Noir by Bernard (1787), Duhamel (1809), Noisette (1821), Couverchel (1839), Audibert Frères (1854), Sauvaigo (1889), Trabut (1904), Starnes and Monroe (1907), Blin (1942), and Simonet et al. (1945); as Albacor or Aubaco by Estelrich (1910); as Ficu Minni di Scava by Cupani (1696); as Negro Largo by Hogg (1869), Moore (1872), Hyde (1877), Barron (1869a, 1891), Coleman (1887b), Wright (1894), Forrer (1894), Wythes (1890a, 1902), Thomas (1902), Stubenrauch (1903), Bunyard and Thomas (1904), Starnes and Monroe (1907), Royal Hort. Society (1916), E. A. Bunyard (1925, 1934), Arnold (1926), Davis (1928), and Fruit-Grower (1936); as Grosse Rouge de Bordeaux by Delbard (1947); as Negro d'Espagne by Hogg (1866) and Barron (1891); as San Pedro Black by Eisen $(1888,1901)$ and Kirkman (1922); as Portugal Black by Eisen (1901); as Brown Turkey by West (1882) and Condit $(1921 b, 1922 b, 1933)$; as Douro Black by Wright (1894) and Eisen (1901); as Fico Nero by Vallese (1909); as Ficus carica violacea by Risso (1826); and as Breva Negra by Tamaro (1948). Eisen regarded Grosse Violette de Bordeaux as a synonym. Illustrations in color by Duhamel, Noisette, Hyde, Moore, Wright, Condit 
(1941a), and Delbard. Illustrations in black and white by Gallesio, Semmola, Hogg (1869), Eisen (1901), Starnes and Monroe, Vallese, Condit (1921b, 1933), E. A. Bunyard (1934), Tamaro, and Baldini.

The history and identity of San Piero have been reviewed by Condit (1944) ; from this account we glean the following notes. According to Gallesio, this variety has been commonly grown in Italy, southern France, and in Spain. It appeared in England about 1866 under the name Negro Largo; Mr. Fleming at Cliveden received it from France, and it was later distributed by the firm of Veitch and Sons, Chelsea. The identity of Negro Largo with San Piero was confirmed by E. A. Bunyard (1934), who agreed with Hogg that it was known in France as Noire de Languedoc. The description of San Pietro or Mecklingea by Glady (1883) conforms more with San Piero than with San Pietro. In Japan, San Piero is grown under the name Masui Dauphine. San Piero trees have been found in the eastern United States at the following places: Saxis, Hampton Institute, and Diamond Springs, Virginia ; and Accomac and Crisfield, Maryland. At Crisfield, San Piero is being grown commercially.

The date of first introduction of San Piero into California is not known with certainty. John Rock of Niles received Negro Largo from England in 1883; he obtained "Aubique Leroy" from France in 1889-the last part of the name was probably a mistinterpretation of Noire. San Piero cuttings were distributed by the United States Department of Agriculture, according to Van Deman (1890), although no localities were listed as recipients. The Chiswick collection from England included the following: P.I. No. 18,872, as Large Black Douro; No. 18,882, as Black Douro; No. 18,889, as Negro Largo; and No. 18,905 as Warren's Brown Turkey. All of these were probably identical with San Piero. Cuttings received in 1924 from Málaga, Spain, as P.I. No. 58,665, labeled Pacuecas, proved to be the same as San Piero. P.I. No. 93,277, introduced in 1931 from England as Negro Largo, is different from San Piero, and its true identity has not been established. In its catalogue for 1890-1891, the California Nursery Company, Niles, listed Negro Largo as a new variety. The California Experiment Stations tested this variety between 1891 and 1903 under the names Negro Largo and Black Genoa. For reasons not now apparent, the name Negro Largo was dropped, and Black San Pedro was substituted for it.

A variety known as Black Douro or Black Portugal has long been grown in California, and it has proved to be identical with San Piero. The name indicates that it might have been secured from their homeland by some Portuguese residents of the San Francisco Bay region, as suggested by Eisen (1901, p. 264). To add still further to the confusion, this variety is designated by some as Brunswick! Commission merchants in Los Angeles market the large, fresh figs of San Piero as Brunswick, although most growers call them Brown Turkey or Black San Pedro. The Thompson, or Thompson Improved Brown Turkey, is identical with San Piero. The same is true of Granata, grown by B. R. Amend, Portland, Oregon. The following account is based on trees in production at Riverside since 1930.

Trees are vigorous, precocious, very productive, often somewhat dwarfed by heavy erops; terminal buds violet-brown. Leaves medium to large, some- 
what glossy above, variable as to lobing ; some are 3-lobed, with upper sinuses shallow, others 5-lobed, with upper sinuses of medium depth, lower sinuses shallow; basal lobes commonly auricled (especially on leaves of sucker growth), with the borders overlapping; margins coarsely crenate.

Breba crop fair, stimulated by terminal-bud pruning of dormant twigs, as described by Hodgson (1925) ; figs large, up to $33 / 4$ inches long and $21 / 2$ inches in diameter, oblique-pyriform, sometimes elongated; average weight 105 grams; neck thick and short, merging gradually into body; stalk thick and short; ribs prominent, generally coloring earlier and deeper than body; eye large, open, scales tinted pink, even on immature fruit; white flecks numerous, variable in size; color greenish purple, darker on side exposed to sun and on the apex; bloom delicate, pruinose; meat violet; pulp strawberry; flavor rich; quality good. (Plate $24, A$.)

Second-crop figs medium to large, or commonly very large on sucker wood of heavily pruned trees, obovate to oblique-pyriform; average weight 70 grams; neck variable, thick and short, or sometimes up to $1 / 2$ inch long and curved; ribs prominent; eye large, open, scales purple; surface somewhat glossy, with prominent bloom; white flecks large, scattered, some elongated, violet at maturity; color purplish black, with lighter shades on neck; pulp strawberry, center hollow, as shown in plate 11 and by Condit (1941a, fig. $11, A)$; flavor fairly rich. Quality fair to good when matured on the tree. Consumed fresh; worthless for drying, on account of poor color and susceptibility to spoilage, therefore seldom grown in the San Joaquin Valley. (Plates $10 ; 11 ; 12 ; 24, B$.)

Caprified figs have darker color of skin, a deeper strawberry in the pulp, larger, fertile seeds, and better flavor, than uncaprified ones.

Santagatese. Described by Ferrari (1912) as a variety of limited culture in Sicily, producing large, turbinate figs, reddish purple in color, with lightstrawberry pulp.

São Luiz. Described and illustrated by Mello Leotte (1901) and Bobone (1932) from specimens grown at Loulé. Second-crop figs turbinate, with short, thick neck and short stalk; skin thin, of fine texture; color violetblack; pulp light red; quality very good.

Saraïna (syns. Sarasina, Ficus carica saracenica Risso). Described by Risso (1826), Sauvaigo (1889), and Eisen (1901), as a variety of southern France, much subject to "couler," or dropping of fruit of the first crop.

Second-crop figs medium or above, oblong-turbinate; skin thick, firm, checking, adhering to the meat; color black; pulp red.

Sarreigne (syns. Petite Bourjassotte, Verdalo, Pichotte Barnissotte, Ficus carica garideli Risso). Described by La Quintinie (1692), Cupani (1696), Tournefort (1719), Garidel (1715), Bernard (1787), Rozier (1805), Duhamel (1809, with color illustration), Risso (1826), Noisette (1829), Couverchel (1839), Sauvaigo (1889), and Eisen (1901). Careful comparison of the various descriptions of Sarreigne and Barnissenca shows that these two varieties are confused as to identity. Tournefort described Petite Bourjassotte, and quoted the previous description of Cupani. Bernard quoted verbatim the Latin descriptions of both of the above authors, and stated that the variety is called Verdalos near Draguignan and Sarreignos at Cuers 
and Hyères. Duhamel listed the variety as No. 18, and also gave credit to former accounts. Number 62 of Risso, given as Ficus carica garideli, is apparently the same variety as Sarreigne. Sauvaigo, and later both Eisen and Simonet, appear to be in error in linking $F$. carica garideli with the variety name Bernissenque, which is No. 28 of Duhamel and $F$. carica bernardi of Risso. (See account of Barnissenca.) The name Verdalo, according to Duhamel, was applied to the variety because of the green color, which persists near the stalk.

Trees are reported to be common throughout Provence. Eisen recommended the variety for the warm valleys of California, but no reports of plantings have been found. The following description of fruit is compiled from various accounts.

Figs medium, about 2 inches in diameter, spherical to pyriform, abruptly narrowed toward the short stalk, which adheres tenaciously to the twig; skin thick, not much subject to checking ; color dark violet, shading to green toward the stalk; pulp bright red; quality good in hot climates.

Sbayi. Described and illustrated by Grasovsky and Weitz (1932) as a Palestinian fig, "distinguished by its purple ribs, running from stalk to eye." Figs medium, oblate, without neck; stalk short; eye open, scales pink; color greenish brown; pulp light red, sweet. Good for fresh consumption.

Schiavo (syns. Prigisotto, Melagnano). Described by Pasquale (1876, with figure), Pellicano (1907), and Ferrari (1912), as an Italian fig, grown at Cosenza, and recommended for the coastal district on account of the excellent quality of the dried product.

Leaves are coriaceous, deeply 5-lobed.

Brebas large ; oblong; reddish violet.

Second-crop fig's medium, black; pulp violet.

Selteni. Described by Minangoin (1931) from Gabès, Tunisia. Leaves medium, 3-lobed; upper sinuses deep. Figs with long, slender neck; eye wide open; color brown to violet; pulp red.

Señora (syns. Forastera, Ivernenca, Orihuela, Ampurdan, Verguna). Described and illustrated by Estelrich (1910) as a variety from the Balearic Islands, considered to be one of the best-quality figs of Spain. It is marketed fresh in large quantities in Palma, but does not carry well to distant markets on account of susceptibility to spoilage.

Second-crop figs are oblique-turbinate to spherical, with short, thick neck and short stalk; skin checking crisscross at maturity; color greenish, tinged with violet; pulp deep red; seeds very much in evidence; flavor delicate; quality excellent. Season generally too late to permit proper drying of the crop.

Shunnari. Described by Grasovsky and Weitz (1932), with illustration of a fig of each crop. The tree is not prolific, and is therefore not commonly planted in Palestine.

Brebas above medium to large, pyriform, characterized by a bright-red ring around the eye; color purplish black.

Second-crop figs medium, oblate-spherical, with short, thick neck; stalk short; body color light green, with brown ribs; skin thin; pulp light red; seeds few. Quality good for drying. 
Shunnari Asmar. Described by Grasovsky and Weitz (1932) as a "black, medium-sized fig, rendered distinctive by a bright-red circle around the open eye"; pulp light red ; texture rather dry; seeds few.

Sidi-ben-Agous. Listed by Guillochon (1913, 1927, 1929), and described by Minangoin (1931), as Zidi-el-Agouch. Leaves large, variable in size and shape, mostly 3-lobed. Figs with prominent neck; eye wide open; skin smooth, violet in color; pulp light red.

Signora (syn. Monaca at Brindisi). Described and figured by Vallese (1909) as a variety confused with Dottato Rosso in some localities; described in detail by Donno (1952).

Tree moderately large; leaves 3 - to 5-lobed; buds and branches described by Donno $(1951 a)$.

Breba crop none. Second-crop figs turbinate to obovate, with short, thick neck; stalk short; ribs fairly prominent; eye open, scales violet; skin checking at maturity ; color obseure violet or almost black on the body, to yellowish rose toward the stalk; pulp pale red, very sweet; seeds few; quality excellent, both fresh and dried.

Smari (syns. Swadi, Khussum, Shalati el Abed). Described and figured by Grasovsky and Weitz (1932) as a very inferior fig, grown throughout Palestine. In the Gaza subdistrict, the tree is said to be used as a stock for better varieties.

Figs small, pyriform; neck prominent; stalk short; eye open, scales spreading, "surrounded by a distinct, grey star"; color black; pulp pale red; flavor bitter.

Sofêno. Described and illustrated by Mello Leotte (1901) and Bobone (1932). Tree productive of two crops. Brebas pyriform, chestnut brown. Second-crop figs oblique-turbinate, practically without neck; stalk short; color green, flushed with violet; pulp carmine; texture coarse; quality good.

Sopa e Vinho. Described and illustrated by Bobone (1932) as a Portuguese variety, producing one crop only at Cacela in late August and early September. Figs medium, turbinate, with short, thick neck; stalk short; color green, tinged with violet; pulp carmine; texture fine; quality good.

Souaba-el-Adjia Rose. Described by Guillochon (1913, 1927, 1929), and by Minangoin (1931); the latter from Menzel Temine, Tunisia.

Leaves medium, 5-lobed; upper sinuses deep, petiolar sinuses open. Terminal bud attenuate, green. Figs large, 3 inches long by 17/8 inches in diameter; shape ovoid, triangular in cross section; eye open; skin color violet-purple; pulp light red.

Sprengel. Described by Risso (1826) as Ficus carica sprengellia. Figs above medium, pyriform; stalk long; skin thin, checking irregularly, black in color; pulp red, hollow at the center.

St. Domingo. A variety imported from Chile into the Union of South Africa, producing pyriform figs, above medium in size, with short, slightly curved stalk and thick neck; eye small, closed, with red scales; color brown to purplish brown; pulp hollow, pinkish amber; seeds small. Tree prolific, maturing fruit over a long season. In a letter dated February 23, 1953, Dr. Daniel du Preez, Stellenbosch, reports that this variety is ideal for home gardens. It is also known locally as New Brunswick and Greef's Black. 
Sukkari. Described by Grasovsky and Weitz (1932) as a special variety of the Acre subdistrict of Palestine. Figs very small, subpyriform; eye closed, scales purple; color brown, with purple ribs; pulp pale red.

Sultane (syn. Grosse de Juillet). Described by Duchartre (1857), Du Breuil (1876), Mazières (1920), Bois (1928), and Simonet et al. (1945); the last with illustration of both first- and second-crop figs. Simonet and Chopinet (1947) described and illustrated this variety as Noire de Juillet. The following account is after that of Simonet et al. (1945) from fruits produced at Sollies-Pont, in southern France.

Tree very productive.

Brebas medium to large, pyriform to turbinate, with short neck; average weight 85 grams; stalk up to $1 / 2$ inch long; ribs prominent; eye small, closed, sometimes slightly depressed, scales violet; skin firm, black on apex and body, shading to reddish brown toward the stalk; meat violet; pulp red; quality fair. Season late July.

Second-crop figs medium, turbinate; average weight 57 grams; stalk 1/4 inch long; skin unusually firm, resistant to injury during transport; color black, with prominent, pruinose bloom; meat white; pulp dark red, of fine texture; quality good. Season September.

Sultani (syns. Fayoumi, Ramadi, Barshoumi, Sidi Gaber, Hejazi). Described and figured by Badie and Ghamrawi (1931) as the most common and widely distributed variety of Egypt. The following all proved to be identical in the variety plot at Riverside: P.I. No. 80,299, introduced into California in 1929 from Palestine as Sultane; No. 81,678, from the Tarring Fig Garden, England, in 1929 as Madagasear; and No. 80,152, from Ariana, Tunisia, in 1929 as Bidh-el-Atrous. The fruits show characters very similar to those described for the Sultani of Egypt. Therefore, all of the above will be treated here as one and the same variety. Bidh-el-Atrous is treated by Guillochon $(1913,1927,1929)$ as a small, violet fig, with green ribs. Madagascar is briefly described by Spence (1846) as a small, globular, green sort, with narrowly lobed leaves, found in a West Tarring orchard. J. L. (1890) stated that the name Madagasear, "evidently a misnomer," was attached to a very large fig, frequently met with at Lansing, England.

Trees in Egypt and in California are vigorous, producing two crops. Leaves large, commonly nonlobed. The following description is from fruits produced at Riverside since 1940, in comparison with the account by Badie and Ghamrawi.

Breba crop fair; figs above medium, pyriform; ribs prominent; eye large, scales pink; color green, flushed with chocolate brown; pulp coarse, strawberry in color; quality poor.

Second-crop figs above medium to large, pyriform; stalk variable, short and thick, or sometimes slender and up to 1 inch long; color attractive, brownish violet; meat unusually thin; pulp light strawberry, texture gelatinous; seeds small and inconspicuous. Quality poor in Riverside, much inclined to split at maturity. Season late.

Temri. Briefly described by Guillochon $(1913,1927,1929)$ as a medium, elongated, violet fig, fruiting over a long season, and good for drying in Tunisia. Reported by Hodgson (1931), and by Valdeyron and Crossa-Ray- 
naud (1950), as a second-crop fig, of fair quality when dried but not fit for export.

Probably the same as Temeri, described by Minangoin (1931) as a small, rose-colored fig, with red pulp ; tree productive of two crops, the second improved by caprification.

Toulousienne. Described by Eisen $(1888,1901)$, and by Starnes and Monroe (1907), the latter with figure of fruit. Illustrated in color, but not described, by Wright (1894). See also Condit (1941a, fig. 2, $F$ ). The identity of Toulousienne is in doubt. Barron (1891) and Eisen (1901) reported it to be the same as Grisé Savantine Bifère, which, in this monograph, is referred to as Saint Jean. It was introduced into California in the Chiswick collection under P.I. No. 18,895, and has fruited in variety collections at Niles, Chico, Fresno, Menlo Park, and Riverside. In none of these trials has Toulousienne shown promising characters, and the variety may as well be discarded in favor of much better ones. Eisen stated, "quality of fig good, but appearance is insignificant." The following account is of tree and fruit, grown at Riverside since 1931.

The tree is of moderate vigor and size, with violet-brown terminal buds. Leaves below medium, dull on upper surface, mostly 3-lobed; upper sinuses shallow, broad; base subcordate; margins crenate. (Plate 13.)

Breba crop none. Second-crop figs below medium, up to $13 / 4$ inches in length and diameter, turbinate, with short, thick neck that is sometimes slightly flattened; average weight 18 grams; stalk mostly short; ribs very slightly elevated and inconspicuous; eye medium, open, scales rosy violet; white flecks large, scattered, conspicuous, as shown by Condit (1941a, fig. $9, C)$; surface dull, with thick, pruinose bloom; color of body violet-brown to purplish black, the neck often remaining light green until full maturity; meat thin, white; pulp strawberry, somewhat hollow at the center; flavor moderately rich and sweet. Dried figs of small size and poor in color. (Plate $26, F$.)

Caprified figs deep purplish black in color, with dark-strawberry pulp; flavor acid.

Much subject to splitting and subsequent spoilage.

Tributaria. Described by Ferrari (1912) as an Italian variety that resembles Paradiso, but figs are a little more oblate, with a short stalk. The tree is vigorous, and productive of two crops. Consumed fresh.

Trois Récoltes (syn. Précoce d'Espagne, probably). Described by Audibert Frères (1854), Barron (1891), Eisen (1901, after Barron), and Schneider (1902). The name signifies "three crops," as does the name Trifero, a greenish-yellow fig, regarded in this monograph as synonymous with Dottato. Audibert Frères treated Précoce d'Espagne as a variety very similar to Trois Récoltes. Hogg (1866) described Précoce d'Espagne, and stated: "This is a very early variety, and in Spain it is called Tres fer, or thrice bearing."

According to Hogg, the figs are small, spherical; stalk 1/4 inch long; color dark green, tinged with brown; pulp light strawberry, richly flavored.

P.I. No. 18,852 of the Chiswick collection was labeled Trois Récoltes, but no record is available of its behavior at Chico, California. 
Verdal (syns. Verdala, Grosse Verdale, Verdal Longue, Agen, D'Agen, Grosse du Draguignan, Ficus carica virescens Risso). Described by Risso (1826) under the appellation "figue à fruit vert" (fig with green fruit). Sauvaigo (1889) described the same variety as Verdale or Grosse Verdale. Hogg (1866) treated D'Agen and "Gros de Draguignan" as distinct varieties. Eisen (1888) gave "Gros du Dragnignan," with Agen as a synonym; in 1901 he reversed the nomenclature, listing Grosse du Draguignan as the synonym, with the last name correctly spelled. Other accounts are by Audibert Frères (1854), Escribano y Pérez (1884, probably), Barron (1891), Shinn (1893), Stubenrauch (1903), Sánchez (1922), Condit (1921b, 1947), Blin (1942), Simonet et al. (1945, as Verdale), and Soc. Pomol. de France (1947). The spelling Verdal is used here to designate this variety, bearing green fruits tinged with violet, as distinct from Verte (syn. Verdale), bearing fruits of an over-all green color.

Risso stated that the fruits commenced to ripen in late June, but later writers regard it as a one-crop variety. Hogg reported it as "one of the finest figs I know." Eisen also described it as "one of the best figs," ripening very late, and "requiring caprification at Niles." It was introduced into Algeria (Trabut, 1904), and according to Plant Immigrants (No. 146, p. 1334), produced one crop of excellent figs from September to December. It may be this variety which Estelrich (1910) described and figured under the name Verdal de Oriola.

According to Eisen (1901, p. 66), Agen was one of the varieties imported by John Rock from England in 1883. P.I. No. 18,870 of the Chiswick collection was listed as D'Agen. Notes taken on this introduction in September, 1921, at the United States Plant Introduction Garden, Chico, California, showed a medium-sized, greenish-violet fig, excellent in quality and well worthy of further trial. The same variety was grown by the California Experiment Stations as Verdal Longue and distributed for trial, especially in southern California. Dooryard trees have been found at Oroville, Monrovia, Riverside, San Diego, and Carlsbad. About 1930, a grower at Carlsbad had a small commercial planting from which excellent figs were marketed up to Christmas, or even later. Cuttings were introduced into Georgia from California, but no record of production has been found. Fruiting trees were seen in a variety collection at Angleton, Texas, in August, 1940. The following account is of trees and fruit grown at Riverside since 1931, and at Los Angeles during eight fruiting seasons.

Tree somewhat spreading, with outer branches drooping; terminal buds green. Leaves medium, somewhat glossy above, mostly 5-lobed; both upper and lower sinuses of medium depth and width; base subcordate to truncate; margins very slightly crenate.

Brebas rare, medium, turbinate; stalk up to $3 / 4$ inch long, curved; eye medium; white flecks large, conspicuous ; color greenish violet; pulp strawberry; flavor rich.

Second-crop figs medium, up to $13 / 4$ inches long and $17 / 8$ inches in diameter, turbinate to obovate, with short, thick neck; average weight 43 grams; stalk thick, up to $1 / 2$ inch long; ribs narrow, slightly elevated; eye medium, open, scales chaffy, tinged with violet; surface somewhat glossy, with prominent 
bloom; white flecks large, conspicuous; skin checking crisscross at maturity; color green, tinged with violet or light brown; meat thin, white; pulp strawberry; flavor rich; quality good. (Plate $26, C$.)

Caprified figs medium to large, oblate-spherical; color attractive, greenish violet; bloom especially prominent; pulp solid, dark strawberry, rich in flavor. Considerably better in size, appearance, and quality than uncaprified fruit. Season late.

Verdal de Valence. Eisen (1901) quotes the description of this variety by Barron (1891) and adds that the name is very doubtful. It is given as a fig below medium, turbinate; color tawny red; pulp red; quality mediocre.

Verdal Round (syns. Verdal Ronde, Petite Verdale). Described and figured by Eisen (1901). Simonet et al. (1945) had not seen this variety, but referred to Eisen's description and quoted briefly from it. According to Eisen, it is one of the earliest figs, ripening in June and July ; it is not clear whether his account is of the first or second crop. Figs below medium, shortpyriform, uniformly bluish green at apex, lighter toward the stalk; pulp blood red, sweet, highly flavored.

Eisen stated that it was extensively distributed in southern France, and was highly regarded in parts of California. The identity of this variety and the present location of trees are not known.

Vernino (syns. Natalino Nero, Pasquale, Camaldolese, Della Cava, Tre Volte l'Anno, Verneo Nero, Arneo Nero, Allison). Described by Gasparrini (1845), Savastano (1885), Eisen (1888, 1901), Vallese (1909), De Rosa (1911), and Condit (1947). Leaves and fruit figured by Vallese, who treated Arneo Nero and Verneo Nero as distinct kinds; De Rosa described the two as synonymous. In his account of 1845, Gasparrini listed this variety as Vernino, but added that some called it Natalino, or Christmas fig; others called it Pasquale, since the fruits sometimes remained on the tree during the winter and matured near Pasqua, or Easter. The name Tre Volte l'Anno refers to the tendency of Vernino to produce fruit at various times of the year. Trees usually produce a second crop only, late in the season.

Few trees of Vernino have been found in California. The late G. P. Rixford mailed cuttings to the University of California in 1926 from a tree at Loomis, and reported the location of another specimen on the Bidwell place at Chico. Another tree has recently been found growing on the J. J. Mashio ranch in Hunter's Valley, near Hornitos; this and several other varieties were probably imported by Italian settlers long before 1900. P.I. No. 130,464, obtained as Allison in 1931 from Angleton, Texas, as No. 8,379 of that station, proved to be identical with Vernino. See accounts of Allison by Stansel and Wyche (1932), and by Close (1933). A variety grown commercially near Bishop, Georgia, known locally as "Breedlove," has recently proved to be identical with Vernino in the collection at Riverside, California. The following description is from a single tree, fruiting at Riverside since 1933.

Leaves medium, 3- to 5-lobed; upper sinuses shallow and narrow, lower sinuses very shallow, basal sinuses broad; base commonly truncate or subcordate; margins coarsely serrate; surface dull. Terminal buds of branches tawny.

Breba crop none. Second-crop figs small to medium, up to $1 \frac{1}{2}$ inches in 
length and 15/8 inches in diameter, oblate-spherical to pyriform, with short, thick neck; average weight 28 grams; stalk short; ribs very slightly elevated, narrow; eye medium, slightly protruding, commonly surrounded by a zone of color lighter than that of the body; eye scales of green figs prominently pink, becoming violet at maturity; white flecks large and conspicuous; surface glossy, with pruinose bloom; skin tough or rubbery in texture; color purplish black on body, greenish toward the base; meat thin, white; pulp solid, strawberry in color (darker when caprified) ; flavor fairly rich ; quality only fair. Season late. A small fig, of no particular value. (Plate 28, C.)

Verte Brune. Described by Garidel (1715), Bernard (1787), Rozier (1805), Duhamel (1809), Lamarck (1817), Bory de Saint Vincent (1824), Noisette (1829), Couverchel (1839), Hogg (1866), Eisen (1901), and Leclerc (1925). Verte Brune is another variety of doubtful identity. Duhamel quoted the Latin description of Garidel, and referred also to the accounts by Bernard, Rozier, and Lamarck. He stated, under both Verte and Verte Brune, that in Provence these figs are sometimes designated as TrompeChasseur or Trompe-Cassaire, literally, "hunter's deception," because of the persistent green color of the maturing fruit. Hogg and Eisen treated Verte Brune as a synonym of Peau Dure. The latter gives a second Verte Brune as synonymous to Cuers, and a third as a distinct variety. In our description of Verte, it is pointed out that the green skin of that variety is often stained by the pulp to a brownish cast. It may be, therefore, that Verte Brune is the same as Verte, with the brownish or violet skin flush decidedly pronounced. The following brief description is after that of Eisen.

Two crops; brebas not described. Second-crop figs medium to small, oblique-spherical, "compressed at the stalk"; eye reddish; skin checking; color green, with a violet flush in the sun; pulp blood red; quality good.

Victoria. Described and figured by Estelrich (1910) from trees grown near Porreras and Inca, Mallorca. Figs small, black; stalk reddish; pulp bright red.

Violet Sepor. Described by Wythes (1900b), Bunyard and Thomas (1904), Starnes and Monroe (1907, with illustration of fruit), and Arnold (1926). "A valuable free-bearing sort, suitable for pot culture and forcing," according to George Bunyard. Figs reddish brown, with light-red pulp; flavor delicate.

Violeta Negra (syns. Violeta Florentina, Africano). Described by Tamaro (1948) as a variety introduced from Africa, but cultivated in all parts of Italy.

Tree vigorous ; leaves medium-sized; one crop only. Figs medium, shortpyriform, with thick neck; ribs elevated; skin checking at maturity, violet in color; pulp red. Used primarily fresh, but also dried.

Zaiti. Described by Minangoin (1931) from Hammamet, Tunisia. Leaves medium, thin, 3-lobed, with deep upper sinuses. Figs spherical, with short, thick neck; eye open; skin glossy, thick; color black; pulp red; seeds numerous.

Ziza Kheden. Briefly described by Eisen (1901) as an Algerian variety. Figs large, oblong, with black skin color and red pulp. 


\section{Common-type Figs with Skin Dark (Various Shades of Red, Brown, or Violet to Black); Pulp Color not Designated}

Adsi Ahma. A purple fig of Egypt, described by Badie and Ghamrawi (1931) as of the same shape as Bayoudi.

Andreva. Described and figured by Estelrich (1910). Leaves, when expanded, somewhat convex. Tree produces two crops, of which brebas are pyriform and black in color. Fruit of both crops used for cattle feed and for drying.

Balafi (syn. Fuente de Balafi). Described and figured by Estelrich (1910). Tree productive; leaves 3-lobed. Figs turbinate-spherical, slightly oblique at the base; stalk short; skin thick, greenish, with cinnamon tinge; pulp of agreeable flavor.

Banyols. Described and figured by Estelrich (1910); see also short account by Priego y Jaramillo (1922). Tree large, with drooping branches that suggest a torrent. Leaves large, 3-lobed. Figs medium, oblique-turbinate; skin yellowish brown, checking at maturity; quality good. Used both fresh and dried; cattle feed on them.

Blava. Described and figured by Estelrich (1910). Variety was named for the bluish-green color of the fruit, which is of medium size, agreeable flavor, and is used both for drying and for cattle feed. It matures early.

Capoll Llarch. Described and figured by Estelrich (1910). Figs medium, oblique-pyriform, with short, thick neck; average weight 33 grams; skin checking at maturity; color green at the base, greenish violet on the body; pulp not highly flavored. Season early. Used mostly for cattle feed.

Colombo Selvatico. Described by De Rosa (1911). Trees with small, 3-lobed leaves. Brebas with body spherical, but narrowing toward base, apex sometimes depressed; color green, tinted with violet. Second-crop figs pyriform, $21 / 4$ by $13 / 4$ inches; stalk short; skin violet; flavor strong, not especially agreeable.

Dominique (syn. Saint Dominique). Listed by Eisen $(1888,1901$ ) as a violet-colored French fig.

Foundling. According to Howard (1945), Foundling was so named by Luther Burbank, who found it in 1885 in a shipment of White Smyrna (Blanche) trees imported from the eastern Mediterranean. The single tree bore two crops of large, yellowish-brown figs, of fine flavor.

Franche. Described by Audibert Frères (1854) as a variety highly regarded by French growers for its brebas, which mature about the first of August, when there are few if any other figs in the market. The only fruit characters given are "size good; color tawny or dark gray."

Gallipolino. Described by Guglielmi (1908) as a variety grown near Presicce, Lecce Province, for its fresh fruit. Figs medium, oval; stalk short; skin thin, violet in color.

Gazir. Described by Guillochon $(1913,1927,1929)$ as a medium-sized fig, violet in color. On the other hand, Minangoin (1931) described Gazir as a yellow fig with rose-colored pulp when caprified. 
Gombaya. Described by Eisen (1901) as a medium fig, spherical, bright rose in color. Grown and much esteemed near Valencia, Spain.

Grá. Described and figured by Estelrich (1910) as De Grá, a variety commonly grown at Alcudia, Mallorca, for cattle feed. The figs are of medium size, conical, mulberry in color, with green spots.

Grosse Sultane. Described by Soc. Pomol. de France $(1887,1947)$; apparently different from the Sultane described by Simonet et al. (1945). One crop only. Figs large, turbinate, olive green to violet in color; prominently striated; quality good.

Hamri. Described by Guillochon $(1913,1927,1929)$ as a Tunisian variety, large to very large in size, violet in color; matures in August; used both fresh and dried. Hameri, described by Minangoin (1931) as a fig from El Oudiane that is yellow, with violet ribs and red pulp, may be the same variety.

Mahounaise. Described by Duchartre (1857), Du Breuil (1876), and Eisen $(1888,1901)$, as a red fig, grown at Salon and Saint-Rémy, France.

Mare de Déu. Described and figured by Estelrich (1910) as a variety resembling Albacor, and often confused with Martinenca and Calderona. Second-crop figs oblate, without neck; stalk short; color black. Season midSeptember to late October in Mallorea.

Miraya. Described and figured by Estelrich (1910) as a variety similar to Parejal, but distinct in fruit characters. Figs large, 21/4 inches long by $1 \frac{11}{2}$ inches in diameter, turbinate, with short, thick neck; stalk short; color purplish black. Consumed fresh; also very good for drying.

Monica. Described by Guglielmi (1908). Cultivated in the district of San Vito d'Otranto. Leaves 3-lobed, with cordate base. Figs elongated-oval, medium in size; skin checked, violet in color. Consumed fresh. Matures in September.

Piemontese. Described by Gasparrini (1845) as an Italian variety, bearing two light crops of black figs. Brebas elongated, large ; flavor fair. Second-crop figs medium, mediocre in quality.

Plata. Described and figured by Estelrich (1910). Fruit is short-stalked, spherical; skin prominently checked at maturity; color tawny or cinnamon.

Porquena (syn. Porquena Negra). Described and figured by Estelrich (1910) as a variety grown almost exclusively on the island of Mallorea for cattle feed.

The figs are below medium to small, spherical, black in color.

Porto (syn. De Porto). Described by Du Breuil (1876) and Eisen (1888, 1901) as a black fig, grown in southern France for fresh fruit and for drying.

Quasbi. Described by Minangoin (1931) from Ras-el-Djebel, Tunisia. Leaves large, 5-lobed; upper sinuses deep, nearly closed, lower sinuses open. Figs large, oblong; ribs indistinct; eye wide open; skin color dark violet; pulp solid.

Quasse Blanche. Described by Duchartre (1857), Du Breuil (1876), and Eisen (1901), as a reddish-gray fig, grown at Baudol, in southern France, for drying.

Redona de Grá. Described and figured by Estelrich (1910) as a latematuring fig, used fresh for fattening hogs on the island of Mallorea. Figs small, spherical, black in color. 
Renyach. Described and figured by Estelrich (1910) as a large, black fig, used for hog feed and for drying; not widely planted.

Roca. Described and illustrated by Estelrich (1910) as a small, spherical fig, ruddy blue in color, maturing from September to mid-October. Consumed fresh by farmers; also fed to hogs.

Rojisca (syn. Cuiro de Bou). Described and figured by Estelrich (1910) as a prolific variety, producing small, spherical figs, reddish brown in color; skin checking crisseross at maturity.

Safranée. Described by Du Breuil $(1876)$ and Eisen $(1888,1901)$ as a reddish-gray fig, good fresh or dried. Grown at Nice and Salon, France.

Sidi-ben-Aied. Listed by Guillochon $(1913,1927,1929)$ as a medium-sized Tunisian fig, dark violet in color.

Sitsel (syn. Peluda). Described by Estelrich (1910) as a variety found at various places on the island of Mallorea; some trees are a century old, and of large size. Figs small, conical, light brown in color; flavor poor. Not consumed fresh, but dried for cattle feed.

Tebessi. Briefly described by Guillochon $(1913,1927,1929)$ as a very large, dark-violet fig, good for drying in Tunisia. Minangoin (1931), on the other hand, described Tebessi as a fig with long neck, thick, green skin, wideopen eye, and hollow, light-red pulp.

Tia Penya. Described and figured by Estelrich (1910) as a variety sometimes confused with Cuello de Dama Blanca (Col de Dame) on Mallorca.

Brebas not described. Second-crop figs pyriform, medium, up to 2 inches long and 11/2 inches in diameter; skin thick; color green, shaded with brown. Consumed fresh; also used as cattle feed.

Tounsi. Briefly described by Guillochon $(1913,1927,1929)$ as a small, copper-colored fig, streaked with violet; matures in late August in Tunisia.

Verdal Negra. Described and figured by Estelrich (1910) as a small, black fig; planted rarely in Mallorcan orchards.

Vernile. Described by Ferrari (1912) as an Italian fig, depressed at the apex; color yellowish, tinted with violet; season late.

Violette Plate. Described by Merlet (1667), Ballon (1692), Liger (1702), and Langley (1728). Tree produces a light breba crop and a good second crop. Figs medium, violet, of excellent quality.

Zarniza. Introduced into the United States in 1901 as P.I. No. 5,920, from Lesina (Hvar) Island, Dalmatia. In Inventory No. 10, Bureau of Plant Industry, United States Department of Agriculture, D. G. Fairchild reported it as a variety producing two crops of dark-colored figs, sometimes dried and packed in small barrels for export. No further mention of it has been found.

\section{Common-type Varieties not Classified as to Color}

Bifero (?). Pasquale (1876) described Bifero under Ficus polymorpha var. bifera of Gasparrini (1845), with Sampiero (San Piero), as a synonym. Pellicano (1907) cited the account of Pasquale, but stated that Bifero figs were light green in color, and required caprification. Portale (1910) described "Bifaro" as a variety producing two crops of spherical figs without caprification. 
Boutiltete. Listed by Du Breuil (1876) and Eisen (1901) as a very good drying fig, grown at Brignoles, France.

Doucette. Listed by Duchartre (1857), Du Breuil (1876), and Eisen $(1888,1901)$, as a good fig, fresh and dried, at Salon, France.

Fabre. Listed only by Eisen (1901) as a large French fig, producing two crops.

Koutsina. Listed by Symeonides (1930) as a variety grown "all over Tylliria district" of Cyprus.

Malaktiana. Listed by Symeonides (1930) as a variety especially popular near Lefkara, Cyprus.

Messongue (syn. Moelle). Listed by Duchartre (1857), Du Breuil (1876), and Eisen (1901, apparently quoted from Du Breuil), as a very large fig, grown at Salerno, Italy. Good both fresh and dried.

Papathoumika. Described by Symeonides (1930) as one of the best varieties of Cyprus for production of dried figs, having a very thin skin and small seeds.

Porcino. Li.sted by Tanara (1651) as producing two crops; good for the fresh-fruit market.

Seirola Negra. Sauvaigo (1889) noted that he had found this variety in the vicinity of Nice. As a synonym, he gave Ficus carica turneria Risso.

Vardina (syn. Vardica). Listed by Symeonides (1930) is producing some of the largest $\mathrm{.gs}$ of Cypru , and most popular for fresh consumption.

$\therefore$ ana a Li ted by Symcorides (19॰0) a a variety grown everywhere on the is and of Cyprus. ... ostly consumed fresh, but in the Paphos district it produces the dried figs known locally as "maxiles." 


\section{INDEXED ALPHABETICAL LIST OF FIG VARIETIES}

Names in boldface type are those under which the varieties are described.

All synonyms appear in lightface.

Symbols: $\mathrm{C}=$ Common $; \mathrm{Cp}=$ Caprifig ; $\mathrm{S}=$ Smyrna $; \mathrm{Sp}=\mathrm{San}$ Pedro

Abachlaou-See Agouarzguilef, 355

Abakor (C), 381

Abakour Amellal = Abakor, 381

Abate (S), 345

Abbanega $=$ Panettaro, 350

Abboudi (C), 414

Aberakmouch $=$ Averane, 355

Aberdin (C), 382

Abetroune (Cp), 332

Abgait $=$ Col de Dame Noir, 432

Abiad Assuan = Assouani, 383

Abiarous (S), 345

Abicou or Abicou Noir = San Piero, 467

À Bois Jaspé = Jasper, 445

Abondance $=$ Franche Paillarde, 437

Abondance Précoce $=$ Franche Paillard (', 437

Aboucherchaou (S), 345

Abouh'archaou = Aboucherchaou, 345

Abougandjour (S), 354

Abouzouggar (S) Listed only, 359

Abruzzes = Dottato, 376

Acriesto $=$ Verdescone, 353

Adam (C), 420

Adam $=$ Dauphine, 365

Adjaffar (S), 354

Adottato $=$ Dottato, 376

Adras Blanc (Cp), 339

Adras Violet (Cp), 332

Adriatic $=$ Verdone, 325, 406

Adsi Abiad = Bayoudi, 384

Adsi Ahma (C), 477

Afghan (S), 354

Africano $=$ Violeta Negra, 476

Africano-See Barnissotte, 323, 423

Agen $=$ Verdal, 474

Aggiunto = Scionto, 344

Agouarzguilef (S), 355

Agouat (Cp), 328

Agoussim (S), 355

Agradable Blanco = Datil, 419

Agresto (C), 382

Agulla (C), 411

Aidin $=$ Sari Lop, 343

Ain-el-Hadjel = Tit-en-Tsekourt, 332

Ajenjar=Azendjar, 355

Ajlouni (C), 382

Akca (S), 345

Ak-kaba (Cp), 335

Akoran ( $\mathrm{Cp}$ ), 328

Albachiara = Abate, 345

Albacor = San Piero, 467

Albacor Blanca = Grosse Jaune, 394

Albacor Comun (C), 421
Albacor de Grá (C), 421

Albanega = Panettaro, 350

Albanera (C), 414

Albero d'Oro = Paradiso, 455

Albicello = Albo, 372

Albicougris = Bordeaux, 424

Albinillo = Albo, 372

Albo (C), 372

See also Troiano, 405

Alekake (S), 345

Algiers No. 1 and No. 2 (Cp), 340

Algiers No. $3=$ Swingle, 342

Alicantina (C), 411

Allamoda $=$ Mota, 350

1llison = Vernino, 475

m:lile = Datil, 419

$\mathrm{r}$-una (C), 421

$\therefore{ }^{\prime \prime} a$ ( $\left.\mathrm{Cp}\right), 328$

… n-

;3s S) 316

Ime a-ree Adras Blane, 339

$\therefore$ mpurdan $=$ Señora, 470

Amudi (C), 382

Andreva (C), 477

Angelina (C), 372

Angélique (C), 382

See also New French, 413

'nr'lique Plack (or A. Noire) = Bordeaux, 424

nri.ivue Jaune (C), 383

Aoriv = Illoul, 337

Apple = San Pedro, 363

Arabaly = Genoa, 392

Aranim-Aberkane (S), 355

Aranim-Amellal (S), 346

Arba = Abate, 345

Arbal (C), 414

Arbauda = Cuore, 434

Arbicone = San Piero, 467

Archipel (C), 414

Argelina = Angelina, 372

Argenteuil-See Blanche, 372

Argentine $=$ Blanche, 372

Argusela $=$ Perroquine, 459

Arneo Bianco (C), 383

See also Zimitza, 411

Arneo Nero $=$ Vernino, 475

Arzagane (Cp), 328

Aseltani $=$ Marabout, 357

Ashridge Forcing = Brown Turkey, 428

Asqalawi-Asmar (C), 421

Assel = Techich, 358

Assel bou Tchiche (C), 383 
Assouani (C), 383

Athènes = Marseillaise, 396

Aubaco $=$ San Piero, 467

Aubane (C), 421

Aubergine-See Brunswick, 418

Aubico Blanco = Grosse Jaune, 394

Aubicon $=$ Gennes, 391

Aubique $=$ San Piero, 467

Aubique Blanche $=$ Grosse Jaune, 394

Aubique Leroy-See San Piero, 468

Aubique Noire $=$ San Piero, 467

Aubiquoun $=$ Bordeaux, 424

Aulique $=$ San Piero, 467

Automne-See Malta, 447

Averane (Cp), 339

Averane (S), 355

Averengo $=$ Datte, 389

Avouzegar (S), 355

Ayers (Cp), 332

Azaich (C), 421

Azaim (Cp), 335

Azaim-See Adras Blanc, 339

Azegoush = Adjaffar, 354

Azendjar (S), 355

Azenjar = Azendjar, 355

Azerou $=$ Thaaranimt Entael Hadjar, 359

Azigzaou (Cp), 328

See also Takourchit, 352

Baalie $=$ Col de Dame Noir, 432

Bacalar Preto-See Lampeira, 368

Bacorinho (C), 421

Badalhouce (C), 383

Bagassa $=$ Mourenao, 453

Baidi (P.I. No. 80,294) = Brunswick, 417

Baioudi-See Bayoudi, 384

Balafi (C), 477

Banegra $=$ Cascitello, 431

Banyols (C), 477

Barbanera $=$ Petronciano, 368

Barbillone (C), 415

Bardajic (S), 346

Bardajik = Bardajic, 346

Bardakji (Cp), 340

Bardakjik = Bardajic, 346

Bardakjik Black (S), 356

Bargemon (C), 421

Barli (S), 356

Barnissenca (C), 421

See also Sarreigne, 469

Barnissenquo = Barnissenea, 421

Barnissotte (C), 369, 422

Barnissotte Blanche (C), 383

Barnissotte White $=$ Barnissotte Blanche 383

Barshoumi = Sultani (of Egypt), 472

Bayoudi (C), 384

Bayswater $=$ Brunswick, 416

Beall (C), 416
Beaucaire $=$ Célestine, 431

Bêbera $=$ Moscatel Preto, 452

Bec de Perdrix (C), 423

Becuelle (C), 423

Belamie (Cp) Listed only, 341

Belle Dame (P.I. No. 69,010) = Brunswick, 417

Belle Dame Blanche (P.I. No. 86,790)= Brunswick, 417

Bellegarde $=$ Barnissotte, 422

Bellona (C), 423

Bellone $=$ Bellona, 423

Belloune $=$ Bellona, 423

Belmandil (S), 356

Berdauda (C), 384

Bernard = Barnissenca, 421

Bernissenca $=$ Barnissenca, 421

Bernissenque $=$ Barnissenca, 421

Bernissou Blane = Barnissotte Blanche, 383

Bernissou Negra = Barnissotte, 422

Bertolina = Caiana, 430

Besoul-el-Khadem (S), 356

Betada (C), 424

Beurzel (Cp), 328

Bezoul-el-Khadem = Besoul-el-Khadem, 356

Bezoult Rhadem = Besoul-el-Khadem, 356

Bezzoso = Dattero, 435

Bianchetta = Albo, 372

Bianco (Cp), 335

Biancolella $=$ Dottato, 376

Biancoletta $=$ Albo, 372

Biancolini = Albo, 372

Biberaeo = Franciscana, 437

Biddin-el-Brel (S), 356

Biddin-el-Djemel = Bidh-el-Djemel, 424

Bidh-el-Atrous = Sultani (of Egypt), 472

Bidh-el-Djemel (C), 424

Bifaro-See Bifero, 479

Bifère de la Malmaison = Malmaison, 447

Bifero (C), 479

Binelli $=$ Dottato, 376

Binellino = Dottato, 376

Binello $=$ Dottato, 376

Binello $=$ Pissalutto, 401

Bioudi-See Bayoudi, 384

Biskra $=$ Choer, 347

Bispo-See Lampeira, 368

Biter Abiod (C), 411

Biter Akhal (C), 424

Black Douro $=$ San Piero, 468

Black Genoa = San Piero, 468

Black Marseilles = Marseillaise Black, 449

Black Martinique $=$ Martinique, 449

Black Mission = Franciseana, 438

Black Naples = Brunswick, 416

Black Portugal $=$ San Piero, 468

Black Provence $=$ Marseillaise Black, 449

Black San Pedro = San Piero, 468

Black Sugar-See Eva, 436 
Blanca $=$ Albo, 372

Blanca Clara $=$ Alicantina, 411

Blancassa (C), 384

Blancassa = Alicantina, 411

Blanche (C), 372

Blanche-See Bourjassotte Grisé, 427

Blanche à Peau Verte-See Blanche, 372

Blanche d'Argenteuil = Blanche, 372

Blanche d'Argenteuil (P.I. No. 92,304) = Brunswick, 417

Blanche Fleur $=$ Blanche, 372

Blanche Hâtive = Blanche, 372

Blanche Longue $=$ Marseillaise Long, 449

Blanche Navello_See Du Japon, 412

Blanche Ronde $=$ Blanche, 372

Blanchette $=$ Dattero, 435

Blanqueta $=$ Alicantina, 411

Blanquette $=$ Blanche, 372

Blanquette-See Pietri, 362

Blanquetto $=$ Lipari, 395

Blanquilla $=$ Pajajero, 399

Blanquita $=$ Albo, 372

Blanquo = Blanche, 372

Blanquo Communo-See Blanche, 372

Blati $=$ Edeisi, 378

Blava (C), 477

Blavette (C), 424

Bleasdale (Cp), 338, 341

Blowers (S), 346

Blue $=$ Brown Turkey, 428

Blue Burgundy $=$ Brown Turkey, 428

Blue Celeste $=$ Malta, 447

Blue Ischia = Ischia Black, 443

Bocarde (C), 424

Bondance Précoce (C), 424

Bontalette (C), 411

Bontard (C), 385

Booung (Cp), 341

Bordeaux (C), 424

See also Negrette, 453, 454

Bordissot Blanca $=$ Barnissotte Blanche, 383

Bordissotte Blanca $=$ Barnissotte Blanche, 383

Borghino (C), 385

Borsamele (S), 343

Bou-Ang (S), 356

Bou Ankir $=$ Medloub, 338

Bouankirk $=$ Col de Dame Noir, 432

Bouche-barrique (C), 426

Bou Defi-See Besoul-el-Khadem, 356

Bouffros = Briasea Doussa, 428

Boughton $=$ Brunswick, 416

Bougiotte $=$ Tameriout, 352

Bou-Harrak (S), 356

Bou-Harraq = Harraki, 395

Bouhioua-See Adras Blanc, 339

Bouin (C), 385

Bouissonne $=$ Mouissonne, 452

Boukrati (C), 385
Boule d'Or-See Dauphine, 365

Bourdissotte Blanche (C), 385

Bourdissotte Noire (C), 427

Bourgassotte $=$ Barnissotte Blanche, 383

Bourgeassotte $=$ Barnissotte Blanche, 383

Bouriageotte $=$ Barnissotte, 422

Bourjassotte Blanche $=$ Barnissotte Blanche, 383

Bourjassotte Grisé (C), 427

Bourjassotte Noire = Barnissotte, 422

Bourjassotte Panachée $=$ Panachée, 400

Bourlier (Cp), 341

Bourtawi $=$ Yaffawi, 381

Boutana (C), 385

Boutiltete (C), 480

Bouton d'Or-See Dauphine, 365

Bouton du Guêtre = Lipari, 395

Bovin $=$ Bouin, 385

Brackett (Cp), 341

Bracotedesco = Panachée, 400

Branco = Urjal, 381

Brawley (Cp), 339

Brayasque $=$ Briasca, 427

Brebal = Franciscana, 437

Breedlove $=$ Vernino, 475

Breva Negra = San Piero, 467

Brianzola (C), 385

Briasca (C), 427

Briasca Doussa (C), 428

Briasca of Grasse = Dattero, 435

Brignolenque (C), 428

Brindisino (C), 375

Brocket Hall = Ischia, 442

Brogiotto-See Imperial, 442

Brogiotto Bianco = Barnissotte Blanche, 383

Brogiotto Fiorentino $=$ Barnissotte, 422

Brogiotto Nero = Barnissotte, 422

Brown Hamburgh = Brunswick, 416

Brown Ischia = Ischia Brown, 444

Brown Italian $=$ Brown Turkey, 428

Brown Naples $=$ Brown Turkey, 428

Brown Turkey (C), 325, 428

See also Ramsey, 462

Brown Turkey $=$ San Piero, 467

Brugeotte (C), 430

Brunswick (C), 325, 370, 416

Brunswick-See San Piero, 468

Bsikri (Cp), 340

Bucuelle = Becuelle, 423

Buino (Sp), 364

Bulletin (Cp), 341

Burjassotte Branco = Barnissotte Blanche, 383

Burjassotte Preto = Barnissotte, 422

Burro-See Lampeira, 368

Buttafarro (C), 386

Byadi (C), 386 
Cabroliana (C), 386

Cachôpeiro Branco (Sp), 360

Cachôpeiro Preto-See Lampeira, 368

Cachopo-See Cachôpeiro Branco, 360

Caiana (C), 430

Caiana Blanca (C), 386

Calabresa (C), 430

Calabria $=$ Dottato, 376

Calderona (C), 430

California Black = Franciscana, 437

Calimyrna $=$ Sari Lop, 325, 343

Calvert $=$ Verte, 410

Camaldolese $=$ Vernino, 475

Campanella $=$ Troiano, 405

Canibianchi-See Cascitello, 431

Canibianco $=$ Cascitello, 431

Cantina = Alicantina, 411

Capa Rôta = Urjal, 381

Cape Brown-See Eva, 436

Cape White-See Blanche, 374

Capo $=$ Cumpini, 434

Capoll Llarch (C), 477

Gasparrini (1845) gives the following ter-

minology, all under the genus Caprificus: gigante $=$ Grande, 341,451

leucocarpa $=$ Bianco, 335

oblongat $a=$ Chiajese, 341

pedunculata $=$ Pedunculato, 341

rugosa $=$ Ricciuto, 334

sphaerocarpa $=$ Rotondo, 331

Caprifigs, Neapolitan (and others, miscellaneous), 342

Capri No. 1 = Stanford, 338

Capri No. $5=$ Samson, 331, 338

Capri Smyrna No. $4=$ Swingle, 342

Carabaseta (C), 386

Carabesseta-See Carabaseta, 386

Cara Lisa $=$ Belmandil, 356

Caravanchina (C), 386

Caravanchina Bianca $=$ Caravanchina, 386

Caravanchina Negra (C), 430

Caravanquin Negra=Caravanchina Negra, 430

Carlina (C), 386

Carvalhal (Sp), 364

Cascella $=$ Cascitello, 431

Cascetta $=$ Cascitello, 431

Casciteddha = Cascitello, 431

Cascitello, (C), 430

Caseta (C), 412

Castagnola (C), 412

Castagnolo (C), 431

Castanhal (C), 431

Castelhano Branco (S), 346

Castelhano da Rocha = Castelhano Preto, 356

Castelhano Preto (S), 356

Castellana (C), 375

Castex-See Grasse, 394
Castle Kennedy (Sp), 364

Catalan (C), 431

Cava $=$ Vernino, 475

Celeste $=$ Malta, 447

Celeste Violette $=$ Malta, 447

Celestial $=$ Malta, 447

Célestine (C), 431

Cernica (C), 432

Cerva $=$ Signorella, 404

Cervone (C), 412

Cesario $=$ Cueritesto, 347

Changelge (S), 347

Chefaki (S), 347

Cheihk-Ali (C), 386

Cheker Injir (S), 347

Chestnut-colored Ischia = Ischia Brown, 444

Chetoui (C), 432

Chiajese (Cp), 341

Chiajese (Sp), 365

Chiattarella (C), 419

Choer (S), 347

Cimeirenca (C), 432

Cimeirenca Blanca (C), 386

Cistallino (C), 412

Citrato (C), 375

Clare $=$ Brunswick, 416

Clarkadota $=$ Dottato, 376

Clauet (C), 387

Claveu (C), 432

Clémentine $=$ Brunswick, 416

Clou = Claveu, 432

Coasca $=$ Dattero, 435

Cœur $=$ Verte, 408

Col de Dame (C), 387

Col de Dame Blane = Col de Dame, 387

Col de Dame Noir (C), 432

Col des Dames $=$ Col de Dame, 387

Col de Señora Blanea $=$ Col de Dame, 387

Col de Señora Negra = Col de Dame Noir, 432

Col di Signora $=$ Col de Dame, 387

Col di Signora (P.I. No. 102,099) = Brunswick, 417

Col di Signora Bianca $=$ Col de Dame, 387

Col di Signora Nero, or Negra $=$ Col de Dame Noir, 432

Col di Signora Panachée $=$ Panachée, 400

Colombaro (Cp), 335

Colombo $=$ Colombro, 360

Colombo $=$ Cascitello, 431

Colombo Bianco (C), 375

Colombo Nero (C), 432

Colombo Pazzo-See Colombro, 360

Colombo Selvatico (C), 477

Colombone $=$ Colombro, 360

Colombra $=$ Colombro, 360

Colombro ( $\mathrm{Sp}$ ), 360

Columbaro $=$ Colombro, 360 
Columbo $=$ Colombro, 360

Columbro $=$ Colombro, 360

Colummaro Nero $=$ Colombo Nero, 432

Colummo $=$ Cascitello, 431

Colummo Bianco $=$ Colombo Bianco, 375

Colummone $=$ Colombro, 360

Comadre (C), 412 (See Eisen reference for description.)

Common Blue $=$ Brown Turkey, 428

Common Brown = See Eva, 436

Confiseurs = Lampeira, 368

Constant Date $=$ Datte Quotidienne, 434

Constantine (C), 433

Constantine-See Rocarde, 463

Coppa $=$ Poppa, 380

Corazón $=$ Cuore, 434

Corbeau $=$ Rherabi, 358

Corbo $=$ San Piero, 467

Cordelia $=$ Croisic, 336

Cordelière (C), 388

Cortese $=$ Dattero, 435

Cortice Crasso $=$ Perouas, 459

Coscialunga $=$ Gambalunga, 391

Cotignac $=$ Cotignacenque, 388

Cotignacenque (C), 388

Cotignana $=$ Observantine, 455

Cotignana-See Saint Jean, 465

Cótigo (C), 433

Cótio (C), 388

Cótio Tinto = Cótigo, 433

Coucourela $=$ Cordelière, 388

Coucourelle $=$ Cordelière, 388

Coucourelle à Plascassier $=$ Becuelle, 423

Coucourelle Blanche = Angélique, 382

Coucourelle Brune (C), 433

Coucourelle Gavotte (C), 433

Coucourelle Grisé = Cordelière, 388

Coucourelle Noire $=$ Coucourelle Gavotte, 433

Cougourdana $=$ Mussega, 399

Cour $=$ Verte, 408

Courgette Rayée $=$ Panachée, 400

Cravé (C), 434

Crosic (Cp), 336

Cuello de Dama Blanca $=$ Col de Dame, 387

Cuello de Dama Negra = Col de Dame Noir, 432

Cueritesto (S), 347

Cuers $=$ Verte, 408

See also Verte Brune, 476

Cuiro de Bou = Rojisca, 479

Cumpini (C), 434

Cuore (C), 434

Cuou de Muelo $=$ Rose Noire, 463

Curigo (C), 434

Cyprus = Ischia Yellow, 395

D'Abouch Takli = Col de Dame Noir, 432

D'Agen = Verdal, 474
Dall'Osso $=$ Merioun, 451

Dalmatia (P.I. No. 102,010) = Brunswick, 417

Dalmatia-See Du Japon, 412

Dalmatian $=$ Brunswiek, 416

Dalmatian-See Ragusa, 413

Damascene (C), 388

Dame Blanche (C), 389

Dame Noire (C), 434

Darji (C), 389

Datil (C), 419

Dattaresi $=$ Dottato, 376

Datte (C), 389

Datte Quotidienne (C), 434

Datteresi $=$ Dottato, 376

Dattero (C), 435

Dattero-See Dottato, 376

Datto = Datte, 389

Dauphine (Sp), 365, 418

Dauphine Violette $=$ Dauphine, 365

Daurada (C), 390

Dè'at-el-Arab = Tbani, 405

De Constantine-See Rocarde, 463

De Cour $=$ Verte, 408

De Cuers $=$ Verte, 408

De l'Archipel = Archipel, 414

Del Capo = Cumpini, 434

Del Giammico-See Col de Dame Noir, 432

Del Giappone $=$ Pastilière, 456

Della Cava $=$ Vernino, 475

Della Lunigiana $=$ Monaco, 397

Della Madonna-See Datte, 389

Della Quaglia = Galluccio, 440

Della Villa = Scancaniso, 354

Delta-See Brown Turkey, 429

Des Confiseurs = Lampeira, 368

Des Dames $=$ Col de Dame, 387

Des Dames $=$ Verte, 408

D'Espagne = Espagnole, 412

D'Espagne-See Melagrano, 450

D'Espagne = Verte, 408

D'Hiver $=$ Verte, 408

Djaferi (S), 347

Djebali (S), 348

Djebali (of Gafsa) (C), 435

Djerbi (C), 436

Doctor Hogg Black (C), 436

See also Franciscana, 438

Dois à Fôlha (C), 412

Domestica (C), 390

Dominique (C), 477

Donicale $=$ Dattero, 435

Dor (P.I. No. 101,715) = Brunswick, 417

D'Or = Angélique, 382

D'Or $=$ Dorée, 390

D'Or $=$ Gentile, 360

D'Or Bifère (C), 436

D'Or de Baume (C), 436

D'Or de Laura (C), 390 
Dorato $=$ Albo, 372

Dorée (C), 390

Dorée Nobis (C), 376

D'Oro = Albo, 372

D'Oro $=$ Gentile, 360

Dottati $=$ Dottato, 376

Dottato (C), 369, 376

See also Gentile, 361; Limoncello, 395

Dottato Bianco $=$ Dottato, 376

Dottato Nero $=$ Merengiana, 451

Dottato Rosso = Merengiana, 451

Doucette (C), 480

Douqueira = Perroquine, 459

Douqueira Blanca (C), 390

Douqueira Negra = Perroquine, 459

Douqueiretta $=$ Cabroliana, 386

Douro Black = San Piero, 467

Douro Vebra = Franciscana, 437

Drap d'Or (Sp), 360, 366

Dr. Hogg's Clare = Monstrueuse, 398

Droubi $=$ Hdeidarmal, 379

Du Japon (C), 412

Dülekgazi $=$ Karayaprak, 349

Dure Peau $=$ Peau Dure, 458

Du Roi (C), 390

Early Forcing = Ischia Black, 443

Early Howick = Brown Turkey, 428

Early Lemon = Angélique, 382

Early Violet (C), 436

Early White (C), 378

Ebeidi $=$ Ghzali, 440

Edeisi (C), 378

Eggplant-See Merengiana, 451

Eisen (S), 343

El-Baioudi-See Bayoudi, 384

El Bitri (C), 391

El Hadj (S) Listed only, 359

El Hamma = Nourchi, 454

El Khadri (C), 391

Elma (Cp), 336

El Nouchi (C), 412

Endrich $=$ Dottato, 376

Endrich = Milco, 330

Erbeyli $=$ Sari Lop, 343

Eseli $=$ Mwazi, 419

Esmirna-See Sari Lop, 343

Espagne-See Verte, 408; Espagnole, 412; Melagrano, 450

Espagnole (C), 412

Esquillarello = Lipari, 395

Euchário Branco = Castelhano Branco, 346

Euchário Preto $=$ Castelhano Preto, 356

See also Castelhano Branco, 346

Euscaire (S), 354

Euscaire Preto = Euscaire, 354

Eva (C), 436

Everbearing (of Texas)-See Brown Turkey, 429
Excelsior (Cp), 329

Eye of the Partridge $=$ CEil de Perdrix, 455

Eyrogue (C), 391

Fabre (C), 480

Fallahi $=$ Byadi, 386

Fallugiana $=$ San Piero, 467

Fara-See Sesso, 350

Fayoumi = Sultani (of Egypt), 472

Ferguson (C), 437

Fetifero $=$ Merioun, 451

Fettouai (C), 412

Ficazzano $=$ Fracazzano Rosso, 367

Ficazzini Vera $=$ Cordelière, 388

Risso (1826) gives the following terminology, all varieties of Ficus carica:

aberdina $=$ Aberdin, 382

acut $a=$ Pounchuda, 402

albida = Blancassa, 384

amara = Amarouna, 421

aubana $=$ Aubane, 421

aulica $=$ Verte, 408

barnissota $=$ Barnissotte, 422

bellon $a=$ Bellona, 423

bernard $i=$ Barnissenca, 421,470

binella $=$ Dottato, 376

bovina $=$ Bouin, 385

browni-See Caiana, 430

caff $r a=$ Maure, 450

caiana $=$ Caiana, 430

candoleana $=$ Caiana Blanca, 386

cemenelea $=$ Cimeirenca Blanca, 386

claus $a=$ Bouche-barrique, 426

clavicularis $=$ Claveu, 432

collina $=$ Caravanchina, 386

cotignana $=$ Observantine, 388 (under

"Cordelière") ; 455

domina $=$ Col de Dame, 387

dulcissima $=$ Briasca Doussa, 428

falaciosa-See Verte, 409

franciscana $=$ Melagrano, 450

fusca-See Coucourelle Brune, 433

gallica $=$ Catalan, 431

garideli $=$ Sarreigne, 469

gorgonea $=$ Gorgone, 393

grassensis $=$ Grasse, 394

grise $=$ Saint Jean, 465

helen $a=$ Rondella Blanca, 403

imperialis $=$ Imperial, 442

labillardiera $=$ Coucourelle Gavotte, 433

linneana $=$ Mussega, 399

longicaudata-See Peconjudo, 458

lute $=$ Daurada, 390

massiliensis $=$ Marseillaise, 396

meirana $=$ Meirana, 450

melitensis $=$ Merengiana, 451

mellifer $a=\mathrm{Meou}, 397$

meridionalis $=$ Barnissotte Blanche, 383 
monstrosa $=$ Grosse Jaune, 394

mourenao $=$ Mourenao, 453

movissona $=$ Mouissonne, 452

nicaeensis $=$ Perroquine, 459

nigra $=$ Negrette, 453

nucleata $=$ Merioun, 451

obovata = Caravanchina Negra, 430

phoceana $=$ Marseillaise Black, 449

pilosa $=$ Perouas, 459

praecox $=$ Praecox, 461

pulchella $=$ Gentile, 360

punctulata $=$ Dauphine, 365

purpureo-violacea-See Salada, 467

radiata $=$ Panachée, 400

richardia $=$ Cuore, 434

richeta-See Ome, 455

rolandina $=$ Dattero, 435

rosa nigra = Rose Noire, 463

saccharata $=$ Sucrada, 404

salernitana $=$ Salerne, 403

saracenica $=$ Saraïna, 469

seirola $=$ Seirolles, 380

serotina $=$ Rubado Negro, 465

siciliana $=$ Sicile, 404

smithii = Levenssana, 446

spiritus-sancti = Saint-Esprit, 465

sprengellia $=$ Sprengel, 471

suffrenia $=$ Pissalutto Nero, 460

tournefortiana = Cordelière, 388

turneria-See Seirola Negra, 480

variabilis $=$ Verdale Blanche, 406

violace $a=$ San Piero, 467

virescens $=$ Verdal, 474

Gasparrini (1845) gives the following terminology, all under the genus Ficus :

deliciosa $=$ Paradiso, 455

deliciosa var. castanea = Datte, 389

deliciosa var. latifolia $=$ Monaco, 397

deliciosa var. maxima $=$ Cervone, 412

dottata $=$ Dottato, 376

hypoleuca $=$ Verdeccio, 381

leucocarpa = Troiano, 405

pachycarpa = Lardaro, 446

pachycarpa var. fasciata $=$ Panachée, 400

pachycarpa var. lusitanica = Lampeira, 368

pachycarpa var. nobilis $=$ Regina, 462

polymorph $a=$ Chiajese, 365

polymorpha var. bifera $=$ San Piero, 467, 479

See also Bifero, 479

polymorpha var. depressa = Barnissotte, 422

polymorpha var. elegans $=$ Dattero, 435

polymorpha var. haematocarpa $=$ Melagrano, 450

polymorph $a$ var. juliana $=$ Lugliatico, 357 polymorpha var. melanocarpa $=$ Petronciano, 368

Ficus carica bifera $=$ Paradiso, 455

Ficus carica kennedyensis = Castle Kennedy, 364

Ficus carica relicta-See Croisic, 336

Ficus hirta $=$ Pastilière, 456

Ficus liparensis = Lipari, 396

Ficus liviana-See Pissalutto, 401

Ficus palmata (Cp), 340

Ficus pseudo-carica (Cp), 340

Fietta (S), 348

Fièvre $=$ Gennes, 391

Figue Fleur (C), 437

Figues Neblados = Marseillaise Long, 449

Figuo Aubiquoun = Bordeaux, 424

Figuo Roso = Rose Blanche, 463

Filera $=$ Tira, 413

Fleur Rouge = Brown Turkey, 428

Florentina $=$ Toscana, 405

Florentine (C), 378

Forastera $=$ Señora, 470

Forbes (Cp), 329

Ford (C), 437

Ford Seedling $=$ Ford, 437

Ford's Seedling = Blanche, 372

Foundling (C), 477

Fourrassa (C), 391

Fqeisi (C), 391

Fracatsani $=$ Dottato, 376

Fracazzano (C), 378

Fracazzano Bianco $=$ Fracazzano, 378

Fracazzano Rigato $=$ Panachée, 400

Fracazzano Rosso (Sp), 367

Fraga $=$ Col de Dame, 387

Fragola $=$ Verdone, 406

Franche (C), 477

Franche Paillard (C), 437

Franciscana (C), 369, 437

See also Dr. Hogg Black, 436; Merengiana, 451

Franciscana = Melagrano, 450

Franque Pagarde $=$ Franche Paillard, 437

Frette (C), 439

Fuente de Balafi = Balafi, 477

Gaddhuzzo $=$ Galluceio, 440

Gagliano del Capo $=$ Tardivo, 332

Gajico (C), 412

Gallipolino (C), 477

Galluccio (C), 440

Gambalunga (C), 391

Gazir (C), 477

Gemini I (Cp), 337

Gemini II (Cp), 333

Gennes (C), 391

Genoa (C), 391

Genoa-See Gennes, 391 
Genoa Black = San Piero, 467

Genoa White $=$ Genoa, 391

Genovese $=$ Datte, 389

Gentile $=$ Dottato, 376 See also Gentile, 360

Gentile (of Bologna) = Albo, 372

Gentile (Sp), 360

Gentilium $=$ Gentile, 360

Gentilla $=$ Gentile, 360

Gentilla Roussa = Moresca, 399

Gentio-See Lampeira, 368

Geraci Black = Royal, 464

Gerusalem $=$ Jerusalem, 445

Ghengelje $=$ Changelge, 347

Ghorabi $=$ Abboudi, 414

Ghozi = Abboudi, 414

Ghozlani $=$ Ghzali, 440

Ghzali (C), 440

Giammico-See Col de Dame Noir, 432

Giappone $=$ Pastilière, 456

Gillette $=$ Croisic, 336

Glati (C), 393

Gök Lop (S), 348

Golden Narbus $=$ Dorée Nobis, 376

Gombaya (C), 478

Gorgone (C), 393

Gota de Goma = Gota de Mel, 393

Gota de $\mathrm{Mel}$ (C), 393

Gounti (C), 393

Gouraud Noir $=$ Franciseana, 437

Gouraud Rouge (C), 440

Goureau (C), 419

Gourreau du Languedoc $=$ Franciscana, 437

Gourreau Noir-See Franciscana, 437

Goutte $=$ Jerusalem, 445

Goutte d'Or $=$ Dorée, 390

Grá (C), 478

Graissane (C), 412

Granado-See Melagrano, 450

Granata $=$ San Piero, 468

Granato (C), 440

Grande (Cp), 341, 451

Grascello $=$ Dottato, 376

Grassale (C), 393

Grasse (C), 394

See also Grassale, 393

Grassenque $=$ Grasse, 394

Greef's Black $=$ St. Domingo, 471

Grisé = Archipel, 414

Grisé $=$ Célestine, 431

Grisé $=$ Grasse, 394

Grisé $=$ Saint Jean, 465

Grisé de Saint Jean = Saint Jean, 465

Grisé Madeleine $=$ Saint Jean, 465

Grisé Savantine $=$ Saint Jean, 466

Grisé Savantine Bifère = Saint Jean, 465

Grisette $=$ Célestine, 431

Grizzly Bourjassotte = Bourjassotte Grisé, 427
Grosse Berdoua $=$ Berdauda, 384

Grosse Blanche de Gênes-See Grosse Jaune, 394

Grosse Blanche Longue $=$ Marseillaise Long, 449

Grosse Blanche Ronde = Blanche, 372

See also Salerne, 403

Grosse Bourjassotte $=$ Barnissotte, 422

Grosse de Juillet = Sultane, 472

Grosse de Juillet-See Dauphine, 365

Grosse du Draguignan $=$ Verdal, 474

Grosse Grisé = Saint Jean, 466

Grosse Grisé Bifère = Saint Jean, 465

Grosse Jaune (C), 394, 451

Grosse Marseilles (C), 440

Grosse Monstrueuse de Lipari = Monstrueuse, 398

Grosse Rouge de Bordeaux = San Piero, 467

Grosse Sultane (C), 478

Grosse Superfine (C), 419

Grosse Verdale $=$ Verdal, 474

Grosse Verte $=$ Verdone, 406

Grosse Violette $=$ Dauphine, 365

Grosse Violette de Bordeaux = San Piero, 467

Grosse Violette de Bordeaux-

See Bordeaux, 425

Grosse Violette Longue $=$ San Piero, 467

Grosso (Cp), 333

Grosso Figo = Barnissotte, 422

Guers $=$ Verte, 409

Guiliana (C), 441

Habtir (S), 356

Hajji Mestan (Cp), 337

Hameri-See Hamri, 478

Hamma (Cp), 333

Hammani (S), 359

Hamri (C), 478

Hamriti (S), 354

Hanover $=$ Brunswick, 416

Hardy Prolific $=$ Archipel, 414

Harraki (C), 395

Harrison-See Brown Turkey, 429

Hâtive d'Argenteuil (C), 441

Hdadi (C), 379

Hdeidarmal (C), 379

Heiny No. 1 (Cp), 329

Hejazi $=$ Sultani (of Egypt), 472

Hélène = Rondella Blanca, 403

Higuera Negra-See Franciscana, 438

Hilgard (S), 348

Hirta $=$ Pastilière, 456

Hirta du Japon $=$ Pastilière, 456

Hiver $=$ Verte, 408

Hmadi (C), 441

Hmari (C), 441

Horaigaki (C), 441 
Hortella $=$ Tira, 413

Hospitalière (C), 412

Howard $(\mathrm{Cp}), 333$

Hunt (C), 441

Iadi $=$ Jadi, 348

Illoul (Cp), 337

Imlloui-See Tadefouit and Tameriout, 352

Imperial (C), 442

Imperiau = Imperial, 442

Incarnadine-See Angélique Jaune, 383

Ingannamiele $=$ Borsamele, 343

Invernale $=$ Arneo Bianco, 383

Invernengo $=$ Arneo Bianco, 383

Invernengo Rosso (C), 442

Inverneo = Arneo Bianco, 383

Invernizzo = Arneo Bianco, 383

Ischia (C), 442

Ischia Black (C), 443

Ischia Brown (C), 444

Ischia Figs, The, 442

See also Verte, 409

Ischia Green $=$ Verte, 408

See also The Ischia Figs, 442

Ischia White = Ischia, 443

Ischia Yellow (C), 395

Isly (S), 348

Italian Large Blue $=$ Brown Turkey, 428

Italian No. $1=$ Taylor, 342

Italian No. $2=$ Rivers, 341

Ivernenca $=$ Señora, 470

Jadi (S), 348

Jalboushi $=$ Tbani, 405

Japanese $=$ Pastilière, 456

Jaspée $=$ Panachée, 400

Jasper (C), 445

Jaune de Toulouse (C), 379

Jaune Hâtive = Early White, 378

Jerusalem (C), 445

Jetta $=$ Fietta, 348

Jorba (C), 412

Jorest (C), 419

Julia $=$ Parejal, 413

Kaab el Ghazal (S), 343

Kaapse Bruin-See Eva, 436

Kadota $=$ Dottato, 325, 376

Kaffi (C), 395

Kahili (C), 446

Kahramani (C), 379

Kalamata (S), 348

Kara Ilek-See Stanford caprifig, 338

Kara Injir (S), 356

Kara Mor (Cp), 333

Karayaprak (S), 349

Kargigna (C), 379

Kassaba (S), 349
Kearney (Cp), 329

Kennedy = Castle Kennedy, 364

Kennedy-See Brunswick, 417

Khadir (S), 349

Khalouli (S), 357

Kharroubi (C), 446

Khazouri (S), 343

Khdari (Sp), 361

Khedri = El Khadri, 391

Khlouth (S), 359

Khurtmani (P.I. No. 80,297) = Brunswick, 417,419

Khurtmani $=$ Mwazi, 419

Khussum = Smari, 471

King (Sp), 360, 361

Kommathri (C), 395

Kongouz (Cp), 341

Kongur (Cp), 337

Kouffi Rouge (S), 357

Kouffi Vert (S), 349

Koutsina (C), 480

Krati $=$ Krawi, 395

Krawi (C), 395

Kus (C), 446

Kuyucak (Cp), 337

Labillardière $=$ Coucourelle Gavotte, 433

Ladaro-See Lardaro, 446

Lampas = Lampeira, 368

Lampas Portoghese $=$ Lampeira, 368

Lampeira (Sp), 368

Lampo Branco-See Cachôpeiro Branco, 360

Lampo Preto-See Lampeira, 368

La Perpétuelle $=$ Brown Turkey, 428

Lardaio = Lardaro, 446

Lardaro (C?), 446

Larde $=$ Datte, 389

Large Black Douro = San Piero, 468

Large Blue $=$ Brown Turkey, 429

Large White Turkey= Brunswick, 416

La Rousse $=$ Rose Blanche, 463

Lattarola (C), 395

Lattarula = Blanche, 374

Lebi (S), 349

Lee's Perpetual $=$ Brown Turkey, 428

Leker Injir = Cheker Injir, 347

Lemon = Blanche, 374

Leon (C), 419

Levant (C), 412

Levenssana (C), 446

Limoncello (C), 395

Limone $=$ Panachée, 400

Liparensis = Lipari, 395

Lipari (C), 395

Lipari-See Ischia, 442

Livia-See Troiano, 405

Llimonenca (C), 412

Lob Injir (or Ingir) = Sari Lop, 343 
Isong Naples $=$ Brown Turkey, 428

Longue d'Août (C), 446

Longue Marseillaise = Marseillaise Long, 449

Loomis (Cp), 337

Lucano (C), 396

Lucrezia $=$ Col de Dame, 387

Lugliarolo = Lugliatico, 357

Lugliatico (S), 357

Lumincella $=$ Dottato, 376

Lungo Bianco $=$ Sesso, 350

Lunigiana $=$ Monaco, 397

Madagascar $=$ Sultani $($ of Egypt), 472

Madama Rosso = Datte, 389

Madel (Cp), 337

Madeleine = Angélique, 382

Madeleine $=$ Blanche, 372

Madeline (C), 447

Madère (C), 447

Madonna $=$ Brunswick, 416

Madonna-See Datte, 389

Madoui (S), 349

Magdalen (C), 379

Magnissalis (Cp), 333

Magnolia = Brunswick, 416, 417

Mahounaise (C), 478

Malaguenho Branco and M. Bravo= Cótio, 388

Malaki (S), 343

Malaki Blanc (S), 349

Malaktiana (C), 480

Malmaison (C), 447

Malta (C), 447

Malta $=$ Merengiana, 451

Mamari (S), 349

Maple-Leaved (S), 350

Mappafero (C), 449

Marabout (S), 357

Marangiano $=$ Merengiana, 451

Maravilla = Panachée, 400

Mare de Déu (C), 478

Marinera (C), 419

Mario or Mariu = Cascitello, 431

Markaridin ( $\mathrm{Cp}), 337$

Markarian No. 1 = Samson, 331, 338

Markarian No. 2 = Markarian, 337

Marquês (C), 396

Marsaoui (C), 419

Marseillaise (C), 396

Marseillaise Black (C), 449

Marseillaise Long (C), 449

Marseillaise Negra = Marseillaise Black, 449

Marseillaise White $=$ Blanche, 372

Marseilles = Blanche, 372

Marseilles $=$ Marseillaise, 396

Martigiano (C), 397

Martinenca $=$ Barnissenca, 421

Martinenca Blanca = Ojo de Perdiz, 379
Martinique (C), 449

Martinique White (C), 450

Marzelli (C), 419

Maslin (Cp), 341

Maslin No. $14=$ West, 353

Maslin No. $52=$ Eisen, 343

Maslin No. $70=$ Bleasdale, 338, 341

Maslin No. 91 (Cp), 340

Maslin No. $114=$ Rixford, 350

Maslin No. $144=$ Mason, 338

Maslin No. $147=$ Loomis, 337, 338

Maslin No. $148=$ Newcastle, 338

Maslin No. 150 (Cp), 338

Maslin No. 153 = Hilgard, 348

Mason (Cp), 338

Mastroleone (C), 397

Mastruglione $=$ Mastroleone, 397

Masui Dauphine = San Piero, 468

Matarassa $=$ Grasse, 394

See also Grassale, 393

Matelassa (C), 419

Matelassiera $=$ Matelassa, 419

Matmata $=$ Nourchi, 454

Mattano $=$ Albo, 372

Maure (C), 450

McFadden (C), 447

Mecklingea-See San Piero, 468

Medloub (Cp), 338

Medot $=$ Dottato, 376

Meirana (C), 450

Melagnano $=$ Schiavo, 470

Melagrano (C), 450

Melanciano $=$ Merengiana, 451

Melanzana $=$ Merengiana, 451

Melette $=$ Angélique, 382

Melinga (C), 450

Melingue $=$ Melinga, 450

Melonceddha $=$ Meloncella, 397

Meloncella (C), 397

Melouba (C), 450

Mendolaro (Cp), 330

Mentonasca (C), 451

Mentone = Mentonasea, 451

Meou (C), 397

Merchini (S), 350

Merengiana (C), 451

Merengiano $=$ Merengiana, 451

Merioun (C), 451

Merlinga (C), 451

Messenia = Kalamata, 348

Messina (C), 452

Messinese = Messina, 452

Messongue (C), 480

Meyer (Cp), 341

Meyer, Paul, No. $1=$ Meyer, 341

Meyer, Paul, No. 2 = Brackett, 341

Mezzith (S) Listed only, 359

Mielleuse $=$ Meou, 397

Migliarolo = Lugliatico, 357 
Mignonne (C), 452

Milco (Cp), 330

Minion = Mignonne, 452

Minna di Schiavo or Minni di Seava $=$ San

Piero, 467

Minuto Bianco (C), 379

Minuto Nero (C), 452

Miraya (C), 478

Mission $=$ Franciscana, 325, 437

Missonne-See Mouissonne, 452

Mitchell (Cp), 341

Moda $=$ Mota, 350

Moelle $=$ Messongue, 480

Moissoa $=$ Mouissonne, 452

Molignano $=$ Petronciano, 368

Monaca $=$ Signora, 471

Monacello = Barnissotte, 422

Monaco (C), 397

Monaco Bianco = Monaco, 397

Monaie (C), 452

Monginenco $=$ Perroquine, 459

Monica (C), 478

Monstrueuse (C), 398

Montesino (Cp), 333

Mor (Cp) Listed only, 341 .

Mor (S), 357

Mor Güz (S), 357

Moresca (C), 399

Moseadello = Albo, 372

Moscatel Branco (C), 399

Moscatel Preto (C), 452

Mota (S), 350

Mouissonne (C), 452

Mouissonne Noire $=$ Mouissonne, 452

Mourenao (C), 453

Mouzai (S), 350

Mrari = Qeisi, 462

Mshaki (C), 379

Mulleisi = Ghzali, 440

Murrey $=$ Brown Turkey, 428

Museau de Lièvre (C), 453

Mussega (C), 399

Mussega Negra = Dauphine, 365

Mwazi (C), 419

Mwazi (Northern) (C), 399

Nain (C), 453

Napoletana (S), 358

Napoletani $=$ Dottato, 376

Napoletano $=$ Dottato, 376

Napoli $=$ Dottato, 376

Napolitaine (C), 453

Napolitano $=$ Napolitaine, 453

Napulitano $=$ Cascitello, 431

Nardeleo $=$ Dottato, 376

Natalino $=$ Arneo Bianco, 383

Natalino or N. Nero = Vernino, 475

Neapolitan $=$ Genoa, 392

Neapolitan $=$ Napolitaine, 453
Neapolitan caprifigs (and others, miscellaneous), 342

Nebian $=$ Verdone, 406

Negra = Franciscana, 437

Negretta $=$ Negrette, 453

Negrette (C), 453

Negro d'Espagne $=$ San Piero, 467

Negro Largo (P.I. No. 18,889)= Barnissotte, 423

Negro Largo $=$ San Piero, 467

Negronne $=$ Bordeaux, 424

Neimi (C), 399

Nerii-See The Ischia Figs, 442

Nero = Ischia Black, 443

Nero $=$ San Piero, 467

Nero $=$ Scavello, 420

Nero-See Cascitello, 430

Nerolello (C), 454

Neveralla $=$ Archipel, 414

New Brunswick $=$ St. Domingo, 471

Newcastle (Cp), 338

New Delta-See Brown Turkey, 429

New French (C), 413

See also Angélique, 382

Niuro = Cascitello, 431

Nocciuola $=$ Galluccio, 440

Noce (Sp), 362

Noire $=$ Madère, 447

Noire de Juillet $=$ Sultane, 472

Noire de Languedoc $=$ San Piero, 468

Noire d'Espagne-See Franciscana, 437

Noir Moutier (C), 454

Noral (C), 454

Nourchi (C), 454

Noursi (C), 399

Obispo $=$ Royal, 464

Observantière Grisé = Observantine, 455

Observantine (C), 455

See also Cordelière, 388

Cil de Perdrix (C), 455

See also Poulette, 460

Ojo de Perdiz (C), 379

Olho de Passarinho= Barnissotte Blanche, 383

Ome (C), 455

Orihuela $=$ Señora, 470

Orzidane $=$ Azaim, 335

Osborn = Archipel, 414

Osborn Prolific (Rust) (C), 420

Osborn's Prolific $=$ Archipel, 414

Osso $=$ Merioun, 451

Ottato $=$ Dottato, 376

Ottato Rosso ( $\mathrm{Sp}$ ), 368

Oumadel = Madel, 337

Paccio $=$ Pazzo, 350

Pacuecas $=$ San Piero, 468

Pagaudière $=$ Dauphine, 365 
Pajajero (C), 399

Pallaro (C), 380

Panachée (C), 400

See also Carabaseta, 386

Panettaro (S), 350

Panettiero $=$ Panettaro, 350

Panetto $=$ Abate, 345

Papathoumika (C), 480

Paradiso (C), 455

Paradiso (of Cavolini) $=$ Abate, 345

Paraíso-See Paradiso, 455

Pardo (C), 456

Parechal $=$ Parejal, 413

Parejal (C), 413

Paretjal Negra $=$ Calderona, 430

Parmigiano $=$ Merengiana, 451

Partridge Eye (C), 456

Pasquale $=$ Vernino, 475

Passacanne (S), 358

Passanudo (C), 401

Passet $=$ Brianzola, 385

Passin $=$ Brianzola, 385

Pastellière $=$ Pastilière, 456

Pastidì̀re $=$ Pastilic̀re, 456

Pastilière (C), 456

Pasu'ella = Pasulito, 350

Pasulito (S), 350

Pata de Cavalo-See Curigo, 434

Paul Meyer No. $1=$ Meyer, 341

Paul Meyer No. 2 = Brackett, 341

Pazzo (S), 350

Peau d'Âne $=$ Peau Dure, 458

Peau Dure (C), 458

See also Verte Brune, 476

Peau Dure-See Drap d'Or, 366

Pecciolo Bianco (C), 401

Pecciolo Nero (C), 458

Peconjano $=$ Peconjudo, 458

Peconjude Grisé = Peconjudo, 4.5 $\mathrm{x}$

Peconjudo (C), 458

Pecouliano $=$ Pecon $. j u d o, 458$

Pídonculée = moro ive? 458

Zci:a: i, 5:

Pedunculato (Cp), $3+1$

Peldure $=$ Peau Dure, 458

Pelo de Buey (C), 380

Pelosa (C), 413

Peloso $=$ Sesso, 350

Peloua $=$ Perouas, 459

Peluda = Sitsel, 479

Penna (C), 459

Pennese (C), 401

Pentolello (C), 459

Pera $=$ Col de Dame, 387

Père Hilarion $=$ Panachée, 400

Pergussata $=$ Pregussata, 461

Pero (C), 401

Peroquina $=$ Perroquine, 459

Perouas (C), 459
Perroquine (C), 459

Perruquière $=$ Perroquine, 459

Perticone (C), 401

Peters White (C), 401

Petite Aubique $=$ Bordeaux, 424

Petite Blanche $=$ Précoce, 413

Petite Blanche Ronde = Lipari, 395

Petite Bourjassotte $=$ Sarreigne, 469

Petite Figue Grisé = Angélique, 382

Petite Figue Violette $=$ Bordeaux, 424

Petite Marseillaise = Marseillaise, 396

Petite Verdale $=$ Verdal Round, 475

Petronciano (Sp), 368

Pheasant Eye $=$ CEil de Perdrix, 455

Pichotte Barnissotte $=$ Sarreigne, 469

Pied de Bœuf (Sp), 368

Piemontese (C), 478

Pietri (Sp), 362

Pilosa $=$ Sesso, 350

Pilosella (C), 413

Piloso $=$ Sesso, 350

Pingo de $\mathrm{Mel}=$ Croisic, 336

Pingo de $\mathrm{Mel}=$ Moscatel Branco, 399

'iombinese = San Piero, 467

Pissalutto (C), 401

Pissalutto Bianco $=$ Pissalutto, 401

Pissalutto Negro = Pissalutto Nero, 460

Pissalutto Nero (C), 460

Pitalouse-See Pissalutto, 402

Pitalusse $=$ Pissalutto, 401

Pittalusse Blanche $=$ Pissalutto, 401

Pittalusse Noire $=$ Pissalutto Nero, 460

Plata (C), 478

Pocock $=$ Blanche, 372

Poire $=$ Bordeaux, 424

Ponte da Quarteria = Marquês, 396

Poona (C), 460

Poppa (C), 380

Porcino (C), 480

Porquena (C), 478

Torquena Negra = Porquena, 478

to $(\mathrm{C}), 478$

1. to rhese = Lampeira, 368

P'rtoghese-See Colombo Bianco, 375

Portugal Black $=$ San Piero, 467

Potentino $=$ Mappafero, 449

Potignacenque $=$ Cotignacenque, 388

Poulette (C), 460

Pounchuda (C), 402

Poussouluda $=$ Pissalutto, 401

Praecox (C), 461

Précoce (C), 413

Précoce de Barcelona (C), 461

Précoce d'Espagne-See Trois Récoltes, 473

Précoce Noire $=$ Barnissotte, 422

Pregussata (C), 461

Preston (C), 462

Preston Prolific $=$ Preston, 462

Prigisotto $=$ Schiavo, 470 
Primaticcio ( $\mathrm{Cp}), 338$

Princessa $=$ Panachée, 400

Processotto (C), 402

Purple Bulletin Smyrna (S), 358

Purple Smyrna (S), 358

Qeisi (C), 462

Quagghia $=$ Galluccio, 440

Quaglia = Galluccio, 440

Quarai (C), 402

Quarteria = Blanche, 372

Quasbi (C), 478

Quasse Blanche (C), 478

Quotidienne = Datte Quotidienne, 434

Raby Castle (C), 380

Raby Castle $=$ Blanche, 372

Ragusa (C), 413

Ragusaine $=$ Ragusa, 413

Rainha = Barnissotte Blanche, 383

Ramadi = Sultani (of Egypt), 472

Ramsey (C), 462

Rargigna = Kargigna, 379

Ravignon (C), 402

Rayonne $=$ Panachée, 400

Rebanquio (C), 402

Recousse Noire (C), 462

Recousse Violette-See Recousse Noire, 462

Reculver $=$ Franciseana, 437

Redd-el-Gouch (C), 402

Redona de Grá (C), 478

Regalo = Barnissotte Blanche, $38: 3$

Reggitana (C), 420

Regina (C), 462

Reginella (C), 413

Rei (C), 462

Reina = Regina, 462

Reine (C), 380

Reine $=$ Mussega, 399

Renyach (C), 479

Rescio $=$ Penna, 459

Rherabi (S), 358

Ricciuto ( $\mathrm{Cp}), 334$

Rivers (Cp), 341

Rivers-See Cravé, 434

Rixford (S), 350

Rizzeddhu = Rizzello, 402

Rizzello (C), 402

Robado $=$ Melagrano, 450

Roca (C), 479

Rocarde (C), 463

Rocardi $=$ Rocarde, 463

Rock (Cp), 334

Rock Fig $=$ Negrette, 453

Roeding No. 1 (Cp), 330

Roeding No. 2 (Cp), 334

Roeding No. 3 (Cp), 334, 338

Roeding No. 4 (Cp), 331

Roja (C), 420
Rojal = Roja, 420

Rojisca (C), 479

Rolandine or Rolandina $=$ Dattero, 435

Rolandine $=$ Archipel, 414

Rolandine Blanche $=$ Dattero, 435

Rolandine Noire $=$ Rose Noire, 463

Roma Branco-See Cachôpeiro Branco, 360

Roma Preto-See Lampeira, 368

Ronde Noire-See Archipel, 414

Ronde Rouge (C), 463

Ronde Violette Hâtive $=$ Dauphine, 365

Rondeletta (C), 463

Rondella Blanca (C), 403

Rondella Negra (C), 463

Rosa (S), 343

Rosa (C), 463

Rose Blanche (C), 463

Rose Noire (C), 463

Rose Peyronne (C), 464

Rossetto $=$ Datte, 389

Rosso (Cp), 335

Rotondo (Cp), 331

Roubauda Blanca = Cuore, 434

Roubauda Negra = Rubado Negro, 465

Rouge de Argenteuil = Dauphine, 365

Rouge de La Frette $=$ Frette, 439

Rougette (C), 403

Round White Smyrna (S), 350

Roussale (C), 464

Roussana (C), 464

Roxo de Valinhos (C), 464

Royal (C), 464

Roya! Black = Roynl, 464

Royale $=$ Blanche, 372

Royal Vineyard = Drap d'Or, 366

Rubado = Cuore, 434

Rubado Negro (C), 465

Rubicone = San Piero, 467

Russello (C), 420

Russuliddu = Galluccio, 440

Rust = Osborn Prolific, 420

Safranée (C), 479

Saint Dominique $=$ Dominique, 477

Saint-Esprit (C), 465

Saint Jean (C), 465

See also Toulousienne, 473

Saint Jean = Brunswick, 416

Saint Jean Blane $=$ Croisic, 336

Saint Jean Gris = Saint Jean, 465

Saint John = Croisic, 336

Saint Peter $=$ San Pedro, 363

Saint Ursule d'Avignon (C), 466

Salada (C), 467

Salateddhu = Salatello, 358

Salatello (S), 358

Salerne (C), 403

Sampiero $=$ San Piero, 467 
Sampiero-See Cascitello, 431; Madère, 447 ; Bifero, 479

Samson (Cp), 331

San Antonio (Cp), 332

San France $=$ Melagrano, 450

San Francesco = Melagrano, 450

San Giovanni (Sp), 363

San Pedro ( $\mathrm{Sp}$ ), 363

San Pedro Black = San Piero, 467

San Pedro White = San Pedro, 363

San Piero (C), 467

See also Roxo de Valinhos, 464

San Piero-See Cascitello, 431; Madère, 447 ; Bifero, 479

San Pietro (C), 403

San Pietro-See Cascitello, 431

San Pietro-See San Piero, 468

Sang de Lièvre (C), 467

Santa Catarina-See Cachôpeiro Branco, 360

Santagatese (C), 469

Santa Scianni = San Giovanni, 363

Santu Vitu = San Vito, 364

San Vito (Sp), 364

São Luiz (C), 469

Saraïna (C), 469

Sarasina $=$ Saraïna, 469

Sari Lop (S), 343

See also Kalamata, 348

Sarnese-See Pissalutto, 401

Sarnese Bianco = Pissalutto, 401

Sarnese Nero $=$ Pissalutto Nero, 460

Sarreigne (C), 469

See also Barnissenca, 421

Sarreignos $=$ Sarreigne, 469

Sbayi (C), 470

Scancaniso (S), 354

Scansaniso-See Scancaniso, 354

Scaranzone (C), 404

Scavello (C), 420

Schiavo (C), 470

Schiavone $=$ Cascitello, 431

Schifo (C), 380

Schwarz (Cp), 335

Scionto (S), 344

Seirola = Seirolles, 380

Seirola Negra (C), 480

Seirolles (C), 380

Seker $=$ Cheker Injir, 347

Selteni (C), 470

Señora (C), 470

Serra (C), 413

Servantine $=$ Cordelière, 388

Sesso (S), 350

Sessune $=$ Sesso, 350

Setosa $=$ Perouas, 459

Sextius (C), 413

Seyroles $=$ Seirolles, 380

Sfari (C), 404

See also Hdadi, 379
Shalati el Abed = Smari, 471

Sharrawi (C), 404

Sheker Injir $=$ Cheker Injir, 347

Shheimi $=$ Yaffawi, 381

Shourtawi = Yaffawi, 381

Shtawi (C), 404

Shuhmani $=$ Neimi, 399

Shunnari (C), 470

Shunnari Asmar (C), 471

Sicile (C), 404

Sidi-ben-Agous (C), 471

Sidi-ben-Aied (C), 479

Sidi Gaber = Sultani (of Egypt), 472

Sigilli (S), 351

Signora (C), 471

Signorella (C), 404

Silver Leaf $=$ Brunswick, 418

Singleton = Ischia, 442

Sirore $=$ Seirolles, 380

Sitsel (C), 479

Slati (C), 404

S. Luiz = São Luiz, 469

Small Blue = Brown Turkey, 428

Small Brown = Malta, 447

Small Brown Ischia-See Ischia Brown, 444

Smari (C), 471

Smith Island Lemon $=$ Troiano, 405

Smyrna No. $2=$ Roeding No. 2, 334

Smyrna No. 3 = Roeding No. 3, 334

Smyrna No. $4=$ Bulletin, 341

Snowden (S), 344

Sofêno (C), 471

Solms-Laubach (Cp), 335

Solms-Laubach No. 1 = Solms-Laubach, 335

Solms-Laubach No. $2=$ Rock, 334

Solms-Laubach No. $3=$ Howard, 333

Solms-Laubach No. $4=$ Schwarz, 335

Soltani-See Soltanine, 358

Soltanine (S), 358

Sopa e Vinho (C), 471

Souaba-el-Adjia Blanche (S), 351

Souaba-el-Adjia Rose (C), 471

Spagna $=$ Melagrano, 450

Sprengel (C), 471

Stanford (Cp), 338

Stanford (S), 351

Stanford Nonsplitting $=$ Stanford (Smyrnatype), 351

St. Domingo (C), 471

Strawberry $=$ Verdone, 406

Striped $=$ Panachée, 400

Sucrada (C), 404

Suffren $=$ Pissalutto Nero, 460

Sugar Fig $=$ Malta, 447

Sugar Fig = Sucrada, 404

Sukkari (C), 472

Sulomo (C), 405

Sultane (C), 472

Sultane-See Marabout, 357

Sultane $=$ Sultani (of Egypt), 472 
Sultane Bi-longue (S), 351

Sultane du Marabout = Marabout, 357

Sultani (of Egypt) (C), 472

Sultani (of Palestine) (C), 413

Sultani (of Syria) (S), 351

Sultanie (S), 344

Superba $=$ Dauphine, 365

Swadi $=$ Smari, 471

Swingle (Cp), 342

Sydawi (C), 405

Taamrouth $=$ Tameriout, 352

Tabelout (S), 352

Tabelout (large-fruited) (S), 352

Taboukal-See Marabout, 357

Tabouyahboult $=$ Alekake, 345

See also Aboucherchaou, 345

Tadefouit (S), 352

Tagouaout $=$ Taranimt, 352

Taharit (S), 352

Taidelt-See Taharit, 352

Taklit (S), 358

Takourchit (S), 352

Tameriout (S), 352

Tapa Cartin $=$ Grosse Jaune, 394, 451

Tapa Cartin Negra = Bouche-barrique, 426

Taranimt $(\mathrm{Cp}), 339$

Taranimt (S), 352

Tardivo (Cp), 332

Tardo $=$ Arneo Bianco, 383

Tarlit-See Taharit, 352

Taroumant (S), 358

Tassa Brown $=$ Royal, 464

Tassiret (C), 413

Taurisano (S), 353

Taylor (Cp), 342

Taylor $=$ Excelsior, 329

Tazarift (S), 353

Tbani (C), 405

Tebessi (C), 479

Techich (S), 358

Teen Kazzi (S), 359

Temeri-See Temri, 472

Temri (C), 472

Texas Everbearing-See Brown Turkey, 429

Thaamriout $=$ Tameriout, 352

Thaaoust (S) Listed only, 359

Thaaranimt $=$ Taranimt, 352

Thaaranimt Entael Hadjar (S), 359

Thaarlit (S) Listed only, 359

Thabelout $=$ Tabelout, 352

Thaberkant (Cp) Listed only, 342

Thabouhiaboult = Aboucherchaou, 345

Thaboukal-See Marabout, 357

Thadhefouith-See Tadefouit, 352

Thaharchou (S) Listed only, 359

Thaiadelst $=$ Alekake, 345

Thameingoult $=$ Aboucherchaou, 345

Thamkarkor Rose (S), 359
Thar'animt (S) Listed only, 359

Thar'animt = Taranimt, 352

Thazaicht (S) Listed only, 359

Thazgouart (S) Listed only, 359

Thompson = San Piero, 468

Thompson Improved Brown Turkey $=$ San Piero, 468

Tia Penya (C), 479

Tiboulenque (C), 413

Tibourenque $=$ Tiboulenque, 413

Tiburtina $=$ Gentile, 360

Tifouzal (Cp) Listed only, 342

Tiger $=$ Panachée, 400

Timlouit (S) Listed only, 359

Tin Baitri = Croisic, 336

Tina ta Spanja = Panachée, 400

Tira (C), 413

Tit-en-Tsekourt (Cp), 332

Tlabi = Tbani, 405

Tordo (C), 405

Torres = Rei, 462

Toscana (C), 405

Tossico (C), 381

Toulousienne (C), 473

Tounsi (C), 479

Treccia $=$ Fietta, 348

Tres Fer-See Trois Récoltes, 473

Três um Prato (S), 353

Tre Volte l'Anno = Vernino, 475

Tributaria (C), 473

Trifero $=$ Dottato, 376

Troano-See Taylor, 342

Troiano (C), 405

See also Napolitaine, 453

Trois Récoltes (C), 473

Trojano = Royal, 464

Trojano $=$ Troiano, 405

Trojano-See Albo, 372

Trojano di Napoli = Royal, 464

Trompe-Cassaire $=$ Verte, 408

See also Verte Brune, 476

Trompe-Chasseur $=$ Verte, 408

Turea $=$ Panachée, 400

Turco (S), 359

Turque = Levant, 412

Ull de Perdiu = Ojo de Perdiz, 379

Umm-et-Tabat $=$ Tbani, 405

Unico $=$ Melagrano, 450

Unnequi (C), 406

Urjal (C), 381

Uttato $=$ Dottato, 376

Vacal (C), 413

Van Lennep (Cp), 340

Vardica $=$ Vardina, 480

Vardina (C), 480

Variegato $=$ Panachée, 400

Vazanata (C), 480 
Velue $=$ Perouas, 459

Velvet $=$ Perouas, 459

Vendôme $=$ Angélique Jaune, 383

Verdal (C), 369, 474

Verdal de Oriola-See Verdal, 474

Verdal de Valence (C), 475

Verdal Longue $=$ Verdal, 474

Verdal Negra (C), 479

Verdal Ronde $=$ Verdal Round, 475

Verdal Round (C), 475

Verdal White $=$ Verdale Blanche, 406

Verdala $=$ Verdal, 474

Verdala Blanca $=$ Verdale Blanche, 406

Verdale $=$ Reine, 380

Verdale $=$ Verdal, 474

Verdale $=$ Verte, 408

Verdale Blanche (C), 406

Verdalle $=$ Verte, 408

Verdalo $=$ Sarreigne, 469

Verdalos $=$ Sarreigne, 469

Verdaou $=$ Berdauda, 384

Verdeal (C), 406

Verdecchio $=$ Verdeccio, 381

Verdeccio (C), 381

Verde Gentil-See Verdone, 407

Verdesco $=$ Verdescone, 353

Verdescone (S), 353

Verdiccio Gentile $=$ Dattero, 435

Verdichio $=$ Verdeccio, 381

Verdillo-See Verdeccio, 381

Verdino (C), 406

Verdino di Brianza-See Verdeccio, 381

Verdolino-See Verdeccio, 381

Verdone (C), 406 See also Verte, 409

Verdone (of Taranto) $=$ Verdescone, 353

Verdoni-See Milco, 330

Verdoni-See Troiano, 406

Verdoso-See Verdeccio, 381

Verguna $=$ Señora, 470

Verneo Bianco = Arneo Bianco, 383

Verneo Nero = Vernino, 475

Vernile (C), 479

Vernino (C), 475

Vernisingue-See Barnissenca, 421

Vernissangue-See Barnissenca, 422

Vernissenque-See Barnissenca, 421

Versailles $=$ Blanche, 372

Verte (C), 408

See also Espagnole, 412; The Ischia Figs, 442 ; Verte Brune, 476

Verte Brune (C), 476

See also Peau Dure, 458

Verte des Dames $=$ Verte, 409

Verte Petite $=$ Lipari, 395

Vescovo (C), 410

Vezzoso $=$ Dattero, 435
Victoria (C), 476

Vigasotte Bianco = Blanche, 372

Villa = Scancaniso, 354

Vindimo Branco-See Cachôpeiro Branco, 360

Vindimo Preto-See Lampeira, 368

Violada Blanca (C), 410

Violet Delicate $=$ Pietri, 362

Violet Sepor (C), 476

Violeta Florentina = Violeta Negra, 476

Violeta Negra (C), 476

Violeta of Genoa = Violada Blanca, 410

Violette $=$ Bordeaux, 424

Violette $=$ Mouissonne, 452

Violette de Bordeaux $=$ Bordeaux, 424

Violette de La Frette $=$ Frette, 439

Violette Perruquine $=$ Perroquine, 459

Violette Plate (C), 479

Vottato $=$ Dottato, 376

Walton $=$ Brown Turkey, 428

Warren's Brown Turkey = San Piero, 468

West (S), 353

White Adriatic $=$ Verdone, 406

White Adriatic-See Milco, 330

White Endich = Dottato, 376

White Genoa = Genoa, 391

White Ischia = Ischia, 442

White Marseilles = Blanche, 372

White Marseilles-See Genoa, 392

White Naples $=$ Blanche, 372

White Pacific $=$ Dottato, 376

White San Pedro = San Pedro, 363

See also Gentile, 360, 361

White Smyrna = Blanche, 372

White Standard = Blanche, 372

Whitmill's Early Purple = Brown Turkey, 428

Wilson (S), 353

Yaffawi (C), 381

Yediver (S), 353

Yel Injur-See Sari Lop, 344

Yellow Neches (C), 410

Zafrani (S), 359

Zaiti (C), 476

Zamozujica (C), 411

Zarniza (C), 479

Zarraki $=$ Ghzali, 440

Zentil = Albo, 372

Zidi (S), 359

Zidi-el-Agouch = Sidi-ben-Agous, 471

Zigarella = Panachée, 400

Zimitza (C), 411

Ziza Kheden (C), 476

Zonto (C), 381 


\section{LITERATURE CITED}

AnONymous

1828. The Brunswick fig. Pom. Mag. of London 1:48. Color plate.

1852. Brown Turkey fig. Gard. Chron. 12:325, 357.

1878. Fig Col di Signora Bianca. Florist and Pomologist 11:121. Color plate p. 473.

1882. Osborn Prolific. Rev. Hort. 54:110, 202. (Introduced into France.)

1908. The Celeste fig. Amer. Fruit and Nut Jour. 5(87):8. (Probably by H. H. Hume.)

1943. New variety of fig, the Delta. Texas Farming and Citriculture 19(7):17. January.

1944. Fig for Florida shows promise. Florida Grower 52(12):10. December. 1 figure of New Delta fig.

1949. Promising new fig. Fruit World [Melbourne] 50(6):16; 50(7):7. See also:

A., $R$. Hort. Abs. 19 (2731). (Preston Prolific.)

1937. Fig White Ischia. Gard. Chron. (ser. 3) 102:437.

AFFLECK, Thomas

1850. Fruits and fruit culture. Farmer and Planter [Pendleton, S.C.] 1:182.

1851. Southern rural almanac and plantation and garden calendar [Washington, Mississippi]. (Fig, p. 67.)

1852. Same. (Fig, pp. 83, 99-100.)

1854. The New Orleans almanac for the year 1854; with Affleck's plantation and garden calendar [New Orleans] 1(2). (Figs, p. 64.)

Aldrovandi, Ulisse

1668. Dendrologiae naturalis: scilicet arborum historiae. 2 vols. $660 \mathrm{pp}$. Typ. Ferroni, Bologna. (De ficu, pp. 427-80.)

Anagnostopoulos, P. Th.

1937. New fruits. Hort. Research [Athens] 4:376-79. 2 figures. (In Greek, with English summary.)

ANDERSON, JAMES

1874. The new practical gardener and modern horticulturist. $988 \mathrm{pp}$. Wm. Mackenzie, London. Color plate of Brunswick. Variety descriptions by A. F. Barron. (Figs, pp. 304, 342-44, 506.)

ANDERSON, W. S.

1924-1928. Horticultural work. Miss. Agr. Expt. Sta. Buls. 225, 232, 246.

ARNOLD, RALPH E.

1926. Select varieties of figs. Gard. Chron. (ser. 3) 80:335.

AsHLEY, T. E.

1940. Home orchards in Mississippi. Miss. Agr. Expt. Sta. Bul. 350:1-37. (Fig, pp. 8, 33.)

1943. Miss. Agr. Expt. Sta. Bul. 393:33.

AUDIBERT Frères

1854. Quelques variétés de figues les plus estimées. Rev. Hort. (ser. 4) 3:229-35.

B., S. H.

1896. White Ischia. The Garden 49:312. April 25.

Badie, M. A., and A. K. Ghamrawi

1931. The growing of figs. Egypt. Min. Agr. Hort. Sect. Giza Booklet 2:1-29. 13 figures.

BALDINI, ENRICO

1953. Alcuni aspetti della coltura del fico nella Provincia di Firenze. Ortoflorofrutticoltura Italiana Riv. anno 78:185-203. Figures 1-18. Fifteen varieties described and illustrated.

BALLON

1692. Nouvelle instruction facile pour la culture des figuiers. 111 pp. C. de Sercy, Paris.

BARron, A. F.

1867. New or little-known fruits. Gard. Chron. 27:1192. November 23.

1868a. Grosse Verte fig. Florist and Pomologist (ser. 3) 1:56. 1 figure.

1868b. De la Madeleine fig. Florist and Pomologist (ser. 3) 1:179-81. 1 figure.

1868c. A selection of choice figs. Florist and Pomologist (ser. 3) 1:211-13. 
1868d. Bourjassotte Grisé. Gard. Chron. 28:1260. December 5.1 figure.

1868e. Fig culture. Gard. Chron. 28:6. January 4.

1869a. On some new fruits and vegetables of 1868. Florist and Pomologist (ser. 3) $2: 49-51$.

1869b. Col di Signora Bianca Panachée. Florist and Pomologist (ser. 3) 2:145. Color plate.

1870. Fig Grosse Monstrueuse de Lipari. Florist and Pomologist (ser. 3) 3:128-29. 1 figure. See also: Gard. Chron. 30:765.

1871. Royal Vineyard fig. Florist and Pomologist (ser. 3) 4:49. Color plate. See also : Jour. of Hort. and Cottage Gardener 20:200.

1891. Figs and their culture at Chiswick. Royal Hort. Soc. Jour. 13:122. Also in: The Garden $39: 575-78$.

BAXTER, WM.

1820. An account of the fig tree, planted in 1648 and now growing in garden of Christ Chureh, Oxford. Royal Hort. Soc. Trans. 3:433-35.

\section{BECKETT, EDWIN}

1941. Fruits for the home garden. New York Bot. Garden Jour. 42:133-40. 1 figure.

BERNARD, BONS .J.

1787-1788. Mémoire sur l'histoire naturelle du figuier. In: Mémoires pour servir à l'histoire naturelle de la Provence 1:17-218. Didot Fils, Paris.

\section{BLANCHARD, J.}

1878. Le figuier de Roscoff. Jour. d'Agr. Prat. 1878:447.

1879. Le figuier de Roscoff. Rev. Hort. 1879:372-76. Figure 79.

BLIN, HENRI

1942. Le figuier en Algérie. Rev. Hort. 114:128-31, 164-68, 207-10. Illustrated.

Bobone, álvaro L. A.

1932. Contribuição para o estudo taxonômico da espécie Ficus carica L. 127 pp.

BoIs, DÉsIrÉ

1928. Les plantes alimentaires chez tous les peuples et à travers les âges. 2 vols. Paul Lechevalier, Paris. (Ficus carica, 2:469-85. Figures 227-30.

Borg, J.

1922. Cultivation and diseases of fruit trees in the Maltese Islands. $622 \mathrm{pp}$. Government Printing Office, Malta. (Fig, pp. 126-48.)

Bory de Saint Vincent, Jean B. G.

1824. Dictionnaire classique. 17 vols. Rey et Gravier, Paris. (Figuier, 6:498-503.)

BRADLEY, RICHARD

1727. Ten practical discourses concerning earth and water as they relate to the growth of plants. 195 pp. Printed by J. Cluer and A. Campbell, Westminster. (Fig, pp. 117, 151-53.)

1757. A general treatise of agriculture. $503 \mathrm{pp}$. Printed for W. Johnston, London. (Fig, pp. 270-73, 281-86.)

Braunton, ERNEST

1936. What of Pastilière figs? Pac. Rural Press 132:59, 272.

BRooks, REID M., and H. P. OLMO

1946. Register of new fruit and nut varieties. Amer. Soc. Hort. Sci. Proc. 47:544-69. (Fig, p. 551.)

1949. Amer. Soc. Hort. Sei. Proc. 53:577.

BROOKSHAw, GEORGE

1812. Pomona Britannica. 60 pp. Typ. Bensley, London. Color plates 74, 75 .

Brotherston, R. P. 1920. Castle Kennedy fig. Gard. Chron. (ser. 3) 68:124.

BunYaRd, E. A. 1920-1925. A handbook of hardy fruits. 2 vols. John Murray, London. (Fig, 2:162-65.) 1934. Cultivation of the fig. Royal Hort. Soc. Jour. 59:61-67. Figures 30-33.

Bunyard, George, and OWen Thomas

1904. The fruit garden. 507 pp. Published at offices of Country Life, London. Illustrated. (The fig, pp. 51-58.)

BURGER, I. J., and A. F. DE WET

1931. Culture of the fig tree. Farming in So. Africa 6:169-70, 207, 251-52. 
BURNETTE, F. H.

1894. Figs at Baton Rouge. Louisiana Agr. Expt. Sta. Bul. 27:927-28. See also: $36: 1274$.

CARBoU, J. B.

1865a. Figue Blanche à Peau Verte. Rev. Hort. 36:31. Color plate.

1865b. La figue Gourreau Noir. Rev. Hort. 36:131. Color plate.

CARRIÈre, E. A.

1881. Figuier Osborn Prolific. Rev. Hort. 53:68. Figure 21.

1884. Influence du milieu à propos du figuier Osborn Prolific. Rev. Hort. 56:61, 387.

Casella, Domenico

1952. La voce Dottato. L'Italia Agricola 89:601-4. 2 figures.

Chandler, W. H.

1934. The dry-matter residues of trees and their products in proportion to leaf area. Amer. Soc. Hort. Sci. Proc. 31:39-56.

Chefrins, A.

1905. Pingo de Mel fig tree. The Garden 67:274. Illustrated.

Christ, J. L.

1809-1812. Vollständige Pomologie. 2 vols. Frankfort. (Feigen, 2:397-408. 3 color plates.) See also: Pomologisches theoretisch-praktisches Handwörterbuch. 431 pp. Leipzig. 1802. (Feigenbaum, pp. 241-44.)

Clark, W. SAM

1920. The Kadota fig. 44 pp. Fig and Olive Journal, Los Angeles. Illustrated.

Clarke, J.

1883. Brown Turkey fig at Penrhyn Castle. Gard. Chron. (n.s.) 20:405.

Clemente, Armando M., et al.

1953. Recomendações gerais sôbre fruticultura. 42 pp. São Paulo, Brazil. Brief descriptions of six varieties. (Figueira, pp. 20-21.)

Close, C. P.

1929. Amer. Pomol. Soc. Proc. 1923-1929:103, 114, 132, 162, 169.

1933. Same. $49: 171,188$.

1935. Same. 51:260.

Colby, George E.

1894. Analyses of figs. Calif. Agr. Expt. Sta. Rpt. 1892-1893:226-35.

Coleman, W.

1880. Brown Turkey fig. Florist and Pomologist 1880:145. Color plate.

1887a. Fig Pingo de Mel. The Garden 31:232.

$1887 b$. Figs for forcing. The Garden 32:37.

CONDIT, IRA J.

1919. Bits of fig history in California. Calif. State Comm. Hort. Mo. Bul. 8:260-65. 1920a. Caprifigs and caprification. Calif. Agr. Expt. Sta. Bul. 319:341-75. Figures 1-23. $1920 b$. Smyrna figs. Assoc. Grower 1(6):11-12. August. Illustrated.

$1920 c$. The Kadota fig. Assoc. Grower 1(8):18, 35. October. Illustrated.

1920d. White Adriatic fig. Assoc. Grower 1(7):10. September. 1 figure.

1921a. The Mission fig. Assoe. Grower 2(1):27, 35. January. 2 figures.

1921b. Miscellaneous fig varieties. Assoc. Grower 2(4):13; 2(5):26. April, May.

1921c. California fig varieties. Calif. Dept. Agr. Mo. Bul. 10:359-66. 2 figures.

1922a. The Stanford Smyrna fig. Assoc. Grower 4(3):6, 20. October. Illustrated.

1922b. The Brunswick vs. Brown Turkey. Calif. Cult. 59:307. Frontispiece.

1923. Commercial fig varieties. Calif. Fruit News $70(1881): 1,17 ; 70(1882): 4-5$.

1924. The fig industry of the Old World: Greece. Assoc. Grower 6(9-10):14-15, 22. 2 figures. Also in: Calif. Fruit News 73(1980):16-18. June 19, 1926.

1925. Fig industry of Spain. Calif. Fruit News 71(1911):5, 15; 71(1912):13.

1927. The Kadota fig. Calif. Agr. Expt. Sta. Bul. 436:1-42. Figures 1-12.

1928a. Gulian P. Rixford-an appreciation. Calif. Countryman 14(5):10-11. Descriptions of Forbes, Excelsior, and Kearney caprifigs. Illustrated.

$1928 b$. Other fig chimeras. Jour. Heredity 19:49-53. 3 figures.

1928c. Fig breeding. Jour. Heredity 19:417-23. Figures 9-11.

1933. Fig culture in California. Calif. Agr. Ext. Serv. Cire. 77:1-67. Figures 1-26. 
1941a. Fig characteristics useful in the identification of varieties. Hilgardia 14(1):168. Figures 1-25. Plate 1 in color.

1941b. The Brunswick (Magnolia) fig. Amer. Soc. Hort. Sci. Proc. 39:143-46.

1942. The Croisic (Cordelia) fig. Amer. Soc. Hort. Sci. Proc. 40:255-58.

1944. San Piero, the Brown Turkey fig of California. Amer. Soc. Hort. Sci. Proc. $44: 211-14$.

1947. The fig. 222 pp. Chronica Botanica Co., Waltham.

1950. Fig characters as affected by climate. Amer. Soc. Hort. Sci. Proc. 55:114-18.

Condit, Ira J., and Mesu'r Baskaya

1948. Figs in Turkey. Calif. Farmer 189:218-19.

CoNDIT, IRA J., and W. T. HORNE.

1933. A mosaic of the fig in California. Phytopath. 23:887-96. 4 figures.

1913. Mosaic spots of fig fruits. Phytopath. 33:719-23. 2 figures.

Cook, L. J.

1925. The fig. The Garden 89:36.

Couverchel, Jean F.

1839. Traité des fruits. 717 pp. Imprimerie de Bouchard-Huzard, Paris. (Figue, pp. 210-18.)

Cupani, Francesco

1696. Hortus Catholicus. 237 pp. Fr. Benzi, Naples. (Ficus, pp. 130-41.)

Cusin, L.

1900. Quelques fruits appréciés par la commission permanente en 1900. Soc. Pomol. de France Bul. Mens. 1900:301-16. (Figue Panachée, pp. 302, 331.)

DAvis, R. A.

1928. Fruit-growing in South Africa. 532 pp. Central News Agency, Johannesburg.

DEAN, R. W. (Fig, pp. 250-61.)

1904. A prolific fig tree. Gard. Chron. (ser. 3) 35:102. (Reculver variety.)

Delbard, Georges

1947. Les beaux fruits de France. 166 pp. G. Delbard, Paris. (Figuier, p. 70.)

Delplace, E.

1933. Manuel d'arboriculture fruitière. 450 pp. J. Lamarre, ed., Paris. (Figuier, pp. 168, 187, 387-91. Figures 415, 416.)

De Rosa, Francesco

1911. Di alcuni fichi Salentini. 36 pp. R. Istit. d'Incorrag. di Napoli Atti (ser. 6) 9.

Dochnahl, Fr. J.

1855-1860. Der sichere Führer in der Obstkunde-oder systematische Beschreibung aller Obstsorten. 4 vols. W. Schmidt, Nuremberg. (Feigen, 4:65-71.)

Donno, Giacinto

1951a. La determinazione di alcune varietà di fico della Provincia di Lecee nel periodo invernale. Facoltà di Agraria Univ. Annali [Napoli] (ser. 3) 19. (Abstract.) 8 pp. Plates $1-4$.

1951b. Alcune varietà bifere di fico coltivate in Provincia di Lecce. Facoltà di Agraria Univ. Annali [Napoli] (ser. 3) 19. (Abstract.) 20 pp. Six varieties described.

1952. Alcune varietà unifere di fico coltivate in Provincia di Lecce. Facoltà di Agraria Univ. Annali [Napoli] (ser. 3) 19. (Abstract.) $31 \mathrm{pp}$. Ten varieties described.

Du Breuil, Alphonse

1876. Culture des arbres et arbrisseaux, à fruits de table. 693 pp. G. Masson, Paris. (Figuier, pp. 602-29. Figures 488-510.)

Duchartre, Pierre E. S.

1857. Flore des jardins de l'Europe. Manuel general des plantes, arbres, et arbustes. Vol. 4. Maison Agr., Paris. (Figuier, pp. 155-61.)

Duhamel du Monceau, H. L.

1755. Traité des arbres et arbustes qui se cultivent en France en pleine terre. 2 vols. E. Michel, Paris. (Figuier, 1:235-44.)

1768. Same. Later edition. (Figuier, 1:207-17.)

1809. Same. New edition. E. Michel, Paris. (Figuier, 4:197-232. Color plates 53-59.) 
EARLE, F. S.

1897. Fig culture in the Gulf states. U. S. Dept. Agr. Div. Pom. Bul. 5:23-32.

1900. Orchard notes. Ala. Agr. Expt. Sta. Bul. 112:157-90. (Figs, pp. 167-68.)

Eisen, Gustav

1885. Fig culture. Pac. Rural Press $30: 126,138-39$.

1887. White Adriatic fig. Florida Agr. 9:399. Also in: Fresno Weekly Republ. 11 (37): 1 . May 20.

1888. The fig of commerce. Rural Californian 11:149-56, 177-81.

1896. Biological studies on figs, caprifigs, and caprification. Calif. Acad. Sci. Proc. (ser. 2) 5:897-1001.

1897. Edible figs: their culture and curing. U. S. Dept. Agr. Div. Pom. Bul. 5:5-22. 1901. The fig. U. S. Dept. Agr. Div. Pom. Bul. 9:1-317. Illustrated.

EsCRIBANO Y PÉREz, José M.

1884. Pomona de la Provineia de Murcia. 224 pp. Imprenta Hijo de Aguado, Madrid. (Higuera, pp. 133-47.)

Estelrich, PEDro

1910. La higuera y su cultivo en España. 228 pp. Libr. Escolar, Palma. Illustrated.

EvREINOFF, V. A.

1947. Les arbrisseaux à fruits. 133 pp. Flammarion, ed., Paris. (Le figuier, pp. 11-64. Figures 1-39.)

Ferrari, E.

1912. La coltivazione del fico nel circondario di Paola (Cosenza). R. Staz. Sper. Agrum. e Fruttic. Acireale ann. 1:141-77.

ForNey, EUGÈnE

1863. Le jardinier fruitier. 2 vols. Arnheiter, Paris. (Le figuier, 2:270-80. Figures 315-25.)

ForRER, Julius

1894. Figs at the Tulare station. Calif. Agr. Expt. Sta. Rpt. 1892-1893, and part of 1894:411-14.

Forsyth, William

1803. A treatise on the culture and management of fruit trees. $523 \mathrm{pp}$. Longmans,

FowLER, A. London. (Fig, pp. 97-102.)

1865. Castle Kennedy fig. Jour. of Hort. and Cottage Gardener (n.s.) 8:449. Quoted in: Florist and Pomologist, July, 1865, pp. 141-42. See also: Gard. Chron. 1864: $1228 ; 1866: 613$.

FranCESChI, F.

1912. Tropical and semitropical fruit-bearing trees, shrubs, and plants grown at Santa Barbara, California, in the year $1912.4 \mathrm{pp}$. Santa Barbara.

FRUIT-GROWER

1936. Outdoor figs. Gard. Chron. (ser. 3) 100:133, 147.

Gallesio, Giorgio

1817. Pomona Italiana. Vol. I. (See specifically: 92 unnumbered pages on the fig.) N. Capurro, Pisa.

Garidel, Pierre J.

1715. Histoire des plantes. 522 pp. Jos. David, Aix. (Figuier, pp. 174-79.)

Gasparrini, Guglielmo

1845. Ricerche sulla natura del caprifico e del fico, e sulla caprificazione. Accad. Sci. Napoli, rend. 4:321-412. Plates 1-8.

GAYNER, F. C. H.

1949. The amateur fruit-grower in South Africa. In: The Fruit Yearbook, Royal Hort. Soc., pp. 79-85. (Fig, p. 81.)

GLADY, E.

1883. Figue San Pietro ou Mecklingea. Rev. Hort. 55 : 458.

GouLd, H. P.

1919. Fig-growing in the south Atlantic and Gulf states. U. S. Dept. Agr. Farm Bul. 1031:1-45.

1923. Same. Revised edition.

1935. Same. Revised edition. 
GrasovskY, A., and J. WeITZ

1932. Fig-growing in Palestine. Palestine Dept. Agr. and Fish.: Agr. Leaflets (ser. 4) Hort. No. 28:1-36. Figures 1-21.

GreEN, THOMAS

1824. The universal herbal. Second ed. 790 pp. Caxton Press, London. (Fig, pp. 56266.)

Guglielmi, G.

1908. Coltivazione industriale del fico nel Leccese. (Abstract.) 32 pp. Boll. Arbor. Italiana an. 4. Tip. F. Giannini \& Figli, Naples.

Guillochon, L.

1913. Traité pratique d'horticulture. Second ed. 522 pp. A. Fortin, Tunis. (Figuier, pp. 263-70.)

1927. La culture du figuier en Tunisie. Rev. de Bot. Appl. (7 ann.) Bul. 65:18-28.

1929. Le figuier en Tunisie. Tunisie Agr. Rev. Mens. Illus. 30:196-99.

HagaN, H. R.

1929. Fig culture in the Smyrna fig district. Calif. Dept. Agr. Mo. Bul. 18:491-512. Illustrated.

Hanbury, William

1770. A complete body of planting and gardening. 2 vols. Printed for the author, London. (Ficus carica, 2:774-76.)

Hancteau, Louis A., and A. Letourneux

1872-1873. La Kabylie et ses coutumes. 3 vols. L'Imprimerie Nationale, Paris. (Figuier, 1:433-41, 501-502.)

Hansen, George

1894. Figs at the Foothill station. Calif. Agr. Expt. Sta. Rpt. 1892-1893, and part of 1894 : $375-78$.

Henslow, George

1902. Stameniferous figs. Gard. Chron. (ser. 3) 32:44. July 19.

HERINCQ, F.

1850. Figue Grosse Superfine de La Saussaye. Rev. Hort., 1850:421-24. Figure 22 in color.

Hodgson, R. W.

1925. Coachella Valley fig-growers employ ancient practice. Los Angeles Times Farm and Orchard Magazine. April 19. Also in: Amer. Fruit-Grower 46:5, 20-21. May, 1926.

1931. La culture fruitière en Tunisie. 193 pp. Soc. Anon. Imprim. Rapide, Tunis. (Le figuier, pp. 96-100.)

1934. Resistance to low winter temperatures of subtropical fruit plants. Amer. Soc. Hort. Sci. Proc. 30:349-54. (Fig, p. 352.)

HoGG, ROBERT

1860-1874. Gardener's yearbook, almanack, and directory. 15 vols. Office of Cottage Gardener, London. See : 1865:32; 1866:31-33; 1868:55-56; 1869:63-65; 1871: 59-60.

1866. The fruit manual. Third ed. 414 pp. Journal of Horticulture, London. (Fig, pp. 102-17.) First ed. 1860.

1869. Negro Largo fig. Florist and Pomologist (ser. 3) 2:5-6. 1 figure.

Holley, William DEForest

1854. The fig. Amer. Cotton Planter 2(3):155-56.

How ARD, W. L.

1945. Luther Burbank's plant contributions. Calif. Agr. Expt. Sta. Bul. 691:1-110. (Fig, p. 16.)

Hume, H. H.

1915. Figs in the southeastern and Gulf states. In: The Standard Cyclopedia of Horticulture [Bailey] 3:1234-35. Plate 42.

Hyde, H.

1877. The best figs. The Garden 12:304.

I., W.

1893. Brown Turkey fig. The Garden 44:353. 
JUIGNET, E. $\mathrm{K}$.

1909. Culture du figuier à Argenteuil. $24 \mathrm{pp}$. Published by the author, Argenteuil.

1873. Castle Kennedy fig. Gard. Chron. 33:1369. October 11.

KIRKMAN, W. T.

1922. The Black San Pedro fig in southern California. Fig and Olive Jour. 6(7):7. January. 1 figure.

KNOOP, JEAN H.

1771. Fructologie. 206 pp. M. Magerus, Amsterdam. (Figuier, pp. 94-104.)

L., J.

1890. Madagascar fig. The Garden 37:427.

LA Brousse

1774. Traité de la culture du figuier. 83 pp. Valade, Amsterdam.

LAMARCK, J. B. DE

1783-1817. Dictionnaire-encyclopédie méthodique. 13 vols. Panchoucke, Paris. (Figuier, 2:489-92.) See also: Supplement by J. L. M. Poiret. 1783-1808. 5 vols. Paris. (Figuier, 2:648-57.)

LAMBERTYE, LEONCE

1874. Le figuier de Roscoff. Rev. Hort. 1874:437-38.

LANGLEX, BATTY

1728. New principles of gardening. $207+191$ pp. Printed for A. Bettesworth and J. Batley, London. (Fig, pp. 40, 55, 72-76.)

La Quintinie, JeAn DE

1692. Instructions pour les jardins fruitiers et potagers. $344 \mathrm{pp}$. Amsterdam. Translated by John Evelyn, The compleat gard'ner (2 vols., 1693). Printed for M. Gillyflower, London. (Figs, 1:136-37; 2:57-66, 92-93.)

Le Berryais, L. R.

1789. Traité des jardins. Third ed. Belin, Paris. First part: Jardin fruitier. (Figuier, pp. 265-72.)

LeClerc du Sablon, Mathieu

1908. Observations sur les diverses formes du figuier. Rev. Gen. Bot. 20:129-50, 207-16.

LECLERC, HENRI

1925. Les fruits de France. 274 pp. Masson et Cie., Paris. (La figue, pp. 205-13.)

LELONG, B. M.

1890. The fig. Calif. State Bd. Hort. Ann. Rpt. 1889:115-36. Color plate of White Adriatic.

1892. California fig industry. Calif. State Agr. Soc. Trans. 1891:130-82.

LHÉRAULT, LOUIS

1872. Culture du figuier Blane d'Argenteuil. 24 pp. Imprimerie Paul Bousrez, Tours.

LiGER, LOUIS

1702. Traité facile pour apprendre à élever des figuiers. 81 pp. D. Beugnie, Paris. In: La culture parfaite des jardins fruitiers et potagers. (Appendix.)

Lindley, George

1831. A guide to the orchard and fruit garden. 601 pp. Longmans, London. (Fig, pp. 162-73.)

LiNDLEY, JoHN

1841. Pomologia Britannica. 3 vols. H. G. Bohn, London. (Fig, 1:48. Color plate of Brunswick.)

LUCKHURST, EDWARD

1880. Grizzly Bourjassotte. Jour. of Hort. 1880:328. See also: Florist and Pomologist $1880: 176$.

McHatTon, T. H.

1909. Remarks on fig varieties. Georgia State Hort. Soc. Proc. 33. In: Georgia State Bd. Entom. Bul. 30:63.

M'Intosh, Charles

1855. The book of the garden. 2 vols. Wm. Blackwood and Sons, Edinburgh. (Fig, 2:551-58.) 
MARTinet, H., and F. Lesourd

1924. Une visite au figuier de Roscoff. Rev. Hort. 96:229.

MASLIN, E. W.

1890. Fig culture and seedling Smyrna figs. Calif. State Bd. Hort. Ann. Rpt. 1889: 401-5. Discussion, pp. 405-11.

MASSEY, W. F.

1893. The culture of orchard and garden fruits. North Carolina Agr. Expt. Sta. Bul. 92:5-73. (Figs, pp. 48-49.)

MAURI, N.

1939a. Les caprifiguiers utilisés en Kabylie pour la caprification. Algérie Serv. de l'Arbor. Bul. (n.s.) 6:1-39. Illustrated.

1939b. Les figuiers cultivés en Kabylie. Algérie Serv. de l’Arbor. Bul. (n.s.) 5:1-66. Illustrated.

1942. Les figuiers cultivés en Algérie. Algérie Serv. de l'Arbor. Bul. 93:1-56.

1944. Same. Second ed. 150:1-56. Notice spéciale de gravures. 103 pp. 98 figures.

MAZiÈres, E. DE

1920. Le figuier, l'abricotier, le prunier. 89 pp. J. B. Baillière et Fils, P־ris. (Figuier, pp. 5-54.)

Mello LeOTTE, F. C. DE

1901. Arboricultura algarvia. 221 pp. Tip. A. de Mendonȩa, Lisbon. (Figueira, pp. 9-90.)

MERLET, JEAN

1740. L'Abrégé des bons fruits. Fourth ed. 171 pp. Claude Prudhomme, Paris. (Des figuiers, chap. 8, pp. 53-60.) First ed. 1667.

Milco, G. N.

1884. Report of Commissioner Milco for the San Joaquin district. Calif. State Bd. Hort. Bienn. Rpt. 1884:56-59. Discussion, pp. 82-89.

1885. Figs and fig culture. Pac. Rural Press 30:211.

1887. Discussion on fig growing. Calif. State Bd. Hort. Bienn. Rpt. 1885, 1886:139-46.

Miller, PhiliP

1768. Gardener's dictionary. Unnumbered pages. Printed for the author, London. First ed. 1731 . Seventh ed. 1759 .

Mills, J. W.

1914. Figs. Calif. Cult. 42:71.

1918. The Mission fig. Calif. Cult. 50:39, 43.

Minangoin, N.

1931. Monographie des variétés de figues tunisiennes. Congrès d'Agron. du Cinquantenaire à Tunis. Compte Rendu 1:338-64. Descriptions of sixty-five varieties.

Mingioli, E.

1904. L'Industria dei fichi secchi. Soc. Agr. Italiana Bol. 9:624-32, 656-63.

Mirbel, C. F. B.

1802-1806. Histoire naturelle. 18 vols. Imprimerie de F. Dufart, Paris. (Figuier, 10: 66-72.)

Montagnac, P. R.

1952. Le figuier dans le sud-ouest de Madagascar. Fruits d'Outre-Mer 7:513-23. Illustrated.

MOORE, THOMAS

1871. Bourjassotte Grisé fig. Florist and Pomologist (ser. 3) 4:31-32. 1 figure.

1872. Negro Largo fig. Florist and Pomologist (ser. 3) 5:145. Color plate.

1879. Some of the novelties of 1878. Florist and Pomologist (imp. ser.) 13:19-22. (Fig, p. 22. Osborn's Prolific.)

MoRren, Ch.

1852. Le figuier de Brunswick ou La Madone. Belg. Hort. 2:35. Color plate.

Mowry, HAROLD, and G. F. WeBER

1925. Hints for the Florida fig-grower. Florida Grower $32(7): 6,12$. August 15 .

NADIR, A., and M. HALIT

1929. Fig industry in Turkey. Calif. Fig Inst. Ann. Proc. 13:33-36. 
NAIK, K. C.

1949. South Indian fruits and their culture. $477 \mathrm{pp}$. P. Varadachary and Co., Madras. (Fig, pp. 384-89. Color plate 9 of the Poona fig.)

NoISETTE, LOUIS

1821. Le jardin fruitier. $95+176$ pp. Audot, Paris. (Figuier, pp. 35-41. Plates 10 and 11 show Figue Blanche and Figue de Bordeaux in color.)

1829. Manuel complet du jardinier. $604 \mathrm{pp}$. Aug. Wahlen, Brussels. (Figuier, pp. 453-57.)

\section{NOMBLOT, ALFRED}

1913. Culture et description des espèces et variétés d'arbres fruitiers. In: Le bon jardinier. (Under the direction of D. Bois and G. T. Grignon.) Libr. Agricole,

NoRWICH Paris. (Figuier, pp. 298-300.)

1898. Fig Castle Kennedy. The Garden $54: 458-59$. December 3.

Ounous, LÉo D'

1863. Les figuiers du sud-ouest. Rev. Hort. 34:59, 456-57.

OzBEK, SabahatTiN

1949. Varieties of figs in the Aegean region. Calismalar: Sayi 98, Ziraat Dergisinin. 15 pp. 11 figures. (In Turkish.)

PASQUALe, G. A.

1876. Manuale di arboricoltura. 536 pp. V. Pasquale, Naples. (Del fico, pp. 485-503. Figures 177-85.)

Pearson, J. R.

1872. Fig culture. Jour. Hort. (n.s.) 23:71.

Pellicano, A.

1907. Il fico nel circondario de Gerace. Boll. Arbor. Italiana 3:122-50.

Penzig, O.

1922. Pflanzen-teratologie. 3 vols. Borntraeger, Berlin. (Ficus carica, $3: 217-18$. )

Plinius Secundus, Gaius (A.D. 23-79).

1855-1890. The natural history of Pliny. English translation by John Bostock and H. T. Riley. 6 vols. H. G. Bohn, London. (Fig, 3:307-13.)

Poitead, Antoine

1838-1846. Pomologie française. 4 vols. Langlois et Leclereq, Paris. (Ficus, $4: \S 9$.)

Porta, Giovanni B.

1583. Suae villae pomarium. 323 pp. H. Saluianum, Naples. (Fico, p. 130.)

1592. Villae Io. Baptistae Portae. 12 vols. 914 pp. A. Wechel, Frankfort. (De ficu, pp. 300-27.)

Portale, F.

1910. La coltivazione del fico nel circondario di Mistretta. Boll. Arbor. Italiana 6:1-53.

PotTs, A. T.

1917. The fig in Texas. Texas Agr. Expt. Sta. Bul. 208:5-41. Illustrated.

Preston, F. G.

1951. The greenhouse. 640 pp. Ward, Lock Co., Ltd., London. (The fig, pp. 197-201.)

PRICE, R. H., and E. A. WhITE

1902. The fig. Texas Agr. Expt. Sta. Bul. 62:1-29.

Priego y Jaramillo, J. M., and S. SÁnchez.

1922. La higuera: su cultivo en España. 31 pp. Calpe, Madrid.

REBoul, M.

1908. Figuiers. Soc. Pomol. de France Bul. Mens. 1908:241, 383.

Reimer, F. C.

1910. Fig culture in North Carolina. North Carolina Agr. Expt. Sta. Bul. 208:187-206.

RIDGWAY, ROBERT

1912. Color standards and color nomenclature. Published by the author, Washington, D.C. 53 color plates.

Risso, Antolne

1826. Histoire naturelle des principales productions de l'Europe méridionale. 5 vols. Levrault, Paris. (Du figuier, 2:130-71. 1 plate.) 


\section{RIVERS, THOMAS}

1873. Fig varieties. Gard. Chron. 33:1432. Also in: Florist and Pomologist 6:285.

Rivière, Auguste

1928. Traité d'arboriculture fruitière. Considérablement augmenté par G. Rivière. 621 pp. Villefranche. (Figuier, pp. 532-41.)

RIVIÈRE, BENOIT

1907. Figue Osborn Prolific. Soc. Pomol. de France Bul. Mens. 1907:38.

RiviÈRE, Gustave

1930. Culture du figuier. Soc. Nat. d'Hort. de France Jour. (ser. 5) 3:394-96, 529-31. Figures 17, 18, 22.

RIXFORD, G. P.

1912. Results of recent investigations in fig culture and caprification. Calif. State Comm. Hort. Mo. Bul. 1:623-33.

1918a. Smyrna fig culture. U. S. Dept. Agr. Bul. 732:1-43. Illustrated.

$1918 b$. Influence on the fig industry of the Maslin seedling fig orchard at Loomis. Fig and Olive Jcur. 3(3):14. August.

1920a. Fig ripening in San Francisco. Pac. Rural Press 100:475.

1920b. A nonsplitting Smyrna fig and its history. Fig and Olive Jour. 4(8):9. January.

RiXFORD, G. P., and F. HEINY

1911. Interesting event in fig culture. Calif. Cult. 36:390.

ROBERTS, R. M.

1917. The Adriatic fig. Calif. First Fig Inst. Proc. pp. 17-19. Fresno.

Roda, Marcellino and GiUseppe

1881. Manuale del frutticoltore Italiano. 324 pp. G. P. Paravia, Rome. (Del fico, pp. 237-49. Figures 158-62.)

Roeding, G. C.

1903. The Smyrna fig at home and abroad. $87 \mathrm{pp}$. Published by the author, Fresno Illustrated.

1914. The fig. In: Roeding's Pract. Hort. 1(2):1-4. Fresno. Illustrated.

ROGERS, JOHN

1834. The fruit cultivator. 384 pp. J. Ridgway and Sons, London. (Fig, pp. 173-82.)

Rolet, ANTONin

1916. Le figuier en Provence. La Vie Agricole et Rurale 6:170-72.

Rolland, Eugène

1900-1914. Flore populaire; ou, Histoire naturelle des plantes dans leurs rapports avec la linguistique et le folklore. 11 vols. Libr. Commissionnaires, Paris. (Ficus carica, $10: 61-78$.)

Royal Horticultural Society

1916. A list of the most desirable varieties of most kinds of fruit, drawn up by the Royal Horticultural Society's Fruit Committee. 190 pp. Spottiswood, Ballantyne and Co., London. (Fig, pp. 8, 14, 25.)

Rozier, François

1781-1805. Cours complet; ou, Dictionnaire d'agriculture. 12 vols. A. Lueques, Paris.

S. (Figuier, $8: 418-45$. )

1878. Osborn's Prolific fig. The Garden $14: 167$.

S., G.

1867. White Marseilles and De la Madeleine figs. Jour. of Hort. (n.s.) 13:212.

1869. Some varieties of figs. Jour. of Hort. and Cottage Gardener (n.s.) 17:394-95.

SAMSON, W. H.

1906. History of the Lob Injir Smyrna fig. 4 pp. Maywood Colony Nursery, Corning, California.

SÁNCHEZ, D. M.

1922. Fruticultura; o, Cultivo de árboles frutales. 204 pp. Bibl. Agr. Solariana, Seville. Illustrated. (Higuera, pp. 154-74.)

SAUNDERs, William

1889. Division of Gardens and Grounds. In: U. S. Secr. Agr. Rpt. 1:111-34. (Figs, pp. 127-28.) 
Sauvaigo, Émile

1889. Note sur les figuiers introduits et cultivés dans les environs de Nice. Soc. Centr. d'Agr., d'Hort., et d'Acclim. de Nice et des Alpes-Maritimes Bul. Mens. 29: 144-67.

1894. Les cultures sur le littoral de la Méditerranée. 318 pp. Libr. J. B. Baillière et Fils, Paris. (Figuier, pp. 225-30. Figure 96.)

1899. Enumération des plantes cultivés dans les jardins de la Provence et de la Ligurie. 414 pp. Nice. (Figuier, pp. 172-78.)

Savastano, L.

1885. Di alcune colture arboree della Provincia di Napoli. 135 pp. Tip. Ferrante, Naples. (Il fico, pp. 27-40.)

SAWYer, SAMUEL

1824. On the management of fig trees in open air. Royal Hort. Soc. Trans. 5:346-48.

SCHNEIDER, Numa

1902. Plantation du figuier. Rev. Hort. $74: 143-45$.

SEMMOLA, Vincenzo

1845. Della caprificazione; esperienze e raggionamenti. Accad. Sci. Napoli, rend. 4: 417-55.

Shinn, C. H.

1892. Fig trees at the experiment stations. Calif. Agr. Expt. Sta. Bul. 96:3-6.

1893. The fig in California. Calif. Agr. Expt. Sta. Rpt. 1891-1892:147-57.

1903. Culture work at the substations, 1899-1901. Calif. Agr. Expt. Sta. Bul. 147: 7-120. (The fig, pp. 15, 54.)

1915. The fig in California. In: The Standard Cyclopedia of Horticulture [Bailey] $3: 1235-38$.

Simonet, M., R. Chopinet, and J. BACCialone

1945. Contribution à l'étude de quelques variétés de figuiers des Alpes-Maritimes et du Var. Rev. de Bot. Appl. 25:44-72. Illustrated.

Simonet, M., and R. Chopinet

1947. Le figuier à Sollies-Pont. Rev. Hort. 118:66-69. Illustrated. 2 color plates.

SIMON-Louis Frères

1895. Guide pratique de l'amateur de fruits. 385 pp. Berger-Levrault, Paris. (Figues, pp. 19-20.)

Siniscalchi, A.

1911. La coltivazione del fico nel Cilento. Boll. Arbor. Italiana 7:25-54.

Socif́té Nationale D'Horticulture de France

1928. Les meilleurs fruits. New edition. Sect. Pomologique, Paris. (Figues, p. 139. 3 figures.)

Société Pomologique de France

1887. Catalogue descriptif des fruits adoptés. Lyons. (Figues, pp. 27-33.)

1947. Same. 561 pp. Arnaud, Lyons. (Figuier, pp. 89-92.)

Solms-LaUbach, H. GraF

1882. Die Herkunft, Domestication, und Verbreitung des gewöhnlichen Feigenbaums. Abhandl. K. Ges. Wiss. Göttingen 28:1-106.

1885. Die Geschlechterdifferenzierung bei den Feigenbäumen. Bot. Zeitung 43:514$22,530-39,546-51,562-71$.

SPENCE, W.

1846. Sussex fig orchard. Gard. Chron. 6:598.

StANSEL, R. H., and R. H. Wyche

1932. Fig culture in the Gulf coast region of Texas. Texas. Agr. Expt. Sta. Bul. 466: 1-28. Figures 1-14.

Starnes, H. N.

1903. The fig in Georgia. Georgia Agr. Expt. Sta. Bul. 61:49-74. Plates 1-15.

Starnes, H. N., and J. F. Monroe

1907. The fig in Georgia. (Second report.) Georgia Agr. Expt. Sta. Bul. 77:42-101. Illustrated.

Stubenrauch, A. V.

1903. The culture substations. Calif. Agr. Expt. Sta. Rpt. 1901-1903:161-93. (Figs, pp. 171, 192.) See also: 1903-1904:139. 
SWINGLE, W. T.

1905. Figs from Italy. Key to seven principal varieties of Neapolitan eaprifigs. In: Inv. No. 10, U. S. Dept. Agr. Bur. Pl. Ind. Bul. 66:230-33.

1909. The Rixford, a new type of Smyrna fig. Pac. Rural Press 77:161, 170. Illustrated.

1928. New crops for Arizona, and the improvement of old ones. Assoc. Ariz. Producer $7(6): 3 ; 5 ; 10-11 ; 13$. June 1 .

SYMEONIDES, P. M. T.

1930. The production of figs in Cyprus. Cyprus Agr. Jour. 24:106-9.

1907. How to grow figs under glass. The Garden 71:332. Illustration of Bourjassotte Grisé.

T., O.

1905. Figs in pots. Gard. Chron. (ser. 3) 38:257-58. Figure 96.

TABAIN, F.

1949. A contribution to the study of the morphological and biological properties of our figs. Radovi Poljoptivred Naueno-Istrazivack. Ustanova [Belgrade] 1:12456. See: Pl. Breeding Abs. 21(1327): Figs in Yugoslavia. (Article not seen, and varieties not included in this monograph.)

TAMARO, D.

1948. Tratado de fruticultura. Fourth ed. (Italian version, by Arturo Caballero.) 939 pp. S. Gili, Cochabamba, Buenos Aires. (Higuera, pp. 800-824. Figures 631-45.)

TANARA, Vincenzo

1651. L'Economia del cittadino in villa del Sig. V. Tanara. 7 vols. 624 pp. Eredi del Dozza, Bologna. (Fico, pp. 376-80.)

TAYLOR, W. A.

1898. The fruit industry. In: U. S. Dept. Agr. Yearbook 1897:305-44. (Fig, pp. 31618. Color plate 5.)

Theophrastus, EResios (372-287 B.c.)

1916. Enquiry into plants. Translated by Sir Arthur Hort. 2 vols. G. Putnam's Sons, New York. (Fig, see index.)

THOMAS, OWEN

1902. Fig culture out of doors and under glass. The Garden 61:414-15, 432. 2 figures.

THOMPSON, ROBERT

1859. The gardener's assistant. 774 pp. London. (Fig, pp. 642-49.)

1925. Same. 6 vols. William Watson, ed., London. (Fig, $3: 34-44$. Figures $33-41$.)

TOURNEFORT, J. P. DE

1719. Institutiones rei herbariae. 3 vols. Typ. Regia, Paris. (Figuier, 1:662-63; 3 : plate 420.) First ed. 1700.

Trabut, L.

1901. La caprification. en Algérie. Algérie Dir. de l'Agr. Serv. Bot. Bul. 32:115-38.

1904. Le figuier en Algérie. Algérie Dir. de l'Agr. Serv. Bot. Bul. 38:1-37. Illustrated.

1922. Sur les origines du figuier. Rev. de Bot. Appl. 2:393-96.

1923-1924. Le figuier. Algérie-Tunisie-Maroc Bul. Agr. 29(2):17-21; (3):33-39; (4): 49-60 (figs. 1-18); (5):73-75 (fig. 19); (6):97-101; (7):117-24 (figs. $20-$ 32 ) ; (8):137-49 (figs. $33-39)$; (10):173-77; (11) :189-92; (12):213-17; 30 (2) $: 25-26$.

Traub, H. P., and G. S. Fraps

1928. Ripening and composition of the Texas Magnolia fig. Amer. Soc. Hort. Sei. Proc. $25: 306-10$.

Tschaen, E.

1908. Le figuier à Sollies-Pont. Jour. d'Agr. Prat. 72(2):186-87. (Bourjassotte or Barnissotte exclusively cultivated.)

Valdeyron, G., and P. Crossa-Raynaud

1950. Les fruits de Tunisie. Ann. Serv. Bot. et Agron. de Tunisie 23:1-124. (Figues,

VALLESE, $\mathrm{F}$. pp. 83,101 . Color plate 47 .)

1904. La caprificazione in Terra d'Otranto. 68 pp. Tip. Soc. Coop., Lecee. 18 figures.

1909. Il fico. 381 pp. F. Battiato, Catania. Figures 1-123. 
Van Deman, H. E.

1890. Report of the Pomologist. In: U. S. Secr. Agr. Rpt. 1890:409-24. (Fig, p. 414.)

VAN VELZER, A. C.

1909. Fig culture. 218 pp. Houston.

W., J. S.

1873. Castle Kennedy. The Garden 3:338. May 3.

WARD, H. W.

1904. Fig trees on walls out of doors. Gard. Chron. (ser. 3) 35:49-50.

W ATTS, R. L.

1890. Fruit trees at the experiment station. Tenn. Agr. Expt. Sta. Bul. 3(5) :75-92. (Figs, p. 90.)

WEST, W. B.

1882. Fig-growing in California. Pac. Rural Press $24: 82-83$.

WESTON, RICHARD

1770-1777. The universal botanist and nurseryman. 4 vols. Printed for J. Bell, London.

White, W. N. (Fig. $1: 109 ; 4: 151$.)

1868. Gardening for the South. Revised ed. 444 pp. Orange, Judd \& Co., New York. (Fig, pp. 363-69.)

WOODARD, OTIS

1938. Fig variety test. Georgia Coastal Plain Expt. Sta. Bul. (18th Ann. Rpt.) 29:112. 1940. Same (20th Ann. Rpt.) 31:113.

Woodroof, J. G., and J. E. BAILEY

1931. Fig varieties and culture. Georgia Agr. Expt. Sta. Circ. 97:1-4. 2 figures.

WRIGHT, JOHN

1891-1895. The fruit-grower's guide. 6 vols. Virtue and Co., London. (Fig, 2:170-200. Figures 55-62. 1 color plate.)

WrThes, G.

$1890 a$. Figs in pots for early fruiting. The Garden $38: 430$.

$1890 b$. New fig, St. John. Gard. Chron. (ser. 3) 7:719.

1893. Figs for forcing. The Garden $44: 168,319$.

1900a. The Brown Turkey fig. The Garden 58:130. 1 figure.

1900b. Early figs at Gunnersbury House. Gard. Chron. (ser. 3) 27:132.

1902. Some valuable late figs. Gard. Chron. (ser. 3) 32:205. 


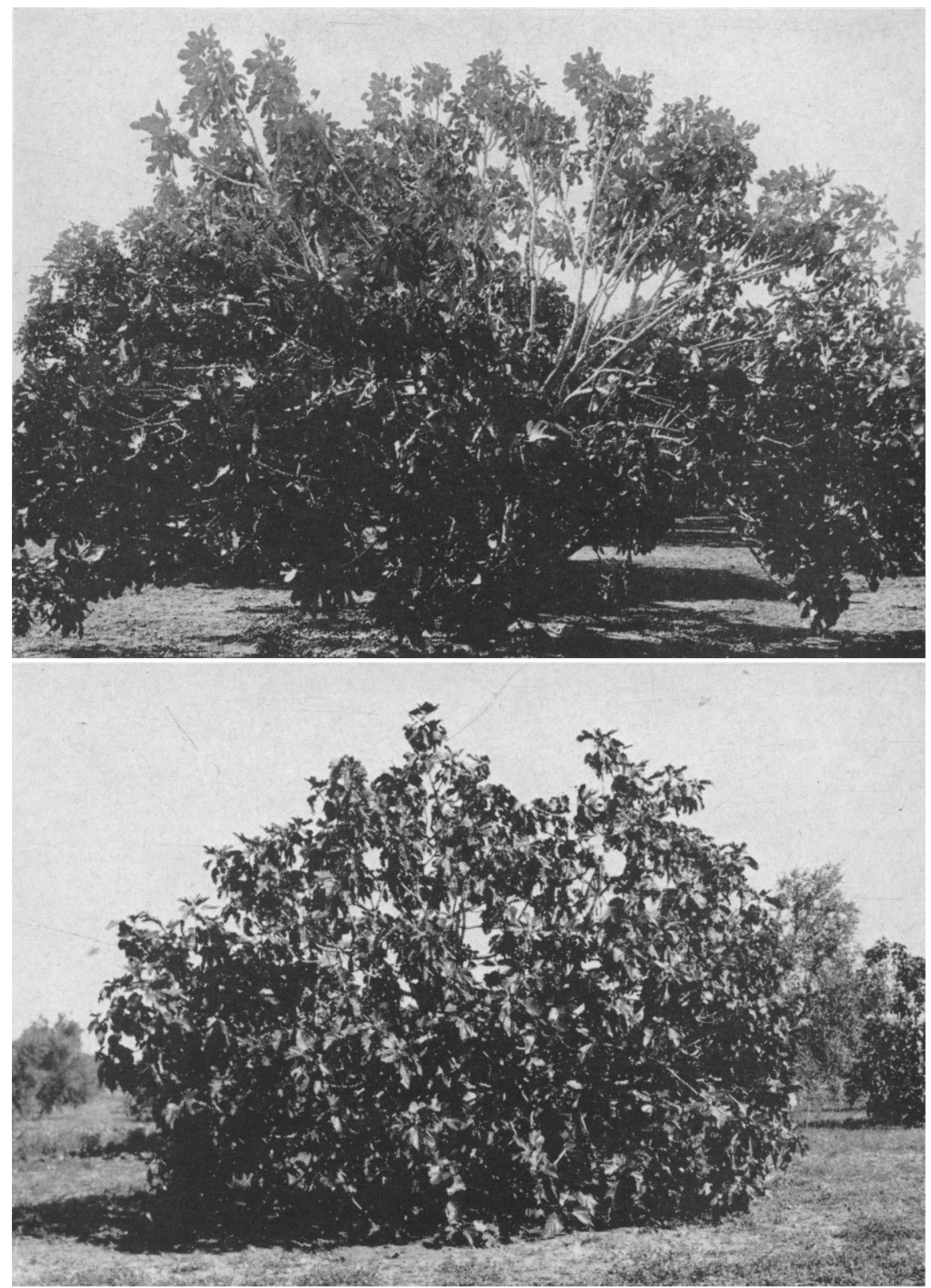

Plate 1. Above: Typical tree of Sari Lop near Modesto, California, showing tendency of branches to become top-heavy and to droop. Below: Typical tree of Dottato at Mesagne, Italy. 


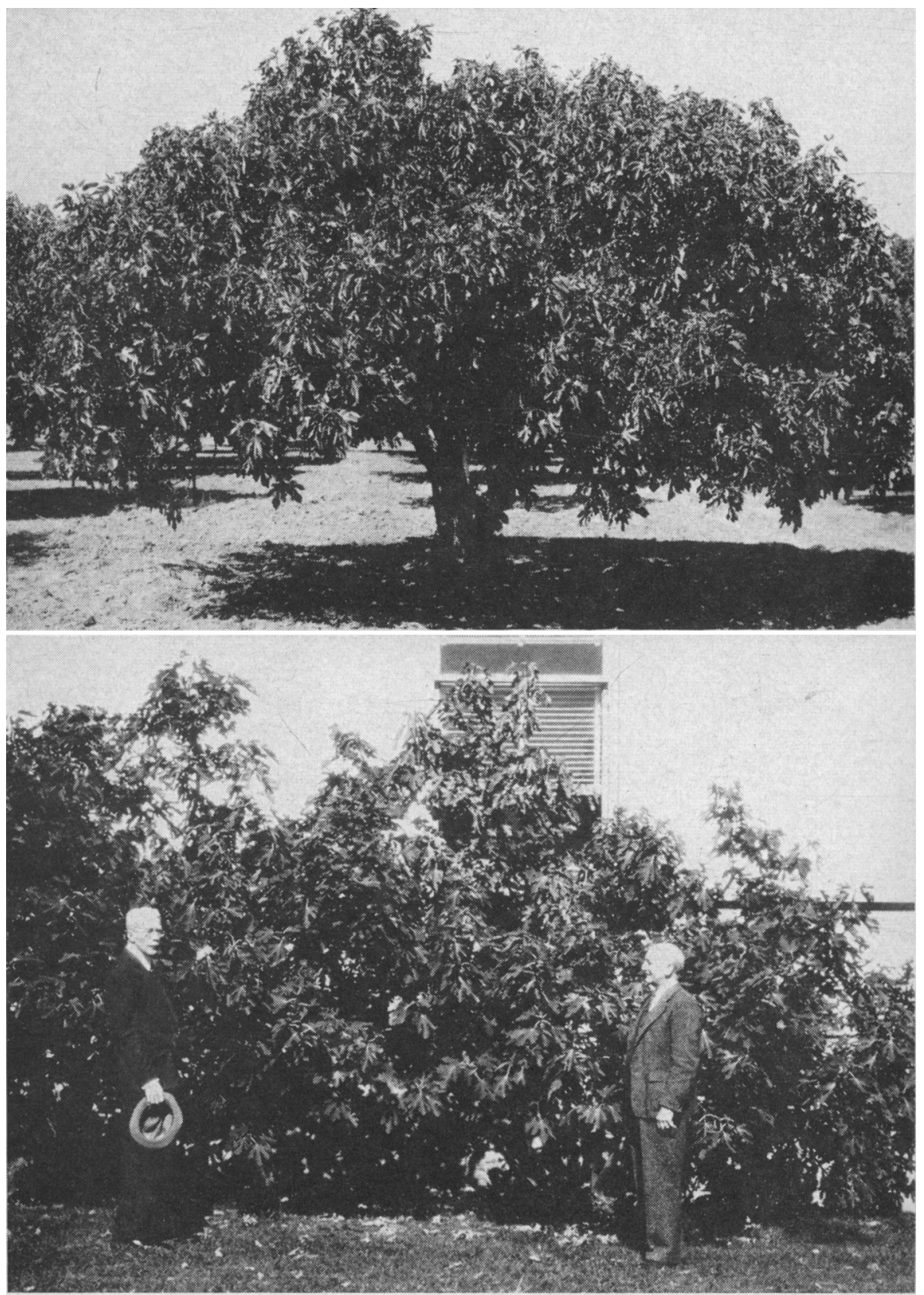

Plate 2. Above: Typical tree of Verdone near Fresno, California. Below: Tree of Brunswick, south side of Naval Observatory, Washington, D.C., in 1940. At left, the late Dr. W. T. Swingle; at right, Capt. Frederick Hollweg. 

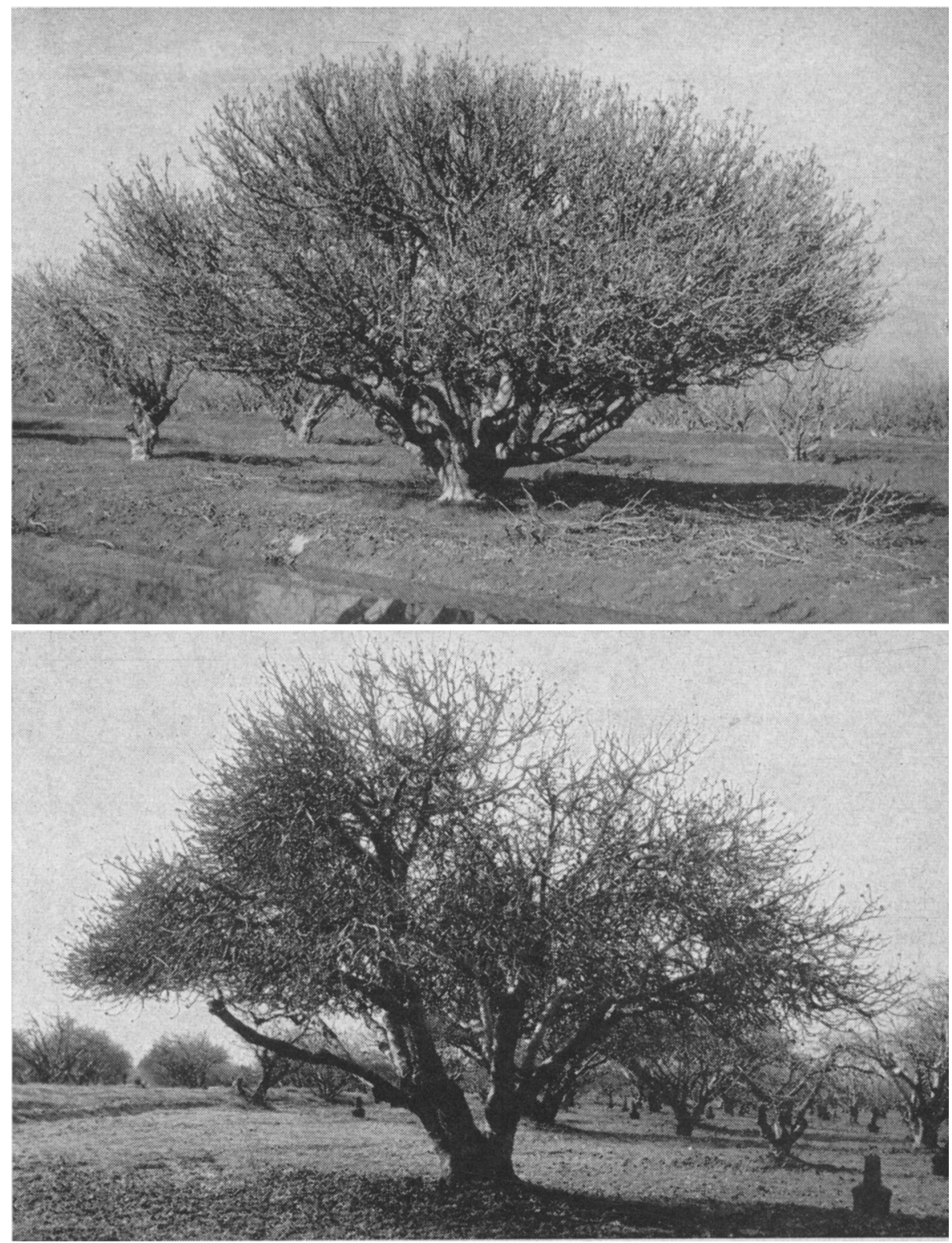

Plate 3. Above: Typical tree of Stanford caprifig. Below: Tree of Roeding No. 3 caprifig. Both are near Fresno, California. 

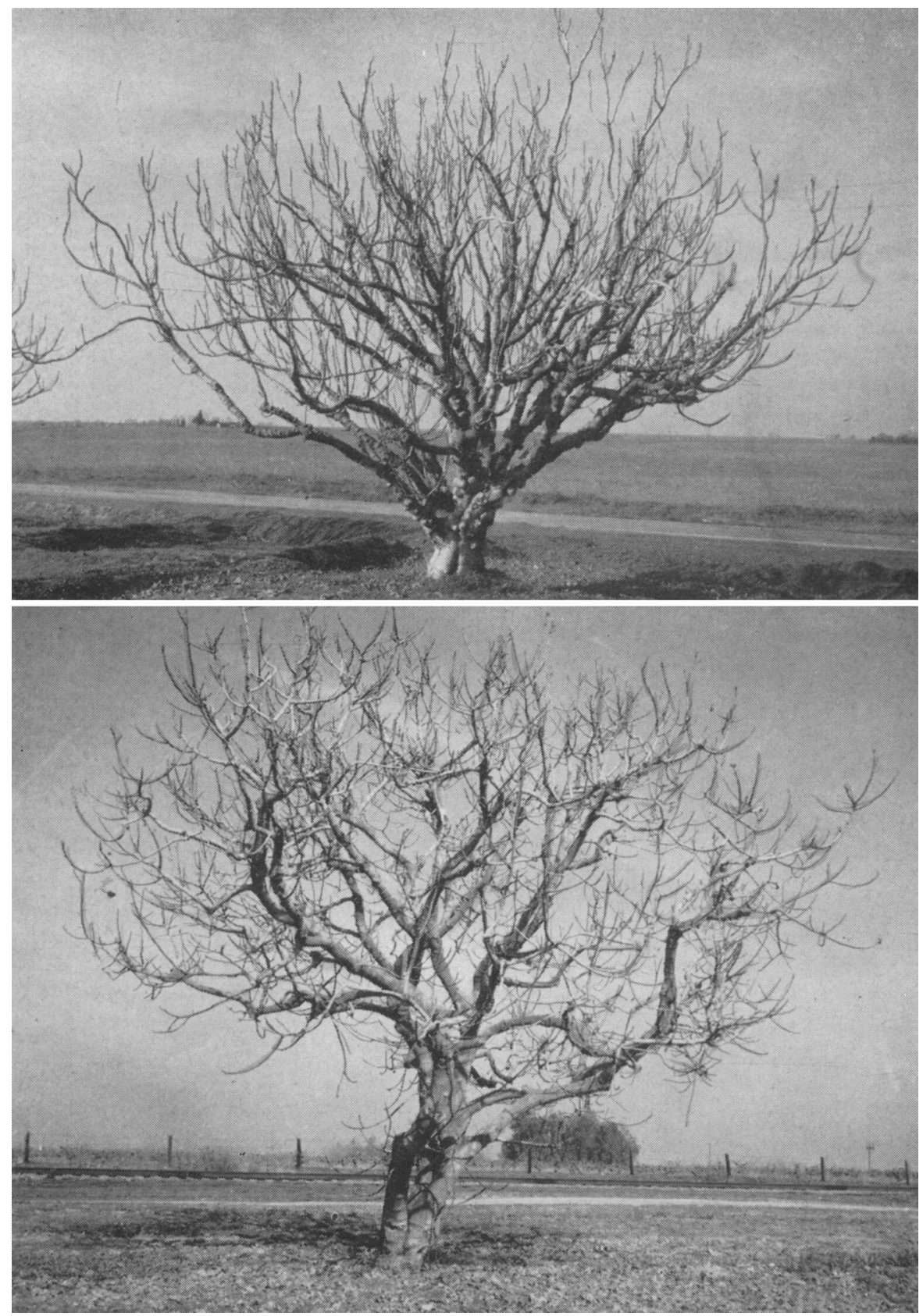

Plate 4. Above: Typical orchard tree of Sari Lop, with nodal swellings prominent on large branches. Below: Typical orchard tree of Franciscana. Both are near Fresno, California. 


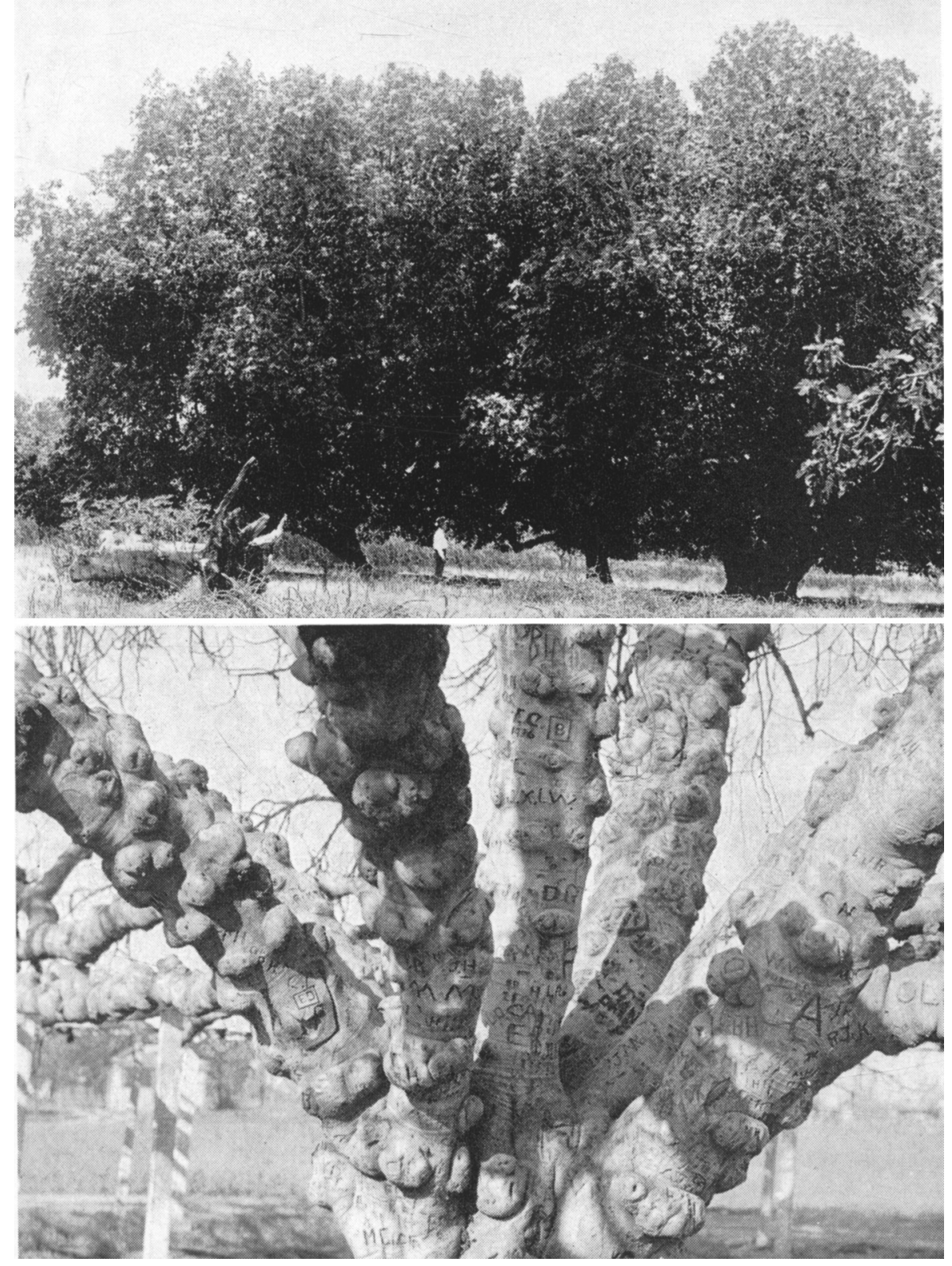

Plate 5. Above: Large Franciscana trees that once grew in the Kelsey orchard at Merced Falls, California. Below: San Pedro fig tree, formerly in park at Parlier, California. The framework branches show nodal swellings that are unusually pronounced. 


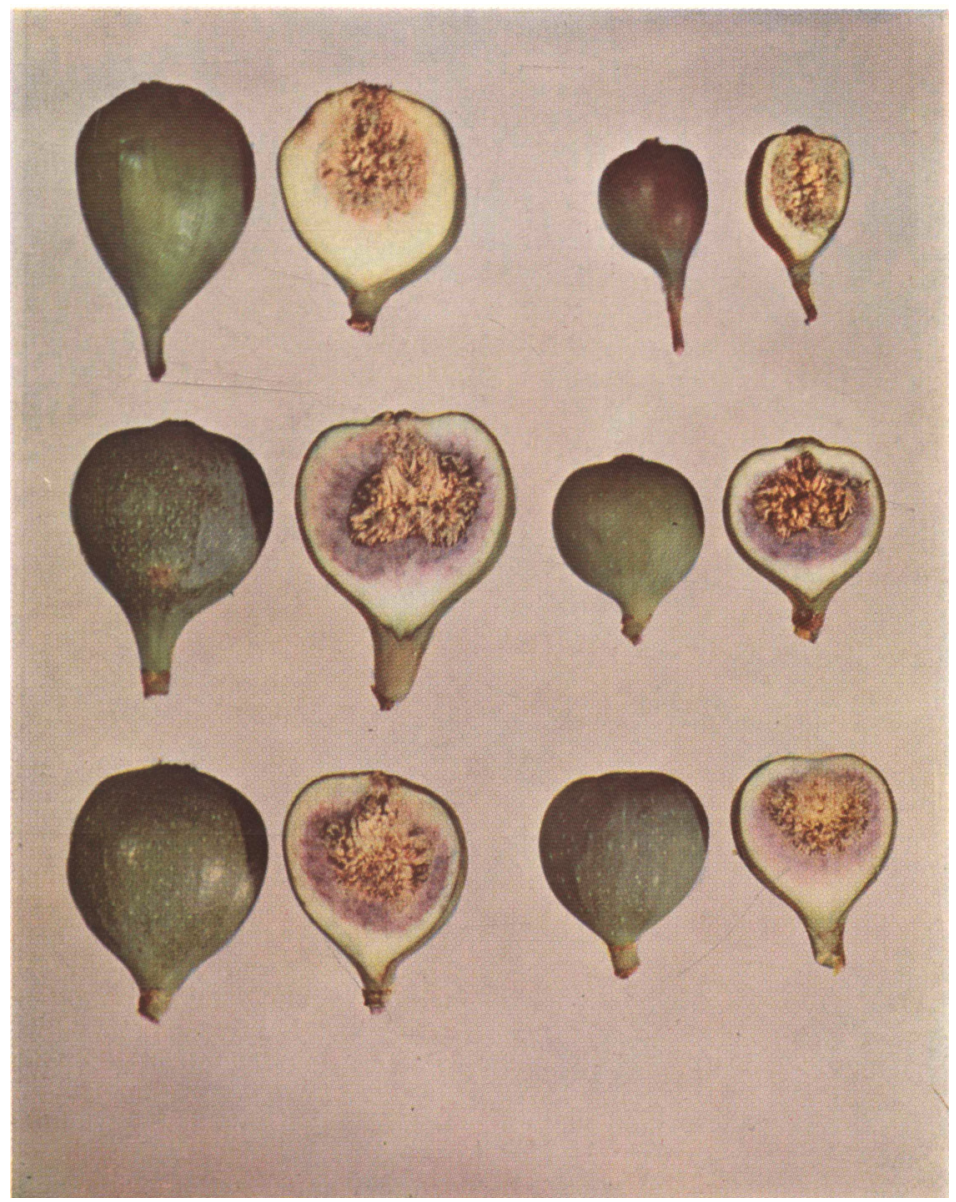

Plate 6. Caprifigs, profichi crop. Above: Stanford; Ficus pseudo-carica. Center: Roeding No. 3 ; Roeding No. 1. Below: Samson; Milco. 


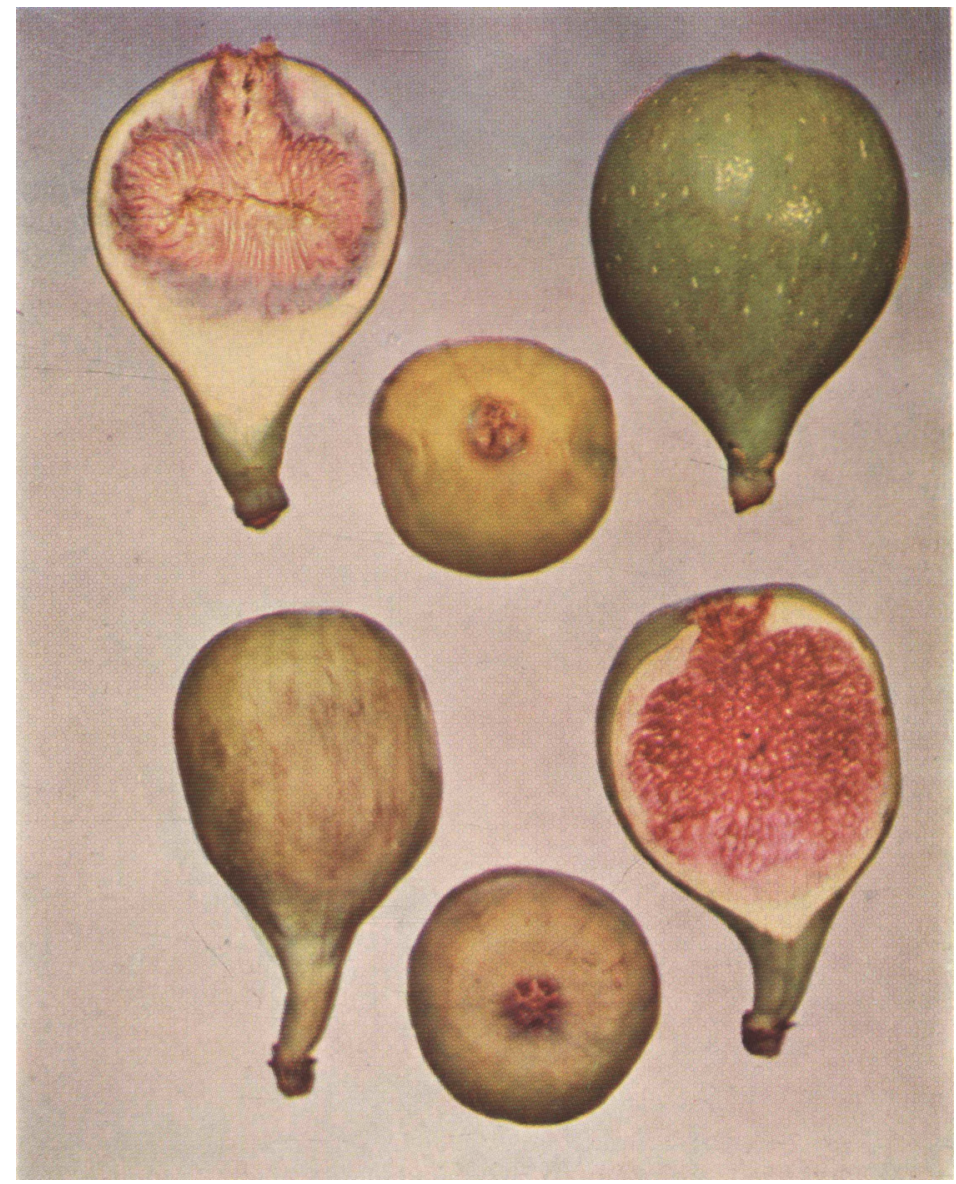

Plate 7. Brebas. Above: Dottato. Below: Verdone. 


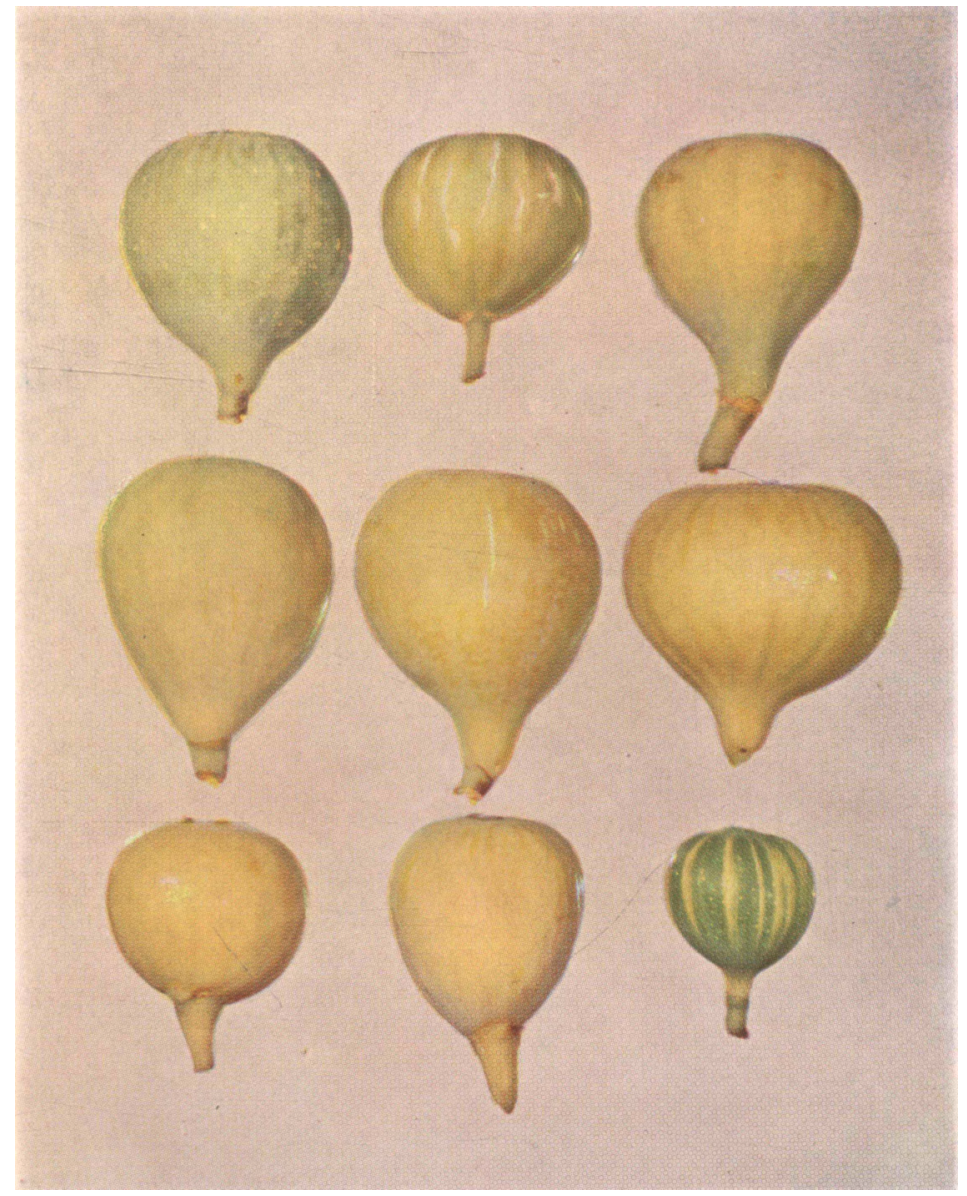

Plate 8. Color green to yellow. Above: Dottato (caprified); Blanche; Castellana. Center: Verdone; Seedling No. 91-12; Sari Lop. Below: Angélique; Troiano; Panachée. 


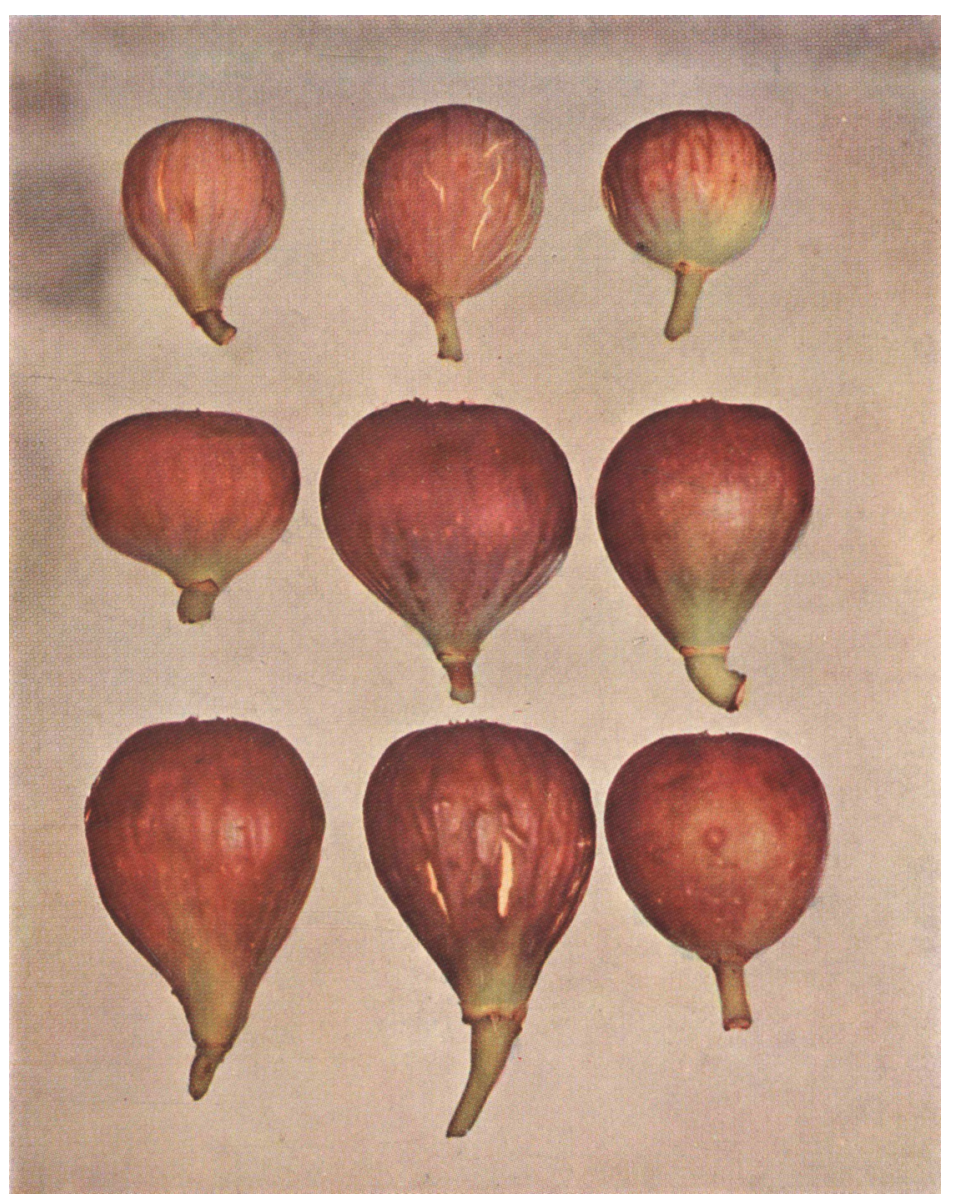

Plate 9. Color medium dark. Above: Malta; Saint Jean; Ischia. Center: Poulette; Archipel; Madeline. Below: Drap d'Or; Pied de Bœuf; Gouraud Rouge. 


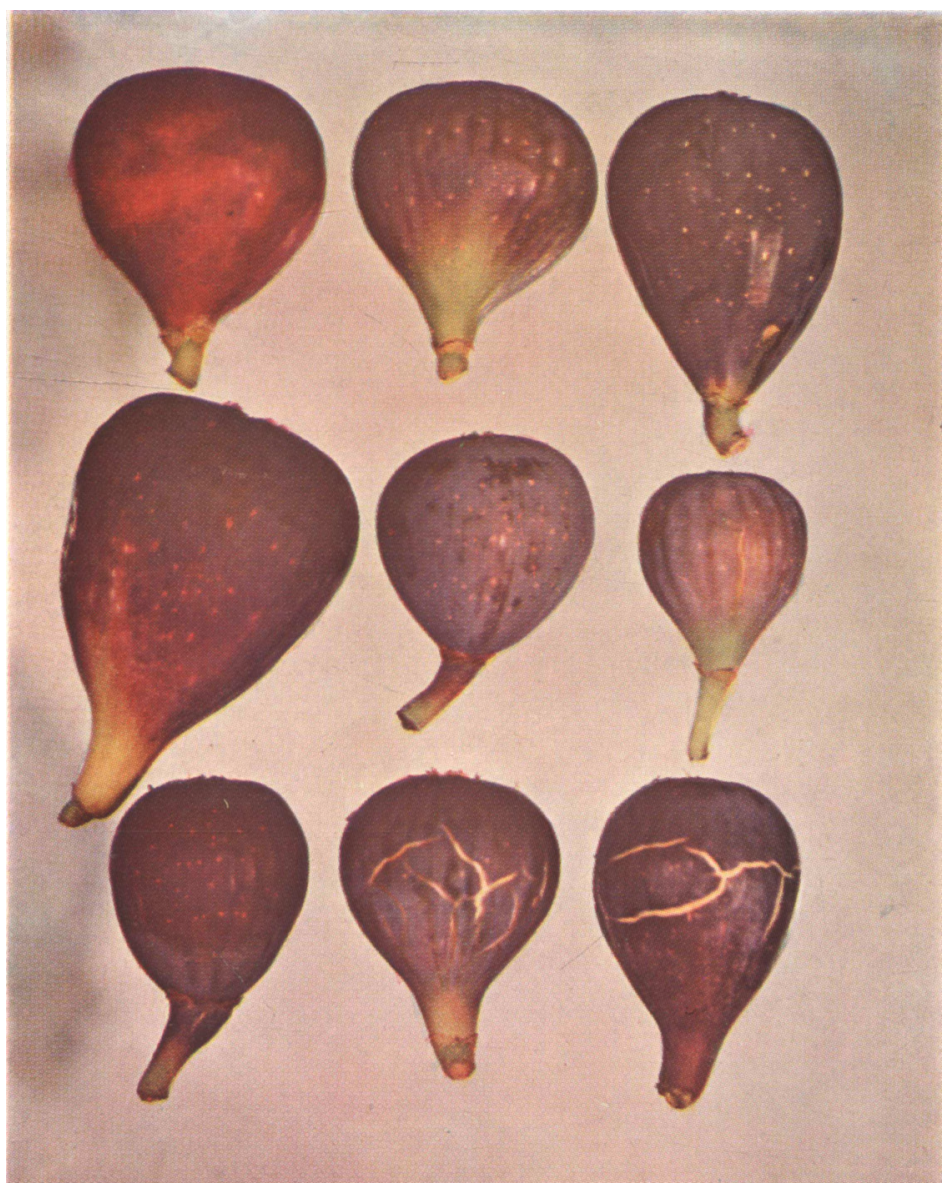

Plate 10. Color dark to black. Above: Beall; Bourjassotte Grisé; Barnissotte. Center: San Piero; Pastilière; Hâtive d'Argenteuil. Below: Bordeaux; Constantine; Franciscana. 


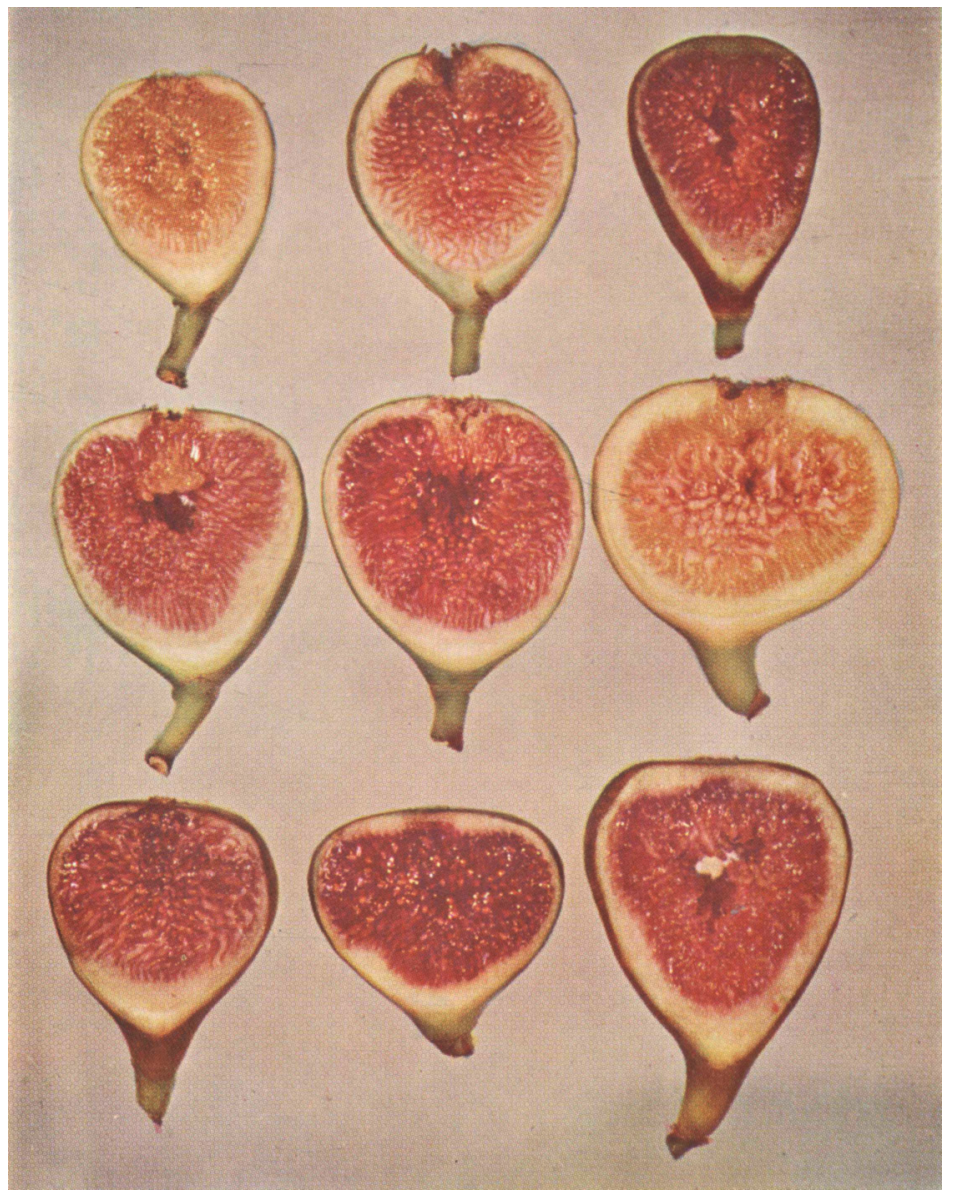

Plate 11. Pulp color. Above: Dottato (uncaprified and caprified); Franciscana. Center: Verdone (uncaprified and caprified); Sari Lop. Below: Madeline; Bourjassotte Grisé (caprified); San Piero. 


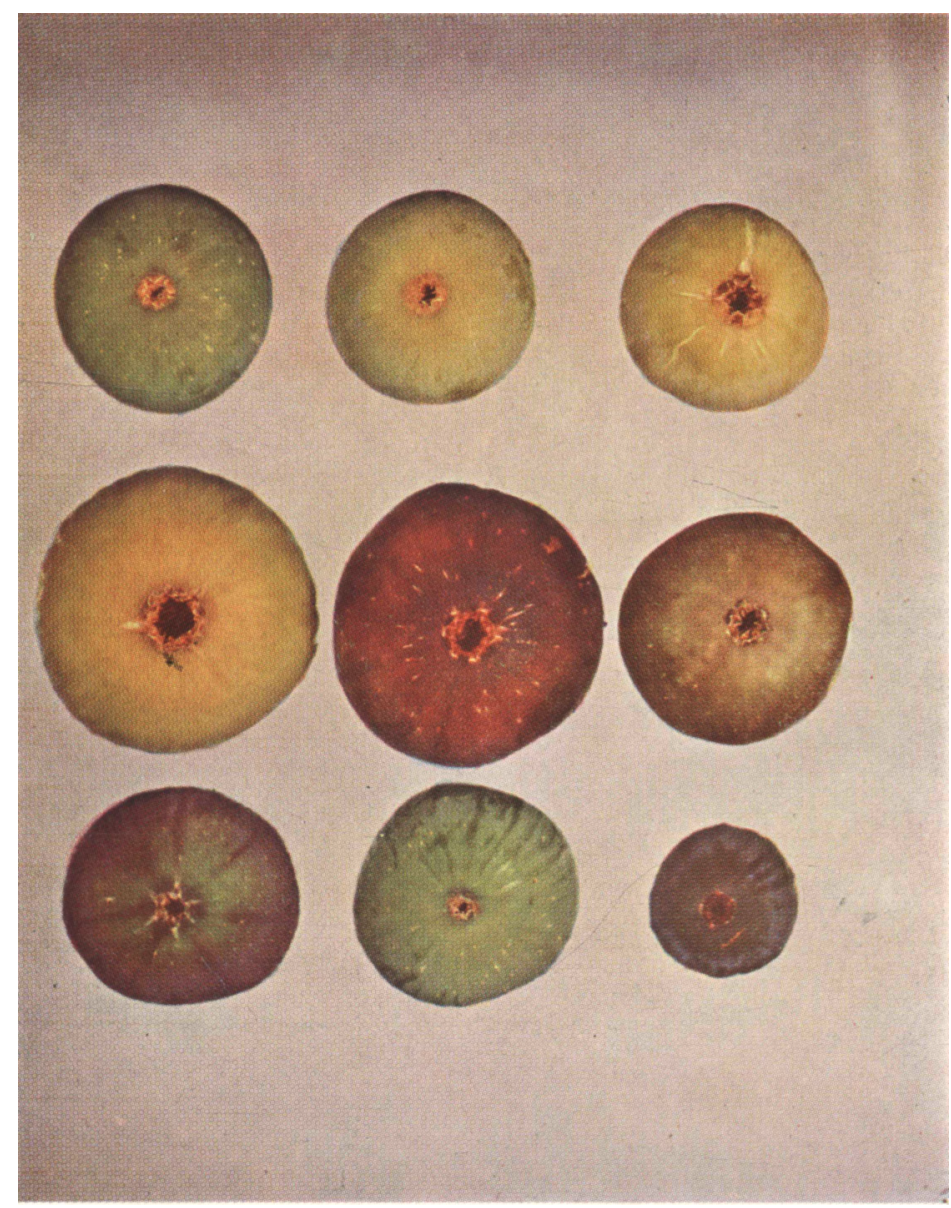

Plate 12. Eyes and eye scales. Above: King; Dottato; Troiano. Center: Sari Lop; San Piero; Madeline. Below: Bourjassotte Grisé; Col de Dame; Figue Fleur, showing lack of bloom at apex. 


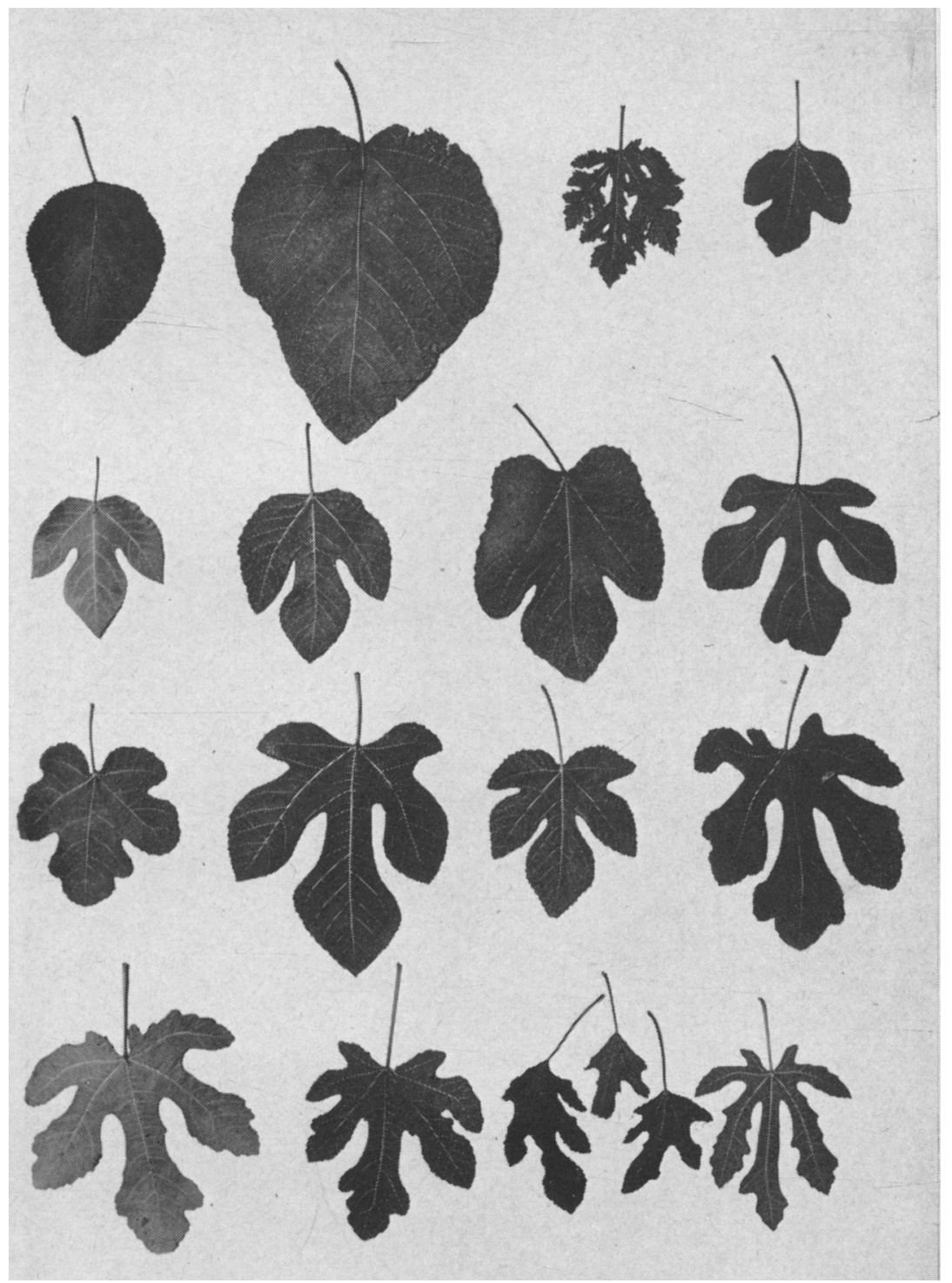

Plate 13. Leaf types, reading left to right. Top row: Ficus palmata; Choer; laciniate leaf of a seedling; Ischia. Second row: Ficus pseudo-carica; Ischia Black; Excelsior; Stanford caprifig. Third row: Toulousienne; Sari Lop; Blanche; Jerusalem. Bottom row: Euscaire; San Pietro; three leaves malformed by mosaic; Brunswick. 


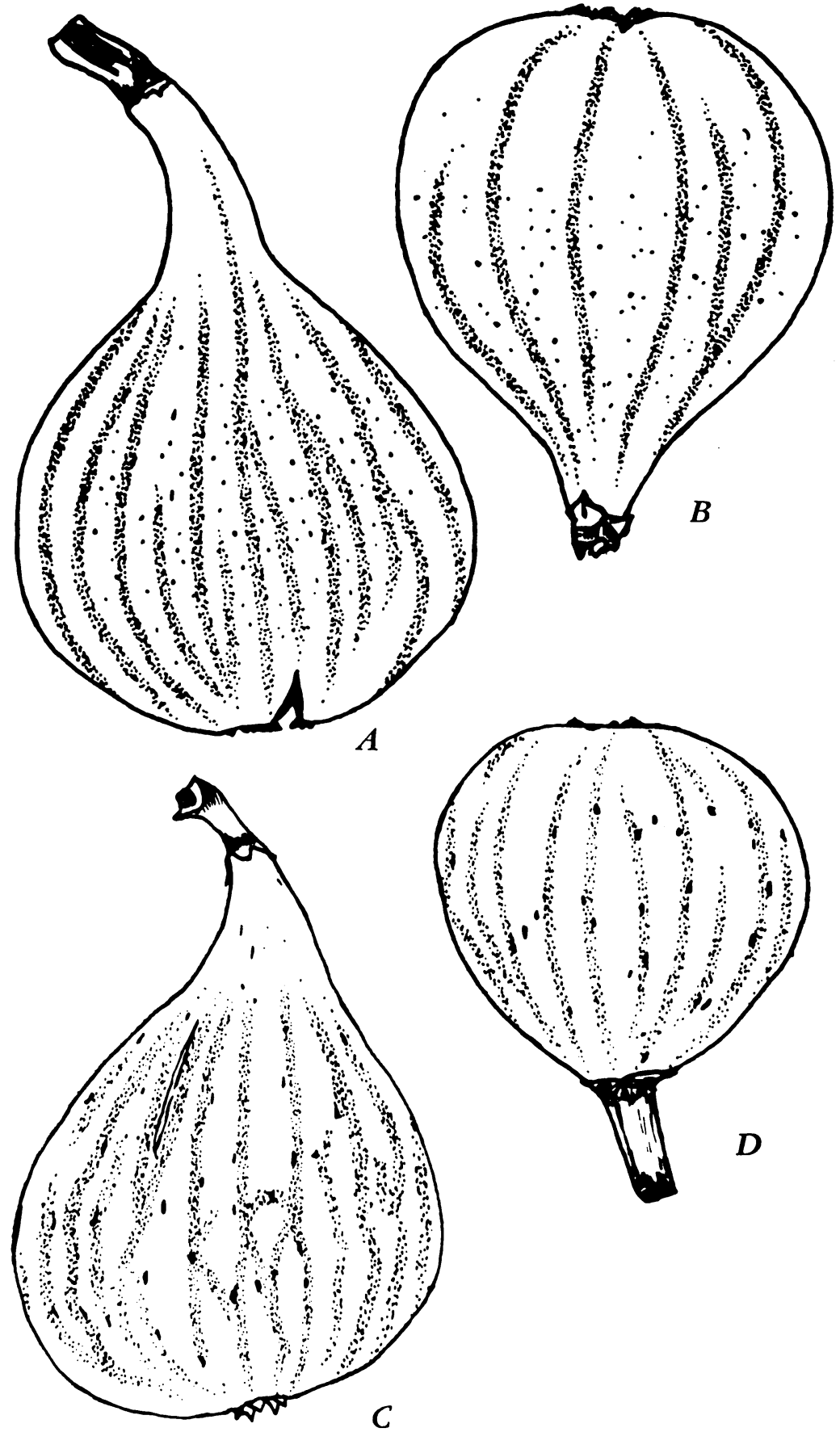

Plate 14. $A$, Marabout; $B$, Choer; $C$, Pied de Bœuf ; $D$, Angélique. All are of second crop. 

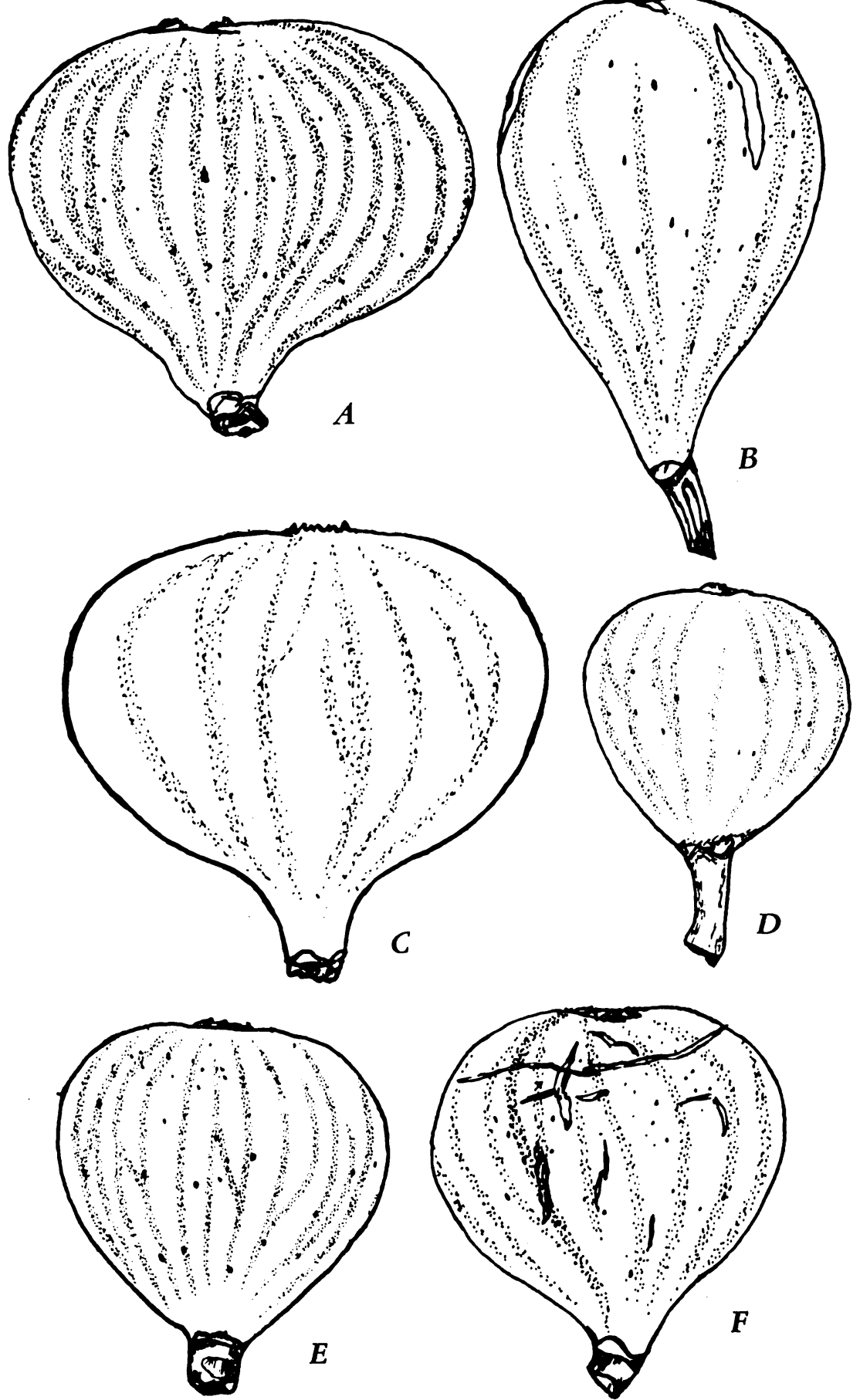

Plate 15. $A$, Kassaba ; $B$, Euscaire ; $C$, Sari Lop; $D$, Ischia ; $E$, Brown Turkey; $F$, Constantine. All are of second crop. 

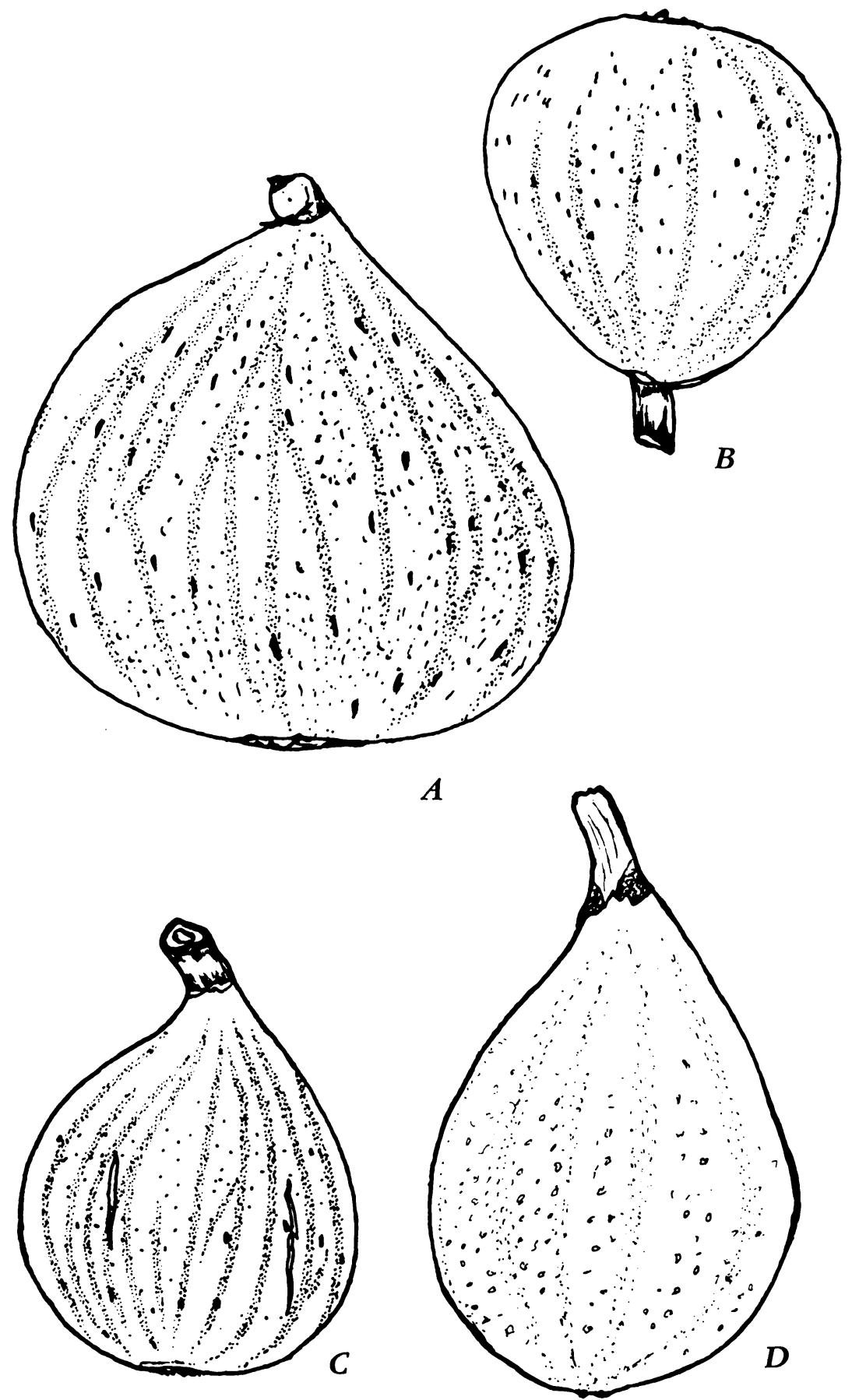

Plate 16. $A, B$, King, breba and second crop; $D, C$, Verdone, breba and second crop.

[ 526 ] 


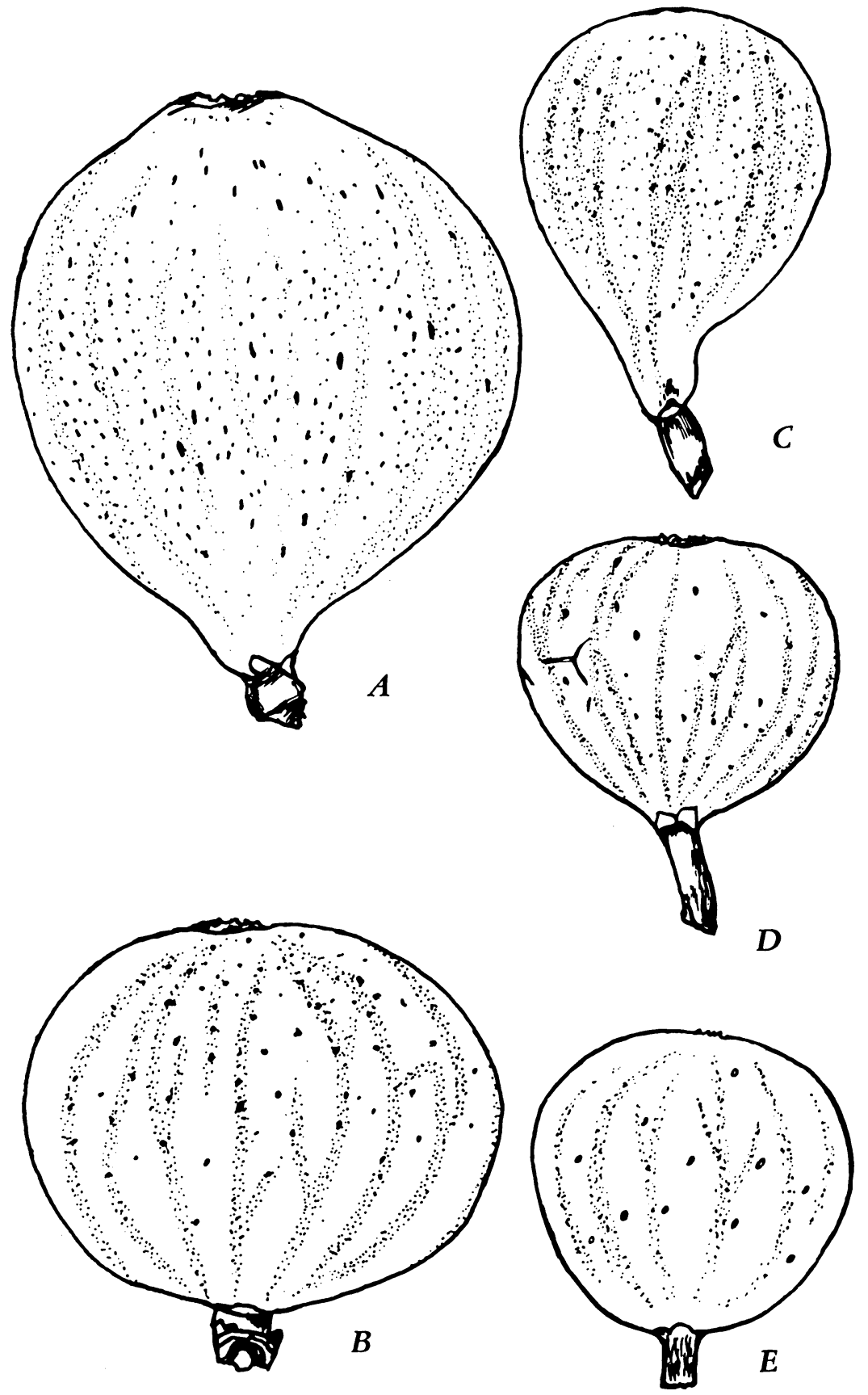

Plate 17. $A, b$, San Pedro, breba and second crop; $C$, Verte; $D$, Grassale; $E$, Noir Moutier. The last three are of second crop. 


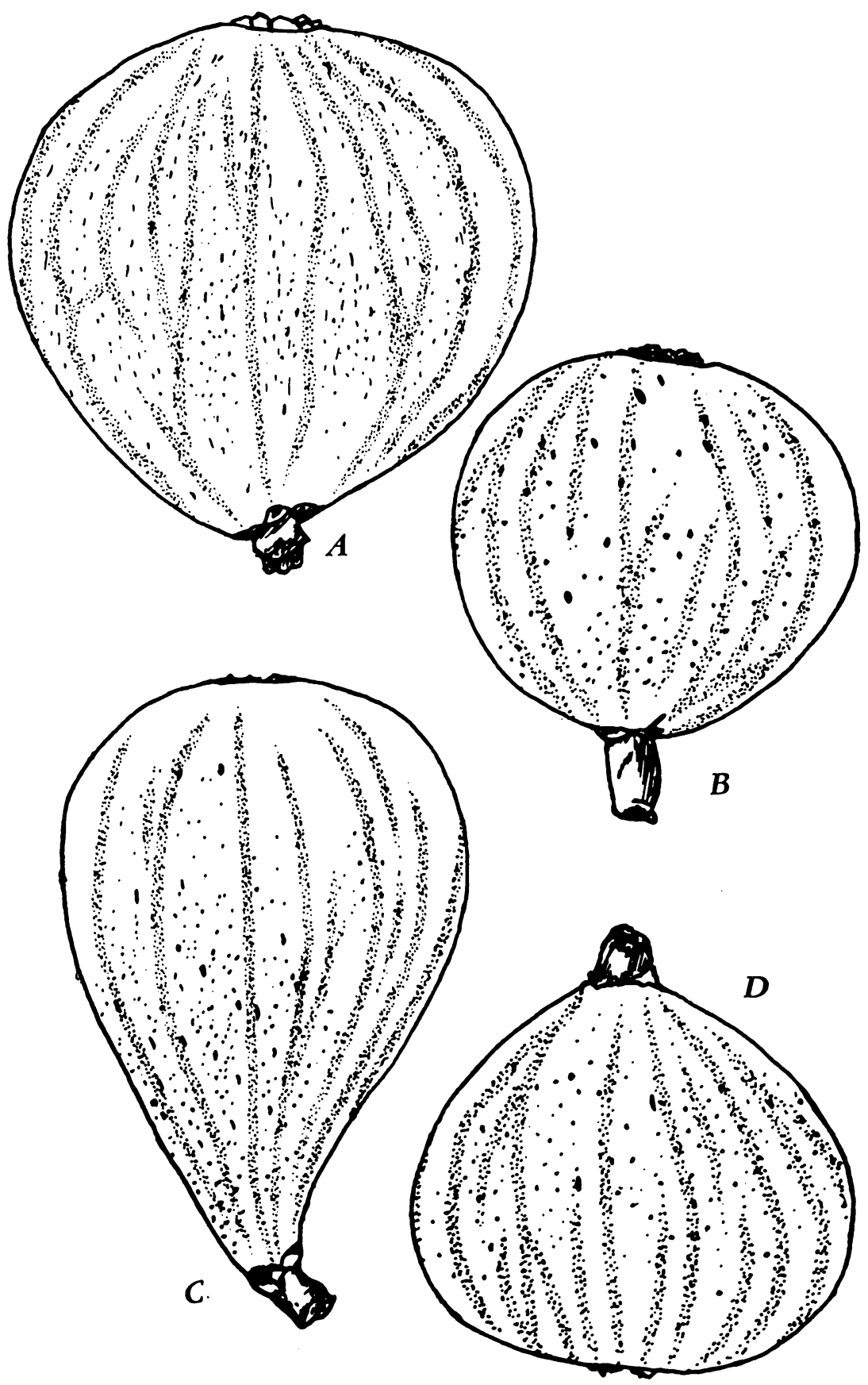

Plate 18. $A, B$, Dauphine, breba and second crop; $C, D$, Beall, breba and second crop. 


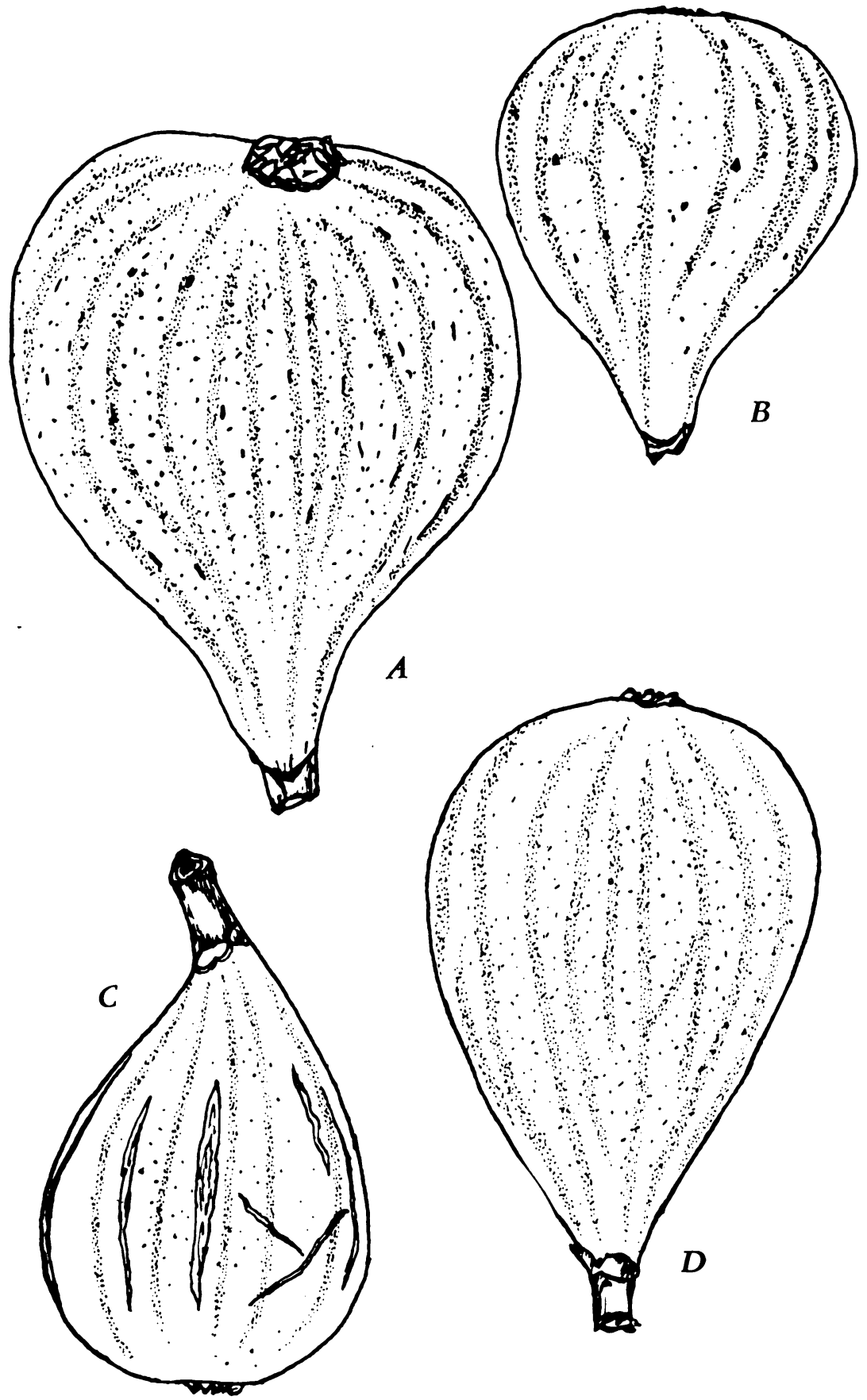

Plate 19. $A, B$, Monstrueuse, breba and second crop; $D, C$, Franciscana, breba and second crop. 

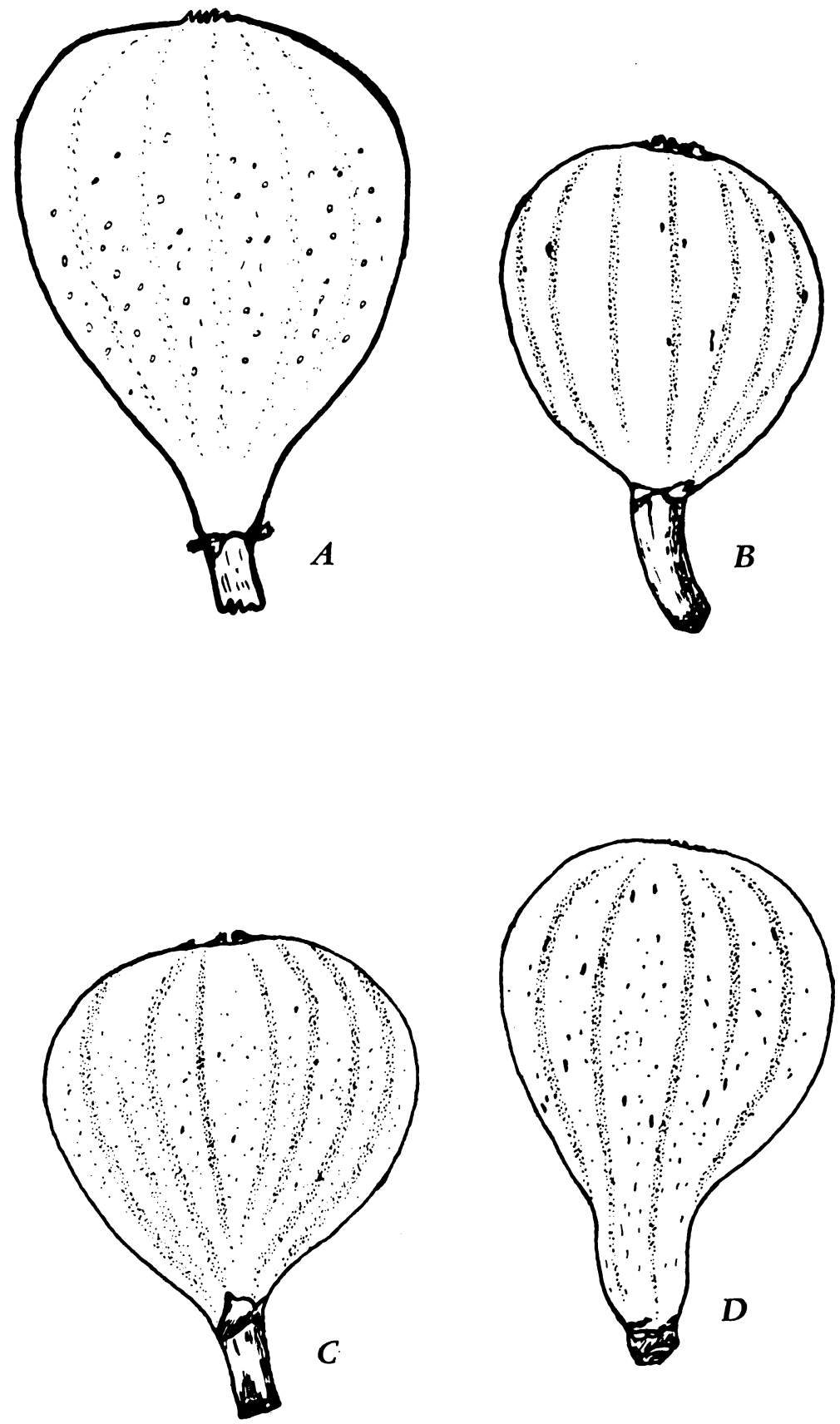

Plate 20. $A, B$, Dottato, breba and second crop; $C$, Bontard; $D$, Col de Dame. The last two are of second crop. 

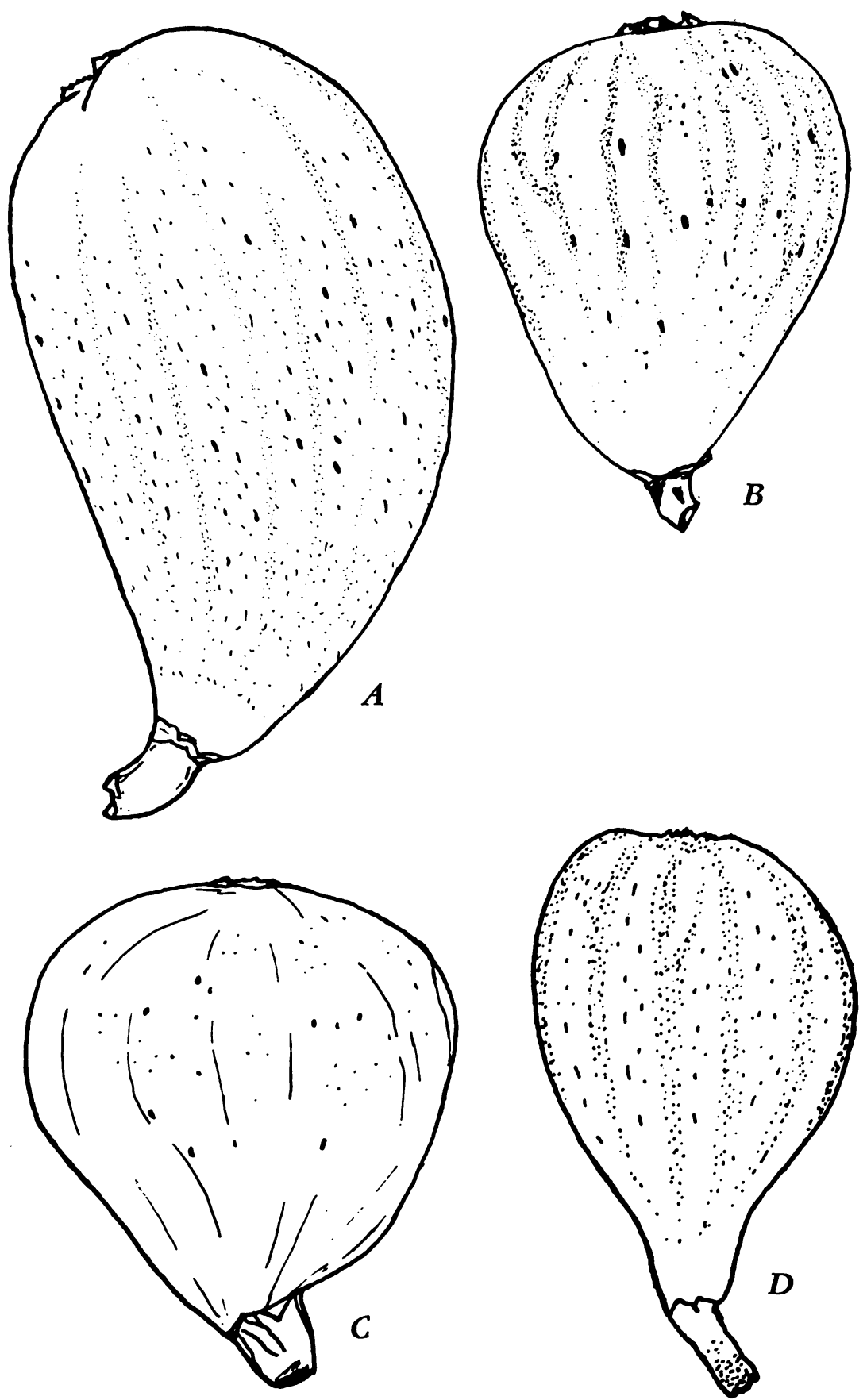

Plate 21. $A, B$, Brunswick, breba and second crop; $C$, Angélique, breba; $D$, Brown Turkey, breba. 


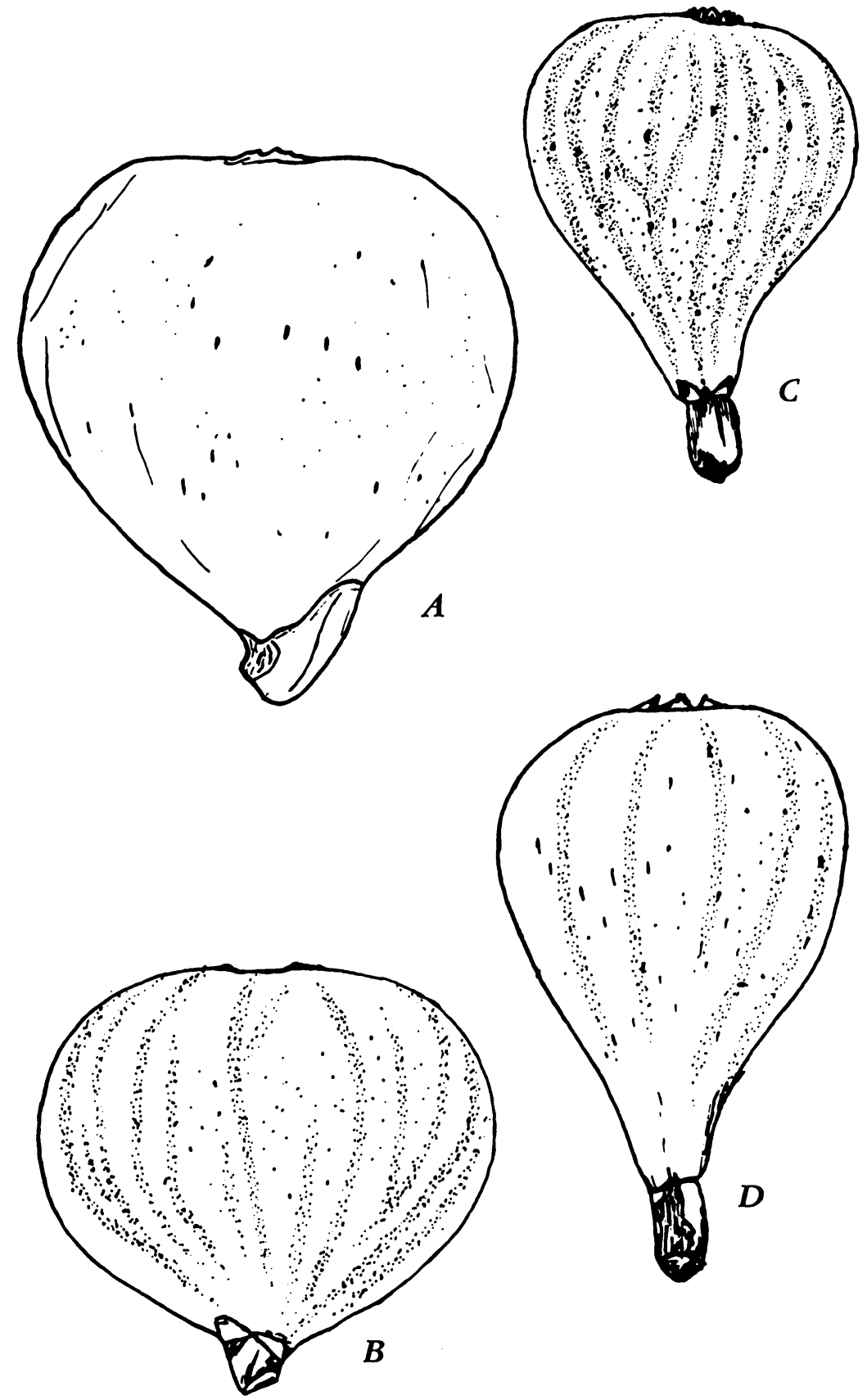

Plate 22. $A, B$, Genoa, breba and second crop; $C$, Gota de Mel; $D$, Datte. The last two are of second crop. 

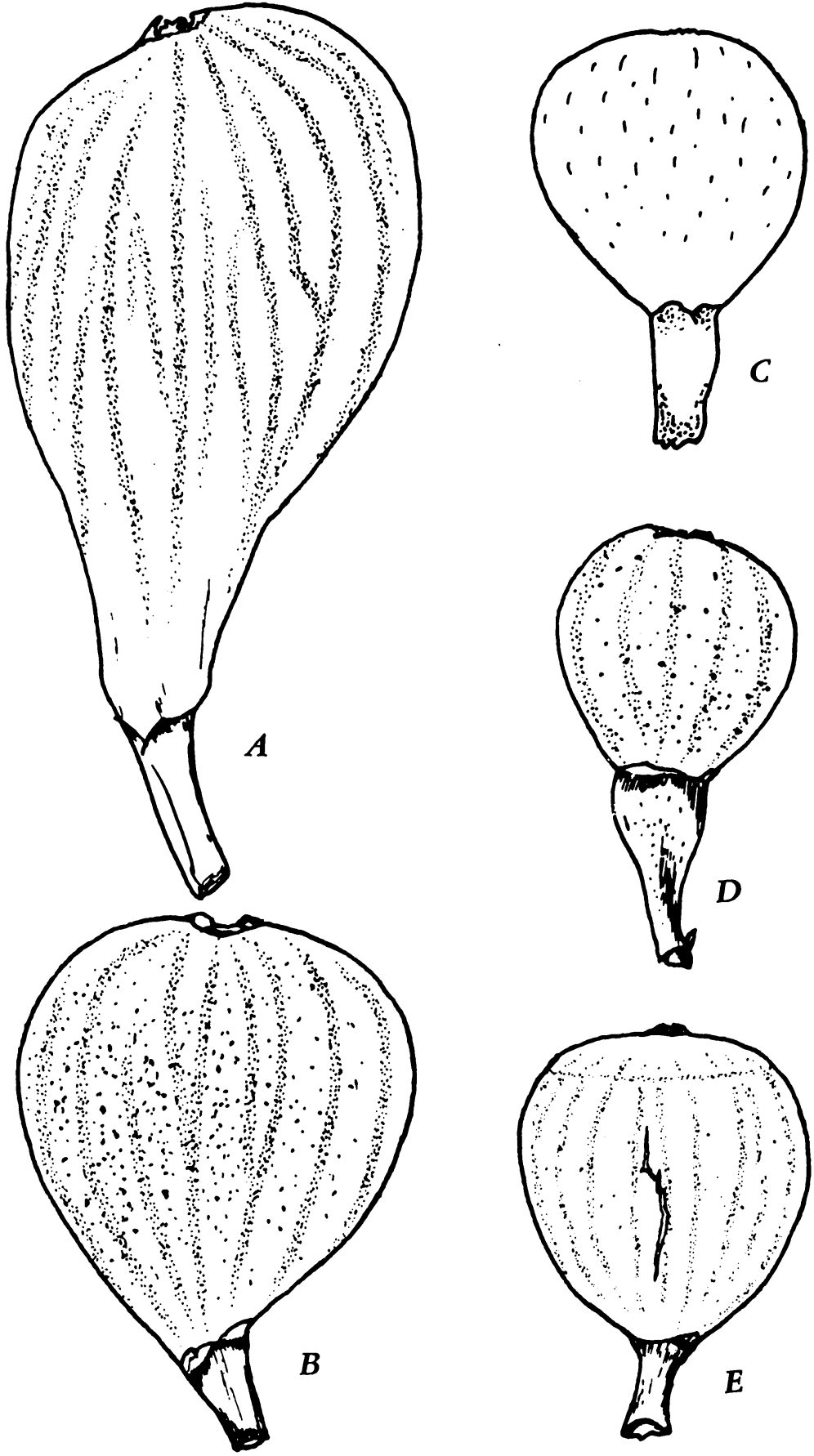

Plate 23. $A$, Pied de Beuf, breba; $B, E$, Saint Jean, breba and second crop; $C, D$, Yellow Neches, breba and second crop. 

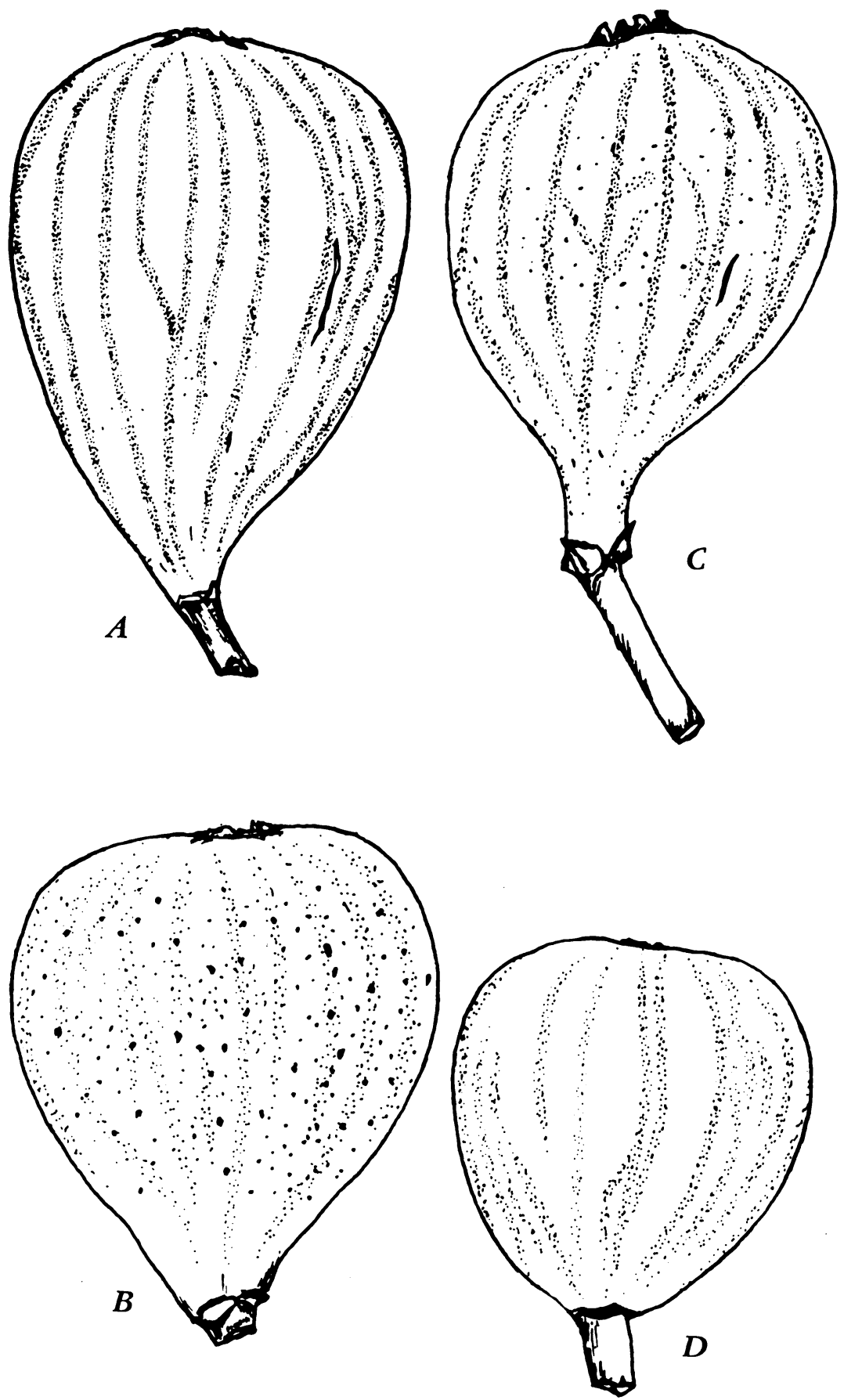

Plate 24. $A, B$, San Piero, breba and second erop; $C$, Drap d'Or; $D$, Gouraud Rouge. The last two are of second crop. 

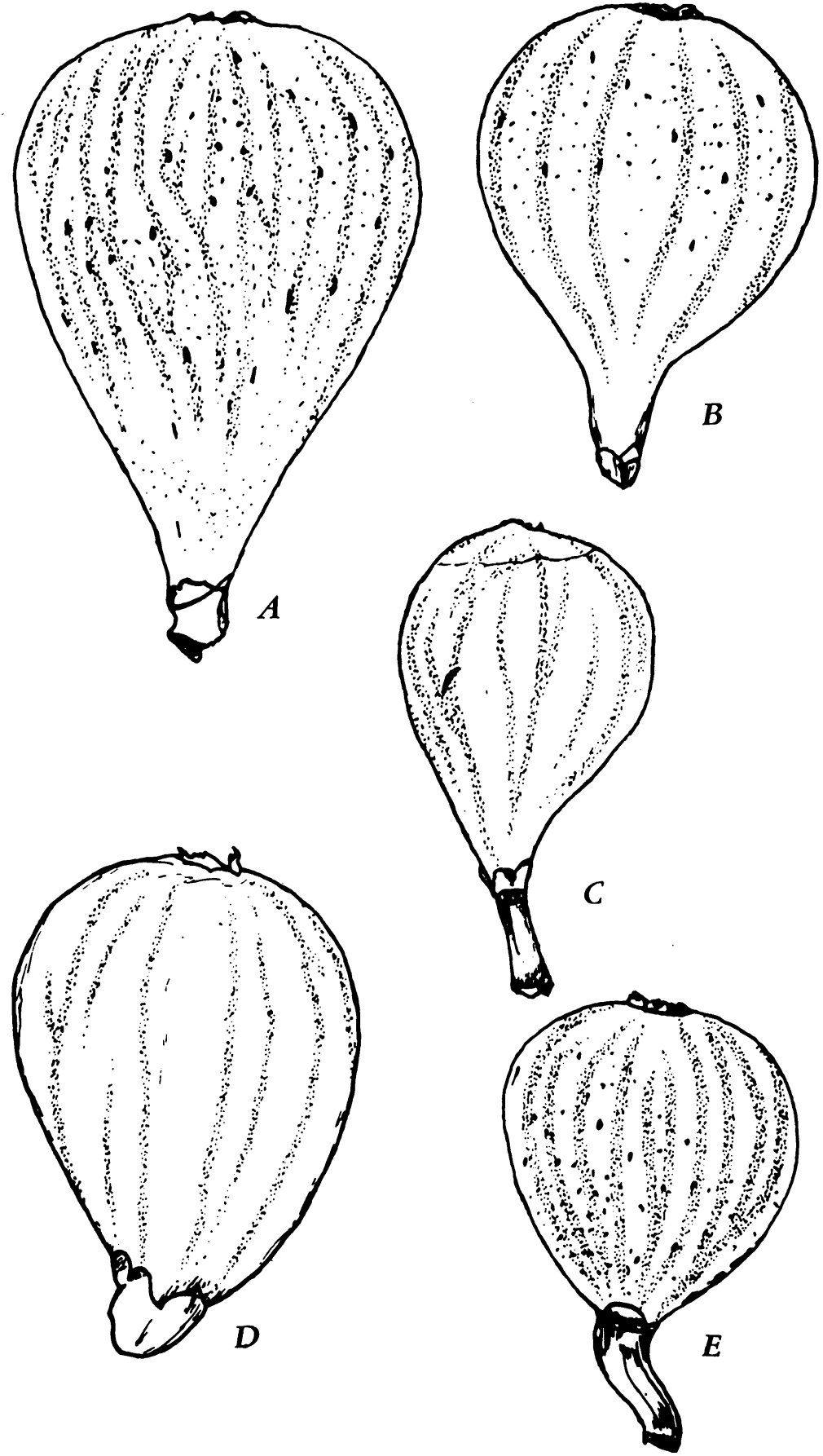

Plate 25. $A$, San Pietro ; $B$, Bourjassotte Grisé; $C$, Malta; all three of second crop; $D, E^{n}$, Bordeaux, breba and second crop. 

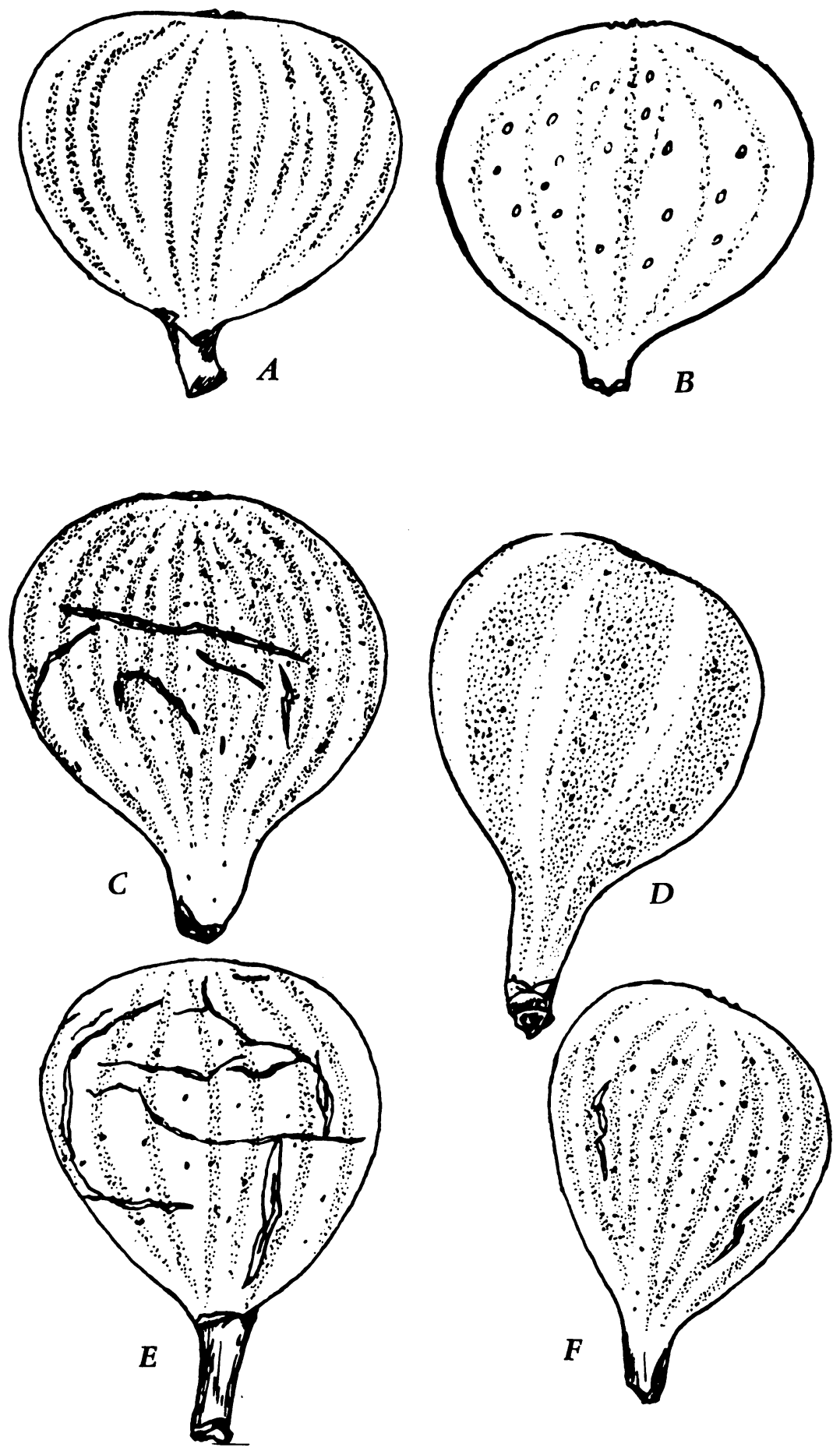

Plate 26. $A$, Blanche; $B$, Royal; $C$, Verdal; $D$, Panachée; $E$, Troiano; $F$, Toulousienne. All are of second crop. 


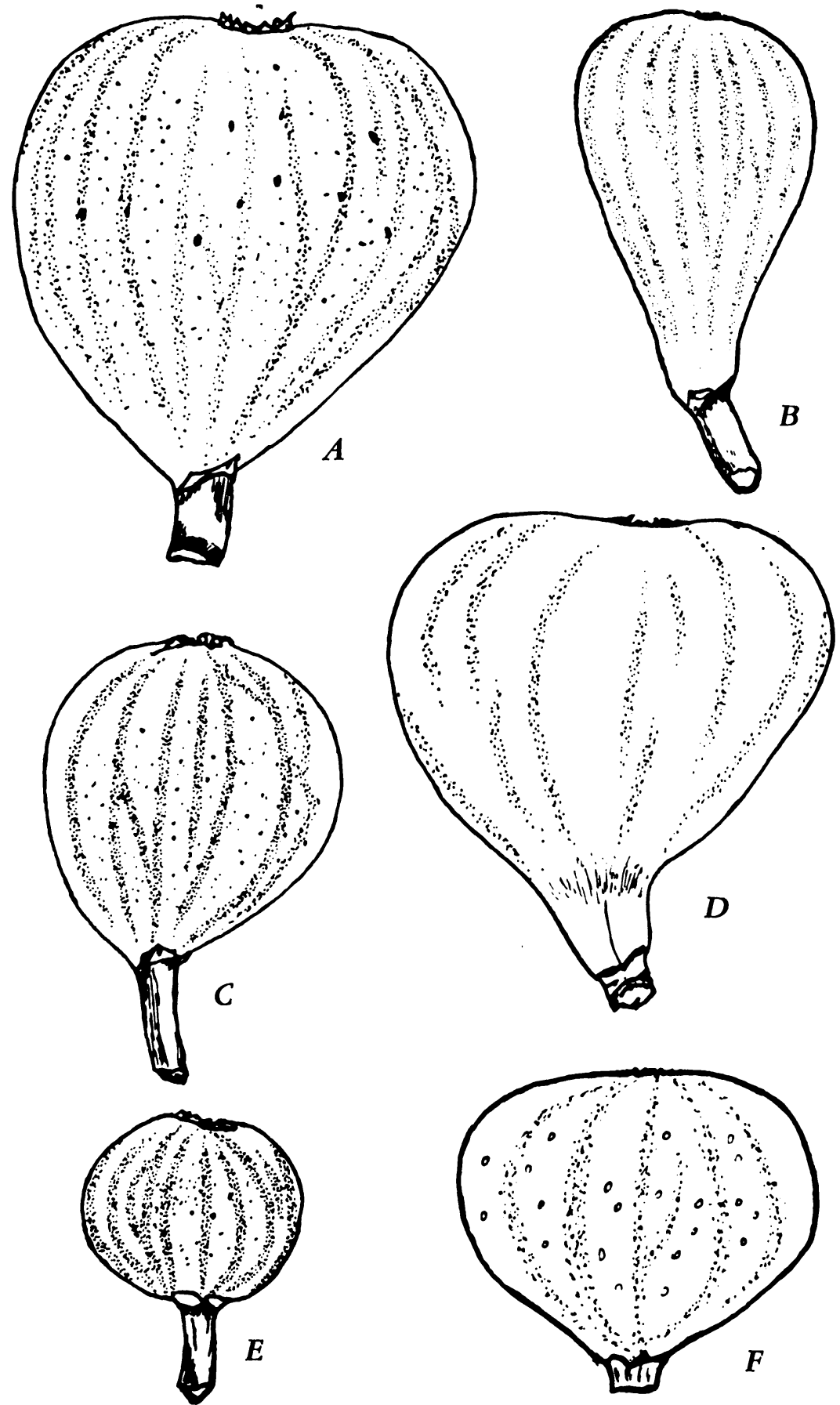

Plate 27. $A$, Barnissotte; $B$, Hunt; $C$, Ischia Black; $D$, Archipel; $E$, Early Violet; $F$, Poulette. All are of second crop. 


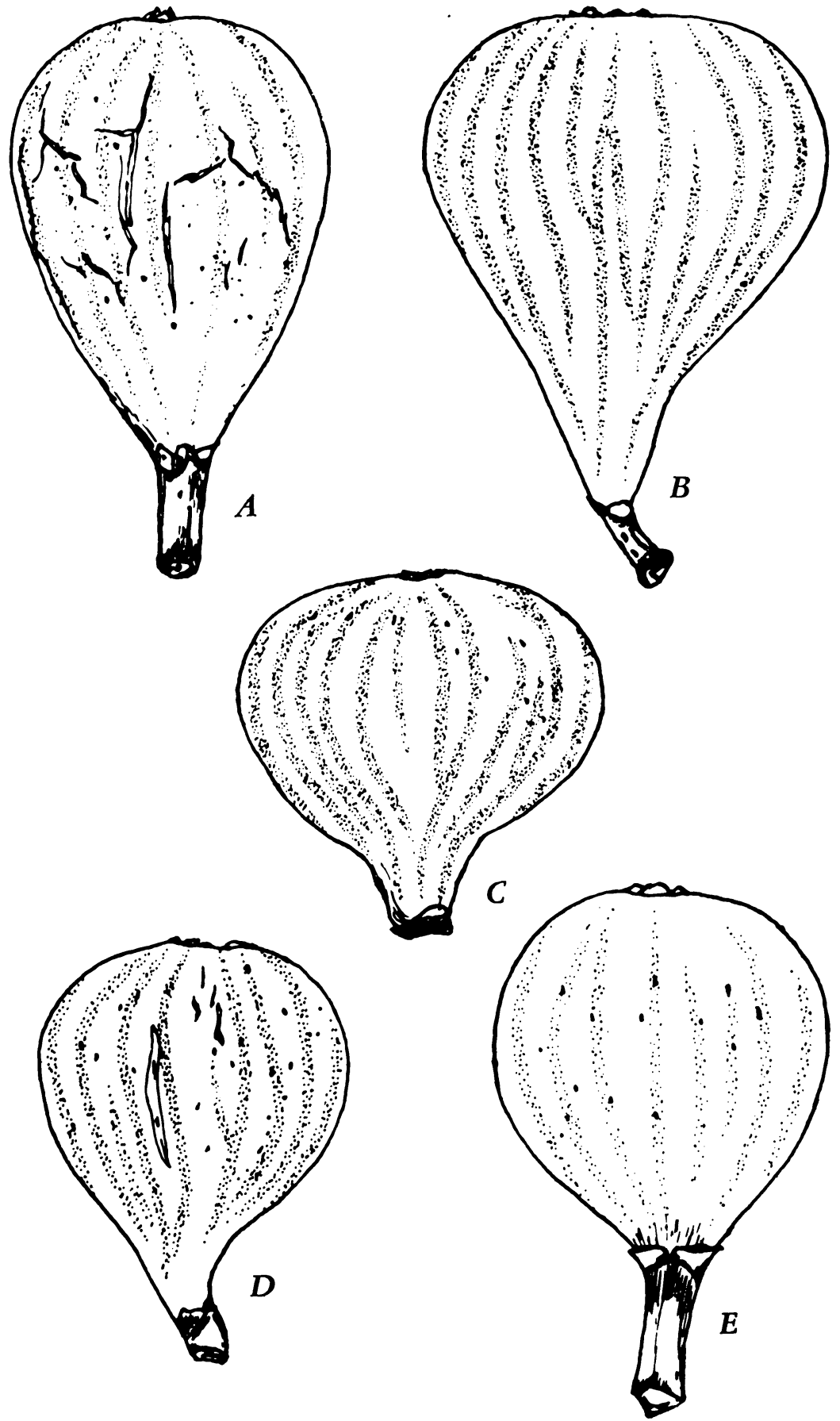

Plate 28. $A$, Partridge Eye; $B$, Osborn Prolific (Rust) ; $C$, Vernino; $D$, Martinique; $E$, Pastilière. All are of second crop. 
The journal Hilgardia is published at irregular intervals, in volumes of about 600 pages. The number of issues per volume varies. Subscriptions are not sold. The periodical is sent as published only to libraries, or to institutions in foreign countries having publications to offer in exchange.

You may obtain a single copy of any issue free, as long as the supply lasts; please request by volume and issue number from:

Agricultural Publications

Room 22, Giannini Hall

College of Agriculture

Berkeley 4, California

The limit to nonresidents of California is 10 separate issues on a single order. A list of the issues still available will be sent on request. 